\title{
Experimental study of Hollow Fibre Reinforced Polymer Piles in soft clay
}

\author{
by \\ Juan David Giraldo Velez
}

A thesis submitted to the Faculty of Graduate and Postdoctoral Affairs in partial fulfillment of the requirements for the degree of:

\section{Master of Applied Science \\ in}

Civil Engineering

Department of Civil and Environmental Engineering

Carleton University

Ottawa-Carleton Institute of Civil and Environmental Engineering

@2013 Juan David Giraldo Velez 


\section{ABSTRACT}

In this thesis, a research program aimed at investigating the performance of fiber reinforced polymers (FRPs) piles in soft clays is presented. The main goal was to determine and characterize the interface shear strength properties of carbon and glass FRPs against clays, identify the influence of material selection and fiber orientation, and compare these results to the performance of traditional piling materials such as steel and concrete. FRP materials have experienced a surge in interest during the recent decades due to their favourable properties such as resistance to corrosion and degradation in comparison to steel and concrete particularly in harsh or contaminated soil conditions such as waterfront applications.

The first experimental program investigates interface shear strength using a direct shear box apparatus. The second experimental program expands on the previous work through conducting static pile load tests under axial and lateral loading conditions of small scale FRP and steel piles in soft clays. The results of this experimental testing indicates that for all of the FRP interfaces tested in both element and small scale pile load tests, the interface shear strength is higher or at least on par with steel interfaces. Material selection and orientation had a limited role on pile performance as most FRP piles presented similar interface shear strength results. The findings presented in this work show that the FRP piles are a viable alternative to steel piles. Further studies in the form of full scale pile load tests are needed in order to corroborate the results presented herein. 


\section{AWCKNOWLEDGMENTS}

I would like to thank my supervisor Dr. Mohammed Rayhani for his support and

guidance through the completion of my graduate work. His insight has helped me greatly on the start of my professional career. I would like to thank my colleagues and friends Hamid Sarabadani, Alireza Afshin, Abdulghader Aldaeef, Ghazi Abul Hosn and Gregoire Baribeau for their invaluable help and support through my research program. Special thanks to the Carleton Civil and Environmental Engineering laboratory staff as their input and help was crucial for the success of this study. Finally I would like to thank my family and friends for supporting me and encouraging me through my studies. 


\section{TABLE OF CONTENTS}

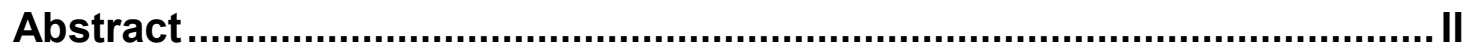

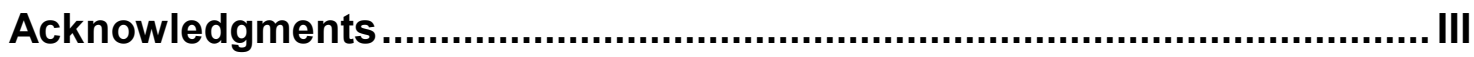

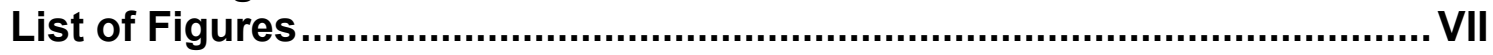

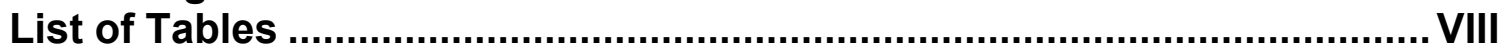

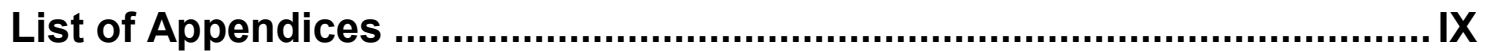

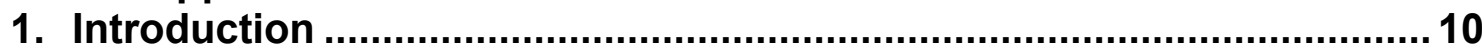

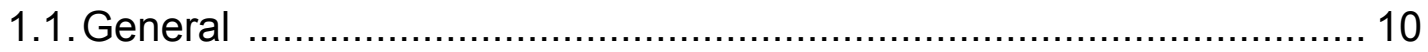

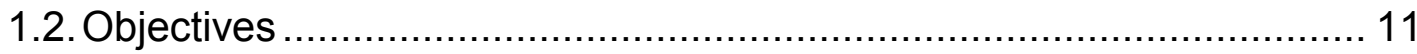

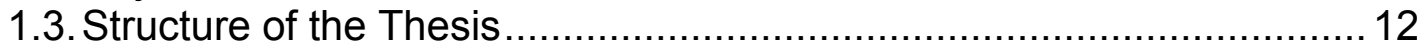

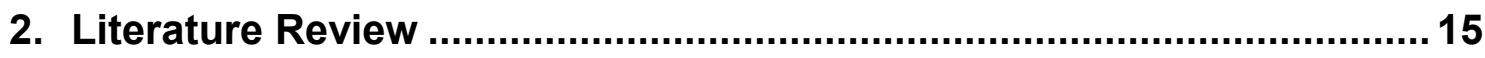

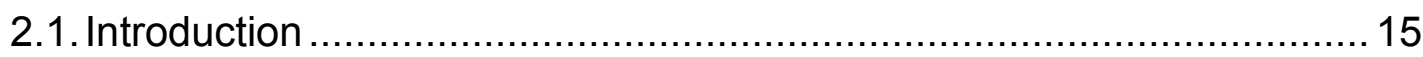

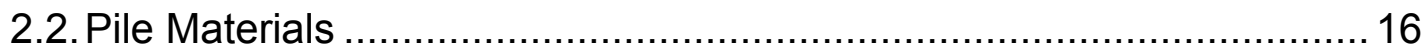

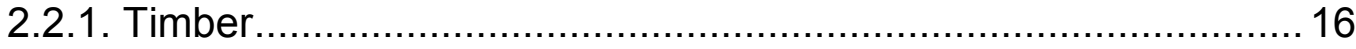

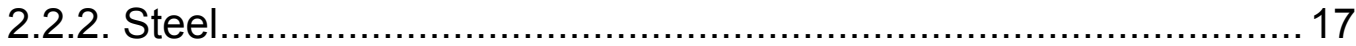

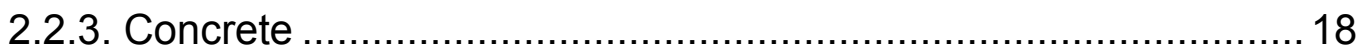

2.2.4. Fiber Reinforced Composite Piling.......................................... 19

2.2.4.1. Steel core piles ........................................................... 21

2.2.4.2. Structurally reinforced plastic piles ................................. 21

2.2.4.3. Concrete-filled FRP piles ................................................ 21

2.2.4.4. Fiberglass pultruded piles ............................................. 22

2.2.4.5. Fiberglass reinforced plastic piles..................................... 22

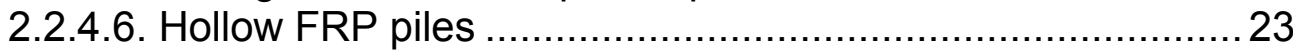

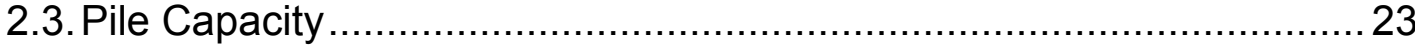

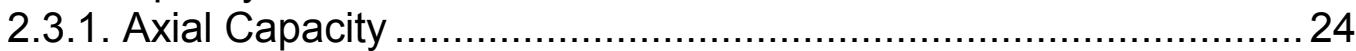

2.3.1.1. Determination of unit shaft resistance ............................. 25

2.3.1.2. Determination of pile toe bearing capacity......................... 28

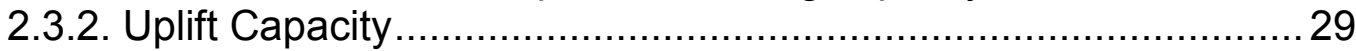

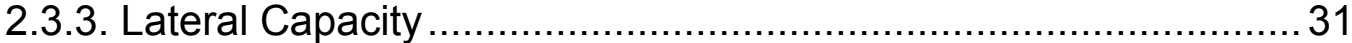

2.3.3.1. Estimating pile ultimate lateral capacity ............................ 32

2.3.3.2. Estimating pile lateral deflections …................................... 33

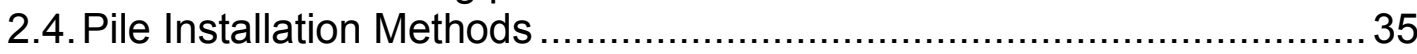

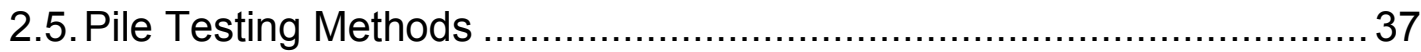

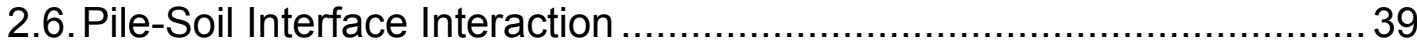

2.6.1. Relevant Studies on Pile-Soil Interfaces ................................... 39

2.6.1.1. Relevant studies on pile-clay interface behaviour................ 30

2.6.1.2. Relevant studies on pile-sands interface behaviour ............ 41

2.6.2. Relevant studies on FRP-soil interfaces .................................. 42

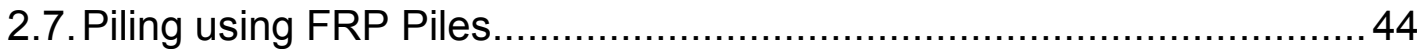

2.7.1. FRP Piles Driving Performance ............................................ 45

2.7.2. FRP Piles Structural Behaviour .............................................46

2.7.3. FRP Piles Under Axial and Lateral Loading ............................... 48 


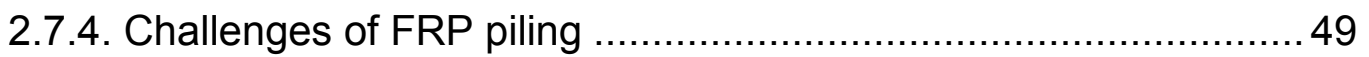

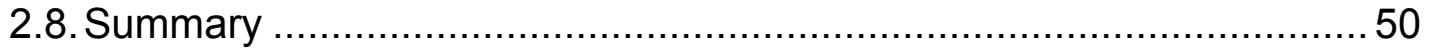

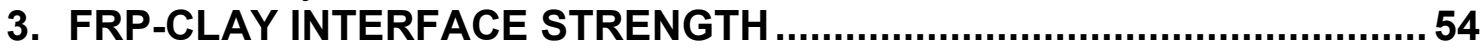

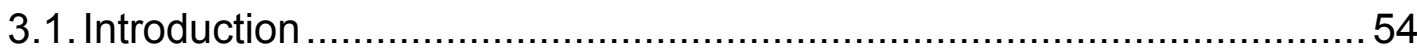

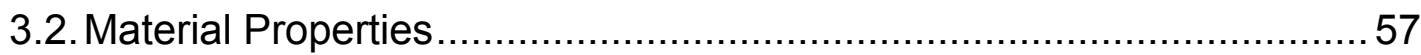

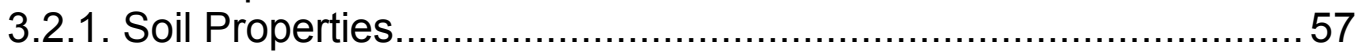

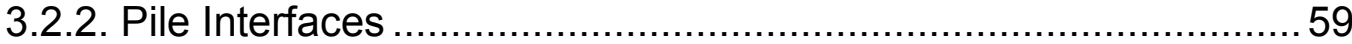

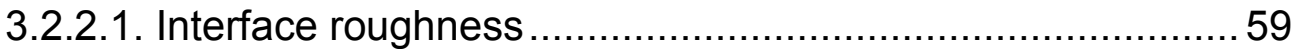

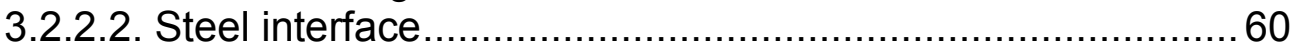

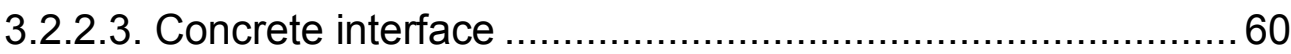

3.2.2.4. Carbon and glass fiber reinforced polymer interface ............61

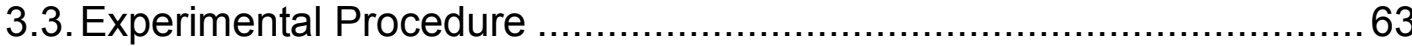

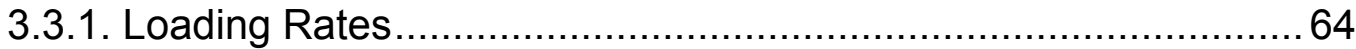

3.3.2. Soil-Interface Specimen Preparation .........................................65

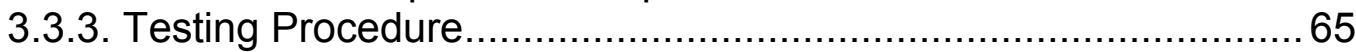

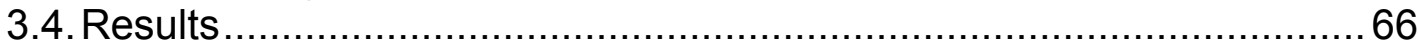

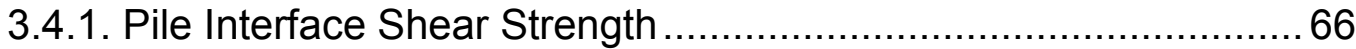

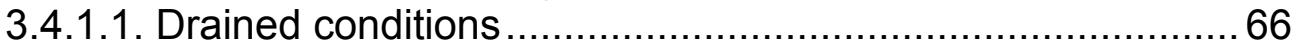

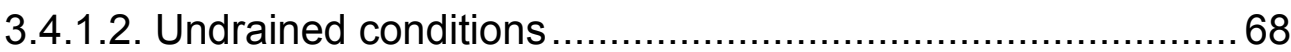

3.4.2. FRP Interface Shear Strength............................................. 70

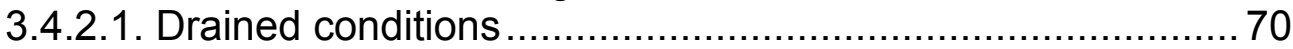

3.4.2.2. Undrained conditions ..................................................... 71

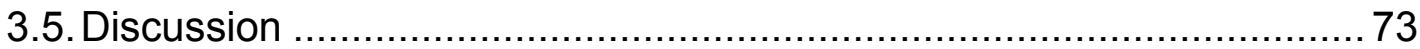

3.5.1. Pile-Soil and FRP-Soil Interface Performance ........................... 73

3.5.2. Effect of Epoxy Resin on Interface Behaviour............................76

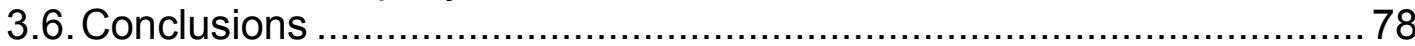

4. LOAD TRANSFER OF HOLLOW FRP PILES IN CLAY ........................80

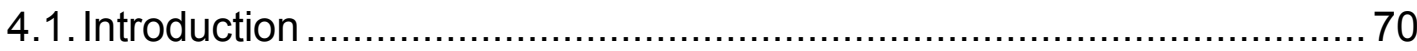

4.2. Soil Sampling and Properties.................................................... 83

4.2.1. Undisturbed Clay Samples Harvesting ……........................... 83

4.2.2. Soil Properties................................................................... 90

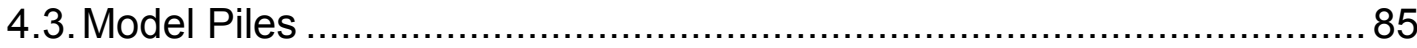

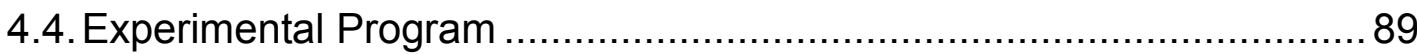

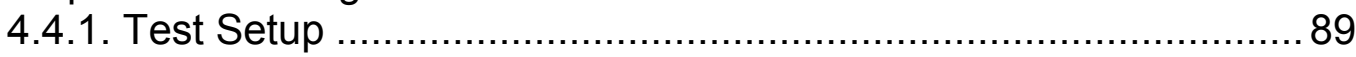

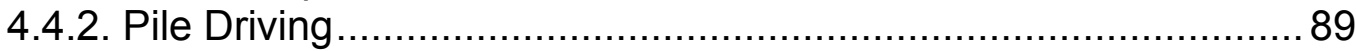

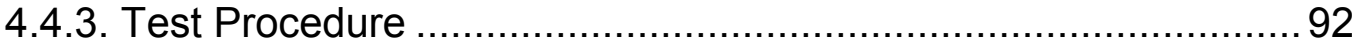

4.4.3.1. Static compressive pile load tests................................... 92

4.4.3.2. Static lateral load tests.................................................. 92

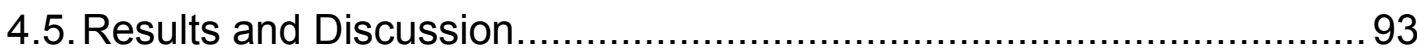

4.5.1. Pile Axial Compression Capacity ......................................... 94

4.5.1.1. Pile shaft resistance .................................................... 93

4.5.1.2. Comparison to published data and empirical estimates ......97

4.5.1.3. Effect of fiber orientation on pile capacity .......................... 99

4.5.1.4. Effect of FRP material selection on pile capacity ................. 101

4.5.2. Pile Lateral Capacity ............................................................ 102

4.5.2.1. Effect of material selection on lateral capacity .................... 104 
4.5.2.2. Comparison to analytical lateral capacity estimates

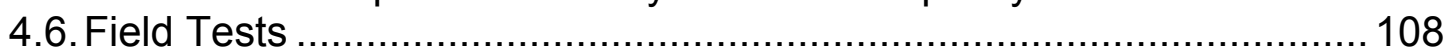

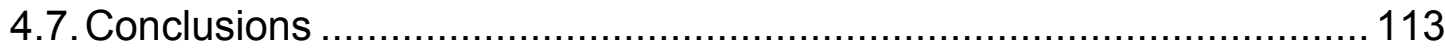

5. CONCLUSIONS AND RECOMMENDATIONS ...................................116

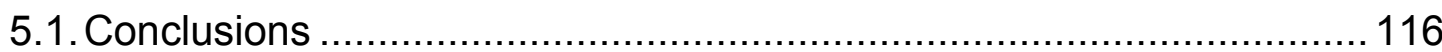

5.2. Recommendation for Future Research ......................................... 120

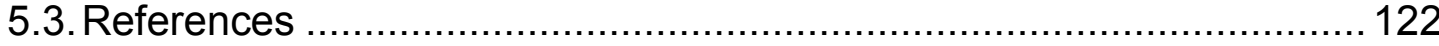




\section{LIST OF FIGURES}

Figure 2.1 - Cross-sectional profile of various FRP piles

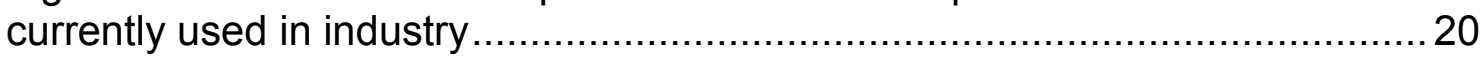

Figure 2.2 - Conceptual Model of $p-y$ soil response of

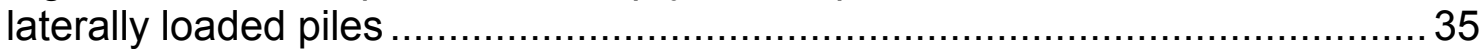

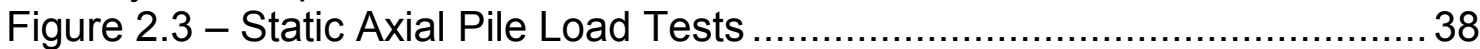

Figure 3.1 - Leda Clay grain size distribution............................................58

Figure 3.2 - Surface interface and profile for steel, Concrete, Carbon

FRP at $90^{\circ}$, Carbon FRP at $0^{\circ}$, Glass FRP at $90^{\circ}$, Glass FRP at $0^{\circ} \ldots \ldots \ldots \ldots . . . . .62$

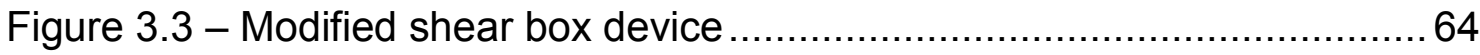

Figure $3.4-$ a) Shear stress-strain at $100 \mathrm{kPa}$ b) Failure

envelopes under drained conditions....

Figure $3.5-a)$ Shear stress-strain at $100 \mathrm{kPa}$ b) Failure

envelopes under undrained condition

Figure $3.6-$ a) Shear stress-strain curve at $100 \mathrm{kPa}$ b) Failure

envelopes for FRP under drained condition

Figure $3.7-$ a) Shear stress-strain curve at $100 \mathrm{kPa}$ b) Failure

Envelopes for FRP under undrained conditions

Figure 3.7 - Comparison of dry fiber (no epoxy) and regular FRP .................77

Figure 4.1 - Soil sample preparation for pile load tests................................. 84

Figure 4.2 - Leda Clay grain size distribution........................................... 85

Figure 4.3 - a) Experimental setup b) Lateral loading schematics .................. 90

Figure $4.4-$ a) Test frame b) Axial loading c) Lateral loading .......................... 91

Figure $4.5-$ a) Cumulative \# of blows vs depth ratio b) Rate of

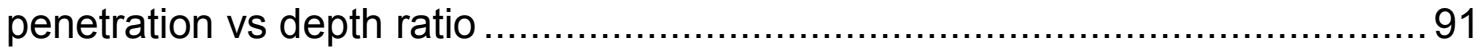

Figure 4.6 - Pile resistance vs pile head movement .....................................93

Figure 4.7 - Average unit shaft resistance of FRP and steel piles ..................97

Figure 4.8 - Relationship of SU to $\alpha$ values based on published data .............98

Figure 4.9 - Comparison of CFRP pile performance

based on fiber orientation 101

Figure 4.10 - Lateral pile resistance vs pile displacement ratio ....................... 103

Figure 4.11 - Comparison of FRP material selection on

lateral pile capacity 105

Figure 4.12 - Comparison of pile flexural stiffness under

3-point bending.... 106

Figure 4.13 - Measured lateral capacities vs LPILE analyses for FRP

and steel piles (G0; Glass FRP, SP: Steel, and C0: Carbone FRP) …........... 108

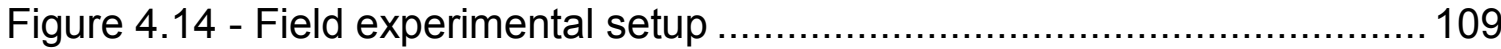

Figure 4.15 - Model piles used for field testing ........................................ 110

Figure 4.16 - Comparison of field and lab compressive load tests.................. 111

Figure 4.17 - Lateral loading response of field and laboratory load tests......... 112 


\section{LIST OF TABLES}

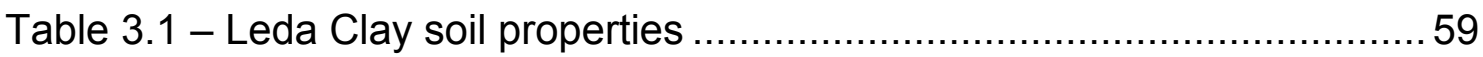

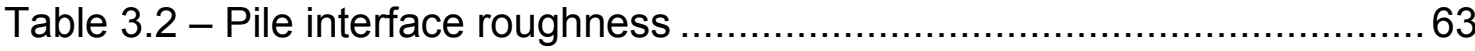

Table 3.3 - Comparison of shear strength properties of

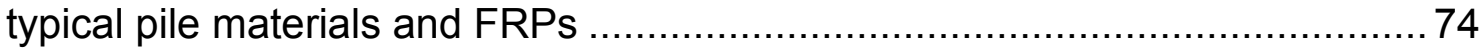

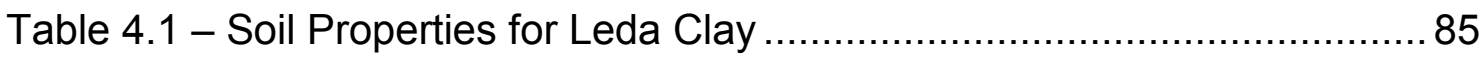

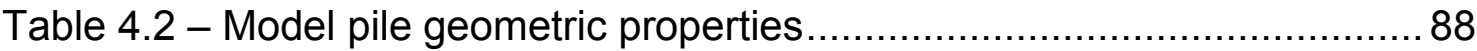

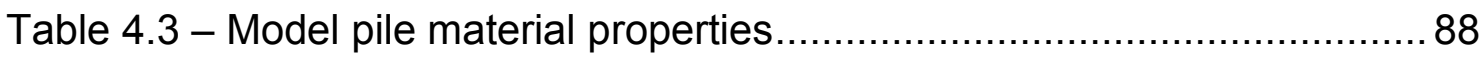

Table 4.4 - Axial compressive capacities of FRP and steel piles ...................97

Table 4.5 - Lateral capacity and properties of FRP and steel piles ................. 104 


\section{LIST OF APPENDICES}

Appendix A - Interface testing lab photos and sheared interfaces ................. 129

Appendix B - Dataset of interface testing program ................................ 132

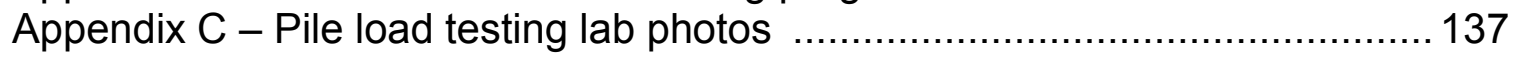

Appendix D - Geo-Studio boundary condition analysis results

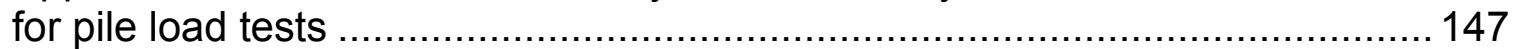

Appendix E - 3-point FRP pipe bending test photos ............................. 150

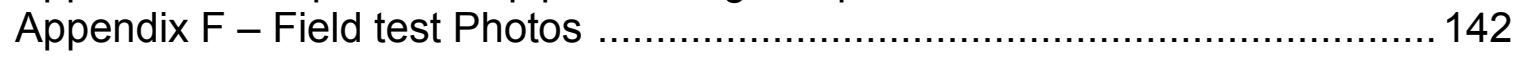




\section{CHAPTER 1 \\ INTRODUCTION}

\subsection{GENERAL}

Pile foundations have been used extensively throughout the world as the preferred method of supporting high load structures both inland and offshore. The most common goal of using piles as foundations is to transfer large surface loads to deep strata. Pile foundations are used where shallow strata does not provide adequate support or excessive settlement is expected. In addition to axial compressive resistance, pile foundations are also used to withstand lateral forces and moments experienced in offshore and high-rise buildings as well as uplift forces.

The classification of pile foundations can be based on two categories: pile material, and method of installation. Piles have traditionally been constructed using timber, concrete or steel; however new trends and research encourage novel materials such as fiber reinforced polymers (FRPs). The methods of installation dictate the design philosophy and behaviour of the pile, including driving, boring, cast-in-place and screwed piling among others.

In the recent decades, use of novel composite materials such as fiber reinforced polymers (FRPs) have been used for many civil engineering applications, mainly in the structural reinforcement of buildings. However, these materials present many attractive properties for the use in pile foundations. Traditional pile materials suffer from limited lifespans especially in harsh environments where the corrosion of steel and degradation of concrete and timber becomes a significant issue. In addition, the maintenance associated with the repair and retrofit of such structures can incur significant costs. FRP 
materials present favourable properties such as high specific strength, lightweight, durability, and resistance to chemical and corrosive environments (Iskander, 2002). There has been a few ongoing research efforts to implement FRP materials towards the piling industry (e.g., Iskander and Hassan, 1998; Guades et al. 2012), however they have yet to been accepted as a standard piling material. Lack of design guidelines, pilot projects demonstrating the viability of the material from a technical and economical point of view, and limited data on FRP-soil interface behaviour have been identified as factors preventing commercial use of FRP piles. Further research in this direction is useful to establish the behaviour of composite FRP materials towards piling applications in a variety of soil conditions.

\subsection{OBJECTIVES}

The objectives of this study are to explore the behaviour and benefits of using composite materials for the construction of hollow FRP piles in soft clays. In order to achieve this, an interface characterization program was carried out with the purpose of determining the interface properties, particularly the shear strength behaviour of FRP interfaces against clays compared to traditional piling materials such as steel and concrete. In addition, small scale laboratory pile load tests were carried out in order to measure axial shaft capacity and lateral capacity of hollow FRP piles in order to assess shaft friction improvements compared to traditional piling materials. Additional field tests of similarly sized FRP piles were then carried out to validate the laboratory results. The research goals include:

1. Investigate the shearing behaviour of various typical pile-soil interface surfaces (clay-steel, clay-concrete) and two types of FRP materials, 
(carbon-clay and glass-clay) through a series of testing programs using a direct shear apparatus.

2. Develop a pile-load testing program for small scale hollow FRP piles (55 $\mathrm{mm}$ diameter) in order to assess the axial and lateral capacity and comparing the performance to that of a steel pile.

3. Validate the small scale testing program through a series of pile-load tests in the field.

The outcome of this research will provide baseline information regarding the interface behaviour of FRP materials in soft clays. Current literature has investigated FRP-sand interface behaviour (e.g., Pando, et. al., 2002; Frost and Han, 1999), and there is seldom information regarding FRP-clays. In addition, the results will provide an insight regarding the use of hollow FRP piles in clays with regards to the frictional capacity compared to that of steel piles. This information encourages geotechnical engineers to consider other alternatives with respect to the geotechnical performance of these new materials.

\subsection{STRUCTURE OF THE THESIS}

This thesis is written in a paper based format and presenting the results two journal articles. The contents of the thesis are divided as five chapters, with the objectives of each chapter summarized below:

Chapter 2 presents a review of typical piling construction materials, their advantages and drawbacks and the motivation that lead to the introduction of FRP as a viable piling alternative. It will also summarize the different types of commercially available FRP piles, their characteristics and intended use. Typical design procedures 
regarding axial pile capacity in compressive, uplift and lateral loading modes. Current research conducted regarding interface element testing of typical piling materials and FRPs against clays and sands are also discussed. It will summarize the results of research conducted with regards to the driving of FRP piles, advantages and technical challenges and how FRP piling compares to traditional piling materials. The chapter will conclude highlighting the research significance of the work presented in this thesis with regards to advancing the current knowledge of the performance of FRP materials as a piling method in clayey soils.

Chapter 3 will present a comprehensive study examining interface shearing performance of various piling materials and FRPs, particularly two FRP materials: carbon and glass. The interfaces tested include: clay-concrete, clay-steel, clay-carbon FRP and clay-glass FRP interfaces. This study is intended to provide quantifiable data regarding the shear strength behaviour of the different interfaces in both drained and undrained conditions against soft marine clay encountered along the Ottawa Valley in Ontario and Quebec. In addition, a comparison of the shear strength properties between traditional piling materials and FRPs in order to assess their viability as piling alternatives are provided.

Chapter 4 presents a laboratory study of small scale pile load tests of FRP and steel piles in soft clays under axial and lateral loading. The testing was carried out using industrial sized steel drums (600 mm diameter by $900 \mathrm{~mm}$ height) where intact clay samples collected from a clay rich deposit. Small model piles of $55 \mathrm{~mm}$ diameter were tested under axial and lateral loading. This research program focuses on characterization of shaft frictional capacity and lateral loading behaviour of FRP piles in clays and conducting a comparative analysis between their performance and that of a steel pile. In addition, in order to validate the laboratory results and isolate any possible 
influence due to boundary conditions influenced by the sample confinement, a series of field pile-load tests were conducted. The results of these tests are summarized therein. Chapter 5 summarizes the results of the study and presents conclusions and recommendations for further research. 


\section{CHAPTER 2}

\section{LITERATURE REVIEW}

\subsection{INTRODUCTION}

Pile or deep foundations have been used since antiquity for the support of structures, particularly when the use of shallow foundations does not provide sufficient bearing capacity or large settlements are expected. Typically, the purpose of a pile foundation is to provide higher bearing capacity by transferring the surface loads to a competent soil stratum by means of toe resistance against bedrock and/or shaft frictional resistance developed by the pile-soil interface along the length of the pile. Although the goal of pile foundations is generally regarded as providing higher bearing capacity, in many cases design is governed by serviceability requirements determined by the settlement and displacement limits, especially with respect to lateral loading conditions (Prakash and Sharma, 1990).

Due to the many different techniques, materials, installation procedures, environmental and soil conditions, there are many types of classifications for pile foundations. Some of the classification criteria as per the Canadian Geotechnical Foundation Manual, (CGS 2007) include: installation method (driven, bored, cast-inplace), soil displacement (high, low displacement), material (concrete, steel, wood, polymer), function (shaft resistance, toe resistance), capacity (high, low), pile shape (round, square, hexagonal, $\mathrm{H}$-shape), environment (land, marine, off-shore), inclination (vertical, battered), length (long, short), structure (bridge, building, machinery, etc.). Given the sensitivity of pile behaviour and performance to different installation 
techniques and different piles and in-situ conditions, a field pile-load test is usually carried out to confirm the design estimates for capacity and settlements.

\subsection{PILE MATERIALS}

Pile foundations have been traditionally manufactured from three materials: timber, steel and concrete. These three materials present great versatility for a vast number of piling applications and a great amount of research and knowledge is currently available regarding their behaviour in different subsurface conditions and with different installation methods. In recent decades, with the advent of composite materials in various fields of science and engineering, there has been a growing interest by geotechnical engineers to use these materials for different geotechnical applications due to their favourable properties (Iskander and Hassan, 1998). In the following sections, a more detailed description of each pile material along with the advantages and disadvantages of each technology are presented.

\subsubsection{Timber}

Timber has been used as a piling material for several thousand years and continues to be used to this day (Ulitskii, 1995). Typically these types of piles are used in northern Canada and Europe primarily due to the low cost and the requirement of raised foundations due to permafrost conditions. Timber piles typically consists vertical tree trunks with a natural taper. Timber piles are driven with the larger diameter section of the

pile as the pile head in order to take advantage of the increased capacity provided by the pile taper. Given the restriction of pile size due to the typical length of the wood used, timber piles have a typical design capacity of 100 to $400 \mathrm{kN}$ (Coduto, 2001). 
The low costs of timber piles present one of the main advantages of the material, especially if there is material availability in the vicinity of a given project. In addition, timber piles are popular as waterfront and fendering applications due to their capacity to resist impact loads derived from timber's energy absorbing properties. Timber piles have been documented to have a long service life when continually submerged (Chellis, 1961). However, above the ground water table or in harsh marine environments, timber piles experience significant degradation through natural decay. Marine borer attack is another threat to timber piles significantly reducing their service life if not treated properly (Iskander, 2002). Traditional treatment substances such as creosote cause significant damage to marine life which has led to becoming a heavily regulated substance. Despite the different measures to prevent damage to the timber piles, it is not always possible. For these reasons, timber piles have generally been restricted to light driving conditions in loose soils and are rarely used in denser soils or as end bearing piles (Coduto, 2001).

\subsubsection{Steel}

Steel piles have been widely used since the 1890 s for buildings and structures due to the versatility of the material. Pile foundations using steel was a natural development of the material due to the large advantages it provided over other traditional materials such as timber. The main benefit of steel piling is their excellent driving capabilities and ability to support high loads and reduce settlement. This behaviour is due to the material's high strength and ductility which allow it to be driven even through dense soils. In addition to easily implemented splicing techniques, piles of much greater lengths became available providing increasing bearing capacity.

Steel piles come in various different shapes depending on the required application. H-piles are piling specific steel sections similar to wide flanges steel sections. These types of piles are suitable for difficult driving conditions due to their high 
strength and low soil displacement while driving. Typically these types of piles are driven to bedrock in order to act as end bearing piles. Pipe piles are steel pipe sections with typical dimensions between 200 to $1000 \mathrm{~mm}$ in diameter and can be manufactured up to $3 \mathrm{~m}$ in diameter with a carrying capacity typically higher than H-piles (Coduto, 2001). Pipe piles can be open ended or close ended, both types of piles cause a greater soil disturbance than $\mathrm{H}$-piles which generally generates higher capacity by the densification of the surrounding soil. Other steel piles include monotube piles which feature a tapered surface with longitudinal flutes.

Although steel piles provide various advantages, they typically incur high capital costs and are vulnerable to corrosion degradation especially in marine and industrial environments. Corrosion of steel piles significantly reduces their service life driving the costs of replacement and repair even higher. The rate of corrosion of steel piles in regular soil has been estimated to be $0.03 \mathrm{~mm} /$ year and up to $1.2 \mathrm{~mm} /$ year in harsh environments such as the splash zone in waterfront installations (Iskander, 2002).

\subsubsection{Concrete}

Concrete piles can be classified in two main categories: precast concrete piles or castin-place piles. A third category can be considered as composite concrete piles where concrete is used in conjunction with other materials such as steel, plastics, or other polymer fibers. Precast piles consist of reinforced or pre-stressed concrete members which are then driven in place at the construction site. Cast-in-place piles use drilling or jetting techniques which create a cavity in the soil which is then filled with a steel reinforcement cage and concrete mix. Concrete piles are an attractive alternative because they can be manufactured to meet specific requirements for particular applications. They can be cost efficient when compared with the high cost of some of the steel alternatives while maintaining large load capacities (Coduto, 2001). 
Some of the shortcomings of concrete piles include the deterioration of the steel reinforcement or pre-stressing tendons of the piles by the infiltration of corrosive substances through concrete cracks especially in contaminated soils or in marine environments. The most harmful agents contributing towards the corrosion of concrete piles are sodium chlorides and calcium chlorides (Iskander, 2002).The corrosion process produces excess material along the steel surface which exerts tensile internal stresses in the concrete leading to further cracking and spalling of the pile. Freeze-thaw cycles further deteriorate cracking tissues generated by corrosion which in turn can reduce the service life significantly. Other issues surrounding concrete piles, specifically precast piles are transportation and handling difficulties, refusal during driving, and splicing difficulties due to the increased difficulty of cutting and splicing concrete piles compared to similarly sized steel piles. Regardless of these drawbacks, concrete piles are advantageous due to their relatively lower costs compared to other alternatives and similar or better performance.

\subsubsection{Fiber Reinforced Composite Piling}

Within the last few decades, the use of composite materials, specifically fiber reinforced and plastic composites has been introduced to many civil engineering fields including geotechnical applications (Hollaway, 2009). Composite piling applications has experienced a surge in interest due to the inherent advantages the technology presents compared to traditional piling materials. Some of the advantages composite piles provide are their inherent resistant to corrosive, contaminated and other harsh environments, high specific strength, low weight, low maintenance and high durability (Guades et al., 2012). There have been various studies in the last few years (e.g., Iskander, 2002; Iskander and Hassan, 1998; Pando et al., 2002; Iskander et al., 2001) describing the current state of composite piling including the different pile varieties (materials), 
structural and geotechnical properties, drivability, and performance based on limited field experience. Although, FRP composite piles present significant advantages, various disadvantages have been identified including higher initial costs, lower relative stiffness, lower driving efficiency, lack of design guidelines as well as lack of a proven long-term record in use. Regardless of these drawbacks, FRP piles present an exciting alternative due to their durability and service life improvements over traditional piling materials.

Typically composite piles have used recycled plastics in conjunction with steel members, or fiber reinforced materials such as wound or pultruded fibreglass or other types of fiberglass reinforced plastics. Since 1987 there have been seven types of different composite piles documented including steel core piles, reinforced plastic piles, concrete filled FRP piles, fiberglass pultruded piles, fiberglass reinforced plastic piles, FRP hollow piles and FRP sheet piles (Guades et al., 2012)(Figure 2.1). Although composite piles have increased in popularity, the majority of their use has been in marine fendering applications. The following sections provide a description of each type of the aforementioned composite piling systems.

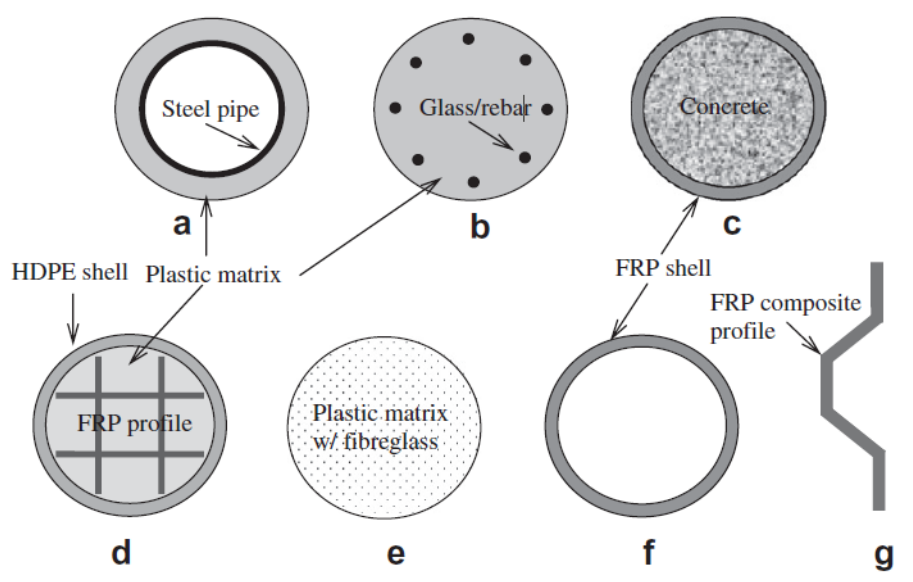

Figure 2.1 - Cross-sectional profile of various FRP piles currently used in industry. (a) steel pipe core piles, (b) structurally reinforced plastic piles, (c) concrete-filled FRP piles, (d) reinforced plastic piles, (f) hollow FRP piles and (g) FRP sheet piles. (Guades et al. 2012) 


\subsubsection{Steel Core Piles}

Steel core piles consist of a steel pipe core encased by recycled plastic shell. The objective of this composite arrangement is to protect the steel pipe which provides the structural strength to the system against corrosion and degradation by using the plastic shell as a protective layer. This type of pile has been used successfully in fendering applications as the plastic layer absorbs impact loads well. Earlier versions of steel core piles suffered from delamination of the plastic layer due to the difference of thermal expansion coefficients of the two materials leading to cracking along the surface of the plastic layers. Although mainly used in fendering applications studies suggest that they can be used as load bearing piles using the same design procedure as of steel piles if the plastic casing is limited to the upper region of the pile exposed to water (Pando et. al., 2003).

\subsubsection{Structurally Reinforced Plastic Piles}

These piles are manufactured using recycled plastic to create a pile matrix reinforced with fiberglass or steel rebars. Additives are used to improve strength, durability and resistance to ultraviolet and chemical deterioration. This composite piling method has been primarily used in fendering applications although it has been deemed appropriate as a load bearing alternative (Guades et al., 2012). Issues presented with structurally reinforced plastic piles include the debonding of the reinforcement bars with the plastic matrix, excessive creep deformation and larger axial and lateral deformations compared to other composite piles of similar dimensions (Pando et al., 2003).

\subsubsection{Concrete- filled FRP piles}

Concrete-filled FRP piles consist of an FRP shell which is in filled with unreinforced concrete. The outer FRP shell provides confinement to the concrete infill which allows for the development of a high axial strength, while the internal compressive resistance of 
the concrete infill provides higher member stiffness preventing local failure of the FRP shell. Findings by Mirmiran et al. (2000) indicated this composite arrangement outperforms equivalent prestressed and reinforced concrete structural member under axial and flexural loads. Additional benefits include an improved service life as the FRP shell serves as a non-corrosive reinforcement. Issues with this type of piling system include debonding at the concrete-FRP interface, although techniques have been developed to improve the bonding mechanism including roughening of the inside shell surface (Ji et al., 2009). Concrete filled FRP piles have been successfully implemented in bridge rehabilitation pilot projects (Pando et al., 2003) which have been serving as a proof of concept for the introduction of FRP products in the piling industry.

\subsubsection{Fiberglass Pultruded Piles}

Fiberglass pultruded piles consist of an outer circular fibreglass shell reinforced with four fiberglass sheets at perpendicular angles creating a tic-tac-toe patter joint at four intersection points (Guades et al., 2012). When used in fendering applications, the top portion of the pile $(350 \mathrm{~mm})$ is protected using a high density polyethylene (HDPE) encasing. The reinforcing inserts are filled with HDPE and the outer fibreglass shell is encased with an HDPE layer intended to act as an energy absorption mechanism in impact related loads. This type of pile has been used as a demonstration project in 1996 at Berth 7 of port Newark NJ (Iskander and Hassan, 1998).

\subsubsection{Fiberglass Reinforced Plastic Piles}

Fiber reinforced plastic piles also known as plastic lumber piles consist of a recycled plastic matrix (HDPE) reinforced with randomly placed fiberglass reinforcement. Manufacturers use a pultruded hardened outer shell with a foam filled matrix containing $20 \%$ fiber reinforcement (Iskander et al., 2001). These composite piles have been manufactured to meet the standards of the lumber industry. This technology has been 
used in the Tiffany Street Pier in New York City and other selected waterfront projects along the east coast.

\subsubsection{Hollow FRP Piles}

Hollow FRP piles consist of an outer shell of fiber reinforced polymers such as glass fiber or carbon fiber. Typically these piles use a thermosetting matrix or epoxy matrix encasing the fiber filaments and can be manufactured through pultrusion, filament winding or moulding processes (Guades et al., 2012). Hollow FRP present the same advantages as concrete filled FRP piles in terms of resistance to degradation and corrosion in addition to providing suitable structural and geotechnical properties to act as load bearing piles. The focus of this thesis will be on this type of pile and the subsequent sections will focus on the current research on hollow FRP piles and concrete filled FRP piles which exhibit similar load transferring mechanisms in the form of FRP-soil interface behaviour.

\subsection{PILE CAPACITY}

Pile capacity of single piles aims at determining the maximum load a pile can withstand under different loading modes in order to determine the critical failure load. Failure conditions can be generated from ultimate limit conditions (bearing capacity) or serviceability limit conditions (excessive displacements). In addition, each loading mode (compression, extension, lateral, dynamic, etc.) must meet design criteria to withstand the failure conditions. Traditionally, foundations have followed an allowable stress design (ASD) philosophy where the determined ultimate pile capacity is divided by a specified factor of safety to account for all the unknowns in the system. In recent decades, the geotechnical community has begun an effort to introduce the load and resistance factor design (LRFD) methodology into the design of foundations (Goble, 
1999). This method uses a probabilistic approach to determine the unknowns which apply to the strength of the foundation materials and the applied loads. Although LRFD is gaining popularity in the geotechnical practice, there is still a lack of widespread implementation and the ASD method is still the common practice for geotechnical engineers. In the following sections an overview of the current methods for the determination of ultimate axial and lateral single pile capacity will be provided.

\subsubsection{Axial Capacity}

The design procedure for determining the axial capacity of single piles embedded in soils has been described in several published works and design manuals (e.g. Chellis, 1961; Coduto, 2001; CGS, 2007). The ultimate bearing capacity for single piles, $Q$, is derived from frictional shaft capacity developed along the pile surface and toe resistance. The contribution of each of these components depends on the soil density and shear strength and on the pile surface characteristics, material and geometry. The geotechnical axial capacity for single piles is determined by summing the shaft resistance (shear strength along the pile shaft) and the bearing capacity at the pile toe, and subtracting the weight of the pile. The general expression for pile axial capacity is as follows:

$$
Q=\sum_{Z=0}^{L} Q_{s}+Q_{t}-W_{p}
$$

where the shaft resistance, $Q_{s}$ is given by:

$$
Q_{s}=C q_{s} \Delta z
$$


where, $C$, is the pile circumference, $L$ is the pile length subdivided into segments of $\Delta z$ length, and $q_{s}$ is the average or unit shaft resistance at any given depth along the pile shaft. Toe bearing resistance, $Q_{t}$ is given by:

$$
Q_{t}=A_{t} q_{t}
$$

where, $A_{t}$ is pile area at the toe, and $q_{t}$, is the bearing capacity of the pile toe.

Determining the unit shaft frictional resistance and toe bearing resistance is a non-trivial task and many methods have been developed both theoretically and empirically aimed at estimating the expected capacity in field conditions. The empirical procedures are typically dependent on the soil type, e.g. cohesionless or cohesive soil.

\subsubsection{Determination of Unit Shaft Resistance}

The unit shaft resistance is a function of the interface friction angle between the pile surface and the soil $\delta$, the lateral earth pressure perpendicular to the surface of the pile, and the effective stresses dependant on pore pressure along the pile shaft. The lateral earth pressure along the pile shaft is in turn a function of the stress level along the length (vertical earth pressure) of the pile and the coefficient of lateral earth pressure $K_{s}$. The frictional resistance $q_{s}$ can be represented by the following relationship:

$$
q_{s}=\sigma_{v}^{\prime} K_{s} \tan \delta
$$

where, $\sigma_{v}^{\prime}$ is the vertical effective stress at a particular depth along the length of the pile, $K_{S}$ is the coefficient of lateral earth pressure and $\delta$ is the soil-pile interface friction angle. In practice, lateral earth pressure coefficient is influenced by various factors including method of installation, soil compressibility, overconsolidation ratio and initial stress levels. In addition, the soil-pile interface friction angle is influenced by the pile material, 
pile surface roughness, soil grain size, normal stresses at the soil-pile interface and installation methods.

Various methods have been proposed to estimate the shaft frictional capacity based on soil type, pile installation method and pile type among other parameters. Vesic (1977) proposed a relationship between lateral earth pressure coefficient $K_{s}$ and the bearing capacity factor $N_{q}$ based on driven pile load test results in loose to medium density sands. The expression takes into account densification of the material surrounding the pile due to the driving action and estimates $K_{s}$ as:

$$
K_{s}=N_{q} / 50
$$

In addition, sand-pile interface tests conducted by Kishida and Uesegui (1987) showed that the roughness of the pile surface influences the shearing behaviour, particularly the interface frictional angle $\delta$. Their tests showed that in average the interface friction angles ranges between 0.75 to 1 times that of friction angle of the soil material. In order to account for the effects of the interface interaction Fleming et al. (1992) suggests to use the critical state friction angle as the interface friction angle e.g. $\phi_{c v}=\delta$ assuming there is no sand dilatation along the pile shaft. Modifying equation 2.4 one can obtain the following equation relating shaft frictional resistance and bearing capacity factor:

$$
q_{s}=\frac{N_{q}}{50} \sigma_{v}^{\prime} \tan \phi_{c v}
$$


Additionally other researchers proposed a combined shaft resistance factor for soils referred as $\beta$ accounting for both confining stresses and interface friction (Meyerhof, 1976). Modifying (2.4), the shaft unit frictional resistance is expressed by:

$$
q_{s}=\beta \sigma_{v}^{\prime}
$$

where $\beta=K_{s} \tan \delta$. The values of $\beta$ have been estimated by various researchers (e.g. Fleming et al., 1992; Meyerhof, 1976) based on pile load test results using different pile installation method, soil types, and pile materials. Typical values recommended in design manuals such as the CEFM (CGS, 2007) suggest a range between 0.3 and 1.5 depending on soil type and installation method. Various researchers have attempted to characterize the pile-soil interface behaviour of various pile materials using simple shear, direct shear and torsional shear testing (e.g. Frost and Han, 1999; O'Rourke et al., 1990; Potyondy, 1961), the results of these studies will be discussed in depth in section 2.6.

Typically, equation 2.7 is used to estimate pile capacity of cohesionless soils, however, Burland (1973) has provided a discussion regarding the values of $\beta$ in cohesive soils. The traditional method for determining frictional resistance in cohesive soils uses a total stress approach. This method uses the undrained shear strength of the soil, $S_{u}$, where the shaft frictional resistance can be estimated using the following expression:

$$
q_{s}=\alpha s_{u}
$$

where $\alpha$ is the adhesion coefficient ranging from 0.5 to 1 based on field test data (Tomlinson, 1957; Fleming et al., 1992). Although equation 2.8 provides a reasonable 
shaft resistance estimate, the actual pile capacity is influenced by pile geometry, installation method, soil properties and time effects such as pile set-up.

Current literature estimates the adhesion $\alpha$ and frictional resistance $\beta$ factors from pile load tests using instrumented steel and concrete piles. To the best knowledge of the author there is no work published in the literature regarding the shaft resistance of FRP piles in cohesive soils although some research has been completed in cohesionless soils which will be discussed in detail in section 2.7.

\subsubsection{Determination of Pile Toe Bearing Capacity}

The bearing capacity at the pile toe can be estimated using the following equation:

$$
q_{t}=N_{q} \sigma_{t}^{\prime}+0.5 \gamma D N_{\gamma}
$$

where, $N_{q}$ and $N_{\gamma}$ are the bearing capacity factors, $\gamma$ is the soil unit weight, D is the pile toe diameter, and $\sigma_{t}^{\prime}$ is the effective stresses at the pile toe. Pile load test data analyzed by Meyerhof (1976) has resulted in practical values for $\mathrm{N}_{\mathrm{q}}$ as a function of soil grain size type for cohesionless soils; various design manuals such as the CFEM (CGS, 2007) provide typical bearing capacity factor values depending on the soil type and pile installation method. The $N_{Y}$ term in equation 2.9 is approximately equal to the typical pile weight cancelling the two terms resulting in being usually neglected in design which simplifies equation 2.9 as follows:

$$
q_{t}=N_{q} \sigma_{t}^{\prime}
$$

Equation 2.10 is typically used to estimate pile toe bearing capacity on cohesionless soils although Skempton (1951) discussed the bearing capacity of clays 
and presented values of $N_{q}$ for cohesive soils proposing values ranging from 3 to 10 . The bearing capacity factor is influenced by soil type and composition, soil angularity, insitu density and mineralogy.

Pile toe capacity in cohesive soils uses the undrained shear strength of the soil $\mathrm{S}_{\mathrm{u}}$ and a bearing capacity factor $\mathrm{N}_{\mathrm{c}}$. The following expression is suggested by the CFEM (CGS, 2007) to estimate the ultimate toe resistance using a total stress approac:

$$
q_{t}=N_{c} s_{u}
$$

where $\mathrm{N}_{c}$, is the bearing capacity factor usually determined as a function of pile diameter varying from a value of 6 to 9 (CGS, 2007) and $S_{u}$ is the undrained shear strength of the soil. Other interpretations of $N_{c}$ suggest interpolating the value between 6 and 9 depending on the penetration of the bearing stratum, using 6 for the penetration less than 3 times pile tip and 9 for penetration of 3 diameters or more.

The equations presented here are derived from results obtained for pile load tests on driven and bored piles using traditional steel and concrete materials. Analogous data regarding the toe bearing performance of FRP piles is virtually non-existent as there is not enough full scale testing data results required to obtain the regression data necessary for determining the bearing coefficients.

\subsubsection{Uplift Capacity}

Uplift capacity of piles is attributed entirely to the weight of the pile plus the pile shaft frictional resistance and can be calculated using the same procedure as compressive frictional resistance using equations 2.7 and 2.8 depending on effective or total stress analysis respectively. However, it is generally accepted that uplift capacity is typically 
lower than pile compressive capacity (Poulos and Davis, 1980; Fleming et al., 1992). Various researchers have attempted to determine a relationship between frictional capacity in compression and tension. Sowa (1970) carried out a series of pullout tests of cast-in-place piles in clays, and the results indicated a good agreement of the alpha, $\alpha$, coefficient between compressive and pull out tests. Uplift capacity tests in sands are subject to greater uncertainty where the effect of the lateral earth pressure coefficient and interface friction differs in uplift and downward loading modes. Ismael and Klym (1979) carried out a series of pullout tests in sands and proposed that it is suitable to use the same $K_{S}$ value in tension and compression. Uplift tests carried out by Rao and Venkatesh (1985) indicated uplift capacity requires higher pile movement to mobilize interface friction than compression load tests and a significant reduction of unit shaft frictional resistance, up to $20 \%$ less than that of compressive tests was observed. Due to the significant uncertainties Poulos and Davis (1980) and design manuals such as the CFEM (CGS, 2007) advocate the reduction of uplift capacity from 60 to $80 \%$ of the frictional capacity of piles in compression.

Various researchers have discussed the mechanisms contributing to the differences in the shaft capacity under compressive and uplift loading modes. De Nicola and Randolph (1993) carried out a parametric model of piles in granular soils under tensile and compressive loading. They argued that one of the underlying reasons for the discrepancy of the capacities was due to the Poisson's ratio effect. Compressive loads induce a pile radial expansion generating higher shaft normal stresses, while uplift or extension loads cause an inverse effect leading to lower frictional capacity. They derived an expression to quantify the ratio between compressive and tensile capacity as a function of the pile's Poisson's ratio and the pile's slenderness ratio L/d. Their approach was consistent with other documented compressive/tensile pile load tests and indicated 
an uplift/compressive capacity ratio ranging from 0.5 to 0.8 consistent with previous findings.

Theoretical approaches have been proposed aimed at determining uplift capacity analytically. Chattopadhyay and Pise (1986) considered the uplift soil failure as a function of the pile slenderness ratio (L/d), soil friction angle $\phi$, and pile interface friction angle, $\delta$. Their proposed method presents reasonable predictions with documented pile test literature. In current practice however, the uplift capacity for straight walled piles is typically estimated by reducing the compressive frictional capacity of the pile by a recommended value ranging from 0.5 to 0.8 depending on installation method and soil type.

\subsubsection{Lateral Capacity}

Pile foundations are often subjected to lateral loads and moments depending on loading conditions. This occurs when supporting structures at harbours which experience lateral wave and ship impact loadings, piles supporting earth retention systems, tall structures exposed to significant wind loading and structures in earthquake prone areas. In this section a brief description will be provided regarding the current methods and design procedures for estimating lateral resistance for single piles.

In current practice, some simplifying assumptions and specified boundary conditions regarding the behaviour of the pile and the surrounding soil are made to estimate lateral pile capacity of vertical piles. Pile head fixity conditions are broadly categorized between fixed head and free head, both of which can occur in practice. Additionally, pile slenderness is considered and different design methods are selected for long piles, where the pile material itself fails before the surrounding soil, as opposed to short piles, where the soil surrounding is the critical failure mechanism. Typically, two 
main methods are employed when estimating the pile lateral resistance: estimating pile ultimate lateral capacity, and estimating acceptable pile deflections at working loads (Prakash and Sharma, 1990).

\subsubsection{Estimating Pile Ultimate Lateral Capacity}

The estimation of pile ultimate lateral capacity is typically conducted through a static equilibrium method where the theory of lateral earth pressure is applied to estimate the forces acting along the pile shaft and evaluate equilibrium conditions. The conventional static approach described by Poulos and Davis (1980) assumes that the pile is unrestrained (pile head is free to rotate), slender, rigid (soil failure will occur before pile failure, also referred as "short piles") and assumes a point of rotation at an unknown depth below ground level. The ultimate lateral resistance is determined to be a function of the pile length, diameter, lateral load eccentricity and soil lateral pressure distribution along the pile shaft. Various static approaches attempt at estimating the lateral earth pressures experienced along the shaft of the pile under lateral loading for different soil types (cohesive, cohesionless), pile types (short, long) and pile head fixity condition (free, fixed). Brinch Hansen (1961) proposed a procedure which allows estimating the ultimate lateral resistance for any distribution of soil resistance; however this method is only applicable for rigid (short) piles.

A more common approach introduced by Broms (1964a and 1964b), takes into account soil type, pile type and pile head fixity by applying simplifying assumptions, such as lateral earth pressure distribution along the pile shaft dependant on soil type (cohesive, cohesionless), and failure mechanisms dependent on the yield moment of the pile itself. Broms's method is commonly used in preliminary design due to its simplistic approach, however ultimate pile capacity estimated through static methods can occur at very high lateral deflections. Typically lateral deflections control the design, especially for 
softer piles such as FRP piles. It is expected that lateral resistance of the FRP piles to be controlled by their deflection limits.

\subsubsection{Estimating Pile Lateral Deflections}

Calculating lateral deflections of single piles is typically carried out through two approaches: the elastic continuum approach and subgrade reaction approach. The elastic continuum approach detailed by Poulos (1971) is based on the idealization of the

pile as a series of discreet pile sections with a constant stiffness, El. A uniform horizontal force is assumed to be acting along each pile segment, where the soil is a uniform, homogeneous, and isotropic material with an elastic modulus and Poisson's ration acting independently from the pile (Prakash and Sharma, 1990). Through the continuum analysis, pile and soil horizontal displacements are equal along the pile shaft elements. In order to calculate the pile displacements at points of interest such as the pile head and toe, equilibrium equations are applied to obtain closed form solutions. Published solutions of the elastic method can be found for cohesive and cohesionless soils and for fixed- and free-head conditions in design manuals such as the CFEM (CGS, 2007) allowing designers to estimate the pile deflections with basic pile and soil parameters such as pile stiffness properties and soil elastic properties. One of the major obstacles with the use and accurate prediction of the deflections using the elastic continuum method is the appropriate selection of the soil elastic properties due to the inherent nonlinear behaviour of typical soil materials (Poulos and Davis, 1980).

The subgrade reaction approach is an extension of the Winkler approach for modelling foundations as a beam on an elastic subgrade. The lateral earth forces are modelled through a Winkler soil model consisting of infinitely closely spaced elastic springs acting independent of each other. The spring stiffness is referred as the modulus of subgrade reaction which is specific for each soil type and soil condition. The 
determination of this value is typically obtained through lateral pile load tests, plate-load tests or empirical correlations with soil parameters (Poulos and Davis, 1980). A limitation of applying the Winkler approach towards the estimation of deflections for laterally loaded piles is the fact that it can only analyze elastic soil deformations. Non-linear behaviour is typically analyzed through the solution of differential equations relating pile deflection, moments and axial forces at a various depths, to the soil reaction. This method, known as a load-deflection analysis or commonly referred as the " $p-y$ " approach, uses a series of curves relating pressure " $p$ " to pile deflection " $y$ " at different depths along the pile to calculate the compatible pressure and deflection values through a numerical solution of a finite difference equation. A conceptual model of a series of $p-y$ curves is presented in Figure 2.2. These relationships have been derived based on instrumented pile load tests in different soil conditions. Matlock (1970), Reese and Welch (1970) and Cox et al. (1971) developed a series of $p-y$ curves for piles in soft, stiff clays and sands respectively. Published curves are typically incorporated in numerical software packages such as LPILE (Ensoft Inc., 2013) which can analyze the finite difference equations and soil conditions based on user inputs and provide pile shaft deflections. The $p-y$ approach is commonly used in industry for pre-cast concrete, drilled shafts, driven pipes, and H-pile types of deep foundations. Limited work has been carried out regarding the modelling of FRP piles using the $p$-y approach which must be validated by full scale pile load tests. Pando et al., (2003) carried out a comparison of the behaviour of concrete-filled FRP piles with an analysis using LPILE software and found reasonable agreement with the deflections measured from an instrumented pile. They did, however, use a non-linear pile modulus as FRP materials exhibit highly nonlinear stiffness parameters. 


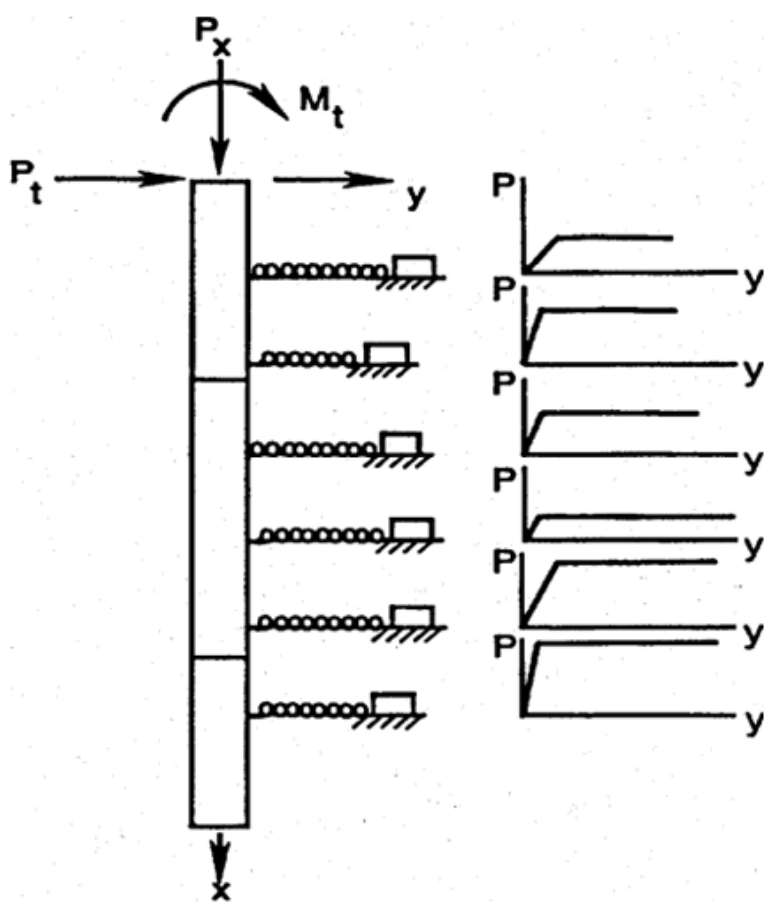

Figure 2.2 - Conceptual Model of $p-y$ Soil Response of Laterally Loaded Piles (O’Neill and Reese 1999)

\subsection{PILE INSTALLATION METHODS}

Pile installation is predominately done through two typical methods: driven piles or drilled piles. Driven piles are installed using an impact or vibratory hammer depending on soil conditions and design restrictions. This method consists of embedding the pile into the soil through impact blows or vibratory motion. Some advantages of driven piles include the wide versatility that can be used for different soil conditions. Driven displacement piles such as pre-cast concrete piles can generate increased shaft capacity due to densification of the soil surrounding the pile. Conversely low displacement piles such as $\mathrm{H}$-piles or steel pipe piles may be required for installation in sensitive clays in order to prevent clay structure collapse. Drawbacks of driven piles include driving refusal when hard underlying strata cause excessive stresses along the pile preventing reaching design embedment or causing structural pile damage. Drilled piles, also known as cast- 
in-place piles, are typically installed by the excavation of a circular hole which is then conditioned with steel reinforcement and filled with concrete creating a coherent reinforced concrete shaft. The excavation hole can be supported by permanent or temporary support casing to prevent caving of the surrounding soil and provide structural reinforcement if a permanent casing is used. Drilled piles can provide some of the largest diameter of any type of piles allowing for increased shaft and toe capacity and can be drilled into hard strata or bedrock creating a pile socket allowing for very high toe resistances (Coduto, 2001). Drawbacks of this piling system include construction difficulties such as bored hole collapse leading to non-uniform pile cross-sections and the need for specialized drilling equipment.

Selection of installation methods is influenced by a large number of variables such as costs, soil conditions, design requirements, equipment and material availability, project logistics, etc. From a geotechnical point of view, installation method is typically chosen based on the structural loads to be supported and soil type. High loading conditions may require the use of large diameter drilled shafts, while piles in sensitive clays may need low displacement driven piles such as steel pipe piles or $\mathrm{H}$-pile in order to prevent clay-structure collapse. Installation methods, materials and pile dimensions are highly dependent to project specifications and soil conditions which must be carefully considered before the selection of any pile design.

Installation of FRP piles have been typically done through a driving mechanism of either hollow, pre-cast concrete-filled FRP shells, or reinforced plastic piles (Iskander and Hassan, 1998). The installation method for FRP piles follows the same principles as those for steel pipe piles or pre-cast concrete piles in terms of driving equipment and testing. This facilitates the introduction of new FRP materials as no specialized technologies need to be developed for the use of this new type of piles. 


\subsection{PILE TESTING METHODS}

Pile capacity estimates through analytical and empirical methods are a preliminary design indication of pile-soil resistance. Typically, depending on project scope and soil profile, pile load test are carried out in order to determine the actual pile capacity representative of piles used in a specific project. Two main types of pile testing methods are carried out regularly in industry to estimate axial or lateral pile capacity: static and dynamic pile load tests.

Static load tests can be carried out to measure pile capacity for both axial loading in tension or compression, and for lateral loading. The basic principle of a static load tests is to apply sufficient force in order to bring the pile to failure. This is typically done by installing a series of reaction piles surrounding the test pile, where a reaction frame is connected with a capacity higher than the expected pile resistance. The test is carried out by applying loads using a hydraulic jack and measuring the pile resistance and displacement through a load cell and a properly calibrated displacement gauge devices such as a linear variable differential transformer (LVDT) unit. An example of an instrumented pre-stressed concrete pile undergoing an axial static test carried out by Pando et al. (2003) is illustrated in Figure 2.3. Interpretation of the load-displacement data yields the ultimate pile capacity based on different load-displacement criteria proposed by various authors (e.g. Davisson, 1972; DeBeer, 1967; Chin, 1970; Kondner, 1963; Fellenius, 1975). Typically static load test procedures are carried out in accordance to standard testing procedures based on ASTM D1143 (2007) and ASTM D3966 (2007) for compressive and lateral loading respectively. In addition, analogous static and semi-static pile load tests such as the Oestemberg load cell or statnamic testing are commonly used in industry. 


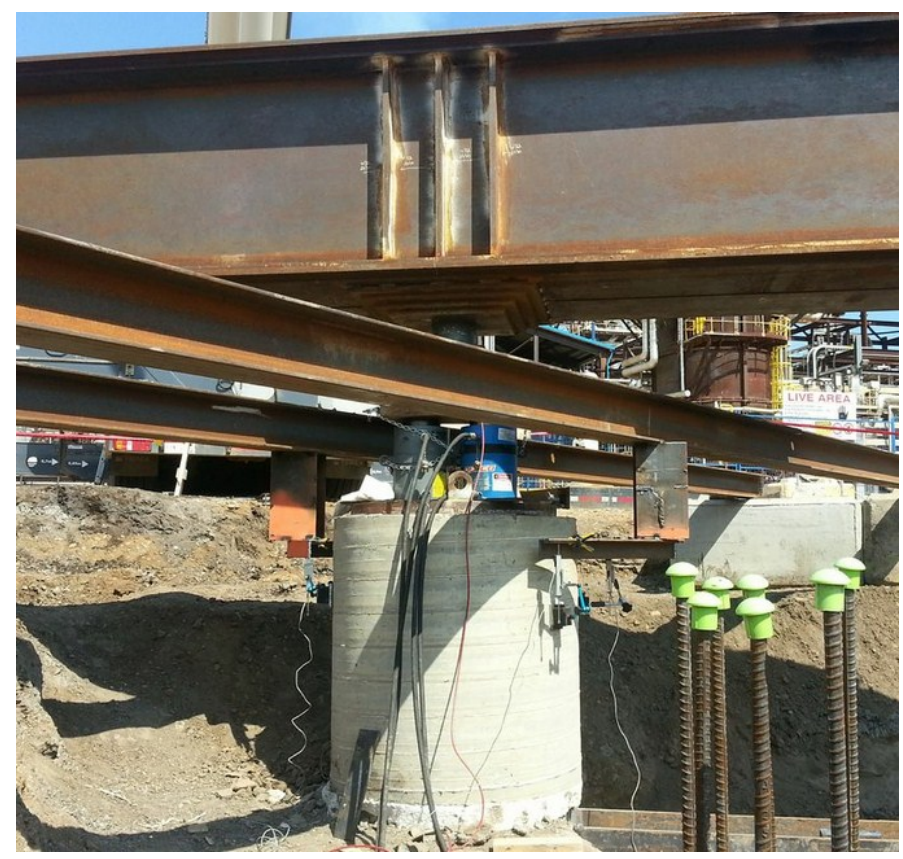

Figure 2.3 - Static Axial Pile Load Test - Courtesy of AATech Scientific

Dynamic load testing, also known as high strain dynamic testing, is commonly used to estimate pile resistance and integrity while driving and at end of driving. This method involves measuring the pile elastic response to the force of the impact hammer during driving. As the impact force is applied, a compressive wave travels down the pile shaft, pile-soil shaft and toe resistance reflects portions of this compressive wave in the opposite direction. These changes in the compressive wave are recorded by accelerometers and strain transducers measuring the pile response, and a pile drive analyzer device computes the pile resistance based on a numerical integration of a dynamic wave equation. Smith (1960) presented a comprehensive approach to model a pile driving system including soil-pile interaction and time dependant effects inherent of the compressive strain wave caused by the driving forces. Current practice utilizes established methods of analyzing dynamic pile driving data such as CAPWAP® and GRLWEAP (Pile Dynamics, Inc, 2010) with standard testing methods described in ASTM D4945 (2012). These methods and numerical integration software have been based on 
the work of various authors over the years such as the approaches described by Rausche et al. (1972) and Rausche et al.(1985) among others.

\subsection{PILE-SOIL INTERFACE INTERACTION}

Pile-soil interface interaction is a critical component contributing towards pile capacity in piles relying primarily on shaft frictional resistance over toe bearing such as open-ended driven piles in clays. Estimating pile resistance mobilized through ultimate shaft frictional capacity as described on section 2.3.1 relies on characterizing the interface shear strength properties. These properties, such as interface friction angle and interface adhesion, are used to estimate shaft resistance, $q_{s}$, based on the appropriate drained or undrained approach using the $\beta$ or $\alpha$ coefficients. Various researchers have carried out tests attempting to characterize interface shear strength parameters using simulated pile-soil interfaces through shear box devices and simple shear instruments. Potyondy (1961) carried out a comprehensive study characterizing the interface shear behaviour between typical piling materials and different types of soil using direct shear test apparatus. He found four critical factors affecting pile-soil interaction: surface roughness, moisture content, soil composition and magnitude of normal loading. A summary of various research programs is presented in the sections below exploring shear strength interface parameters between steel, concrete and FRP materials against clayey and sandy soils.

\subsubsection{Relevant studies on pile- soil interfaces}

Interface shear strength behaviour between soil and common construction materials such as steel and concrete interfaces is an important design parameter given the popularity and versatility of these materials in piling. Typically, interface behaviour has been characterized through empirical correlation of pile load tests under different soil 
conditions. This section will discuss different studies exploring interface behaviour between pile materials, sand and clayey soils and parameters governing the interface shearing strength.

\subsubsection{Relevant studies on pile - clay interface behaviour}

It is typically accepted that the undrained shear strength of saturated clays is not an intrinsic soil property, but it rather depends on a series of factors such as test type, rate of shearing, over consolidation ratio, and soil anisotropy, among others (Silvestri et al., 1989). Research programs studying shear strength of cohesive soils have identified three different shearing failure modes under undrained conditions: turbulent, transitional, and sliding. Turbulent failure was characterized by increased disturbance of the clay microstructure, while sliding failure was primarily due to lack of particles interlocking at the failure surface, transitional failure is an intermediate state between these two types of shearing failure (Lupini et al., 1981). The shape, type and ratio of rotund to platy particles are typically the controlling parameters determining the type of shearing failure. Stark and Eid (1994) identified similar failure mechanisms and concluded that shear strength is influenced by mineral type and clay fraction of the soil. Similarly, interface shear strength is primarily influenced by the interface dependant criteria such as surface roughness, profile, and interaction between soil particles and interface.

Interface behaviour between steel and clays has been explored by various authors in order to characterize the soil and pile parameters affecting the interface shear strength which is a critical factor in pile design. Taha (2010) explored the interface characteristics between a marine clay, steel and concrete investigating the effects of several parameters such as interface roughness, degree of saturation, OCR, dry density and clay salt content. The critical controlling parameter of interface strength was found to 
be the relative steel surface roughness. Similarly Rouaiguia (2012) found that surface roughness had a significant effect on the shearing behaviour of London clays and sandstone interfaces. Lemos and Vaughan (2000) corroborated the findings of Lupini et al. (1981) where they identified similar shear failure modes along steel-clay interfaces. They reported that soils with high clay fractions undergo sliding shear failure where interface roughness does not have significant effects on interface shear strength, whereas soils with relatively low clay fractions undergo turbulent shear failure. Typically, interface shear strength is influenced to a higher degree by surface roughness due to additional particles interacting with the material interface.

Similar element interface characterization has been carried out by other researchers such as Chu and Yin (2006) which studied soil-grout interface shear strength, Ovando-Shelley (1995) who carried out direct shear testing on Mexico City clays and pile interfaces exploring the cyclic response to shearing. Johnston et al. (1987) utilized a direct shear apparatus to characterize pile sockets in weak rock, and Goh and Donald (1984) investigated concrete-soil interfaces for the analysis of retention walls. All these researchers found similar parameters influencing soil-interface shear strength such as the importance of increased surface roughness which allows for the additional interlock between soil particles and pile surface leading to higher shear resistance.

\subsubsection{Relevant studies on pile - sands interface behaviour}

A typical method for measuring interface shear strength of sands is through element testing using direct shear devices. Angular sand particles have been reported to induce consistently higher frictional values compared to rounded particles due to increased interface interlock (Brummund and Leonards, 1973). Steel-sand Interface characterization studies have identified that sand type and interface roughness are parameters with a significant influence on frictional resistance, while normal stresses 
were found to have reduced role controlling interface behaviour (Uesugi and Kishida, 1986; Uesugi, 1987). Other works investigating interface parameters between sands and geosynthetic materials such as high- and medium-density polyethylene (HDPE and MDPE) materials showed that interface shear strength tended to increase with soil density and decrease with reduced polymer hardness (O'Rourke et al., 1990). Pando et al. (2002) presented a comprehensive interface shear strength characterization program for sand against FRP and concrete piles. The results indicated that particle angularity and surface roughness were the controlling parameters regarding interface shear strength. The concrete pile interface was measured at the highest capacity due to the rougher surface topography allowing for increased interlock between soil particles and the concrete surface. Results relating to the FRP interfaces will be discussed in detail in the sections below.

In general, all of the studies investigating sand-interface interaction found similar controlling parameters limiting shear strength. Relative surface roughness and sand angularity were consistently the two key factors affecting interface strength where increased interlock between the interface and the particles allows higher shear resistance.

\subsubsection{Relevant studies on FRP - soil interfaces}

Fiber reinforced polymers have gained interest in recent decades particularly as construction materials of fender piles in offshore structure due to their increased resistance to corrosion and longer service life than piles manufactured using traditional piling materials (Iskander and Hassan, 1998). In an attempt to expand the use of these materials as load bearing piles, interface properties between FRPs and different soil types must be assessed in order to characterize frictional performance and shearing resistance. Various researchers have carried out interface characterization programs 
aimed at determining the frictional performance of FRP materials and compare these results those of concrete and steel.

Frost and Han (1999) carried out a comprehensive research program investigating the interface shear strength between FRP composite materials and granular soils using a direct shear apparatus. The focus of their study was to compare the shearing behaviour between FRP-sand and steel-sand interfaces in order to quantify the shear strength properties. The findings indicated that the type of particle (rounded vs. angular) caused a difference in the shearing behaviour with rounded particles exhibiting a "brittle" behaviour compared to angular sands. More importantly, the interface frictional resistance was linearly related with increased surface roughness for both FRP and steel interfaces. Other parameters such as rate of shearing, sample preparation method or specimen thickness had limited influence on the results. In a similar study conducted by Pando et al. (2002), the relative roughness of the FRP surface was found to be the controlling of FRP-sand interface shear strength. Additionally two other controlling parameters were identified: surface hardness and soil angularity. Higher shear strength was measured on FRP interfaces with lower surface hardness due to additional soil interlocking from particles penetrating the pile surface. It was determined that interface shear strength was comparable to that of prestressed concrete piles; however, full scale testing is needed to corroborate element testing with field results.

Data regarding interface shear strength between FRPs and clays are very limited in the literature, especially experimental field works. The need of quantifying clay-FRP adhesion parameters is clear since pile design under undrained conditions is typically the governing case in saturated clays. Chapter 3 of this work will describe in detail the results of element testing for FRP-marine clays shear strength characterization. In 
general, based on the available literature, FRP-soil interface, particularly FRP-sands interface, is controlled by the same general parameters as traditional construction materials: interface roughness and soil angularity playing major roles. Other parameters such as normal confining pressures, sample preparation, rate of shearing or sample thickness have been reported to have a limited influence. Surface hardness of FRP materials, a parameter specific to FRP piles, was shown to have an influence against sands. It is doubtful that it can play a significant role in the shearing resistance against clays since the clay particles are unlikely to penetrate into the FRP surface in order to cause significant interlocking mechanisms as it is the case with sands. Further work is needed in the shearing behaviour against clays in order to corroborate these similarities.

\subsection{PILLING USING FRP PILES}

The focus of this thesis is on the performance of carbon and glass FRP piles, particularly hollow FRP piles and how they perform as load bearing supports. In the last decade, select large scale pilot projects have used FRP piles as a proof of concept in large transportation projects such as highway overpasses. These types of piles are primarily concrete-in filled FRP shells which can withstand larger axial capacities compared to hollow counterparts. Challenges regarding the wider use of hollow and concrete-filled FRP piles include characterization of pile behaviour under driving conditions, assessing the design and response of the material from a structural perspective, and measuring behaviour of FRP piles under axial and lateral loadings. In the following sections, the current state of practice regarding these aspects of FRP pile behaviour will be discussed in detail 


\subsubsection{FRP piles driving performance}

Pile drivability and performance is a crucial aspect when determining the viability of a type of material or geometry as in many cases driving stresses are the highest loads the pile will ever experience. FRP piles face many challenges in this area due to their inherent lower stiffness, lower pile impedance and density which leads to higher pile damping and energy dissipation (Guades et al. 2012). This is particularly critical for hollow FRP piles as these piles cannot account for a concrete infill to carry a portion of the driving stresses leading to possible pile structural failure during driving such as buckling or pile cracking. Iskander et al. (2001) carried out a numerical parametric study using a typically used wave equation analysis of pile driving (WEAP) software to determine the influence that various FRP pile parameters may have on the driving performance. They found that all FRP piles could attain reasonable capacities as load bearing members, however practical driving records are needed to corroborate these observations. One key finding was the link between pile unit weight (which in turn is directly related to material density and shear wave velocity), pile cross sectional elastic modulus and driving performance. Comparing the performance of stiffer piles to softer FRP piles, it was concluded that the driving response of stiffer piles are heavily dependent on soil properties, while for relatively softer piles, pile material properties play a controlling role.

Ashford and Jakrapiyanun (2001) performed a dynamic pile driving analysis on various hollow and concrete-filled glass FRP piles, steel pipe pile and reinforced concrete pile. Based on the dynamic driving analysis, they found that all of the FRP piles presented favourable results compared to the concrete and steel piles. They discussed the role of pile impedance (a function of pile geometry, cross-sectional area, elastic modulus and shear wave velocity) and how the significantly lower FRP pile impedance 
leads to lower ultimate capacity at driving refusal of 65 to $75 \%$ that of steel and concrete. Finally they emphasized the need for further research in order to verify these results before FRP piles can be accepted as load bearing alternatives. Mirmiran et al. (2000) conducted a similar study analysing the dynamic performance of hollow and concretefilled glass FRP piles and concluded that in-filled FRP pipe piles could be a feasible alternative as the driving stresses and ultimate capacity was similar to that of a prestressed concrete pile. They identified, however, the susceptibility of hollow FRP piles to damage through buckling or fracturing during driving. Similarly driving stresses at refusal of hollow FRP piles were reached at 40 to $50 \%$ that of concrete piles.

Research carried out on the driving performance of FRP piles is favourable for concrete-filled sections, while for hollow sections, structural integrity is at stake. Pile driving to shallow depths or in soft soils such as soft clays can become ideal conditions for the use of hollow FRP piles without jeopardizing structural integrity. Further work regarding the determination of skin friction, settlement and lateral loading behaviour of FRP piles was highlighted by the works previously cited.

\subsubsection{FRP piles structural behaviour}

In addition to applications in the piling industry, there has been increased interest in using FRP materials as reinforcement for structural members such as beams and columns. Researchers have explored the behaviour of hollow, partially filled and fully infilled FRP tubes under axial and flexural loads through various experimental programmes and numerical analyses. These results are important when taking into consideration the structural resistance of FRP piles under various loading modes. An important part of the design of FRP piles is the accurate modelling of the pile structural resistance and elasto-plastic deflections in order to determine when concrete infill is required depending on soil resistance and loading conditions. 
Fam and RizKalla (2001a) carried out a parametric study investigating the compressive behaviour of concrete-filled and partially filled FRP tubes with a central void. They found that the FRP tube provides a confinement effect on the concrete which significantly increases the stub axial capacity over unconfined concrete sections. The controlling failure criteria for these composite sections were identified to be the FRP shell which ruptures in a brittle manner. An analytical model regarding the effect of FRP confinement on composite columns have been proposed by Fam and Rizkall (2001b) as a complementary study which corroborated the experimental findings regarding the increased sectional stiffness and increased confinement effect with smaller central void. An analytical study regarding critical buckling loads of slender FRP piles was conducted by Han and Frost (1999). They found that due to large moduli ratios (E/G) of concretefilled FRP piles, shear deformation effects can have a larger impact on the critical buckling load of FRP piles compared to steel and concrete piles. Pile boundary conditions were found to play a critical role in determining buckling loads where the increase of pile restrain had a significant effect increasing the critical load. In contrast, soil skin friction was found to play a limited role on the critical load. They concluded that FRP piles were more likely to experience buckling when installed in very soft soil conditions or when there is a significant pile projection above ground level.

Flexural behaviour of hollow and concrete-filled FRP piles has been investigated by Fam and Rizkalla (2002). They found that flexural strength is greatly benefited from an infilling or partial infilling with a central or eccentric void on the tensile region of the cross-section. Fiber orientation plays a role in the failure mechanism, as sections with reduced hoop oriented fibers fail due to horizontal shearing while sections with increased axially oriented fibers fail under compressive failure of the of the FRP fibers. In general, concrete-filled or partially filled sections provide higher flexural capacities compared to 
hollow sections. Careful consideration should be given when determining the ultimate flexural resistance due to the anisotropic and non-linear effects of FRP tubes induced by the laminated nature of the material and the fiber orientation effect. A strain-compatibility model used to predict moment-curvature behaviour of FRP tubes was proposed by Fam (2000). This model has been used to estimate the lateral pile behaviour of concrete-filled FRP piles as it will be discussed in subsequent section.

\subsubsection{FRP piles under axial and lateral loading}

In order to establish a confident track record of FRP piles under working conditions, small scale and full scale pile load tests are needed to assess the pile capacity performance under a variety of soil conditions and determine how the current design guidelines predict this behaviour. To date there has been a limited number of small scale and full scale axial pile load tests on FRP piles. A study carried out by Sakr et al. (2004) utilized FRP and steel closed-end piles to test the compressive and lateral performance of driven piles in a closed and pressurised sand filled chamber. A special toe-driving technique was used on FRP piles with the intent of achieving better axial capacity and preventing pile damage due to high driving stresses on the FRP piles. They found that, in compressive capacity, FRP piles performed at a comparable level to that of steel piles, and those driven with the toe driving technique reached higher bearing resistance presumably due to increased soil densification at the pile toe. In terms of lateral performance, the steel pile provided higher capacity at a certain pile head deflection limit over the FRP piles, mainly due to the lower FRP pile stiffness linked to lower elastic modulus. Stiffer fiber materials were suggested as an option intended to increase the piles lateral capacity.

A comprehensive field investigation on the performance of concrete-filled FRP piles was carried out by Pando et al. (2003) using a large scale piles as support of a 
highway overpass in Virginia. The study compared the performance of prestressed concrete piles and various FRP piles including a concrete-filled glass FRP pile. Static and statnamic compressive and lateral pile load tests were carried out on these instrumented piles. Based on the compressive pile resistance, it was identified that the FRP piles performed at similar levels as the prestressed concrete pile. In addition, a series of comparative analyses discussing the measured and calculated pile capacities was performed where it was found that, for the two types of FRP piles used, there was a good agreement of the calculated-to-measured capacity ratio. Finally, with respect to the lateral capacity, lower lateral resistance was measured for FRP piles compared to the concrete pile which was attributed to lower pile stiffness. A series of $p$-y analyses were carried out where good agreements of calculated lateral deflections to the measured deflections were observed. The authors emphasized the need to consider shear deformation effects as pile moduli ratios $(E / G)$ increase such as the case with hollow sections.

To the best knowledge of the author, there has been no type of pile testing in mainly clayey soils intended to identify the frictional capacity of hollow FRP piles. This study will attempt to provide some insight on the behaviour of this type of materials in clays.

\subsubsection{Challenges of FRP piling}

Although material properties make FRP piling an attractive alternative to traditional piling materials, there are several challenges that must be overcome. Material durability under working conditions must be confirmed through pile monitoring programs. Pando et al. (2003) carried out a comprehensive material degradation study through subjecting various FRP samples to temperature cycles, UV exposure and other weathering 
conditions. They found no significant material degradation or reduction in the material mechanical properties.

Pile driving, particularly of hollow FRP pipe piles can be a challenge as it has been measured in various studies as described in section 2.7.2 that hollow FRP piles reach driving refusal at 50 to $60 \%$ the capacity of similarly sized steel pipe piles due to lower pile impedance (Guades et al., 2012). Other alternatives to overcome this drawback are innovative driving techniques such as a toe driving method proposed by Sakr et al. (2004) aimed at reducing pile driving stress across the pile.

Serviceability design criteria can be an issue for FRP piles, particularly hollow FRP piles under significant lateral loading. The material typically present lower elastic moduli than steel and concrete piles, which in conjunction with higher moduli ratio $(E / G)$ can lead to increased lateral deformations (Han and Frost, 1999).

Perhaps the most critical requirement for FRP piling is providing insight to designers regarding the optimal FRP piling system. Weather it be open toe hollow- FRP piles, partially filled FRP-piles, fully concrete filled FRP piles which depend on expected working loads and sub surface conditions. In addition, cost-effective design must be achieved before full scale implementation of this piling system can be used in industry.

\subsection{SUMMARY}

FRP piles have been considered in recent years to be a viable alternative to traditional piling materials such as concrete, steel and timber due to their inherent advantages with respect to their improved service life induced by resistance to corrosion and degradation which steel, concrete and timber piles are vulnerable. In current practice, FRP piles are used in light bearing applications typically on waterfront developments where their higher 
damping due to material properties allow better energy absorption for fendering applications compared to traditional piles. Current FRP pile materials include a variety of plastic and reinforced plastic piles along with fiber wound or casted glass fiber piles.

Pile axial capacity in compression and tension was discussed, where it was highlighted the critical parameters affecting pile capacity such as soil type (cohesive, cohesionless), pile type and geometry, (open ended, closed end), pile material and installation methods, (drilled shaft, driven piles) among other factors. Typical methods for estimating pile shaft resistance are based on soil type for either drained or undrained conditions. Under drained conditions, the frictional pile resistance is estimated based on lateral earth pressure along the pile shaft and interface friction parameters. Under undrained conditions, pile-soil adhesion parameters are used in order to estimate pile shaft resistance. Lateral pile capacity is typically determined according to ultimate failure loads or allowable deflections at working loads, however, in many cases large deflections can occur before the ultimate failure load is reached. For this reason, the design of piles under lateral loads is mostly controlled by the allowable deflection limits. Typically, FRP piles present lower stiffness than similarly sized traditional piles which leads to increased deflections under lateral loading, and hence the design of these piles is often dictated by deflection limits.

Pile installation is typically carried out through either drilling and casting concrete, referred as cast-in-place piles or through driving pre-cast concrete or steel piles. FRP pile installation has been carried out with the same equipment as steel and pre-cast concrete pile for both hollow FRP pipe piles and concrete filled FRP piles. Similarly, pile testing methods and equipment, used for determining the actual pile capacity, can be used for both FRP piles and traditional piles. 
Critical parameters controlling the interface shear strength of FRP surfaces were identified to be related to the relative interface roughness of the FRP material and soil angularity of granular soils. Increased particle interlock is consistently measured to increase the frictional resistance. Interface frictional capacity between FRP piles and cohesive soils is poorly understood due to lack of experimental data; however, it is expected to be affected by similar parameters controlling soil-steel interfaces such as relative roughness and fraction of fines within the soil allowing for increased interlock at the microstructure level.

Current pilot projects using full scale FRP piles have explored three main areas: driving performance, structural behaviour, and pile capacity under axial and lateral loading conditions. The typical type of pile used as a load bearing member is glass wound FRP with a concrete in-fill, however, reinforced plastic piles and hollow FRP piles have also been used. The driving performance has been measured to be on par with traditional piling materials for concrete-filled FRP piles, however, driving of hollow pipes have been measured to reach refusal at $50 \%$ driving stresses of traditional piles. The structural performance was similarly measured to increase for FRP piles with concrete in-fill due to the increased cross-sectional stiffness and a confining effect provided by the FRP shell. Concerns regarding shear deformation effects have been highlighted due to the FRP materials inherent higher elastic to shear moduli ratio, particularly with respect to lateral pile deflections. With respect to pile ultimate capacity in axial compression, it has been found that FRP piles present similar performance to steel and pre-stressed driven piles. Ultimate lateral capacity has been measured to be lower than comparably sized steel and concrete piles due to the FRPs lower elastic modulus and non-linear behaviour. 
The current state of FRP piling is still in its infancy as there is a gap in knowledge regarding the performance of these materials in different soils under different loading modes. Preliminary studies characterizing interface behaviour through element testing such as shear boxes, and pilot projects using full scale specimens have indicated that FRP piles are a viable alternative to traditional piles presenting comparable load bearing performance. Further studies are needed in order to fully characterize the interface behaviour, particularly against cohesive soils. This work will address some of this gap in knowledge as a testing program aimed at identifying interface behaviour between FRPs against soft clays is presented in Chapter 3. Furthermore, small scale FRP pile load tests are carried out and compared to the behaviour of similarly sized steel piles in order to comparatively assess the performance of FRP piles. The results of this work are presented in Chapter 4. 


\section{CHAPTER 3}

\section{FRP-CLAY INTERFACE STRENGTH}

\subsection{INTRODUCTION}

The shear resistance between soils and an interface surface is of significant interest for the design and performance of many geotechnical systems such as friction piles, bored piles, soil nails, anchor rods, retaining walls, and geomembranes among others. These interface shear resistance depends on the soil type, grain size distribution, interface material, surface roughness, normal stresses at the interface and rate of shear displacement (Lemos and Vaughan, 2000). There has been significant work completed on interface characterization of typical pile materials with sandy soils compared to work performed on clayey soils and, in particular sensitive marine clays (Rouaiguia, 2010).

In recent decades, new composite materials have been rising in popularity as construction materials, particularly in structural rehabilitation and construction of new buildings. These composite materials, known as fibre reinforced polymers (FRPs), present significant benefits when used in conjunction with steel and concrete construction by improving the strength and service life of the structure. More recently, there have been initiatives by different researchers, government agencies and FRP manufacturers to use FRP materials in piling and geotechnical applications. In turn, this effort has produced an interest regarding the performance of FRP piles in different soil conditions. However, the use of FRP in the piling industry is largely limited to marine fender piles, load bearing piles for light structures and pilot test projects (Iskander and 
Hassan, 1998). In particular, previous research has focused on improving areas where traditional piling materials face significant vulnerabilities such as in harsh marine environments. Here, the degradation of pile materials can lead to a decrease in structural and geotechnical pile capacity (Frost and Han, 1999), thus reducing its service life. Studies completed in the performance of FRP piles are almost exclusively limited to the behaviour of FRP interfaces in sandy soils; seldom do studies explore the interaction of clayey soils with these composite materials.

Shear strength studies carried out by Pando et al. (2002) on FRP-sand interfaces showed that the angle of friction increases as the relative surface roughness height increases. In addition, surface hardness and particle angularity interact as a higher interface friction angle was observed when angular sands sheared against a relatively softer FRP material due to the sand particles penetrating into the surface. Conversely, a lower friction angle was observed when relatively rounder sand particles were sheared against the harder FRP surface since the particles tend to slide. Pre-stressed concrete pile surfaces presented the highest interface friction angles due to their rougher surface topology which leads to complex particle interlocking mechanisms. A similar study conducted by Frost and Han (1999) showed a linear increase of the friction angle with the relative surface roughness, while little influence on the interface shear parameters was found due to the rate of shearing or sample thickness. In addition, the results indicated similar interface friction and surface roughness parameters between the FRP specimens and steel, which illustrated the viability of using FRP materials as a piling material in granular soils. Studies carried out by Chu and Yin (2006) on strength properties of grout-soil interfaces demonstrated that the interface friction angle was influenced by the level of moisture content of the soil sample and the grout surface shape. Research on grout-soil interface strength is limited, and shear strength 
parameters in different soil types are generally limited to results derived from pile-load tests of soil-nails or micropiles.

Interface shear strength characterization in clayey soils has not been studied as extensively as in sands; however, the importance of shear strength characterization in clays was highlighted by Skempton (1964) in regards to slope stability analysis by measuring the clay residual strength in a shear box apparatus. Lupini et al. (1981) carried out a comprehensive study on the drained residual strength of cohesive soils using a ring shear apparatus, and identified three principal shear failure modes in cohesive soils: turbulent, transitional and sliding. The shearing behaviour was determined to be dependent on the shape and type of soil particles, and the ratio between rotund and platy particles. Stark and Eid (1994) carried out similar work using a ring shear apparatus on a number of different cohesive soils and concluded a dependence of the drained residual shear strength to the mineral type and the clay fraction of the soil. Studies carried out by Lemos and Vaughan (2000) on clay against smooth glass and steel interfaces linked the failure modes observed in pure soil shearing to the clay content of the soil and the surface roughness. Soils with a high clay fraction which undergo sliding shear failure tend to reach soil-soil shear strength and are independent of surface roughness, while soils with lower clay content are dependent on the surface roughness as larger soil particles interact with the material interface. Various studies have been carried out to test different interfaces used in the construction and piling industry against various types of clays (Chu and Yin, 2006; Goh and Donald, 1984; Johnston et al., 1987; Ovando-Shelley, 1995; Taha, 2010). Results from these tests provide robust data regarding the shear interface behaviour for various conditions and materials, however, few if any interface shear testing programs have approached 
characterizing the shear interface strength between clayey soils and FRP materials to the extent that it has been studied in sands.

The goal of this paper, is to investigate the interface shear strength properties of various piling materials and compare their performance with the interface shear resistance achieved by fiber reinforced polymer surfaces. Interface materials tested in this research include steel, concrete, and two types of fiber reinforced polymer surfaces. This work focuses on using a direct shear box apparatus in order to obtain interface shear strength parameters expressed as the effective interface friction angle $\delta$ and apparent interface adhesion $c_{a}$ by testing each interface specimen under drained and undrained conditions. The results will help in determining, from a geotechnical point of view, the suitability of FRP materials in piling and other applications where soil-structure frictional interface is of importance. In addition, results from this work will provide some insight into the mechanisms of soil-FRP interaction such as the influence of surface roughness, the epoxy matrix, and FRP fiber orientation in order to determine the optimal parameters for best frictional interface performance.

\subsection{MATERIAL PROPERTIES}

\subsubsection{Soil Properties}

The soil used in this study is marine clay known as Leda Clay or Champlain Sea Clay which covers the Ottawa valley and Southern Quebec. The clay material formed near the end of the most recent glaciation period in the pre-historic Champlain Sea, where fine sediments and rock flour generated from glacial abrasion of the Canadian Shield settled to form thick deposits of Leda Clay along the St. Lawrence drainage basin.

Intact clay samples were obtained from a known clay rich site at a local landfill in Ottawa, Ontario, Canada from a depth of 2 to 3 meters. Atterberg limit tests were carried 
out in accordance with ASTM D4318 (2010), showing a plastic index of 23\%. In order to establish the particle size distribution, a hydrometer test was carried out in accordance with ASTM D422 (2007) which showed a 40\% clay fraction and an activity of 0.55 (Figure 3.1). The soil is classified as CH according to the USCS (ASTM D2487, 2011). The undrained shear strength of the soil was determined by performing a vane shear test in accordance with the field vane shear test procedure outlined in ASTM D2573 (2008). The undrained soil shear strength was determined to be $S_{u}$ equal to $50 \mathrm{kPa}$. The coefficient of 1-D consolidation was measured according to ASTM D2435/2435M (2011) and presented a value of $1.4 \times 10^{-4} \mathrm{~cm}^{2} / \mathrm{s}$. A direct shear box testing program according to ASTM D3080/D3080M (2012) was performed on intact clay specimens in order to determine its drained and undrained shear strength parameters. The shearing rates used were $0.05 \mathrm{~mm} / \mathrm{min}$ for drained conditions and $2.5 \mathrm{~mm} / \mathrm{min}$ for undrained conditions. The index properties of the Leda Clay used in this study are summarized in Table 3.1. The soil properties measured for the Leda clay specimens in this study correlate fairly well with previously published work on Leda clay-interface interaction (Taha, 2010; Silvestri et al. 1989; Afshin and Rayhani, 2013).

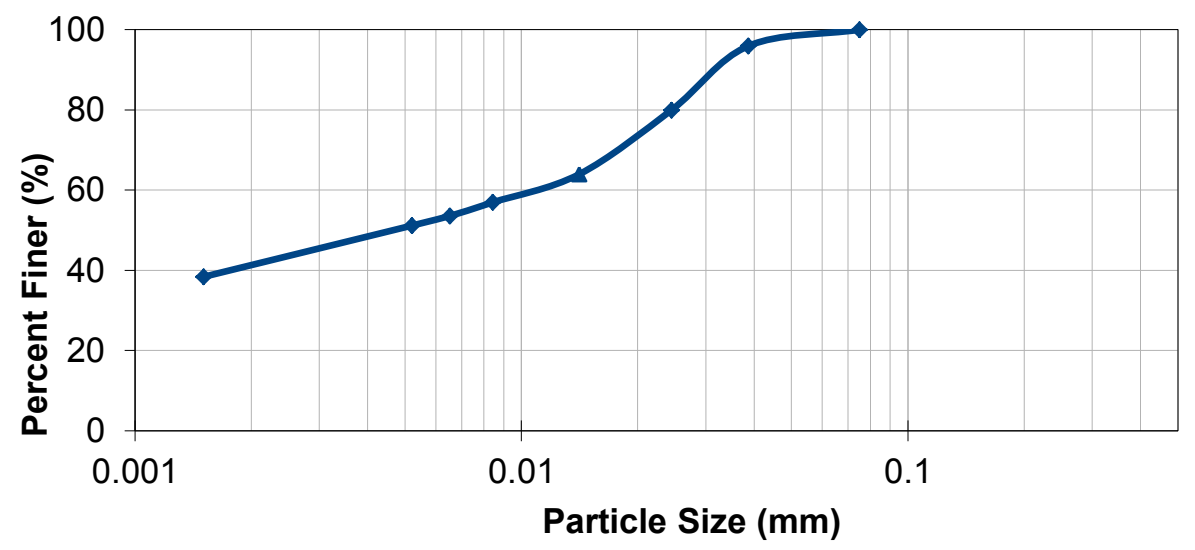

Figure 3.1 - Leda Clay grain size distribution 
Table 3.1 - Leda clay soil properties

\begin{tabular}{cccccccccc}
\hline$\rho, \mathrm{Mg} / \mathrm{m3}$ & $w, \%$ & $\mathrm{LL}, \%$ & $\mathrm{PI}, \%$ & $w_{\text {opt } \%}$ & $\rho_{d(\max )}, \mathrm{Mg} / \mathrm{m}^{3}$ & $C_{v}, \mathrm{~cm}^{2} / \mathrm{s}$ & $s_{u, k}, \mathrm{~Pa}$ & $\phi, \operatorname{deg}$ & $c_{u, k} \mathrm{kPa}$ \\
\hline 1.53 & 49 & 51 & 21 & 30 & 1.41 & $1.40 \mathrm{E}-04$ & 50 & 23.3 & 42.2 \\
\hline
\end{tabular}

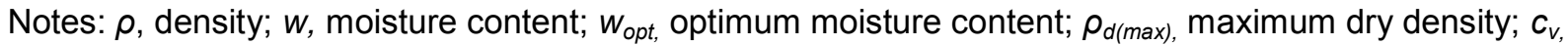
coefficient of consolidation; $s_{u}$, undrained shear strength; $\phi$, internal friction angle; $c_{u}$, apparent cohesion.

\subsubsection{Pile Interfaces}

The interface between the soil and pile material plays a critical role in determining the frictional capacity along the shaft of the pile. In this study, several pile material interfaces are studied in order to establish the shear strength properties in Leda clay. The interface materials tested were: steel, concrete, cement, carbon fiber reinforced polymer (CFRP) and glass fiber reinforced polymer (GFRP).

\subsubsection{Interface Roughness}

Surface roughness has been shown to influence the interface shear strength of noncohesive soils (Potyondy, 1961; Yoshimi and Kishida, 1981; O'Rourke et al., 1990) and cohesive soils (Lemos and Vaughan, 2000). Various definitions of surface roughness have been proposed in the study of interface shear in sands. Macro roughness is the undulations along the surface which cause extra internal work if the shearing follows this path (Kishida and Uesegui, 1987). Micro roughness is relevant at the scale of the particle size of the soil being sheared against the surface. For this study, macro roughness is relevant for the FRP surface samples as the glass and carbon fibers form a distinctive surface waviness which can influence the clay shearing interface. Surface roughness was measured using a $\mathrm{FARO}^{\odot}$ arm measuring device to scan each interface surface across a linear path and recording the vertical tip deviations. Various surface roughness description techniques have been proposed. Kishida and Uesegui (1987) used a normalized roughness value $R_{n}$, based on the median particle grain size 
distribution, $D_{50}$. This normalized surface roughness takes into account both the surface roughness of the material and how it interacts with the soil based on its particle size. A more simplified approach is taken in this study by calculating interface roughness as the average of the displacements measured at each data point, known as a centre line average or total roughness $R_{t}$, and by calculating the root mean square of the same data set to determine the average roughness or $\mathrm{R}_{\mathrm{a}}$ illustrated as follows:

$$
R_{t}=\frac{h_{1}+h_{2}+\cdots H_{n}}{n} \quad R_{a}=\sqrt{\frac{h_{1}{ }^{2}+h_{2}{ }^{2}+\cdots H_{n}{ }^{2}}{n}}
$$

\subsubsection{Steel Interface}

A common pile material used in industry is structural steel. Typical pile shapes include circular steel pipes and $\mathrm{H}$ steel sections. The benefits of steel piles include high load capacity, drivability and high structural capacity, while disadvantages include vulnerability of steel to corrosion in harsh environments and high steel costs. Steel plates were prepared in order to simulate the wall surface of a typical steel pile. The specimens were $90 \times 90 \mathrm{~mm}$ square steel plates with a thickness of $1 / 2$ inch $(12.5 \mathrm{~mm})$ machined to couple with the upper half of the direct shear box apparatus (Figure 3.2). The total surface roughness value $R_{t}$ was $9.7 \mu \mathrm{m}$ and the average roughness $R_{a}$ was

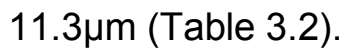

\subsubsection{Concrete Interface}

A concrete sample was prepared by using a pre-mixed cement-fine sand grout with a 1:3 ratio of sand to cement, and $35 \%$ water content by weight. The sample was cast in the lower portion of a shear box device, sealed with a flat Plexiglas surface to ensure a smooth and level surface finish, and allowed to cure for 14 days prior to initial testing (Figure 3.2). The total surface roughness value $R_{t}$ was $7.1 \mu \mathrm{m}$ and the average 
roughness $R_{a}$ was $9.1 \mu \mathrm{m}$. The use of the Plexiglas forming surface can be one of the causes for the low interface surface measurements compared to steel.

\subsubsection{Carbon and Glass Fiber Reinforced Polymer Interface}

Two types of FRP material were used in this study: carbon and glass fiber reinforced polymers. These FRP systems consist of a two part mechanism; a carbon or glass woven fabric and a corresponding epoxy resin acting as the matrix medium for the fiber.

The Clay-FRP interface was prepared by manufacturing a 10x10 inch double layered flat sheet of each material which was then water jet cut into coupons sized to match the bottom half of a shear box device. The surface texture of each material had a distinctive shape with a surface waviness controlled by how the material fabric was woven, and the finish resulting from the application of the epoxy. Both specimens were prepared as per the manufacturer's instructions using epoxy saturated foam paint rollers, and the achieved surface textures were left to cure. The surface profile and topology was significantly different based on the fiber orientation (Figure 3.2).

The large difference in interface roughness between concrete, steel and the FRP materials can be mainly attributed to the interface texture formed by the FRP woven fabrics and the epoxy casting during the manufacturing process. The effect of this interweaving and raised topology with respect to interface shear strength will be discussed below. 

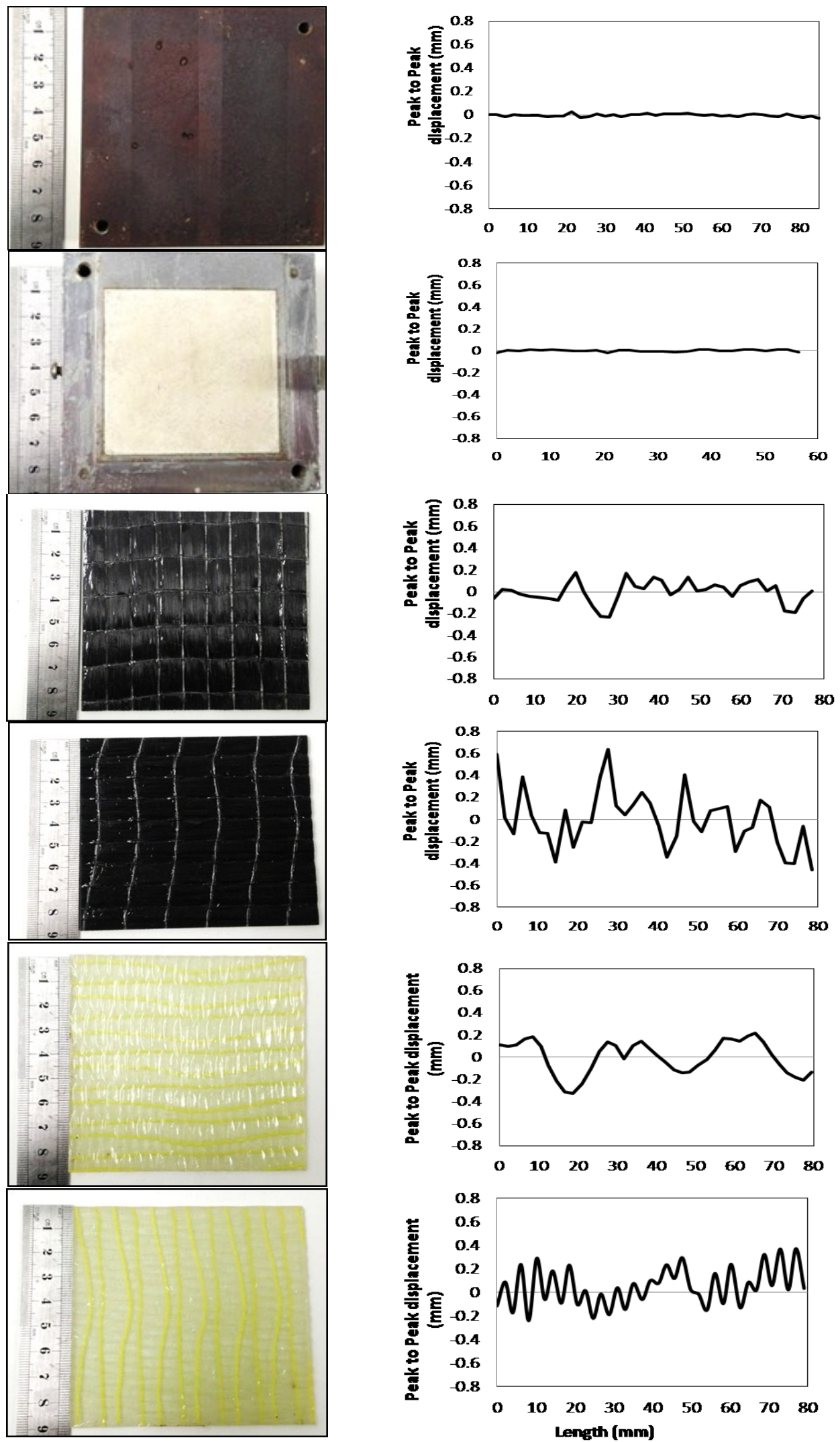

Figure 3.2 - Surface interface and profile for steel, Concrete, Carbon FRP at $90^{\circ}$, Carbon FRP at $0^{\circ}$, Glass FRP at $90^{\circ}$, Glass FRP at $0^{\circ}$. 
Table 3.2 - Pile interface roughness

\begin{tabular}{lcc}
\hline Interface & $\mathrm{Rt}(\mu \mathrm{m})$ & $\mathrm{Ra}(\mu \mathrm{m})$ \\
\hline Steel & 9.7 & 11.3 \\
Concrete & 7.5 & 9.1 \\
Carbon at 90 & 200 & 250 \\
Carbon at 0 & 76 & 99 \\
Glass at 90 & 130 & 149 \\
Glass at 0 & 140 & 173 \\
\hline
\end{tabular}

\subsection{EXPERIMENTAL PROCEDURE}

The interface characterization program was carried out using a direct shear test apparatus (ASTM D3080/D3080M, 2012) and (ASTM D5321, 2008).The direct shear test apparatus consists of a displacement controlled testing apparatus used to apply a fixed displacement rate to the shear box device through a series of gearing mechanisms. The shear box has inside specimen dimensions of $60 \times 60 \mathrm{~mm}$, outside dimensions of $90 \times 90 \mathrm{~mm}$ and a specimen height of $25.4 \mathrm{~mm}$. The normal pressure is applied by a steel bearing arm using weights to apply vertical stresses to the specimen. The shearing stresses are measured through a digital load cell connected horizontally to the top section of the shear box. Horizontal and vertical displacements are measured through linear variable differential transducer (LVDT) connected to a digital logging station using LabView software. The shear box device was slightly modified by replacing the lower half of the standard direct shear box with the interface material for interface tests. A schematic of the modified apparatus is illustrated in Figure 3.3. 


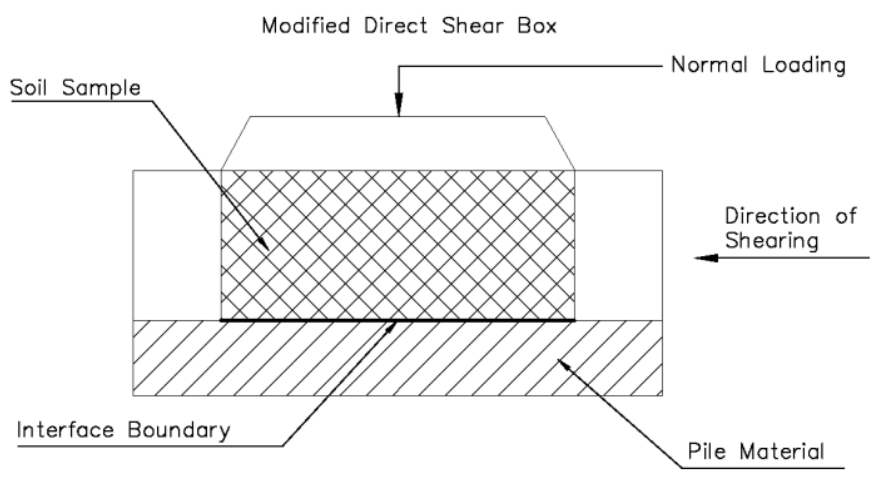

Figure 3.3 - Modified Shear Box Schematic

\subsubsection{Loading Rates}

Two loading rates were used for each test in order to measure drained and undrained conditions. Drained conditions were simulated by using a shearing rate $0.05 \mathrm{~mm} / \mathrm{min}$ or $5 \%$ strain per hour in order to allow pore water pressure dissipation and measurement of the effective interface friction angle $\phi^{\prime}$. Although the drained rate ideally achieves complete pore water dissipation, due to the very low hydraulic conductivity of the clay, it is unrealistic to expect true drained conditions and some excess pore water pressure generation will be developed while shearing. Undrained conditions were simulated by using a shearing rate of $2.5 \mathrm{~mm} / \mathrm{min}$ in order to measure the interface adhesion component $\mathrm{C}_{\mathrm{a}}$. The shearing rates were kept consistent throughout the testing for all interfaces in order to objectively compare the shear strength parameters independently of the rate effects which can have an influence on the residual shear strength parameters of soil-on-soil tests (Lupini et al., 1981) and soil-on-interface tests (Lemos and Vaughan, 2000). 


\subsubsection{Soil-Interface Specimen Preparation}

Four different soil-interface materials were tested: steel, concrete, and two types of FRPs. For the steel-soil interface a square plate of mild steel was placed in the lower half of the shear box and an undisturbed specimen of Leda clay was carefully cut to match the upper-half opening of the box and fitted to ensure a complete steel-clay contact at the interface. The concrete interface was made by filling the lower half of the shear box with a concrete mix and allowing it to cure against a smooth Plexiglas surface in order to create a smooth shearing surface similar to pre-stressed concrete piles. The box was reassembled and a clay specimen was fitted, ensuring complete interface contact.

Finally the FRP surfaces were created by manufacturing coupons of each material to carefully fit on top of the lower half of the shear box. A metal stopper was attached to the underside of the FRP coupon in order to lock it against the inside edge of the shear box and prevent any slippage of the interface. A clay sample was then carefully fitted on the re-assembled shear box in order to ensure a complete clay-FRP contact.

\subsubsection{Testing Procedure}

Interface testing was carried out in accordance with ASTM D3080/D3080M (2012). The modified shear box device was placed within a metal container which was laid upon a set of linear ball bearings allowing unrestricted horizontal displacements. The containing metal box was filled with water to ensure saturated conditions and to prevent clay cracking along the interface. The normal loading was applied through a steel bearing arm connected to the top section of the shear box. Three different normal pressures of 50, 100 and $150 \mathrm{kPa}$ were applied to simulate typical lateral earth pressures along the 
pile shaft at a moderate driving depth. The normal pressure was applied until the vertical settlement normalized to a constant value. Horizontal shearing was then initiated on the sample.

The shearing rates applied were achieved through the use of a precise screw type actuators calibrated to $0.05 \mathrm{~mm} / \mathrm{min}$ and $2.5 \mathrm{~mm} / \mathrm{min}$ in order to simulate drained and undrained conditions, respectively. The shearing was carried out up to a strain of 8 $-12 \%$ or until residual shear strength conditions had stabilized. Following failure of the specimen, the assembly was dismantled and a visual inspection of the shearing surface was carried out in order to identify the possible failure mechanism acting along the interface.

\subsection{TEST RESULTS}

\subsubsection{Pile Interface Shear Strength}

Direct shear tests were carried out on two typically used pile materials: steel and concrete against clay under three different normal pressures of 50, 100 and $150 \mathrm{kPa}$. In order to characterize the shear strength parameters of the interface, two rates of shear displacement were used to determine the interface friction angle $\phi$ and the interface adhesion value $c_{a}$. Shear stress vs. horizontal strain curves illustrate the failure mechanism at the interface and the influence of the shearing rate. Horizontal strains were calculated based on shear box dimensions and measured shearing displacement.

\subsubsection{Drained Conditions}

Figure 3.4a illustrates the shear stress - strain curve for steel, concrete, and clay-clay interfaces for $100 \mathrm{kPa}$ normal pressure. In all three cases friction is mobilized at very low displacements, in the range of $0.5-1 \%$ horizontal strain. The steel and clay-clay interfaces reach a peak shear stress value and maintain a constant residual strength at 
or nearing the peak value measured. In contrast, the concrete interface specimen experiences a strain hardening behaviour and reaches a maximum value at a strain level of $7 \%$ before stabilizing to constant residual shear strength. The steel interface shearing strength is lower than clay, while the concrete interface presented higher strength values (Figure 3.4a). According to Lupini et al. (1981) and Lemos and Vaughan (2000), shear strength in clays and clay interfaces can be related to the type of failure at the interface which is dictated by the ratio of rotund to platy particles in the soil which can be related by the clay fraction. At a high ratio of rotund particles, these particles tend to rotate neglecting the effect of the orientation of the platy particles; this is known as turbulent shearing. At larger clay fractions, sliding of the platy particles tends to occur due to the well-defined particle orientation leading to lower shear strength; this failure mode is known as sliding shear. A third intermediate state known as transitional shear occurs in between the rotational and sliding shear behaviours. Typically interface friction angles over $25^{\circ}$ can be attributed to a turbulent shear mode (Rouaiguia, 2010). The failure envelopes (Figure 3.4b) follow a Mohr-Coulomb failure mechanism illustrating a higher friction angle for concrete, followed by steel. Table 3.3 summarizes the results in terms of the ratio between the interface frictional angle and the clay internal frictional angle $\delta / \phi$ 

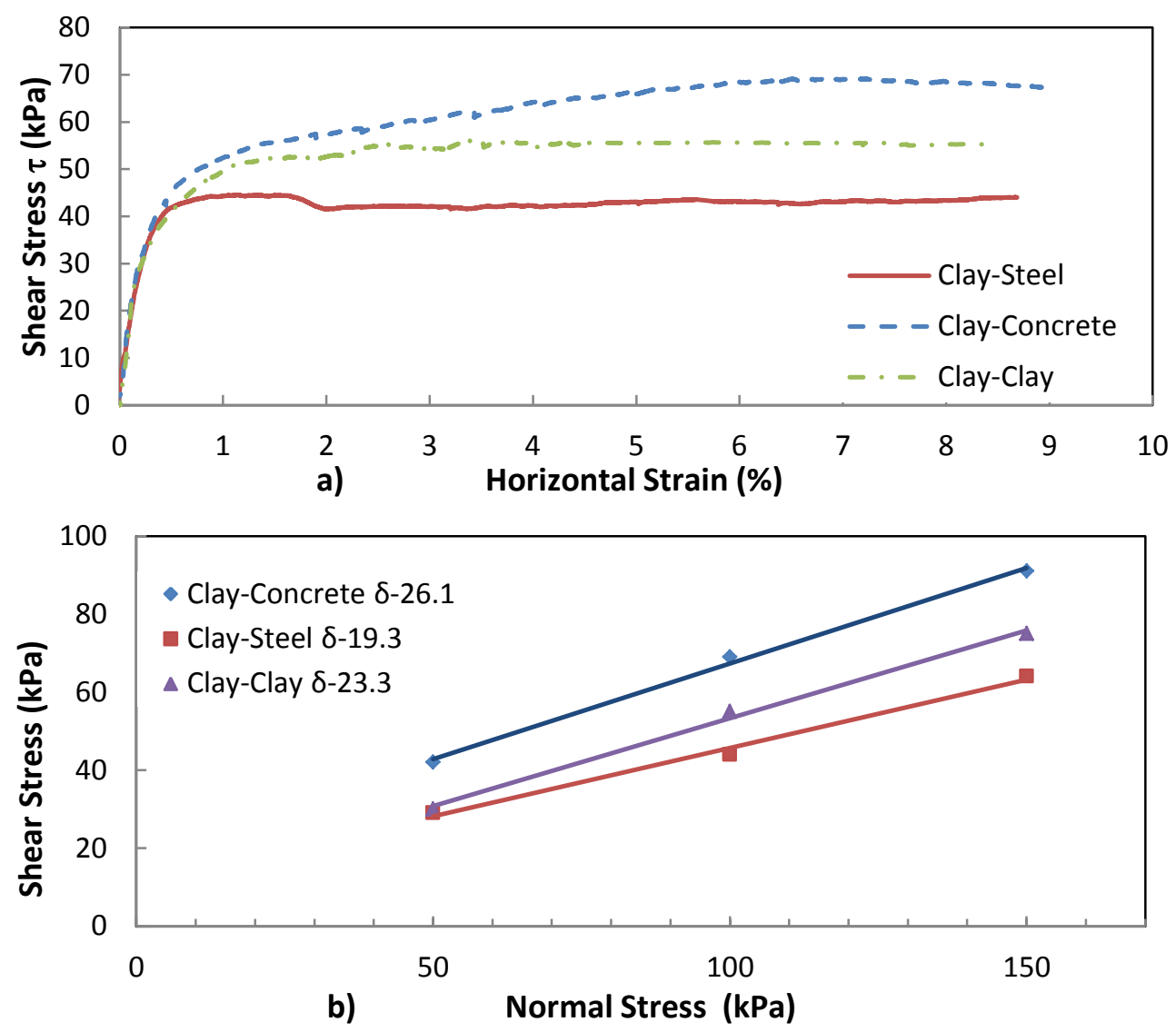

Figure $3.4-$ a) Shear Stress-strain at 100kPa b) Failure envelopes under drained conditions

\subsubsection{Undrained Conditions}

Tests carried out under undrained conditions were used to determine the cohesion of the soil and the apparent adhesion between the different interface surfaces and clay. Figure 3.5a illustrates the shear stress-strain curve for the different interfaces at a constant normal stress of $100 \mathrm{kPa}$. As shown, the frictional strength is mobilized at very low horizontal strains in the range of $0.5-1 \%$ reaching peak shear strength and quickly collapsing to a residual strength state. The steel and concrete interfaces stabilize at a horizontal strain of $2 \%$. The clay specimen experiences a strain hardening behaviour until reaching peak strength at $3 \%$ of horizontal strain, and a strain softening region until 
stabilizing at $8 \%$ strain to reach a residual strength state. Figure $3.5 \mathrm{~b}$ illustrates the failure envelopes for the different interfaces exhibiting Mohr-Coulomb behaviour. Table 3.3 summarizes the results in terms of the ratio of the interface adhesion to the soil's apparent cohesion $c_{d} / c$. The results for concrete interfaces indicate a good agreement with the accepted ratio of 0.7 in terms of the soil cohesion, however the steel interface presented an adhesion/cohesion ratio of 0.33 , which can be attributed to relatively smoother surface of the steel compared to the concrete and possible absorption of pore water by the concrete.
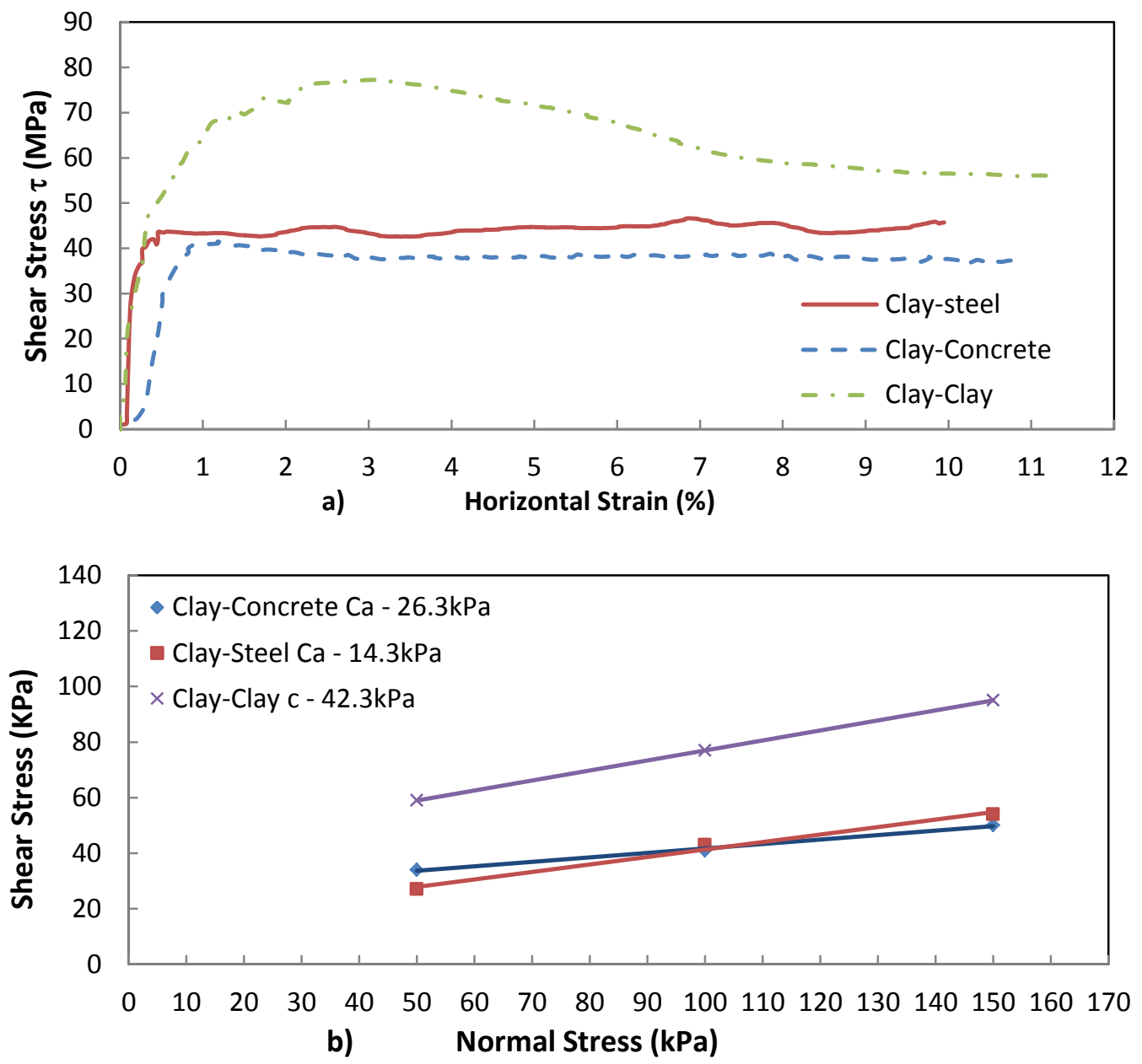

Figure $3.5-$ a) Shear stress-strain at $100 \mathrm{kPa}$ b) Failure envelopes under undrained conditions 


\subsubsection{FRP Interface Shear Strength}

In this section the interface shear strength of clay and FRP materials (carbon, C, and glass, G) oriented at $90^{\circ}$ and at $0^{\circ}$ along the primary fiber is investigated. The goal is to identify if the greater waviness of the FRP surfaces (Figure 2) contributes to higher shear strength values when sheared against clay and if so, identify which FRP material and orientation provides optimal results.

\subsubsection{Drained Conditions}

The direct shear tests carried out with the FRP specimens are analogous to the steel and concrete. Figure 3.6a shows the shear stress-strain curves for the four FRP coupons along with the results for the clay. The displacement required to mobilize friction along the FRP interfaces was in the range of 0.3 to $0.5 \%$ and residual strength conditions were reached by G0 and C0 interfaces at 1.4\% while G90 and C90 showed a strain hardening behaviour, reaching a constant strength at approximately $3.5 \%$ strain. The FRP specimens G0 and C0 also experienced a slight stress relaxation past the peak shear strength reached, while G90, C90 and pure clay maintained a constant residual strength at or near their peak shear strength.

Figure 3.6b presents the failure envelope results for each of the FRP interfaces and their respective drained effective interface friction angle $\delta$. Table 3.3 summarizes the ratio of the interface friction angle to the soil's internal friction angle $\delta / \phi^{\prime}$. In all cases, the interface friction angle corresponds to a value between $0.86 \phi$ to $0.98 \phi$, with the $\mathrm{C} 90$ specimen presenting the highest value and G0 the lowest although the results for all FRP specimens fall within a narrow range of $12 \%$ variation. Comparing these results to those obtained for steel and concrete, FRP interfaces demonstrate reduced frictional 
resistance compared to concrete, but slightly higher friction angle (5-19\%) compared to the steel interface.
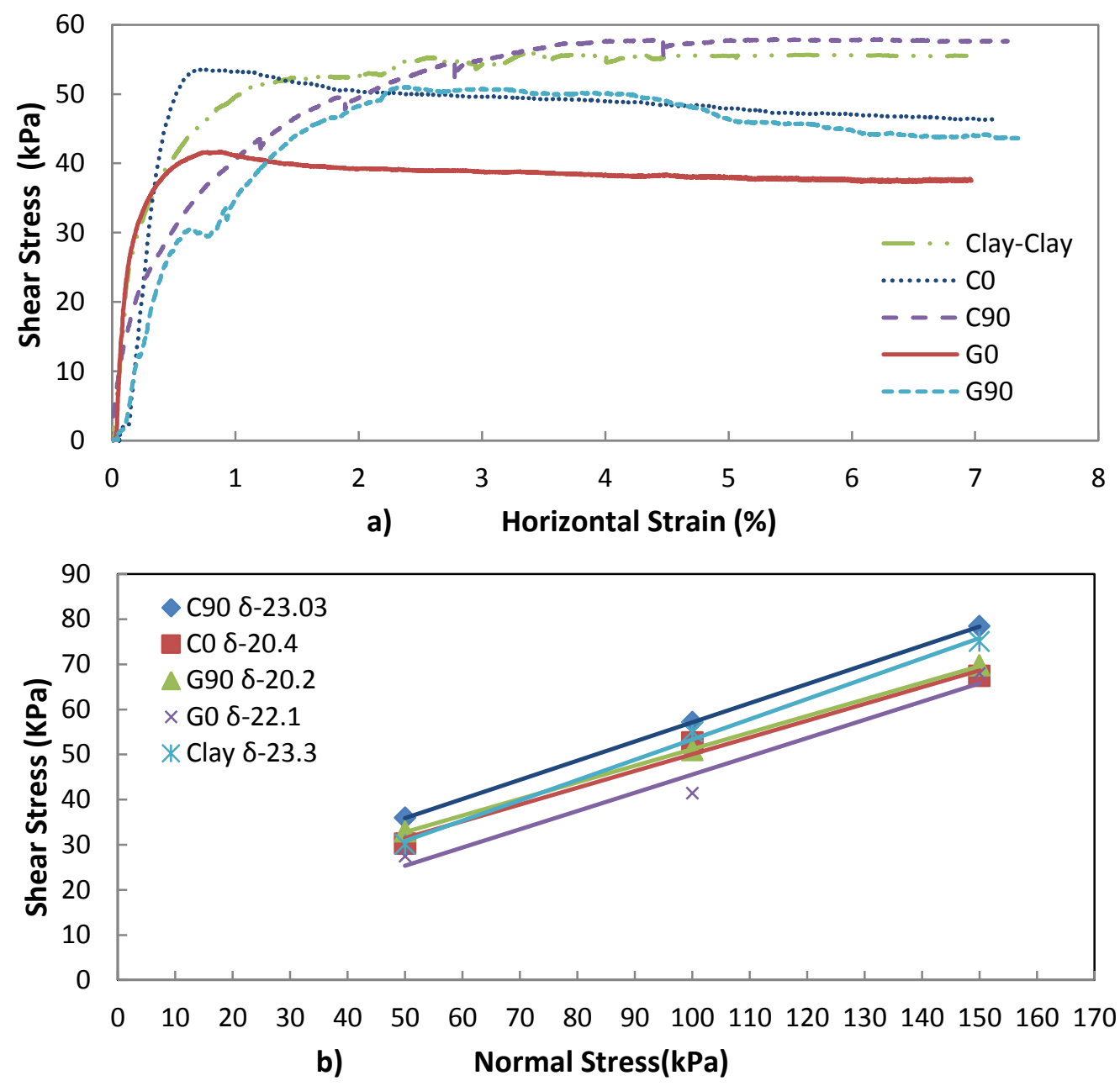

Figure 3.6 - a) Shear stress-strain curve at $100 \mathrm{kPa}$ b) Failure envelopes for FRP under drained conditions

\subsubsection{Undrained Conditions}

The results for undrained conditions for the FRP samples show the apparent adhesion values of each interface. Figure 3.7a presents the shear stress-strain curves for the FRP interfaces and clay at $100 \mathrm{kPa}$ normal pressure. The results show that all four FRP interfaces present very similar shearing behaviours under the fast loading rate. All the FRP specimens mobilize the frictional capacity at a very low strain of $0.1-0.2 \%$, and reach a maximum shear strength value at a strain of $1 \%$ which remains virtually constant 
throughout the shearing. For a normal pressure of $100 \mathrm{kPa}$, the residual shear strength of the four FRP specimens presents a very narrow spread at $47 \mathrm{kPa}$ for $\mathrm{C} 0$ and $40 \mathrm{KPa}$ for C90 for the highest and lowest values respectively. When compared to the shearing behaviour of clay, all the FRP specimens show significantly lower shear strength values at $100 \mathrm{kPa}$ normal pressure.
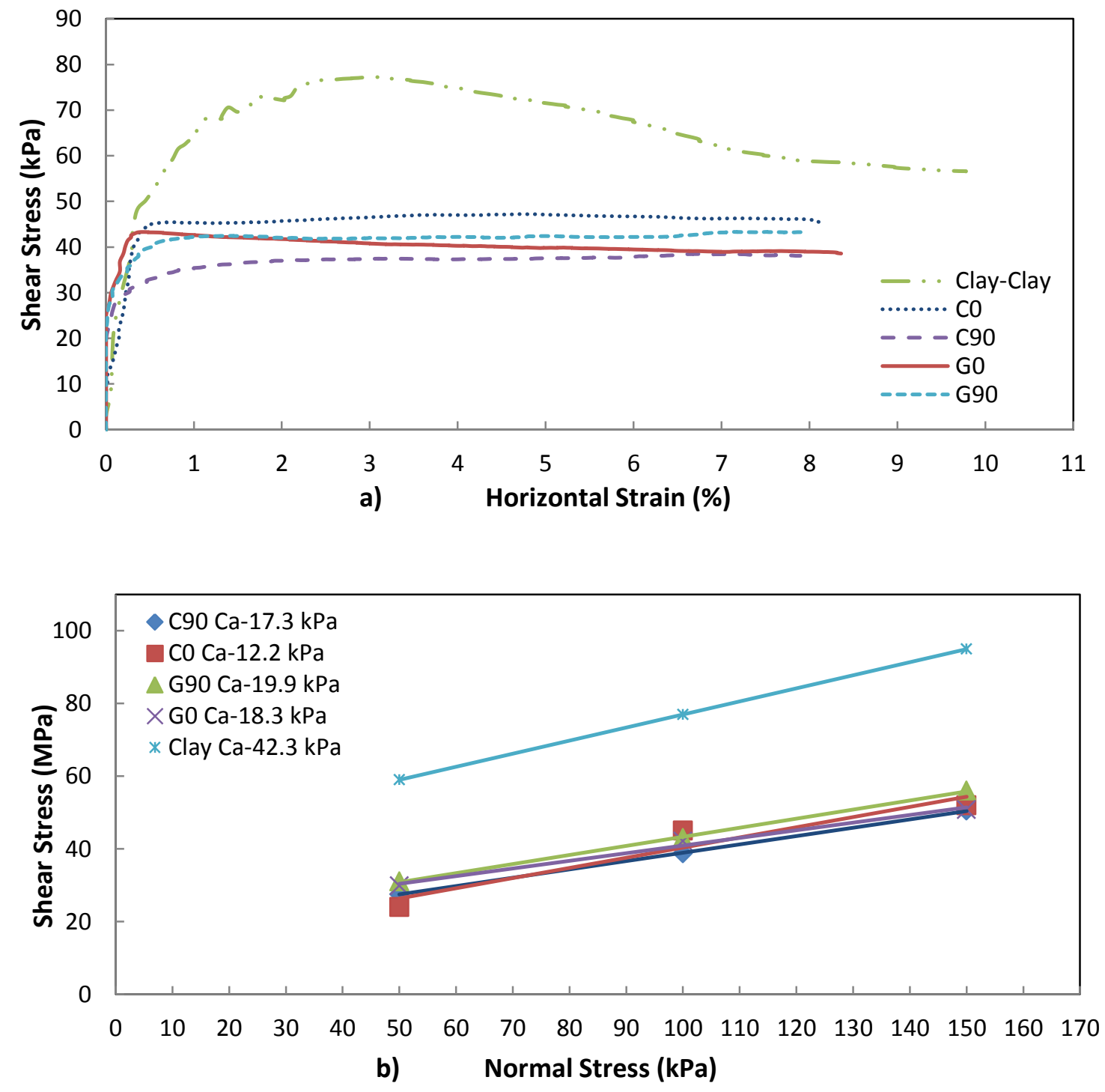

Figure 3.7 - a) Shear stress-strain at 100kPa b) Failure envelopes for FRP under undrained conditions 
Figure 3.7b shows the failure envelopes of each of the FRP interfaces and Table 3.3 summarizes these results and compares the calculated apparent interface adhesion, $\mathrm{c}_{\mathrm{a}}$, to the measured soil cohesion $\mathrm{c}$. The ratio $\mathrm{c}_{\mathrm{a}} / \mathrm{c}$ indicates that for FRP specimens the interface adhesion is between 40 to $47 \%$ that of the soil and in particular, the carbon interface C0 has a significantly lower value at $28 \%$ of the soil. Comparing these results to the previously presented values for steel and concrete, FRP interfaces demonstrate reduced performance compared to concrete, but a similar or higher adhesion compared to the steel interface.

\subsection{DISCUSSION}

\subsubsection{Pile-Soil and FRP-Soil Interface Performance}

The Interface performance of both traditional pile materials and FRPs was evaluated and compared in order to assess the viability of FRP against current piling materials. The results have been analyzed with respect to the performance of each material in both drained and undrained conditions and the compiled results of the testing program are summarized in Table 3.3.

The drained tests on the traditional piling materials indicate a strong frictional shear resistance from the concrete interface and a moderate resistance from the steel interface. These results support the idea of the development of turbulent shearing mechanisms along the concrete interface due to disturbance of the clay particles at the interface microstructure and the development of sliding or transitional shearing mechanisms along the steel interface. From a surface roughness perspective, it is difficult to assess its influence as both steel and concrete demonstrated similar surface roughness values at $R_{t}=9.7$ and $R_{t}=7.5$ respectively. The most likely influencing factor is the reduction of pore pressure at the concrete interface due to absorption of pore 
water by the concrete. In addition, ion exchange between the concrete interstitial fluid and soil pore water can increase the soil salinity, in turn increasing its shear strength (Taha, 2010).

Table 3.3 - Comparison of shear strength properties of typical pile materials and FRPs

\begin{tabular}{|c|c|c|c|c|}
\hline \multicolumn{5}{|c|}{ Interface Friction Angle } \\
\hline Interface & $\delta$ & $\delta / \phi$ & $\begin{array}{l}\text { \% of steel } \\
\text { capacity }\end{array}$ & $\begin{array}{l}\% \text { of concrete } \\
\text { capacity }\end{array}$ \\
\hline Concrete & 26.1 & 1.12 & - & - \\
\hline Steel & 19.3 & 0.83 & - & - \\
\hline C90 & 23.02 & 0.97 & $119 \%$ & $88 \%$ \\
\hline G90 & 20.2 & 0.86 & $104 \%$ & $77 \%$ \\
\hline G0 & 22.04 & 0.92 & $113 \%$ & $84 \%$ \\
\hline $\mathrm{CO}$ & 20.4 & 0.87 & $105 \%$ & $78 \%$ \\
\hline \multicolumn{5}{|c|}{ Interface Apparent Adhesion (kPa) } \\
\hline Interface & $\mathrm{C}_{\mathrm{a}}$ & $\mathrm{C}_{\mathrm{a}} / \mathrm{c}$ & $\begin{array}{l}\% \text { of steel } \\
\text { capacity }\end{array}$ & $\begin{array}{l}\% \text { of concrete } \\
\text { capacity }\end{array}$ \\
\hline Concrete & 26.3 & 0.62 & - & - \\
\hline Steel & 14.3 & 0.34 & - & - \\
\hline C90 & 17.3 & 0.40 & $120 \%$ & $65 \%$ \\
\hline CO & 12.3 & 0.29 & $86 \%$ & $46 \%$ \\
\hline G90 & 19.9 & 0.45 & $135 \%$ & $75 \%$ \\
\hline G0 & 18.3 & 0.43 & $127 \%$ & $70 \%$ \\
\hline
\end{tabular}

The interface to soil friction angle ratios $\delta / \phi$ deviate slightly from the common values typically used in practice which advocates using $2 / 3 \phi$ as a reasonable value for the interface frictional angle $\delta$ (CGS, 2007). The steel-clay interface presents reasonable correlation with the typically used data while the concrete-clay shows higher ratios. The concrete-clay interface exhibits turbulent shearing due to the absorption of water at the interface which can have the net effect of increasing the friction angle values. 
The FRP interface test results under drained conditions showed lower interface resistance strength compared to concrete, while presenting an angle of friction up to $19 \%$ higher than the steel interfaces. From these results it can be concluded that the surface waviness of the FRP materials has probably affected the interface frictional capacity in clays, particularly compared to steel interfaces. Upon inspection of the sheared interfaces it was identified that, in some instances, the clay material was wedged in between the ridges formed by the FRP surface, and shearing of the clay occurred along the flat plane in between the ridges. This behaviour was identified more often on the specimens sheared perpendicular to the fiber orientation, i.e., the $90^{\circ}$ orientation. In other instances, the clay material showed evidence of sliding along the grooves of the ridges presented in the FRP fiber. This type of behaviour would occur more frequently on the specimens sheared along the fiber orientation, i.e., the $0^{\circ}$ orientation. In both cases, it is possible that the clay particles undergo shearing by particle sliding or turbulent shear failure, evidenced by the higher measured friction angle of FRP interfaces over steel. Based on these results it is difficult to assess with certainty which material and fiber orientation presents the best results as they are within a $15 \%$ difference. Pile load tests are needed in order to best establish the material performance under field conditions.

The performance under undrained conditions follows a similar trend as to the drained conditions with respect to concrete presenting higher adhesion values. However results for FRP compared to steel show that FRP interfaces presented an interface adhesion improvement between 20 to 35\% higher for G90, G0 and C90 while C0 presented a lower interface adhesion of $86 \%$ that of steel. As discussed earlier, this could be attributed to smoother surface of the steel interface compared to FRPs, and hence the associated shearing mechanisms involved for both cases (sliding vs 
turbulence). Similar to the drained results, the adhesion values for the top 3 FRP interfaces are within a $15 \%$ variation, making it difficult to determine which material or orientation provides better performance.

Considering both drained and undrained conditions, FRP materials present a lower shear strength resistance compared to concrete interfaces; however they present higher or comparable performance to that of steel interfaces. The introduction of FRP piles in the FRP industry can lead to possible cost reductions due to the effect of economies of scale in the composite industry as demand increases. Through communication with the FRP manufacturer, it was reported that at the time of publication, the price of the CFRP raw materials was double that the GFRP fibers per unit area (R. Ortiz, personal communication, May 2013). Further work is needed regarding the cost benefit of carbon fibers vs. glass fibers in terms of pile performance.

\subsubsection{Effect of Epoxy Resin on Interface Behaviour}

During the experimental program, it was observed that the manufacturing process of casting the fiber composites in an epoxy matrix created a smooth, although topographically varied, FRP surface. With the goal of investigating the effects of the epoxy resin on the interface frictional behaviour, an additional test using a dry (no epoxy encasement) C90 specimen was conducted with the purpose of evaluating whether or not the individual fibers interacted with the soil particles influence the interface shear behaviour.

The additional test was conducted by placing an appropriately cut portion of dry carbon fiber on top of the steel specimen used in previous interface tests. This steel 
plate was bolted to the top half of the shear box, ensuring that the C90 specimen was securely in place. A soil specimen was then placed in the top half of the shear box and then a drained shearing test was conducted in the same manner as described in the experimental procedure. Special care was taken in order to prevent any possible sliding of the FRP sample against the steel plate support by placing an extended portion of the material underneath the shear box thus using the normal pressure for clamping action.

Figure 3.8 presents the shear stress-strain curves for dry-fiber C90, epoxy encased $\mathrm{C} 90$ and soil at $100 \mathrm{kPa}$ normal pressure under a drained shearing rate. The results from these tests indicate that although the material fabrics are free to interact with the soil particles, the behaviour is significantly softer than the epoxy cast C90 specimen. Upon visual inspection of the sheared surface, both the clay and FRP surface presented minimal disturbance suggesting a sliding type of shear failure across the interface. The interface friction angle of the C90 dry-fiber sample was calculated to be $\delta=19.3^{\circ}$ which is $83 \%$ of the friction angle calculated for the epoxy cast C90 specimen. These results show that there is no merit pursuing uncased fabric material interaction, in addition to being impractical to use the material in this uncured state.

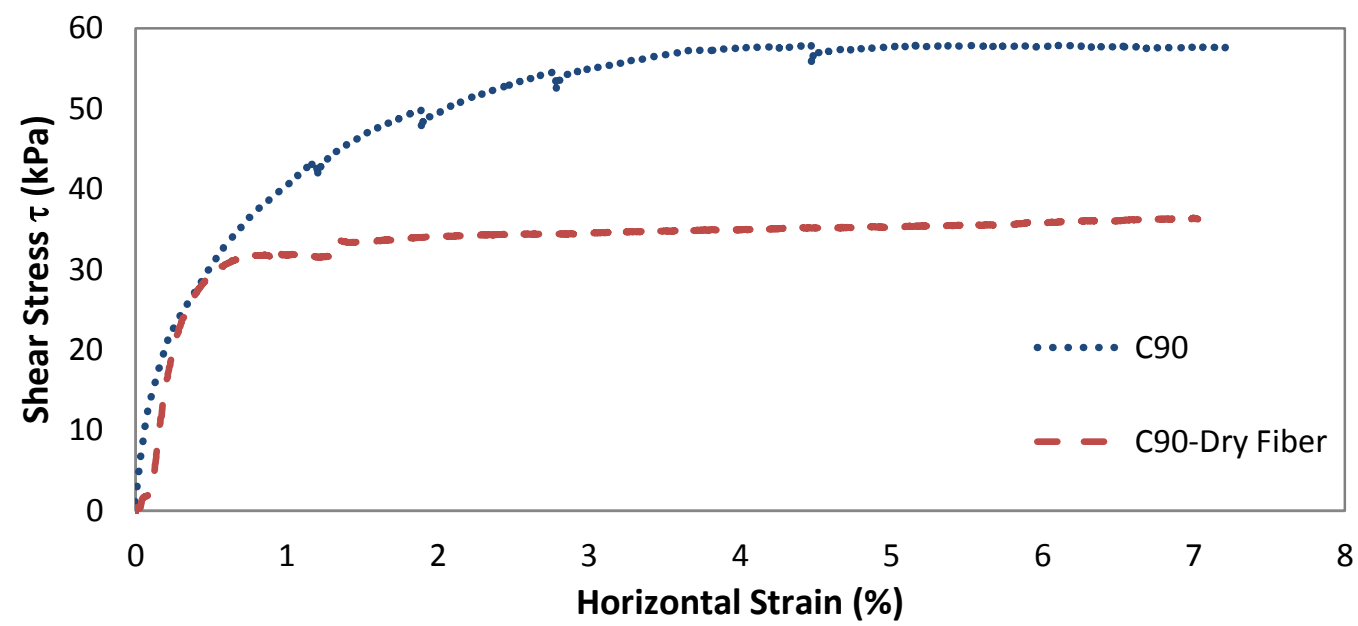

Figure 3.8 - Comparison of dry fiber (no epoxy) and regular FRP performance under a normal pressure of $100 \mathrm{kPa}$ (drained condition). 


\subsection{CONCLUSIONS}

An experimental program was carried out with the goal of determining the interface shear strength properties of various typical pile materials and two different fiber reinforced composite materials against soft clay. The test results were used to quantify the performance of each interface and evaluate the viability of FRP materials compared to typical piling materials. The experimental program used a direct shear box device intended to measure the interface friction angle $\delta$ and the apparent interface adhesion $c_{a}$ by carrying out the tests under drained and undrained conditions. The following points illustrate the main findings of this paper:

- In both drained and undrained conditions the concrete interface outperformed the FRP interface while the FRP specimens matched or performed better compared to the steel interface under both loading rates.

- The concrete interface presented a high interface frictional coefficient with a $\delta / \phi$ ratio of 1.12. This result is higher than the typically used ratio of 0.5 to 0.7 which could be attributed the absorption of water by the concrete, thereby decreasing the pore pressure at the interface.

- The steel interface displayed a lower capacity in both drained and undrained conditions than concrete indicating a sliding type of shear failure at the interface in contrast to concrete which presents evidence of turbulent or transitional shear failure.

- The FRP materials present between 105 to $119 \%$ of the interface friction angle of steel and between 77 to $88 \%$ that of concrete. In addition, FRP interface adhesion was observed between $86 \%$ and $135 \%$ of the interface adhesion of steel and between $65 \%$ and $75 \%$ of the interface adhesion of concrete.

- The results indicate the best performing FRP interface was carbon FRP oriented at $90^{\circ}$ with respect to the primary fiber (C90) in drained conditions and glass FRP 
oriented at $90^{\circ}$ with respect to primary fiber (G90) under undrained conditions. However, the capacity increase, particularly over G90 and C0, was not significant enough to conclusively determine a superior material (carbon or glass) or fiber orientation along the shearing direction $\left(0^{\circ}\right.$ or $\left.90^{\circ}\right)$. Specimen $\mathrm{C} 0$ was the only exception under undrained conditions measuring approximately $35 \%$ lower interface adhesion than the other three FRP interfaces.

- FRP surface topology and the waviness pattern dictated by the fiber weaving and orientation while shearing was found to have a possible significant influence on the shearing strength.

- Investigation into the effect of the epoxy surface finish vs. no epoxy dry-fiber was carried out and indicated a lower frictional performance compared to the epoxy cast specimen.

The results presented in this study identified that FRP piles whether constructed using carbon or glass fibers can perform at the same level or higher than traditional steel piling under both drained and undrained conditions in clays. This finding is coupled with a major advantage of the FRPs such as their corrosion resistance and longer service life, an area where steel piling presents weaknesses. The FRPs interfaces were found to present 105 to $119 \%$ of the capacity of steel against clays under frictional resistance $\left(\phi^{\prime}\right)$ and between 86 to $135 \%$ of interface adhesion $\left(c_{a}\right)$ respectively. Further work should focus on the effect of a roughened epoxy surface (without compromising the fiber integrity) to accurately quantify the effects of surface roughness of the FRP shearing against clays in addition of pile load tests in order to simulate interface behaviour under field circumstances. 


\section{CHAPTER 4}

\section{LOAD TRANSFER OF HOLLOW FRP PILES IN CLAY}

\subsection{INTRODUCTION}

Pile foundations are typically constructed using three types of materials or a combination of thereof: steel, concrete and wood. However, the use of these materials faces several challenges when installed in harsh environments such as waterfront or contaminated and harsh soil conditions. Steel and concrete are subject to corrosion and degradation which leads to significant reduction of pile cross-sectional area impacting pile performance, structural integrity and drastically reducing service life. In order to address this adverse performance, researchers have been exploring the use of alternate materials such as glass, carbon fibers and plastic composites as piling alternatives as development and use in other industries of these technologies drive prices of production down to an attractive price point and a commercially viable technology. In recent decades researchers and industry partners have strived to develop and introduce the use of FRP piles targeted towards waterfront and harbour fendering applications. Iskander and Hassan (1998) highlighted the predominant use of fiber reinforced polymer (FRP) piles as fendering and light load bearing in harbours and piers. They cited the lack of an established track record, design guidelines and high initial material costs as reasons for the limited use in other piling applications. Typical FRP piles are fabricated using either a high density polyethylene (HDPE) matrix reinforced with steel or glass 
fiber, or fabricated from carbon or glass fiber into hollow shells (Guades et al., 2012). Carbon or glass FRP hollow shells are also in filled with concrete where the outside fiber shell acts as the pile reinforcement and protection of the concrete. In addition the confinement provided enhances the structural strength and stiffness of the pile (Fam and RizKalla, 2001a; Fam and Rizkall, 2001b).

FRP pile performance and soil-pile interface behaviour has been poorly characterized due to the lack of widespread use of the material. Researchers such as O'Rourke et al. (1990) carried out direct shear box interface characterization test between sands and HDPE geotextiles where it was found interface shear strength to increase with sand density and decrease with surface roughness. Frost and Han (1999) conducted a series of interface characterization test between FRP interfaces and sands where they identified various parameters affecting interface shear strength including normal stress levels, soil particle angularity and particularly interface surface roughness. Further studies carried out by Pando et al. (2002) confirmed that interface surface roughness and particle shape and angularity has a significant role in the shear strength behaviour of the soil-pile interface.

Pile drivability and installation is crucial when assessing the use of FRP piles as deep foundation. Due to inherent material properties such as lower stiffness, impedance and density leading to higher damping, hollow FRP piles present a limited driving performance compared to traditional piles. Iskander et al. (2001) carried out a numerical analysis focusing on the drivability of FRP composite piles. They identified that material properties such as specific weight and elastic modulus played a critical role over driving performance, whilst for stiffer piles, driving behaviour depended mostly on soil properties. Ashford and Jakrapiyanun, (2001) analysed the dynamic pile driving response of a series of steel, concrete and FRP piles. Their results indicate that FRP 
piles perform comparatively well compared to traditional piles, however lower material impedance limited the ultimate capacity achieved at driving refusal. (Mirmiran et al. (2002) analysed the dynamic response to driving for a series of concrete, concrete infilled and hollow FRP piles, and concluded that concrete in-filled FRP piles performed on par to conventional concrete piles, however hollow FRP shells were at risk of compression failure and could support driving stresses of up to $50 \%$ at driving refusal compared to the concrete pile.

Pando et al. (2006) carried out a large scale pile load test investigating the performance of FRP piles as the supporting structure for a highway overpass in Virginia. They compared driven pre-cast concrete piles to concrete in-filled FRP piles. Axial pile load tests showed that the FRP piles performed comparably to the concrete pile. They highlighted the importance of non-linearity effects of the flexural stiffness of FRP piles and increased deflections caused by shear deformations due to high elastic modulus to shear modulus ratios. Sakr et al. ( 2004) compared the performance of driven FRP piles to steel piles in sand and found that FRP piles performed favorably in axial compression compared to steel piles; however under lateral loading, the FRP piles exhibited larger deflections due to the inherent lower pile stiffness.

Most of the pile load test and interface characterization studies using FRP materials have been conducted in sandy soils. There is a gap in knowledge regarding the behaviour of these materials, particularly frictional resistance under undrained conditions in clayey soils. The objective of this research program is to provide baseline information regarding the performance and comparison of FRP and steel piles in soft clays. This includes driving response, ultimate pile capacity under axial and lateral pile load tests and pile response under large lateral deflections. In addition, FRP material influence, comparing both carbon and glass fiber piles, fiber orientation and soil 
interaction will be explored to determine optimal conditions for increased pile performance under field conditions. This was achieved through a series of small scale pile load tests where model piles were driven in undisturbed clay samples collected in industrial sized steel drums. Following driving, axial and lateral static load tests were carried out. In addition a select number of field tests were conducted to corroborate the laboratory results. A description of the experimental setup and analysis of the results is presented in the sections below.

\subsection{SOIL SAMPLING AND PROPERTIES}

\subsubsection{Undisturbed Clay Sampling}

Pile load tests were carried out in undisturbed clay samples contained in industrial sized steel drums (876 mm in height and $597 \mathrm{~mm}$ in diameter). Soil harvesting was conducted at a clay rich site in Navan, Ontario (Figure 4.1). The sampling procedure was conducted as follows: 1) a thick section of clayey material was prepared by removing top soil and leveling the surface ensuring a clean profile of clay of at least 1.5 meters was present, 2) steel drums were placed upside down on the leveled soil surface, 3) using an excavator each steel drum was carefully embedded in the clay layer ensuring no cracking and minimal disturbance of the surrounding soil, 4) following embedment, the samples were carefully excavated and extracted, 5) the filled drums were sealed to prevent soil desiccation and maintain the in-situ conditions, 6) the soil containers were then shipped to the testing facility where the pile load tests were conducted. Figure 1 illustrates the soil sampling procedure during the encasing of the steel drums.

\subsubsection{Soil Properties}

The soil used for this study is a type of marine soft clay formed from glacier action along the Ottawa River lowlands. This material, typically referred as Leda clay or Champlain 
Sea clay, is the result of glacier abrasion against the Canadian Shield leaving a fine rock flour which was deposited along the prehistoric saltwater Champlain Sea that flooded the region. The corresponding ASTM Soil characterization tests were carried in order to determine the soil properties. Soil unit weight was measured at $15.3 \mathrm{kN} / \mathrm{m}^{3}$ and it was classified as highly plastic clay $(\mathrm{CH})$ according to the United Soil Classification System. Undrained shear strength was measured with a vane shear apparatus according to ASTM D2573 (2008) and was measured as $55 \mathrm{kPa}$ throughout the steel drum depth profile. Atterberg limit tests were performed according to ASTM D4318 (2010) with measurements of a liquid limit and plasticity index of $51 \%$ and $23 \%$ respectively. Grain size distribution was determined as per ASTM D422 (2007) using a hydrometer test, and the results are illustrated in Figure 4.2. The soil internal friction angle was determined using a direct shear box apparatus according to ASTM D6528 (2007) and was measured as $23.3^{\circ}$, Table 4.1 summarizes the complete list of measured soil properties.

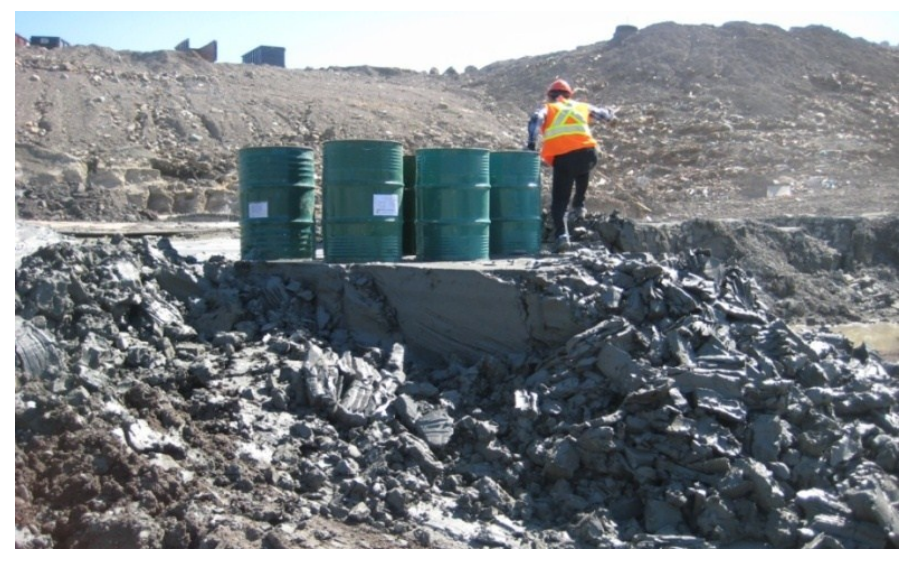

Figure 4.1 - Soil sample preparation for pile load tests 


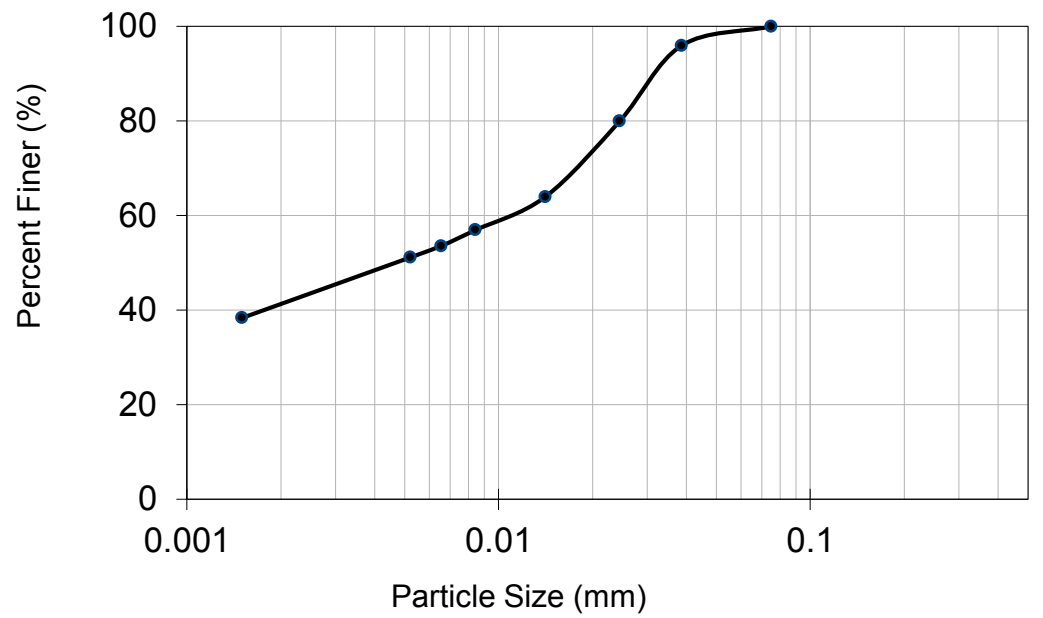

Figure 4.2 - Leda Clay grain size distribution

Table 4.1 - Soil Properties for Leda Clay

\begin{tabular}{cccccccccc}
\hline$\rho, \mathrm{Mg} / \mathrm{m} 3$ & $w, \%$ & $\mathrm{LL}, \%$ & $\mathrm{PI}, \%$ & $w_{\text {opt } \%}$ & $\rho_{d(\max )}, \mathrm{Mg} / \mathrm{m}^{3}$ & $C_{v}, \mathrm{~cm}^{2} / \mathrm{s}$ & $s_{u}, \mathrm{kPa}$ & $\phi, \operatorname{deg}$ & $c_{u}, \mathrm{kPa}$ \\
\hline 1.53 & 49 & 51 & 21 & 30 & 1.41 & $1.40 \mathrm{E}-04$ & 50 & 23.3 & 42.2 \\
\hline
\end{tabular}

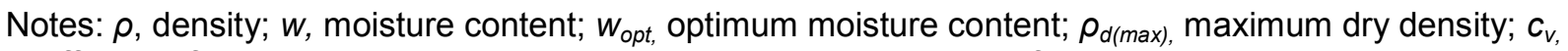
coefficient of consolidation; $s_{u}$, undrained shear strength; $\phi$, internal friction angle; $c_{u}$, apparent cohesion.

\subsection{MODEL PILES}

A series of model FRP piles were manufactured with commercially available carbon and glass fabrics typically used for the reinforcement and retrofit of structural members. The raw material is in the form of fiber bundles woven into a coherent fabric in a uniaxial direction. Saturating the fabric in epoxy forms the FRP structure which can be molded to a number of different shapes and arrangements. The structural integrity of the cured fiber is provided primarily along the fiber direction. The manufacturing of the model FRP piles was carried out by using a steel mandrel where around which the fiber fabric is fitted and allowed to cure following epoxy impregnation. Following 48 hour curing time, as per manufacture guideline, the pile is extracted from the steel mandrel and cut to the required length. Pile dimensions were selected by carrying out a stress distribution 
analysis using commercially available geotechnical numerical software (Geostudio, 2007). The goal of this analysis was to identify pile length and diameter where boundary conditions of the soil confinement did not have a significant impact on the test results. The numerical analysis simulated small scale pile load testing by modelling the geometry of the clay sample confined by the steel drum. Boundary conditions for the sample were simulated by applying displacement constrains along the outside model nodes representing the steel drum confinement of the soil sample. The pile was simulated as a steel member embedded in the soil with the appropriate geometric and elastic properties.

The model used linear-elastic properties for the soil and pile materials and mohrcoulomb material properties for the soil-pile interface. The analysis was carried out using axisymmetric behaviour under total and effective stress conditions utilizing interface parameters for steel under drained and undrained conditions discussed in chapter 3 for the pile interface adhesion. The pile load test was simulated by applying 10 displacement increments of $1 \mathrm{~mm}$ in either the axial or lateral dimension at the pile head location for a total pile displacement of $10 \mathrm{~mm}$. Please see appendix $\mathrm{D}$ for model illustration of the numerical analysis and stress distribution results. It was found through various iterations that dimensions of $700 \mathrm{~mm}$ in pile length and diameter of $55 \mathrm{~mm}$ would induce less than $10 \%$ of the applied stresses at the soil boundary, accordingly these were the dimensions used for the model piles. The selected dimensions allow for $5 d$ distance between the steel drum wall and pile providing adequate spacing preventing influence from the boundary. Similar spacing of $3 d$ to $5 d$ is typically used for preventing group pile effects for frictional piles (Tomlinson, 1994; Franke, 1988).

Five open-end model piles were manufactured for a total of 2 glass FRP piles (GFRP) and 3 carbon fiber (CFRP) piles. Pile wall thickness and diameter to thickness 
(d/t) ratio was maintained as constant as manufacturing permitted ranging from 3.6 to $4.15 \mathrm{~mm}$ in thickness and from 13.3 to $15.1 \mathrm{in} d / t$ ratios. These dimensions also allowed for a comparison to the control steel pile with a wall thickness of 3.45 and $d / t$ of 14.2 . For all piles a total of 3 layers of fiber material were used which was the controlling parameter dictating the wall thickness. Piles were manufactured with uniaxial alternating fiber direction allowing isolating the pile response to fiber orientation. In addition, different fiber orientation and material fabric cause a change in pile texture due to the weaving pattern of the fiber fabric. The GFRP piles were manufactured with three layers in either $0^{\circ}$ or $90^{\circ}$ orientations. Similarly the CFRP piles had the same arrangement with the addition of a third pile with two inner layers with fibers arranged along pile axis $\left(0^{\circ}\right)$ and one outer layer with fibers perpendicular to pile axis $\left(90^{\circ}\right)$. A control steel pile was prepared in order to compare the pile performance. Table 4.2 presents a summary of the geometric properties of the model piles tested. Additionally, a steel encasing mechanism at the pile head was used to apply axial and lateral loads to the piles and to prevent pile damage during driving.

Mechanical properties for the FRP composites as reported by the manufacturer are ultimate tensile strength of $986 \mathrm{MPa}$ and $575 \mathrm{MPa}$ and $95.8 \mathrm{MPa}$ and $26.1 \mathrm{MPa}$ tensile modulus for CFRP and GFRP respectively. Additionally, unidirectional pile samples in the $0^{\circ}$ alignment were prepared and tested under three point bending according to ASTM D790 (2010) in order to characterize the pile flexural strength. Ultimate values for elastic modulus E, pile stiffness and other mechanical properties are listed in Table 4.3. It was observed however that that pile stiffness El, varied non-linearly with the loading level. This non-linear behaviour is a typical of FRP piles (Pando et al., 2006) and its implications regarding pile response will be discussed in subsequent sections. Finally, the epoxy/fiber ratio ranging between $50 / 50$ and $45 / 55$ as fiber saturation was observed 
in this range. This is typically the epoxy saturation ratio used for FRP piles and tubes (Fam and Rizkalla, 2002).

Table 4.2 - Model pile geometric properties

\begin{tabular}{lccccccc}
\hline Pile & $\begin{array}{c}\text { Diameter } \\
\mathrm{d}(\mathrm{mm})\end{array}$ & $\begin{array}{c}\text { Toe Area } \\
\left(\mathrm{mm}^{2}\right)\end{array}$ & $\begin{array}{c}\text { Length } \\
\mathrm{L}(\mathrm{mm})\end{array}$ & $\begin{array}{c}\text { Thickness } \\
\mathrm{t}(\mathrm{mm})\end{array}$ & $d / t$ & $\begin{array}{c}\text { Fiber } \\
\text { direction }\left({ }^{\circ}\right)\end{array}$ & $\begin{array}{c}\text { Epoxy to Fiber } \\
\text { Content }(\%)\end{array}$ \\
\hline C-0 & 54.7 & 629.8 & 700 & 4.12 & 13.3 & 0 & 52.5 \\
C-90 & 55.1 & 639.2 & 700 & 3.98 & 13.8 & 90 & 53.5 \\
C-0/90 & 57.1 & 649.4 & 700 & 4.15 & 13.8 & $90 / 0$ & 55 \\
G-0 & 55.4 & 608.5 & 700 & 3.79 & 14.6 & 0 & 53.5 \\
G-90 & 54.5 & 590.5 & 700 & 3.62 & 15.1 & 90 & 55.5 \\
SP & 49 & 493.7 & 700 & 3.45 & 14.2 & N/A & N/A \\
\hline
\end{tabular}

C/G - denotes fiber material, number denotes fiber orientation SP - Steel Pile

Table 4.3 - Model pile material properties

\begin{tabular}{lccccccc}
\hline Pile & $\begin{array}{c}\text { Ultimate } \\
\text { Tensile } \\
\text { Strength } \\
(\mathrm{MPa})\end{array}$ & $\begin{array}{c}\text { Tensile } \\
\text { Modulus } \\
(\mathrm{GPa})\end{array}$ & $\begin{array}{c}\text { Moment } \\
\text { of Inertia } \\
\left(\mathrm{mm}^{4}\right)\end{array}$ & $\begin{array}{c}\text { Initial } \\
\text { Flexural } \\
\text { Modulus } \\
(\mathrm{GPa})\end{array}$ & $\begin{array}{c}\text { Ultimate } \\
\text { Flexural } \\
\text { Modulus } \\
(\mathrm{GPa})\end{array}$ & $\begin{array}{c}\text { Initial } \\
\text { Stiffness } \\
(\mathrm{EI}) \mathrm{kN}-\mathrm{m}^{2}\end{array}$ & $\begin{array}{c}\text { Stiffness } \\
\text { at Failure } \\
(\mathrm{El}) \mathrm{kN}^{2} \mathrm{~m}^{2}\end{array}$ \\
\hline $\mathrm{C}-0$ & 986 & 98.5 & $2.04 \mathrm{E}+05$ & 30 & 56.2 & 6.12 & 11.46 \\
$\mathrm{C}-90$ & 986 & 98.5 & $2.10 \mathrm{E}+05$ & - & - & - & - \\
$\mathrm{C}-0 / 90$ & 986 & 98.5 & $2.29 \mathrm{E}+05$ & - & - & - & - \\
G-0 & 575 & 26.1 & $2.04 \mathrm{E}+05$ & 25 & 32.6 & 5.10 & 6.8 \\
G-90 & 575 & 26.1 & $1.91 \mathrm{E}+05$ & - & - & - & - \\
SP & 400 & 200 & $1.29 \mathrm{E}+05$ & 200 & 200 & 25.75 & 25.75 \\
\hline
\end{tabular}

C/G - \# denotes fiber material, number denotes fiber orientation SP - Steel Pile 


\subsection{EXPERIMENTAL PROGRAM}

\subsubsection{Test Setup}

A testing frame was assembled at Carleton University to apply monotonic axial and lateral loads for pile load tests. Schematics of the test assembly are shown in Figure 4.3a. The horizontal reaction beam is assembled using two channel sections attached to the vertical columns. A steel plate is placed across the channel section which serves as a reaction platform allowing for the application of compressive loads. Axial load is applied using a hydraulic jack coupled to a steel rod connected to the pile head which runs vertically aligned with the pile axis. Force measurement is carried out using a load cell placed at the jack - pile head connection ensuring proper alignment. Lateral loading is applied using a lateral bracing system connected to the vertical reaction columns. A steel rod is used to attach the pile head to the hydraulic jack which is resting horizontally against the reaction lateral brace. The steel rod is attached to the pile head by means of a U-shaped brace around the pile head which is connected to the steel rod by an end bearing joint allowing for horizontal self-alignment as load is applied. A schematic top view for the lateral loading system is illustrated in Figure 4.3b.

All model piles were open-end and driven to an embedment depth of $700 \mathrm{~mm}$. Driving records and rates of penetration for the different piles are shown and discussed in the following sections. The load tests were carried out immediately following driving to prevent time dependent pile set-up effects. Axial and lateral resistance was measured using a load cell connected to a data logging station, while axial and lateral displacement at the pile head was recorded with an LVDT device connected to the reference beams. All the data was collected by an automated data logging station with calibrated recording software. Figure 4.4 a shows experimental assembly before driving of the pile. Figure 
$4.4 \mathrm{~b}$ illustrates the assembly of the pile head system and the vertical steel rod undergoing axial loading and Figure 4.4c shows the set up undergoing lateral loading.

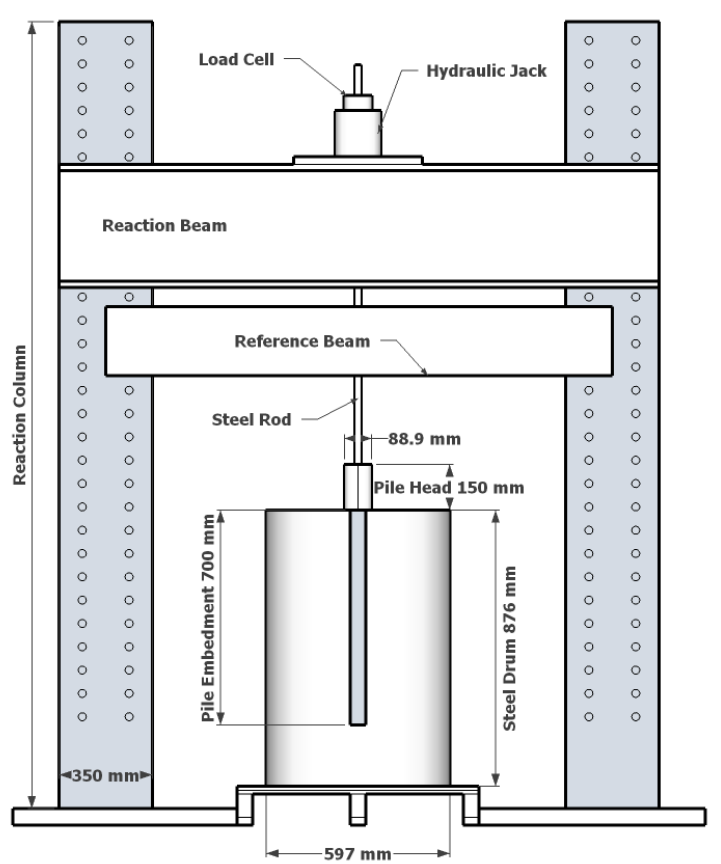

a)

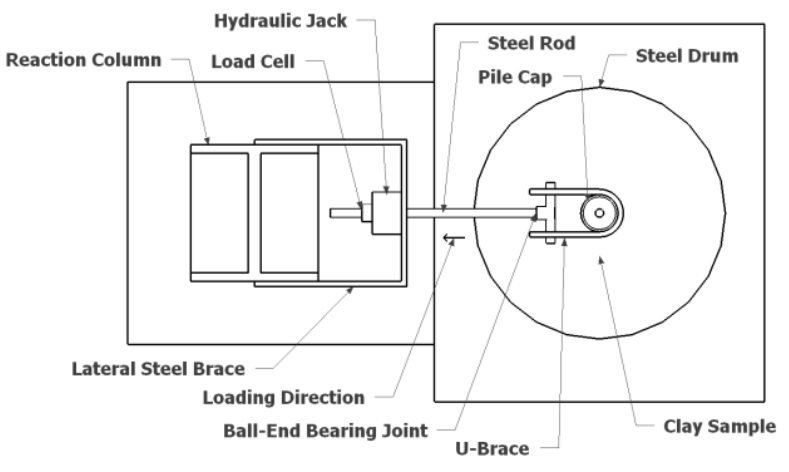

b)

Figure 4.3: a) Experimental setup and b) lateral loading schematics

\subsubsection{Pile Driving}

Pile driving was carried out using a pulley and drop hammer setup. The drop hammer weight and drop distance were kept constant throughout the test at $19.5 \mathrm{lb}$ and $150 \mathrm{~mm}$ respectively. The impact energy was approximately 15 joules per blow. Driving was carried out at approximately $10-15$ blows per minute with a rate of penetration ranging from $10 \mathrm{~mm} / \mathrm{blow}$ at shallow depths to as low as $2 \mathrm{~mm} / \mathrm{blow}$ when reaching the target depth. Figure 4.5a shows cumulative blow count vs. penetration depth ratio $d / z$ (diameter over depth) and Figure 5b shows the rate of penetration vs. depth ratio. It is evident there are two main regions where there is a marked increase of driving resistance at approximately 4 diameters of penetration. In addition, all FRP piles 
presented similar penetration ratios, while the steel pile penetration ratio was up to $25 \%$ lower at the lower driving depths.

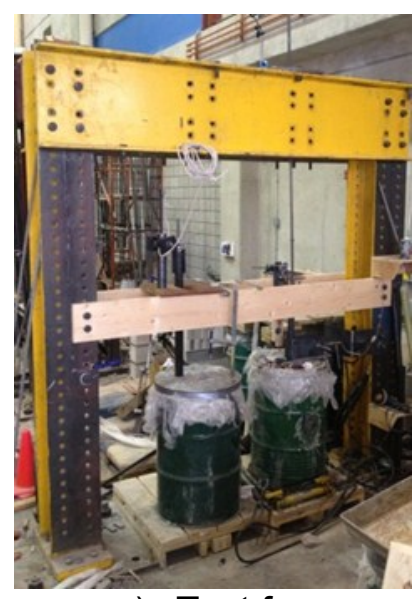

a) Test frame

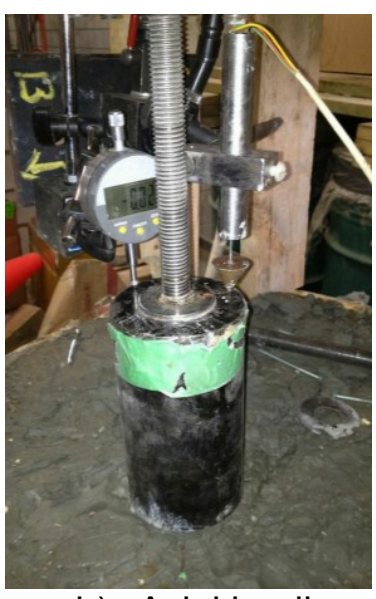

b) Axial loading

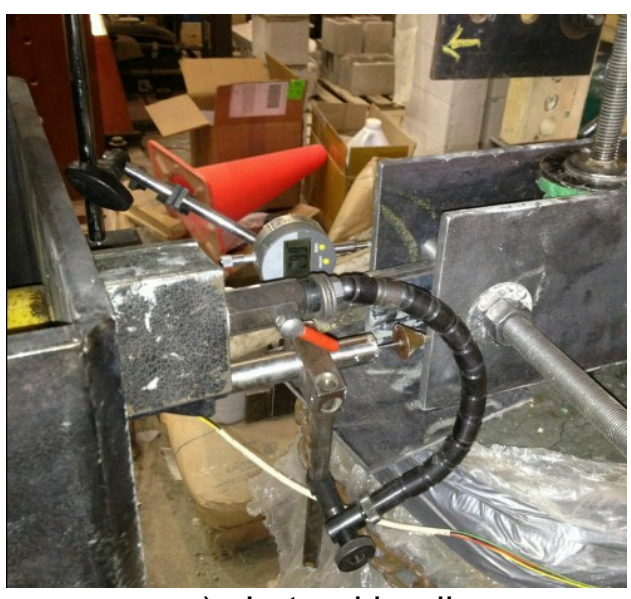

c) Lateral loading

Figure 4.4 - Experimental assembly for axial and lateral load tests

\section{Cumulative \# of blows}

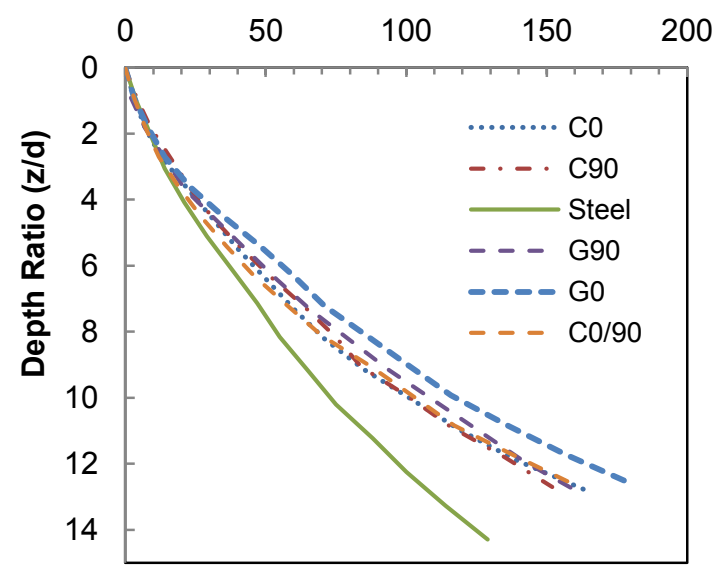

a)
Rate of Penetration (mm/blow)

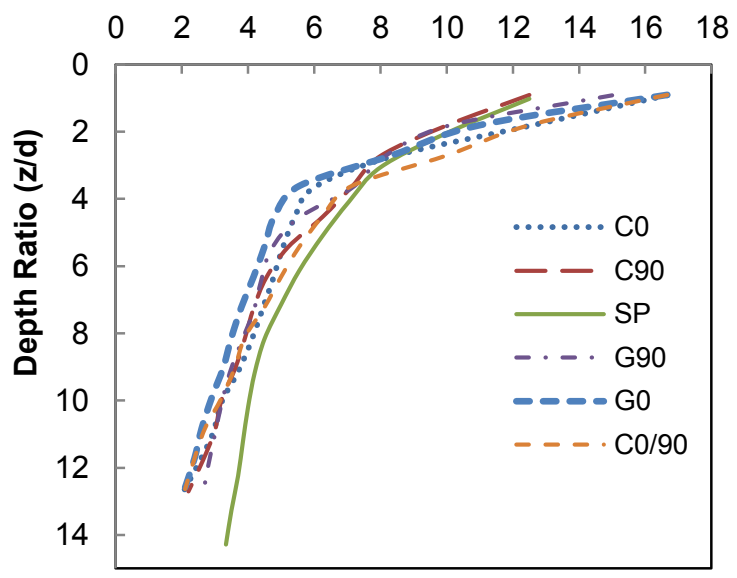

b)

Figure 4.5: a) Cumulative \# of blows vs depth ratio; b) Rate of penetration vs depth ratio 


\subsubsection{Test Procedure}

\subsubsection{Static compressive pile load tests}

Compressive pile load test were carried out following a modified method based on ASTM D1143. The pile head mechanism is used to connect a steel rod to the hydraulic jack and reaction frame allowing for the application of compressive loads. The loading procedure was designed to bring the pile to failure by applying incremental loading at 100 second intervals allowing for interface forces to reach equilibrium. The failure criteria used to determine ultimate pile capacity was pile resistance at pile head displacement of $10 \%$ pile diameter as suggested by De Nicola and Randolph (1999). For all tests the number of loading cycles required to reach the mentioned failure criteria was 14 to 17 . Pile unloading was carried out in 4 steps and pile rebounding was measured.

\subsubsection{Static lateral load tests}

Following axial compression test, a lateral pile load test was carried out according to a modified procedure based on ASTM D3966 (2013). The test was carried out by applying load increments at 100 second intervals. Unlike compressive tests, lateral load tests did not reach defined failure behaviour. Typically, the design criteria for lateral pile capacity are based on limiting pile head deflection. The failure criteria used for determining ultimate pile capacity was the capacity measured at $6.25 \mathrm{~mm}$ pile head displacement as suggested by (Prakash and Sharma, 1990), however the loading test was continued until approximately 0.20 displacement ratio (pile head movement/pile diameter) to observe pile behaviour at large lateral deflections. The average number of cycles required to reach the failure criteria ranged from 20 to 25 , unloading was then carried out in 4 to 5 cycles and pile rebound was measured. 


\subsection{RESULTS AND DISCUSSION}

\subsubsection{Pile Axial Compression Capacity}

Pile load test results are summarized in Figure 4.6 where axial load capacity is plotted against vertical pile head movement. Ultimate pile capacity was defined as the load corresponding to a pile head displacement equal to $10 \%$ pile diameter (De Nicola and Randolph, 1999). At this level of displacement $(5.5 \mathrm{~mm})$, pile capacity was observed to remain approximately constant with each additional loading cycle. Table 4.4 summarizes the pile capacity for all FRP and steel piles. In all cases, ultimate capacity for the FRP model piles was 25 to $40 \%$ higher than the steel pile with the exception of the C0 pile which was on par with the steel pile ultimate capacity. The loading response of all piles was similar, with a rapid linear increase of pile resistance at very low pile head displacements, attributed to ultimate shaft frictional capacity being mobilized followed by a hardening region until ultimate capacity is reached at approximately 5.0 to $5.5 \mathrm{~mm}$ of displacement.

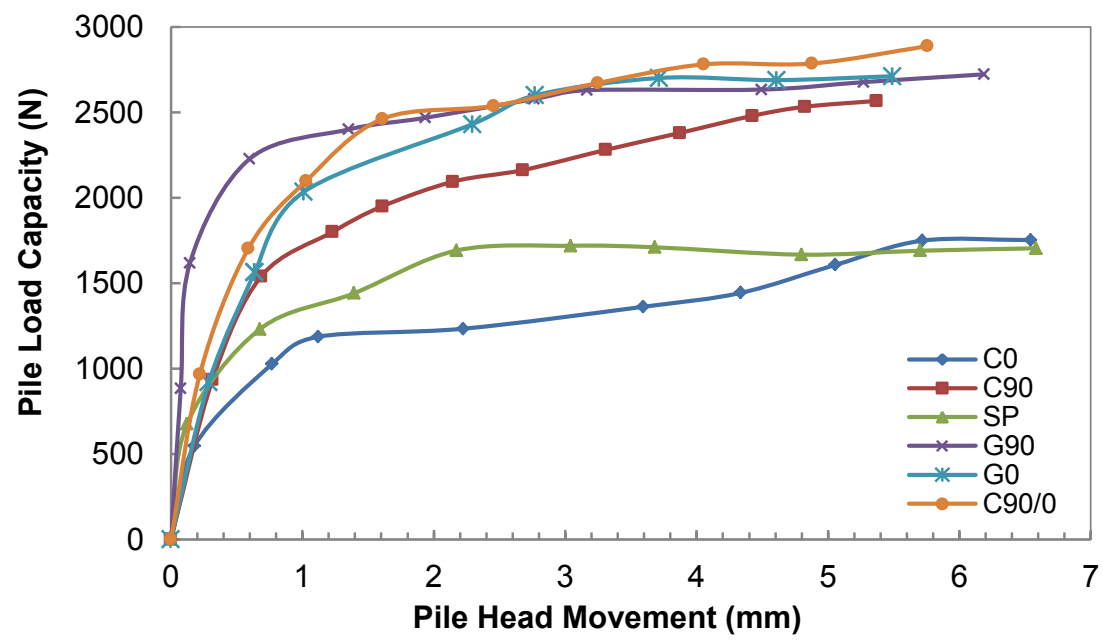

Figure 4.6 - Pile resistance vs pile head movement 
Frictional resistance was observed to engage at very low displacements ranging from $0.08 \mathrm{~mm}$ to $0.16 \mathrm{~mm}$ corresponding to $0.15 \%$ to $0.30 \%$ pile diameter. Pile $\mathrm{G} 90$ presented the fastest rate of capacity increase while the steel and C0 pile presented the most gradual increases. The rapid change in slope of the load-displacement curve after the early portion of loading can be attributed to frictional failure of the soil surrounding the pile shaft. Further pile movement engages soil at the pile toe providing a very gradual increase of capacity due to the open end nature of the pile geometry.

Based on the pile load tests results shown above, it is evident the FRP piles tested present a significant improvement over traditional steel piles in terms of their geotechnical performance in soft clays. Full scale pile load tests required to verify pile driving performance, structural resistance, and long term effects such as creep and weather resistance. As FRPs gain a better established track record and increased industry use, economies of scale will bring prices down to match that of steel piling. Furthermore, GFRP piles exhibited some of the largest pile resistance tested while material costs are half of the CFRP piles.

\subsubsection{Pile shaft resistance}

Pile capacity of open-end piles in cohesive soils is developed primarily in the form of soil-pile adhesion, also referred as pile shaft resistance, in undrained conditions. Various authors (Poulos and Davis, 1980; Fleming et al., 1992) and design guidelines such as the CFEM (CGS, 2007) estimate the pile bearing capacity as a function of pile geometry (length and diameter) and soil-pile interface resistance. The shaft resistance $\left(Q_{S}\right)$ is typically estimated from the following equation:

$$
Q_{s}=C L q_{s}
$$


where $C$ is pile circumference, $L$ is pile embedment and $\mathrm{T}_{\mathrm{s}}$ is the average shear strength, also known as unit shaft resistance, along the soil-pile contact area. Furthermore the average shear strength $\mathrm{T}_{\mathrm{s}}$ can be expressed in terms of the soil undrained shear strength $\left(S_{u}\right)$ and an empirical reduction factor, $\alpha$, accounting for pile-soil adhesion which is typically correlated to $S_{u}$. $T_{s}$ is estimated by the following equation:

$$
q_{s}=\alpha S_{u}
$$

Bearing capacity of open-end driven piles in clay is mainly provided by shaft resistance, with a minimal contribution from toe bearing resistance. Toe bearing resistance has been estimated and removed from the total pile capacity in order to isolate the shaft resistance. Toe capacity $\left(Q_{b}\right)$ was calculated according to the following expression:

$$
Q_{b}=N_{c} S_{u} A_{b}
$$

where $N_{c}$ is a bearing capacity factor, typically 9 for pile diameter under $0.5 \mathrm{~m}$ as suggested by CFEM (CGS, 2007). $S_{u}$ is the soil undrained shear strength, and $A_{b}$ is the pile toe contact area. In average, the calculated toe bearing capacity was estimated to be approximately 10 to $15 \%$ that of the measured pile resistance for all model piles.

The average unit shaft resistance, $q_{s}$, was estimated from the measured pile capacities by dividing the load transferred to the soil between the pile head and toe by the surface area of the pile, as follow:

$$
q_{s}=\frac{Q-Q_{b}}{C l}
$$

where $Q$ is the measured pile capacity, $Q_{b}$ is the toe resistance, $C$ is pile circumference, and $L$ is pile embedment. Figure 4.7 illustrates the comparison of average unit shaft resistance plotted against displacement ratio (pile head movement / average pile 
diameter) for all piles. In all cases failure was estimated to occur at a displacement ratio of approximately 0.1. It is clear that both glass fiber G0, G90 and the carbon C90/0 model piles reached the highest shaft resistance of approximately $20 \mathrm{kPa}$ compared to steel pile at $13.5 \mathrm{kPa}$ for an overall improvement of up to $30 \%$ increase. In contrast, pile C0 presented an overall decrease in shaft resistance by up to $15 \%$ at pile failure. The higher shaft resistance of FRP piles are attributed to their surface roughness compared to the steel. Pile surface texture plays a significant role in the increased shaft resistance where grooves and texture of the pile fabric create increased contact area between the soil and pile. Similar behaviour was observed when different FRP fabrics were shear against soft clay in a direct shear box (Giraldo and Rayhani, 2013). Large scale pile load tests are needed to corroborate these results.

The corresponding a-coefficient for each pile load tests was estimated based on equation 2. The $\alpha$ value for piles $\mathrm{G} 0, \mathrm{G} 90$ and $\mathrm{C} 90 / 0$ was 0.36 , for pile $\mathrm{C} 90$ it was 0.33 and for pile $\mathrm{C} 0$ it was the lowest value at 0.21 . In addition, the control steel pile was measured at $\alpha$ of 0.25 . The calculated values are, in general, lower than the typical estimates reported in literature for clays of similar undrained shear strength (Poulos and Davis, 1980; Fleming et al., 1992; CFEM, 2007).

Additionally, estimated shaft resistance calculated based on undrained interface parameters obtained from direct shear box testing in Chapter 3 are shown in Table 4.4. The results indicate good agreement with the measured shaft resistance values from pile load testing with the largest discrepancy of $8 \%$ between estimated and measured values indicating reasonable validation of the results obtained in Chapter 3. 
Table 4.4 - Axial compressive capacities of FRP and steel piles

\begin{tabular}{lccccc}
\hline Pile & $\begin{array}{c}\text { Compressive } \\
\text { Capacity } \\
(\mathrm{N})\end{array}$ & $\begin{array}{c}\text { Measured Shaft } \\
\text { Resistance } \\
(\mathrm{N})\end{array}$ & $\begin{array}{c}\text { Estimated } \\
\text { Shaft } \\
\text { Resistance(N) }\end{array}$ & $\begin{array}{c}\text { Tore } \\
\text { Resistance } \\
(\mathrm{N})\end{array}$ & $\begin{array}{c}\text { Shaft } \\
\text { Resistance } \\
\text { Ratio (\%) }\end{array}$ \\
\hline C-0 & 1670 & 1330 & 1453 & 340 & 79.6 \\
C-90 & 2567 & 2220 & 2041 & 345 & 86.4 \\
C-0/90 & 2786 & 2436 & N/A & 350 & 89.8 \\
G-0 & 2711 & 2383 & 2255 & 328 & 89.9 \\
G-90 & 2722 & 2404 & 2194 & 318 & 88.3 \\
SP & 1710 & 1440 & 1546 & 266 & 84.2 \\
\hline
\end{tabular}

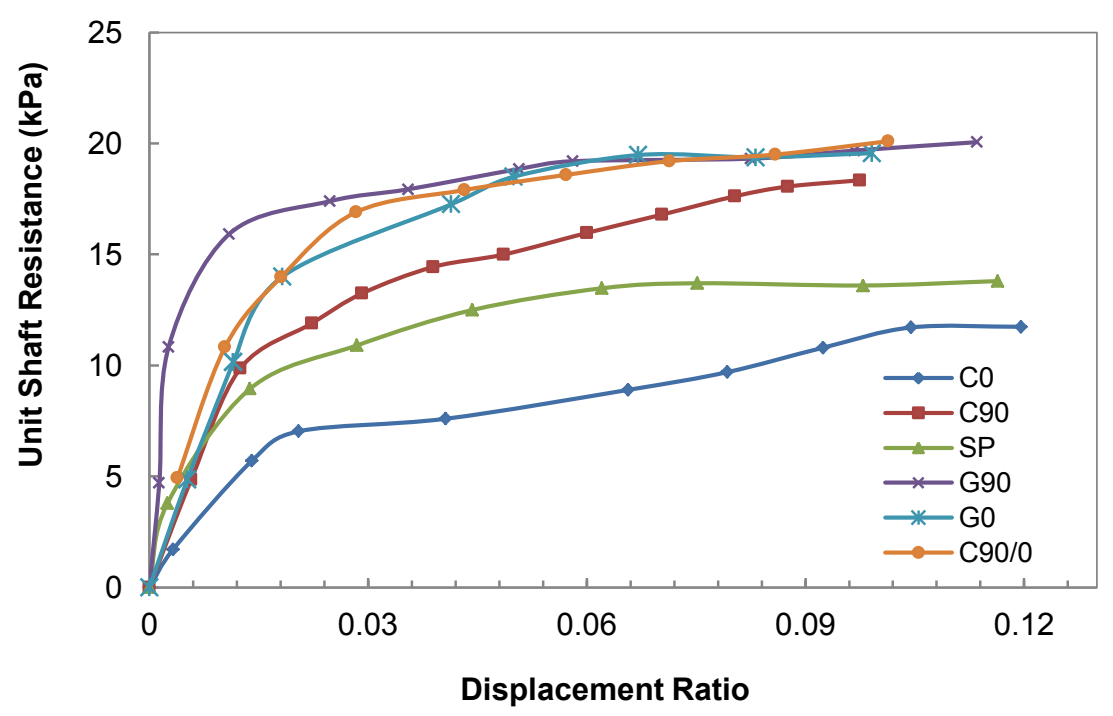

Figure 4.7 - Average unit shaft resistance of FRP and steel piles

\subsubsection{Comparison to published data and empirical estimates}

Pile design and capacity estimation in cohesive soils and under undrained conditions is typically carried out by using empirical relationships correlating undrained shear strength to pile frictional resistance for the sake of simplicity and costs (O'Neill, 2001). Typical design guidelines such as the CFEM (CGS, 2007) provide experimental data correlating Su to $\alpha$ values in order to provide for a preliminary capacity estimate. This correlation procedures typically have a large spread of uncertainty varying up to $+/-35 \%$ from the average as reported in pile load tests carried by (Chow, 1997). Figure 4.8 presents 
published data extracted from CFEM (CGS, 2007) and Poulos and Davis, (1980) illustrating the scatter and trends of $\alpha$-coefficients of various piles in uplift and compression and the results obtained for the FRP and steel piles tested in this study for the different FRP model piles tested. The calculated $\alpha$ coefficients for the FRP and steel piles are below the general trend for similar tests at similar soil shear strengths. These empirical correlations are subjected to a series of uncertainties such as soil changes during installation, excess pore pressure equilibration and dissipation, and pile loading and embedment length effects (Randolph, 2003). It should be emphasized that pile testing in the current research was carried out immediately following driving in order to avoid the effects of pile set-up due to pore water dissipation. This is suspected to be a factor influencing the lower than average values obtained as it is uncertain the level of set-up for the data sets shown in Figure 4.8.

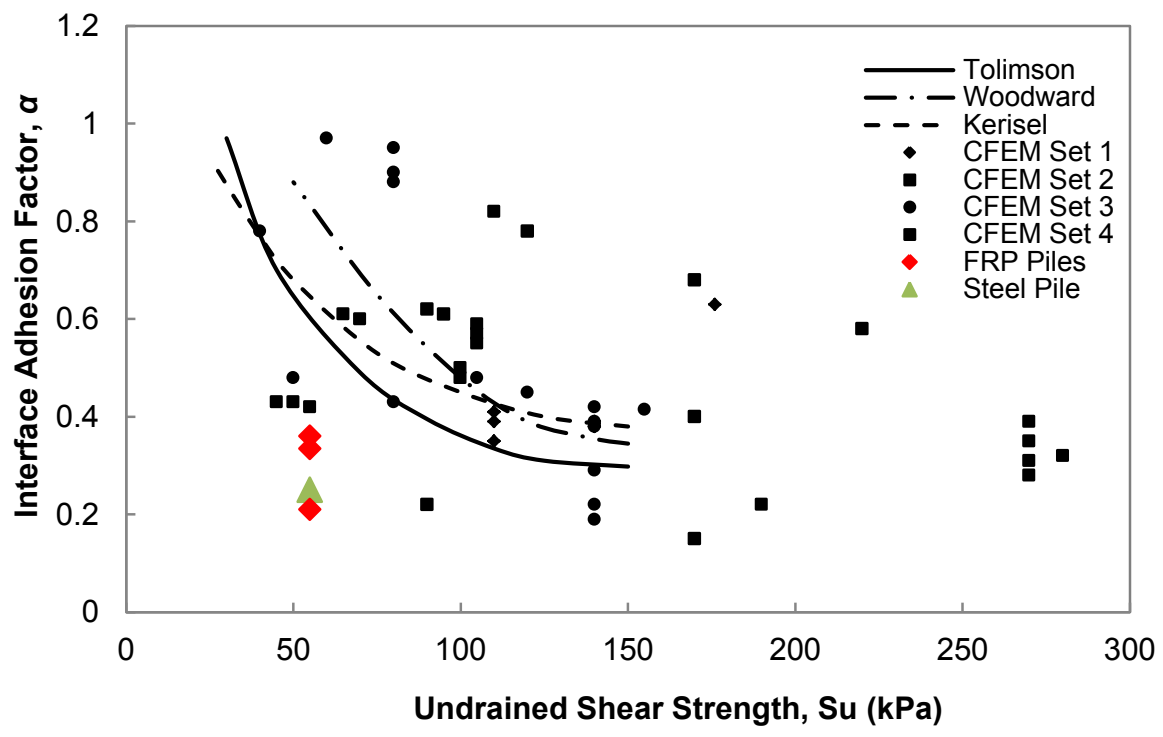

Figure 4.8 - Relationship of Su to $\alpha$ values based on published data

It is generally accepted that the behaviour and shear strength of soil surrounding a driven pile is not only dependant on the shear strength of the soil but also on the past stress history (Randolph, et al., 1979). Approaches to relate the soil strength ratio 
defined as $S_{u} / \sigma_{v}^{\prime}$ to the undrained correlation parameters $\alpha\left(q_{s} / S_{u}\right)$ and drained correlation coefficient $\beta\left(q_{s} / \sigma_{v}^{\prime}\right)$ have been carried out. (Randolph \& Murphy, 1985) calibrated a method to estimate the $\alpha$-coefficient through a series of driven piles in clay according to the following expressions:

$$
\alpha=0.5\left(S_{u} / \sigma_{v}^{\prime}\right)^{-0.5}
$$

for strength ratios of $S_{u} / \sigma^{\prime}{ }_{v}$ less than or equal to 1 and,

$$
\alpha=0.5\left(S_{u} / \sigma_{v}^{\prime}\right)^{-0.25}
$$

for strength ratios greater than unity. This approach was applied to the model piles tested and yielded an $\alpha$-coefficient of 0.27 which falls between the values measured for the FRP piles on the upper end and the steel pile at 0.25 . These values are within reasonable agreement with the experimental results since piles tested at shallow depths lead to low confining pressures which yield high strength ratio values which when estimating $\alpha$ with equation 4.6, lead to the low coefficients discussed above. Large scale pile load tests are needed in order to explore the behaviour of shaft resistance at higher confining pressures. It is expected that at larger confining pressures, the $\alpha$-coefficient, will fall in line with published data models.

\subsubsection{Effect of fiber orientation on pile capacity}

Fiber orientation was investigated in order to characterize its influence on pile capacity. Since pile surface texture was dictated by the weaving pattern of the fiber fabric used to manufacture the piles, changing the direction of the fiber significantly modified the pile texture in contact with the soil. More importantly, GFRP piles had a distinct interweaving fiber bundling pattern which gave the pile surface protruding ridges and valleys approximately of $0.5 \mathrm{~mm}$ peak to valley distances which changed direction depending on 
pile manufacturing. In contrast, for CFRP piles the texture was streamlined with less pronounced ridges. However CFRP oriented at $0^{\circ}$ allowed for streamlined groves along the pile axis which is suspected to allow the unobstructed sliding of clay, leading to the lower pile capacity measured. Figure 4.9 illustrates the frictional performance of three CFRP model piles each with fibers parallel and perpendicular to each other against pile displacement ratio. The third pile C90/0 has the outer surface with fibers oriented at $90^{\circ}$ with the objective of providing better soil-pile resistance, while the inner fibers provide the pile with structural integrity. This combination is shown to present the best results in terms of shaft resistance for the CFRP piles with over a 35\% increase of the C90/0 pile at pile failure. Further testing and stringent manufacturing quality control ensuring pile surface texture repeatability are needed to characterize the influence of pile texture and fiber orientation in a consistent manner. With respect to GFRP piles, both piles reached similar frictional capacity at failure suggesting that the pronounced texture of the pile surface interacting with the soil is independent of grooves orientation, suggesting the increased surface area available at the soil-pile interface was responsible for the increased shaft resistance. However, it was observed that pile G90 experienced shaft resistance mobilization at lower displacement ratios than pile G0. No GFRP pile with combined fiber orientation was produced since pile G90 was observed to have sufficient structural integrity required to withstand testing at the low axial loads used in this small scale study. Further analysis of optimal fiber orientation is needed in order to establish optimal structural integrity of the pile in order to avoid structural failure. In both cases, (GFRP and CFRP) the optimal outer surface fiber orientation was $90^{\circ}$ with pile shaft resistance. The CFRP piles showed a higher sensitivity to fiber orientation than GFRP piles with. Inner layers of FRP should be arranged in a fashion to increase pile structural 
integrity. Full scale pile load tests are needed in order to explore the pile behaviour under working loads.

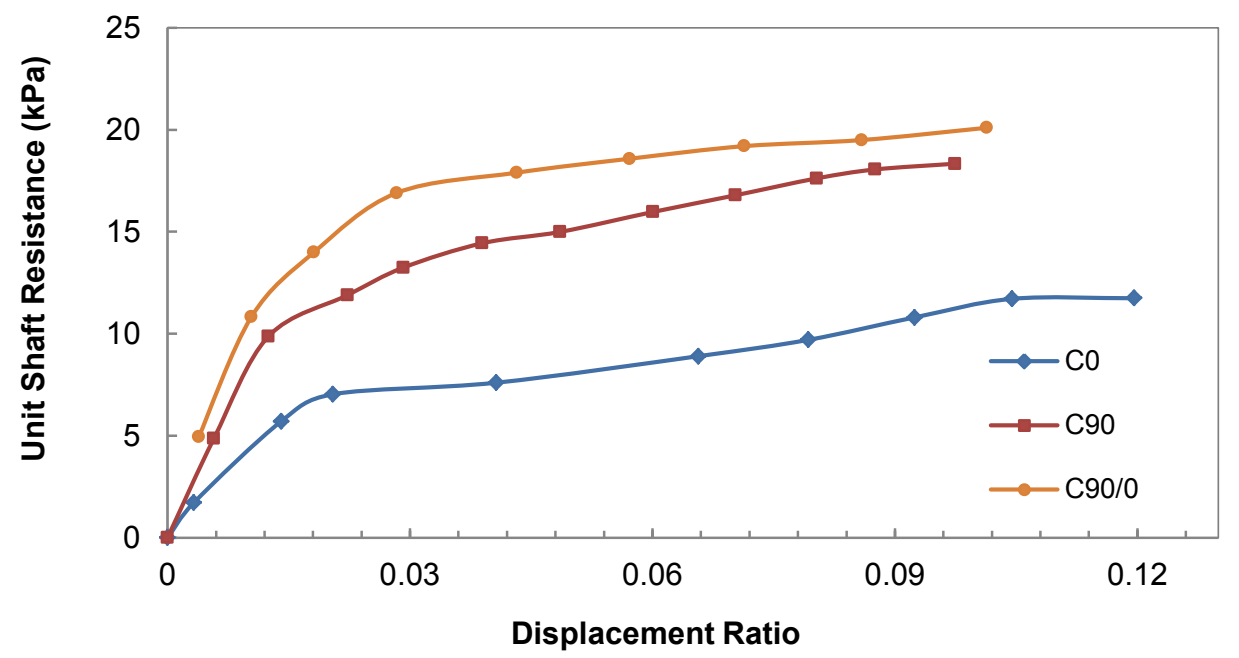

Figure 4.9 - Comparison of CFRP pile performance on based on fiber orientation

\subsubsection{Effect of FRP material selection on pile capacity}

Selection of pile material has an important role in two key aspects of pile performance: pile structural integrity and geotechnical response. Structural integrity is directly linked to the mechanical material properties such as elastic modulus and yield strength, whereas pile geotechnical performance is strongly influenced by the pile surface texture which is dictated by the weaving of the fabric. Based on the results of this study, the GFRP piles tested in both $90^{\circ}$ and $0^{\circ}$ orientations presented a significant improvement over steel, while fiber orientation strongly influenced pile resistance for CFRP piles leading to significantly lower pile capacity in the $0^{\circ}$ fiber direction. Fiber weaving and texture had a significant effect and the GFRP pile specimens showed protruding ridges due to the fabric weaving manufacturing process which is suspected to allow for increased soil-pile 
surface area or a better soil-pile interlocking mechanism. From a geotechnical point of view, the surface texture produced by the GFRP material yields a better performance than the CFRP fabric. Further work is needed in order to compare CFRP and GFRP in terms of structural response specially under working load conditions. To date most studies regarding structural response of hollow and concrete filled FRP tubes have been conducted with GFRP fibers since the high cost of CFRP materials has not made the production of CFRP piles feasible for large scale use. However, studies on the structural response of GFRP piles have shown that hollow CFRP piles are susceptible to buckling (Han \& Frost , 1999). In addition, long term deformations such as creep can be significant issues for FRP piles due to material anisotropy, lower moduli and higher shear to elastic moduli ratios compared to steel. Approaches to increase structural performance of FRP piles include the partial or total infilling of the hollow void with concrete in order to take advantage of the confining effect of the concrete by the FRP shell (Fam \& RizKalla, 2001a; Fam \& Rizkall, 2001b). Further work with large scale pile load tests is needed in order to fully assess and estimate pile structural capacity. Based on the work conducted for this research program, the GFRP piles presented a better response over the GFRP counterparts due providing high capacity in both of the tested fiber directions in contrast to the CFRP results which showed higher variability.

\subsubsection{Pile Lateral Capacity}

Pile lateral capacity is typically determined from estimating the ultimate lateral failure load divided by a factor of safety or estimating the allowable lateral load corresponding to acceptable pile deflections based on various design criteria. The failure load, based on the static lateral loading test, was taken as the pile resistance measured at $6.25 \mathrm{~mm}$ (0.1 displacement ratio) of lateral pile head movement (Prakash \& Sharma, 1990). However, the loading test was carried out until a pile head movement of $20 \%$ pile 
diameter (displacement ratio) to observe the behaviour of the model piles under large deformations. All piles were assumed to behave as short free - head piles as the $L / d$ ratio for all the piles ranged from 13.5 to 12.7 . Typically, short pile behaviour is expected of $L / d$ ratios of 10 to 12 (Tomlinson, 1994). In addition, the maximum applied lateral load was lower than the load at failure under 3-point bending tests of select FRP piles illustrating flexural material failure is not the controlling parameter for the tested piles.

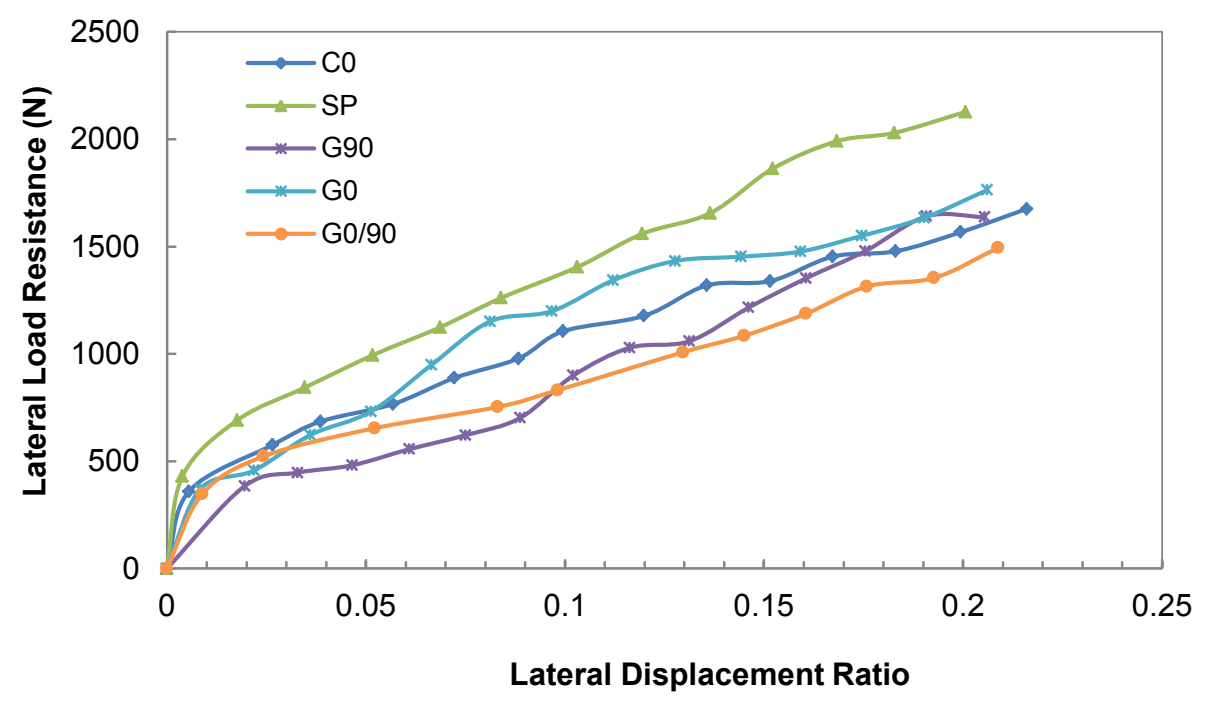

Figure 4.10 - Lateral pile resistance vs pile displacement ratio

Figure 4.10 illustrates the results for 5 pile load tests showing lateral resistance and pile displacement ratio (lateral movement divided by pile diameter). Pile C90 failed structurally when subjected to lateral loads due to the lack of longitudinal fiber reinforcement; hence the results are not included in this analysis. In all cases the loaddisplacement behaviour exhibits two approximately linear sections. At low lateral displacement ratios of 0.01 to 0.02 , loading response is characterized by a rapid increase of lateral resistance, followed by an approximately linear trend with a less pronounced slope. The steel pile presented an increase in lateral resistance up to $28 \%$ higher at failure compared to the FRP piles. Similar behaviour was reported by (Sakr et 
al., 2004) in scale piles tested in a pressure chamber filled with sand. The lower pile response was mainly attributed to lower flexural stiffness of the FRP piles (Eplp). In addition (Pando et al., 2006) discussed the susceptibility of FRP piles, especially hollow FRP piles to increased lateral deflections due to shear deformation effects caused by high ratios of elastic to shear modulus. Table 4.5 shows a summary of the lateral capacity for the different piles and their corresponding flexural stiffness (EI) estimated from 3 point loading tests on piles with $0^{\circ}$ fiber orientation. It was observed based on these flexure tests that the piles at peak lateral displacement ratios of 0.2 were only approximately under 20 to $30 \%$ of their ultimate flexural capacity well below structural failure. Full scale load tests are needed to explore FRP pile behaviour under working load conditions.

Table 4.5 - Lateral capacity and properties of FRP and steel piles

\begin{tabular}{lcccc}
\hline Pile & $\begin{array}{c}\text { Lateral } \\
\text { Capacity at } \\
6.25 \mathrm{~mm}(\mathrm{~N})\end{array}$ & $\begin{array}{c}\text { Pile Stiffness } \\
\left(\mathrm{E}_{\mathrm{p}} \mathrm{I}_{\mathrm{p}}\right) \text { at } 2000 \mathrm{~N} \\
\text { load }\left(\mathrm{kN}-\mathrm{m}^{2}\right)\end{array}$ & $\begin{array}{c}\text { Pile Stiffness } \\
\left(\mathrm{E}_{\mathrm{p}} \mathrm{I}_{\mathrm{p}}\right) \text { at failure } \\
\left(\mathrm{kN}-\mathrm{m}^{2}\right)\end{array}$ & $\begin{array}{c}\text { Lateral } \\
\text { Resistance } \\
\text { Ratio to Steel }\end{array}$ \\
\hline C-0 & 880 & 6.4 & 6.8 & 80.0 \\
C-90 & $\mathrm{N} / \mathrm{A}$ & $\mathrm{N} / \mathrm{M}^{*}$ & $\mathrm{~N} / \mathrm{M}^{*}$ & 86.4 \\
C-0/90 & 650 & $\mathrm{~N}^{*} \mathrm{M}^{*}$ & $\mathrm{~N} / \mathrm{M}^{*}$ & 59.0 \\
G-0 & 950 & 9.7 & 11.4 & 86.6 \\
G-90 & 580 & ${\mathrm{~N} / \mathrm{M}^{*}}_{\mathrm{N} / \mathrm{M}^{*}}$ & 52.0 \\
SP & 1100 & $25.75^{*}$ & $25.75^{*}$ & \\
\hline
\end{tabular}

${ }^{*} \mathrm{~N} / \mathrm{M}$ - not measured under 3-point bending

${ }^{¥}$ calculated based on $200 \mathrm{GPa}$ elastic modulus

\subsubsection{Effect of material selection on lateral capacity}

Pile response under lateral loading is typically controlled by soil response, pile stiffness and soil-pile interface interaction. For this research program, lateral response is mainly controlled by the model pile structural properties such as the piles flexural stiffness $E_{p} l_{p}$ since soil conditions and pile geometry is approximately equal for all cases. Figure 4.11 shows the lateral response of piles C0 and G0 illustrating no significant difference in pile 
behaviour with pile G0 showing only a 5\% increase in pile capacity. Figure 4.12 illustrates results for flexural stiffness vs loading level carried out under 3-point bending. It is shown that the pile behaviour is highly non-linear at low loading levels reaching a plateau after approximately $30 \%$ of failure load. The FRP model piles under lateral load at 0.2 displacement ratio face a load at the pile head of approximately $2000 \mathrm{~N}$ corresponding to approximately $20 \%$ of the failure loading under 3 -point bending. This indicates that the pile flexural stiffness for piles undergoing lateral loading is in the range of 6.7 to $9.3 \mathrm{kN}-\mathrm{m}^{2}$ for $\mathrm{G} 0$ and $\mathrm{C} 90$ correspondingly. Although 3-point bending does not accurately represent the bending moments applied to a pile under lateral loading, these values give a basic understanding on the why these piles experience higher deflections than the steel counterpart. Large scale instrumented piles are needed in order to accurately model pile behavior of FRP piles under lateral loading in order to accurately identify the variability of pile stiffness at working loads. Based on this study it is difficult to identify which material preforms optimally under lateral loading since the pile stiffness behaves non-linearly and the soil yielded before pile failure. It was obvious however, that both all FRP piles present a significantly softer response than steel.

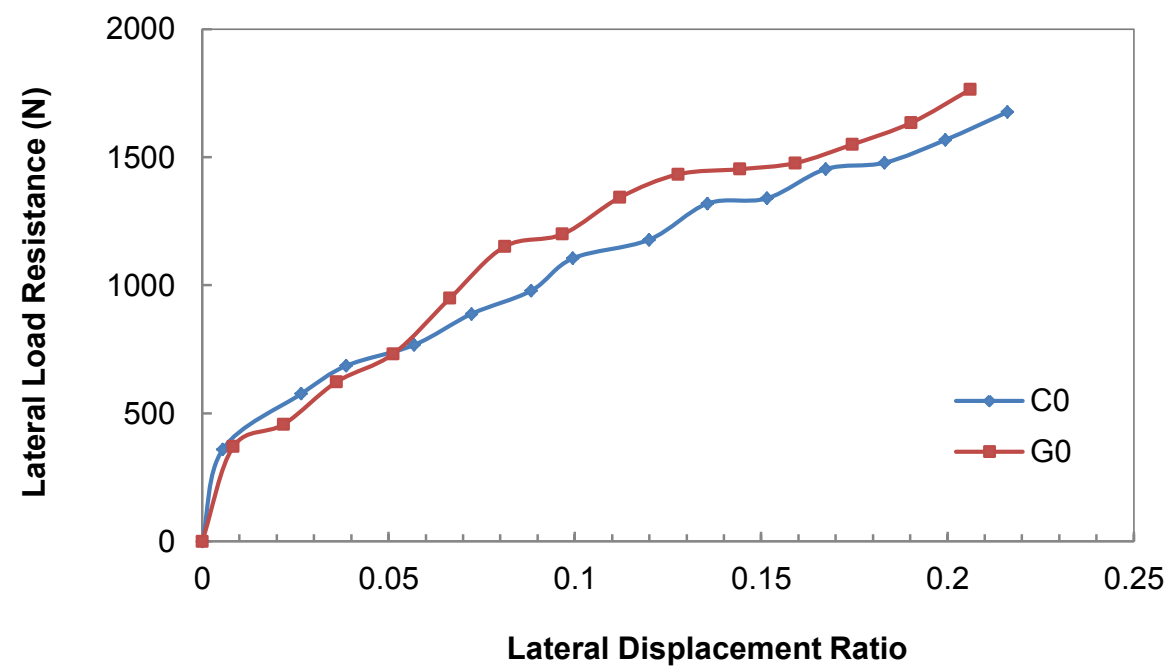

Figure 4.11 - Comparison of FRP Material Selection on Lateral Pile Capacity 


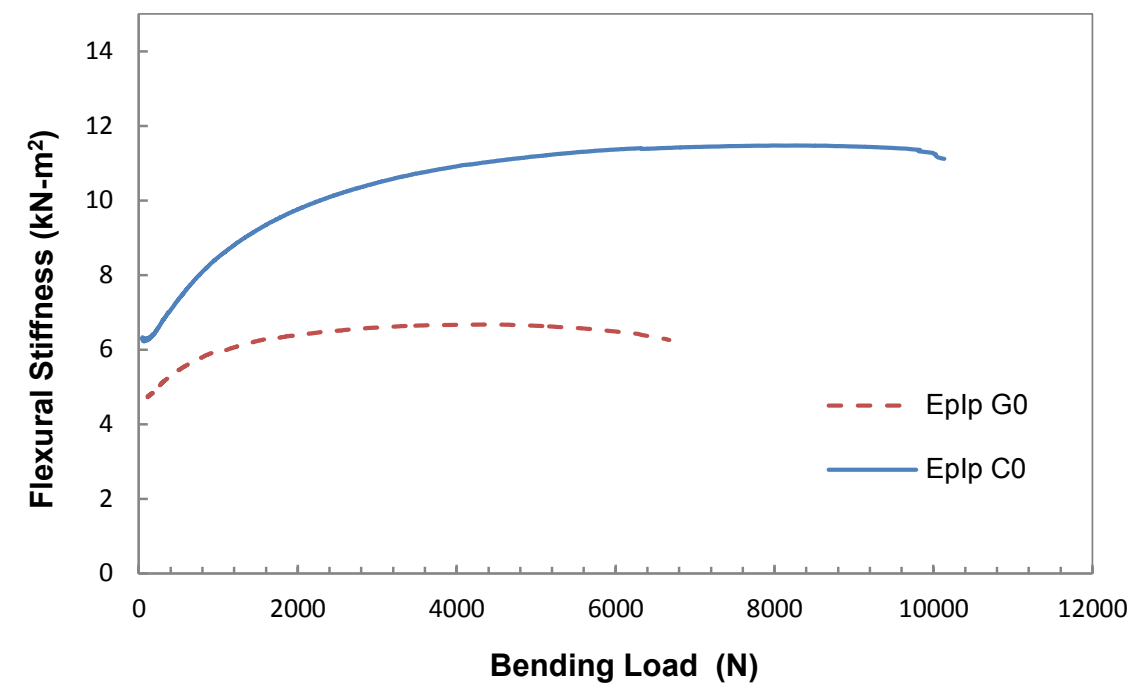

Figure 4.12 - Comparison of pile flexural stiffness under 3-point bending

\subsubsection{Comparison to analytical lateral capacity estimates}

Lateral pile capacity is usually carried out by estimating ultimate pile capacity through methods considering lateral earth pressure theory such as the Brinch Hansen Method (Brinch Hansen, 1961) or Brom's theory (Broms, 1964) or by estimating acceptable deflections at a working load. Estimating pile deflections typically uses elastic continuum solution and modulus of subgrade reaction approaches such as $p-y$ curves to calculate pile deflections at a given loading condition. A numerical analysis was carried out using the $p-y$ method to compare typical design approaches applied to the response of the FRP piles. P-y curves are typically developed for specific soil types and pile geometries (Prakash and Sharma, 1990). The family of $p-y$ curves used for this was based on (Matlock, 1970) which was developed for soft to medium clays. The analysis was carried out using the commercially available software typically used for design estimates LPILE (Ensoft, Inc, 2012) which allows the input of pile properties, boundary and loading conditions and built in $p-y$ curves. 
The simulation used the same laboratory parameters described in section 4.2.2 with a uniform clay layer of $900 \mathrm{~mm}$ thickness, pile dimensions and geometric properties and stiffness response based on results measured from the 3-point bending tests on piles at similar loading level as the lateral loading test. The soil was modeled as elastoplastic medium with Mohr-Coulomb constitutive behaviour, while the pile was modeled as a linear elastic element. Loading was applied in 10 increments until a total of $2000 \mathrm{~N}$ lateral loading was reached. Measurements of pile head deflection at the different loading intervals were then compared to the lateral test results. It is important to note that the numerical simulation using LPILE does not take into account the steel drum sample confinement and assumes an infinitely long soil layer in the horizontal direction. This effect can be one of the reasons for some of the discrepancies observed between the measured and estimated lateral deflections of some of the tested piles as discussed below. The results compare the behaviour of the steel pile, C0 and G0 piles are show in Figure 4.13.

Reasonable agreement was found between the steel pile and LPILE results with similar pile head displacements throughout the loading procedure. Both FRP piles presented reasonable agreement with the LPILE results although about $10 \%$ lower than the measured behaviour at large pile head deflections of over 0.2 displacement ratio. This shows that widely available design software can be successfully used to model this new type of material. Other studies such as Pando et al. (2006) carried out a similar analysis for concrete filled FRP piles in sand using a similar approach using LPILE software where they found good agreement between the modelled and measured pile deflections. It is recommended that full scale tests using instrumented piles are carried out in order to accurately measure pile deformations along the shaft in order to 
characterize the pile stiffness non-linearity especially in hollow FRP piles in order to better predict pile deflections under working loads.

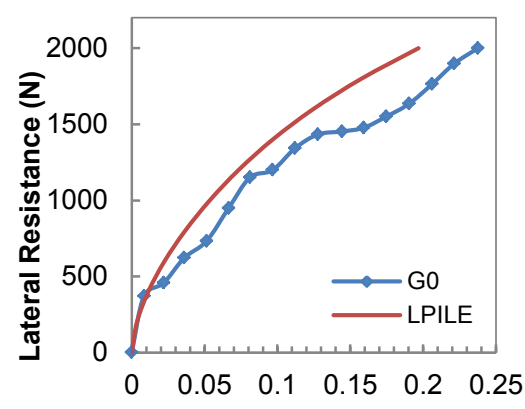

Latera Displacement Ratio

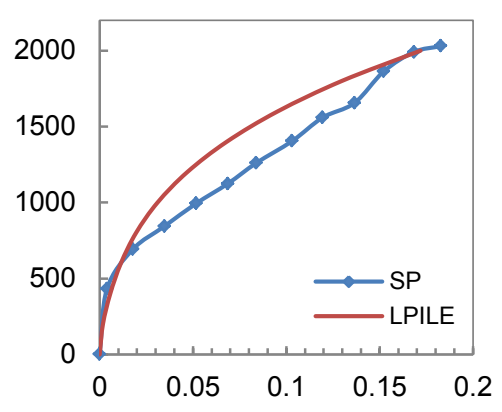

Latera Displacement Ratio

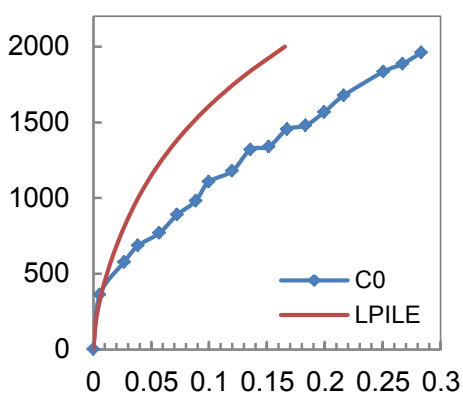

Lateral Displacement Ratio

Figure 4.13 - Measured lateral capacities vs LPILE analyses for FRP and steel piles (G0; Glass FRP, SP: Steel, and C0: Carbone FRP)

\subsection{FIELD TESTS}

In order to corroborate the laboratory results and rule out any effects due to clay confinement effects in the steel drums, mirror pile load tests for selected pile specimens were carried out in the field. The testing location known as the "Canadian Geotechnical Research Site No. 1 at Gloucester" south of Ottawa Ontario, has been traditionally used for measuring the behaviour of deep compressible clay layers (McRostie and Crawford, 2001). Undrainded shear strength parameters for the shallow layers of this site have been reported to be between 15 to $25 \mathrm{kPa}$ (Selvadurai, et. al, 1980) compared to the undrained shear strength of the clay used in the laboratory tests of $55 \mathrm{kPa}$. The field tests were carried out using a similar experimental setup to the laboratory tests with two 110 $\mathrm{mm}$ diameter steel reaction piles acting as the frame supports and wood beams spanning across the support piles acting as the reaction beam. Each reaction pile is estimated to have a capacity at least six times that of the model FRP piles. Figure 4.14 
shows the field setup and a model FRP pile under axial loading. The piles tested in the field were a control steel pile, C90-0 and G90 model piles of similar dimensions to those tested in the laboratory (Figure 4.15).

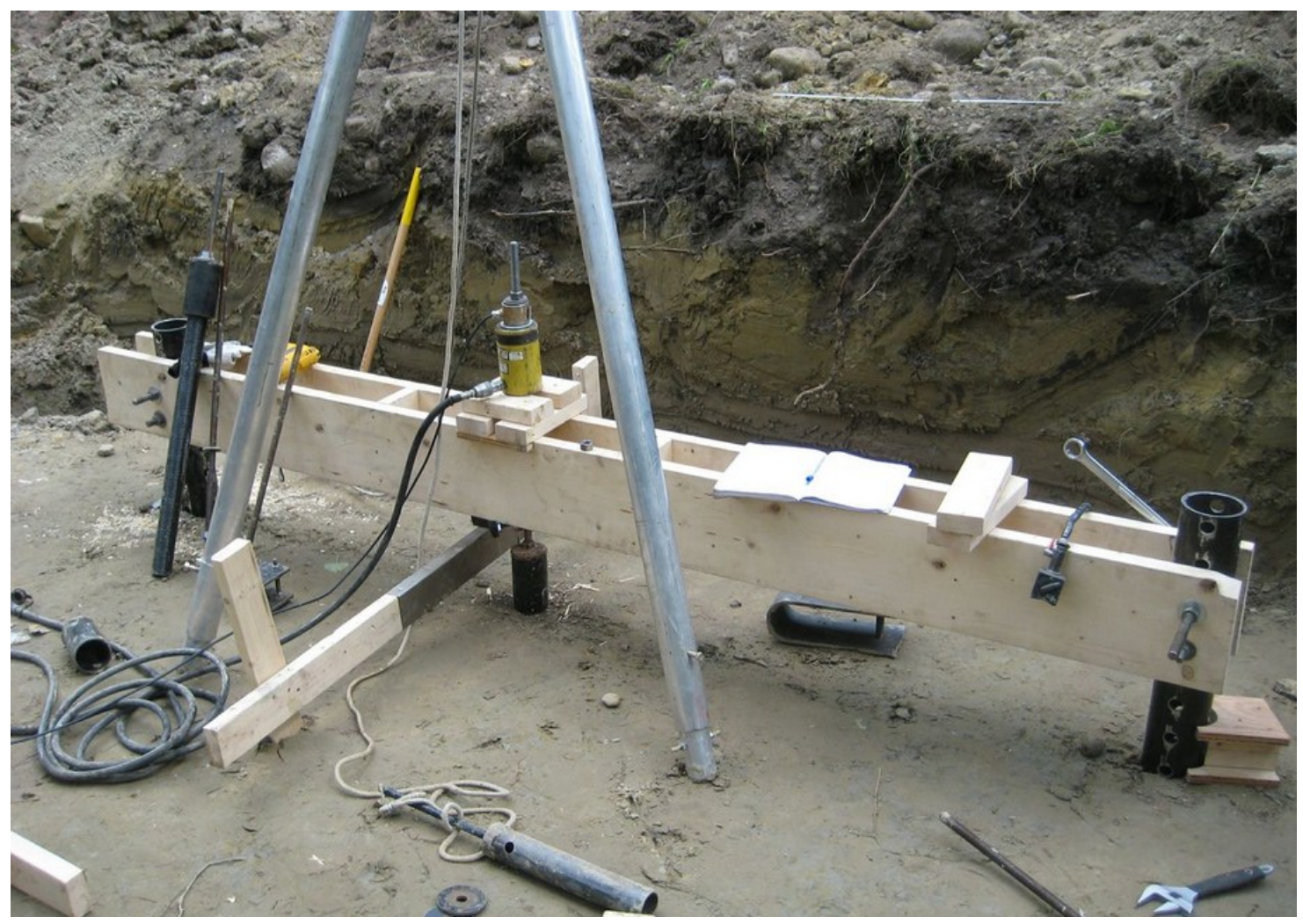

Figure 4.14 - Field experimental setup 


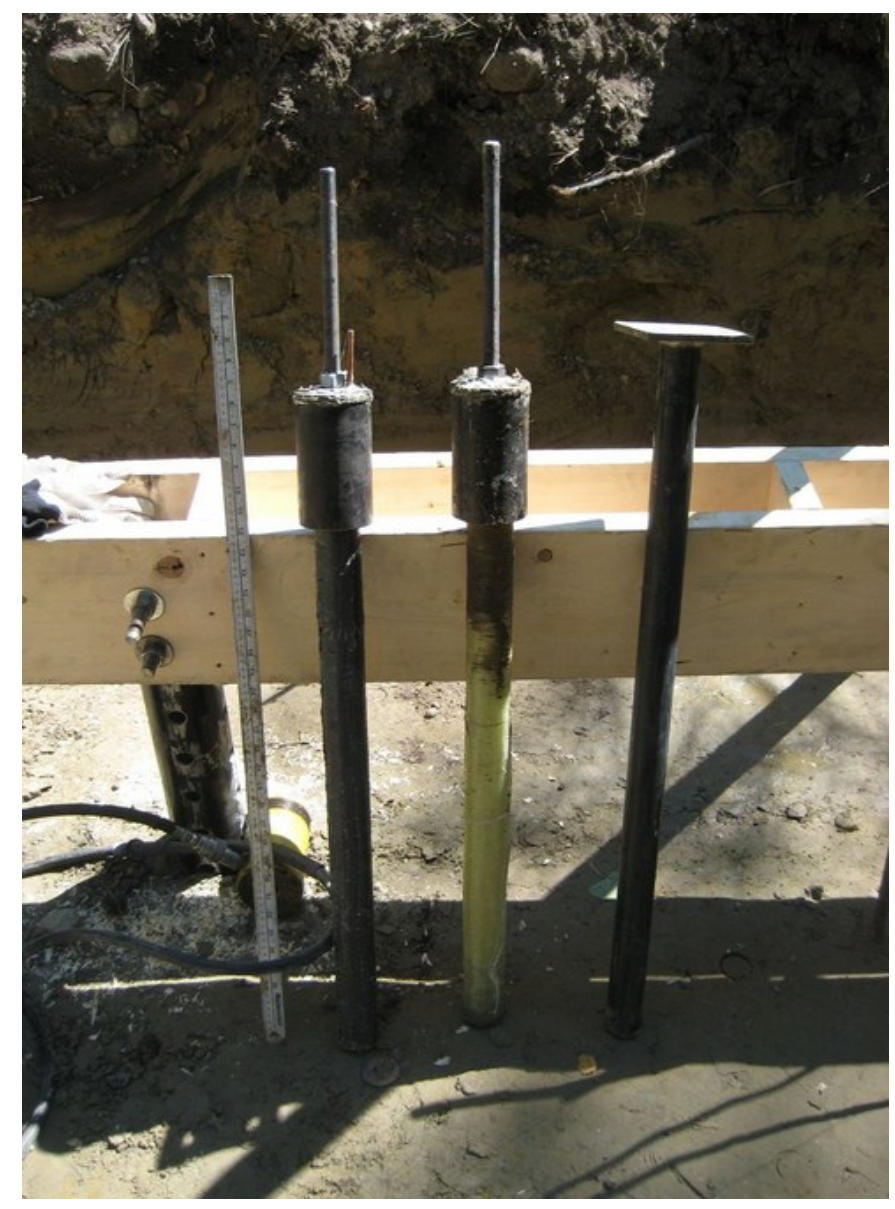

Figure 4.15 - Model piles used for field testing

Figure 4.16 presents a series of performance comparison of lab and field results for each of the piles tested. The general trend of the field tests is similar to those of laboratory testing where an initial steep load increase is observed, linked to the shaft frictional resistance, followed by a gradual hardening region related to the engagement of toe resistance with further pile movement. Failure was estimated similarly to the laboratory tests at a pile head displacement of $6.5 \mathrm{~mm}$. The general trend of the pile behaviour of the field tests is similar to the laboratory tests although the overall absolute capacity values are not. The absolute value comparison show that the laboratory tests present an ultimate capacity up to $40 \%$ higher than the field tests, however the relative difference between the test materials, e.g. steel and C90/0 in the field vs. laboratory 
tests remains within $10 \%$ difference, while this difference was more significant for pile G90. These discrepancies can be accounted by the different types of soil used in laboratory and field where the undrained shear strength of the soil material used in the laboratory tests was up to $50 \%$ higher to that of the soil in the field. Additionally pile manufacturing differences as each FRP pile was manufactured independently and other uncertainties associated with field testing can influence the discrepancies measured.

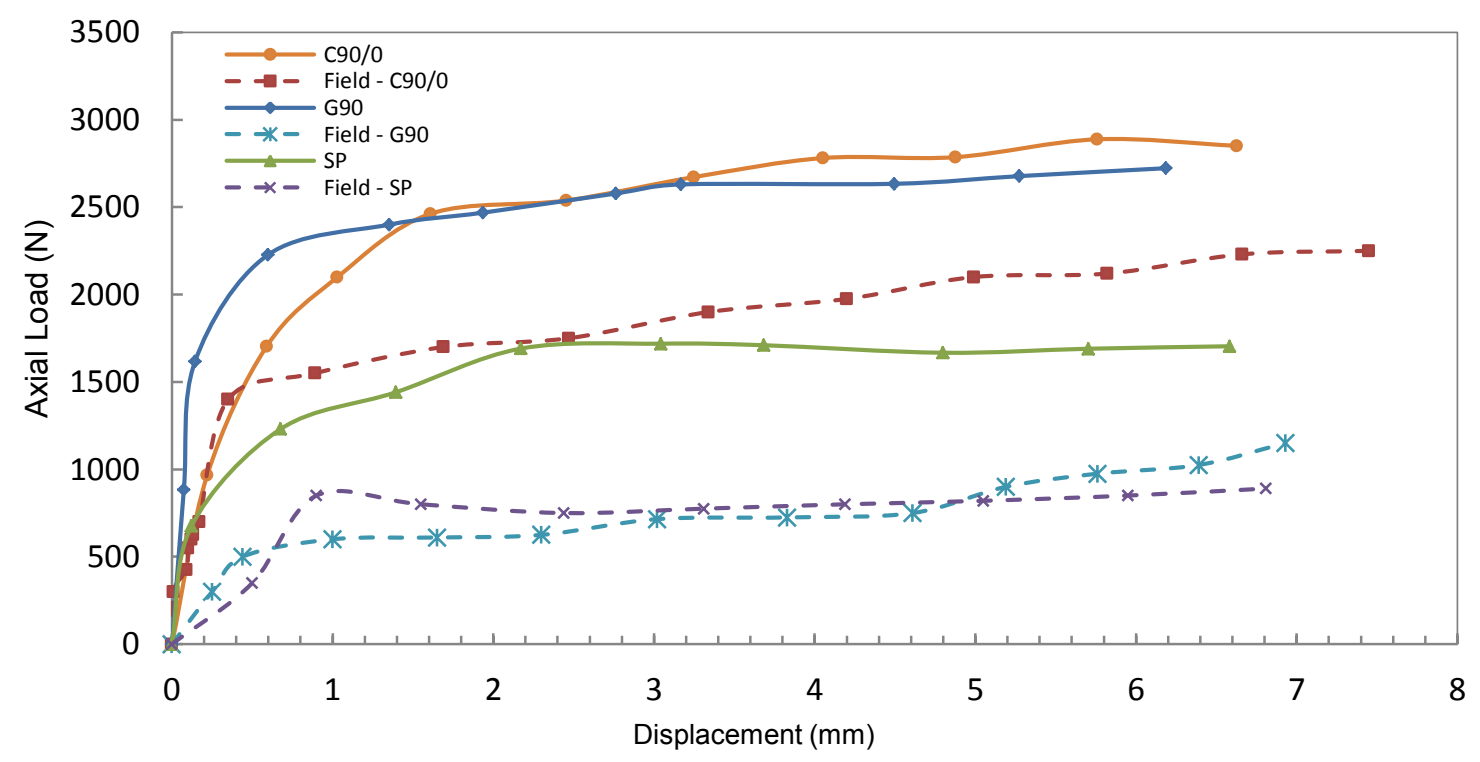

Figure 4.16 - Comparison of field and lab compressive load tests

With respect to pile behaviour under lateral loading, Figure 4.17 illustrates a comparison for the three piles tested in the field and the corresponding laboratory results. The pile responses of the field test are comparable to the laboratory tests as in all cases loading increases approximately linearly with increased pile head displacement. However, the rate of load increase which is related to the pile stiffness is significantly higher in the field compared to the laboratory tests. When observing the 
behaviour of the FRP piles tested, in the laboratory load test, both C0/90 and G90 had an almost identical behaviour. However, in the field tests, the C0/90 pile presented a much stiffer response compared to pile G90. This response is consistent with the stiffness values measured from the 3-point bending tests which indicated a stiffening response at higher bending loads. A possible explanation to this behaviour is the deformation of the steel drum as the lateral loading increased, which in turn changed the behaviour of the load transfer through the pile resulting in softer pile response. These results might indicate that although in-lab testing using large scale samples can be appropriate for axial compressive loading, lateral load tests results are influenced to a large degree due to the nature of the testing.

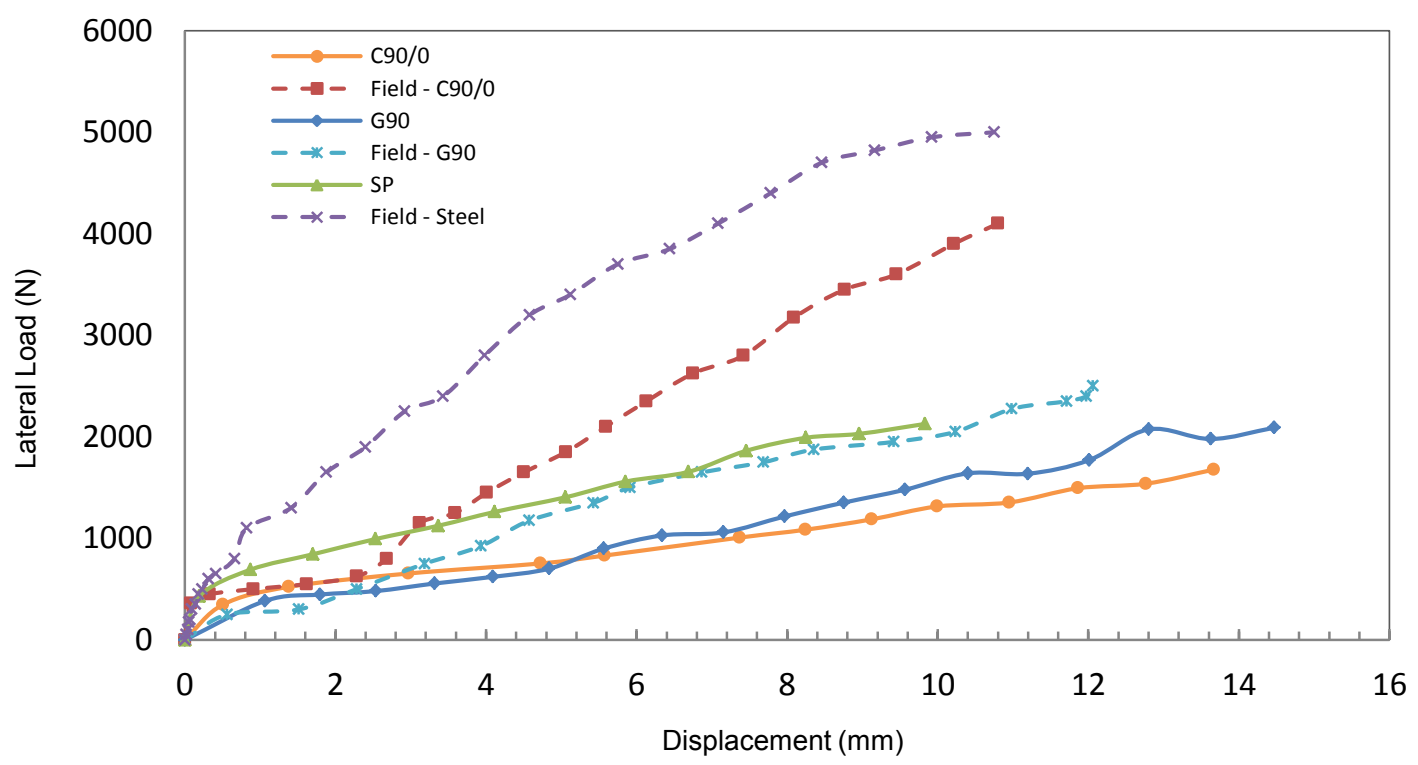

Figure 4.17 - Lateral loading response of field and laboratory load tests 


\subsection{CONCLUSIONS}

A series of small scale static pile load tests in a laboratory and field environments were carried out to characterize the performance of open-end FRP piles in clayey soils. The major findings of this research programme are summarized below:

- Compressive ultimate pile resistance of the model FRP piles was up to $40 \%$ higher than the control steel pile. Similarly skin frictional resistance of the FRP piles was measured to be up to $30 \%$ higher with both CFRP and GFRP.

- GFRP piles presented a highly textured surface due to the raw fiber weaving pattern with both directions $0^{\circ}$ and $90^{\circ}$ showing significant protrusions. In contrast the CFRP pile presented less a pronounced surface texture with the $90^{\circ}$ orientation showing an increased profile.

- FRP pile texture and waviness appeared to have a significant influence on pile performance with CFRP piles ranging from just $5 \%$ capacity increase to up to $40 \%$ by changing pile fiber direction and surface texture. In contrast, the GFRP piles presented virtually same ultimate capacity at a $40 \%$ increase over steel despite changes in fiber orientation.

- The pile-soil adhesion coefficient $\alpha$ was compared to published values in literature and for all piles the measured values were lower than the suggested trend for cohesive soils with similar undrained shear strength. This can be attributed partially to the fact that no pile set-up was allowed to take place as the pile load tests were carried out immediately following driving.

- Lateral loading of the piles showed that the lower stiffness of the FRP piles leads to increased pile head deflections at similar loading levels compared to the baseline steel pile. These results agree with similar tests carried out in sandy soils 
- The modelling of the steel, C0, and G0 piles under lateral loading was carried out using LPILE numerical software to compare common design methods to the performance of FRP piles. The steel pile presented comparable results while both FRP piles presented higher pile head deflections compared to the numerical simulation. In the analysis, linear elastic properties were provided as input as it is the common practice in pile design. FRP piles however can present non-linear behaviour under loading which can lead to the measured discrepancies.

- Field compressive pile load tests showed that the general behaviour and trend of the FRP piles compared to the steel pile is consistent with the laboratory results: in all cases the FRP piles presented higher or at least similar capacity to the steel pile. It was observed that boundary conditions did not influence the laboratory test results to a significant margin as pile response was similar in field and lab tests.

- Field lateral pile load tests showed a similar linear pile response to laboratory results; however, for all piles a significantly stiffer response was measured. With respect to the behaviour of the FRP piles, it was evident that the carbon C0/90 pile presented a stiffer response compared to the glass G90 pile. This is in disagreement with laboratory results which showed no significant difference in stiffness between the two pile materials. Field results are in better agreement with the 3-point bending tests which indicated that the carbon piles to be stiffer. This discrepancy could have been caused by the deformation of the steel drum in the hoop direction.

The results of this study highlight the viability of FRP piles in soft clays as an alternative solution to traditional steel piles. Axial compressive capacity was measured to be up to $40 \%$ higher than the steel, where pile surface and texture appeared to have a significant influence in pile performance. Lateral response of FRP piles showed higher deflections at similar loading levels compared to steel. These results are in line with similar research 
conducted in sands and are primarily due to the lower elastic modulus and stiffness compared to steel and prestressed concrete. 


\section{Chapter 5}

\section{CONCLUSIONS AND RECOMMENDATIONS}

\subsection{CONCLUSIONS}

In this thesis two studies were presented exploring the performance of FRP piles in soft clays. In the first study a characterization program was carried out aimed at describing the behaviour of carbon and glass FRP interfaces against clays and compared the behaviour to traditional piling materials such as steel and concrete. In the second study, the performance of small scale FRP piles manufactured using either glass or carbon fibers were tested in axial compression and lateral loading. Both studies were aimed at presenting a comparative analysis of the behaviour of FRP materials and piles in soft clays to those of traditional piling materials in order to assess the viability of FRPs as piling materials. In addition, various parameters were investigated such as FRP material and fiber orientation with the goal of identifying the optimal conditions for best performance. Presented below are the major findings of both research programs.

- In both drained and undrained conditions the concrete material outperformed the FRP interfaces while the FRP specimens matched or performed better compared to the steel interface under both loading rates.

- The FRP materials present between 105 to $119 \%$ of the interface friction angle of steel and between 77 to $88 \%$ that of concrete. In addition, FRP interface adhesion 
was observed between $86 \%$ and $135 \%$ of the interface adhesion of steel and between $65 \%$ and $75 \%$ of the interface adhesion of concrete.

- The interface test results indicate the best performing FRP interface was carbon FRP oriented at $90^{\circ}$ with respect to the primary fiber (C90) in drained conditions and glass FRP oriented at $90^{\circ}$ with respect to primary fiber (G90) under undrained conditions. However, the capacity increase, particularly over G90 and C0, was not significant enough to conclusively determine a superior material (carbon or glass) or fiber orientation along the shearing direction $\left(0^{\circ}\right.$ or $\left.90^{\circ}\right)$. Specimen $\mathrm{C} 0$ was the only exception under undrained conditions measuring approximately 35\% lower interface adhesion than the other three FRP interfaces.

- FRP surface topology and the waviness pattern dictated by the fiber weaving and orientation while shearing was found to have a possible significant influence on the shearing strength.

- The steel interface displayed a lower capacity in both drained and undrained conditions than concrete indicating a sliding type of shear failure at the interface in contrast to concrete which presents evidence of turbulent or transitional shear failure.

- Compressive ultimate pile resistance of the model FRP piles was up to $40 \%$ higher than the control steel pile. Similarly skin frictional resistance of the FRP piles was measured to be up to $30 \%$ higher with both CFRP and GFRP.

- GFRP piles presented a highly textured surface due to the raw fiber weaving pattern with both directions $0^{\circ}$ and $90^{\circ}$ showing significant protrusions. In contrast the CFRP pile presented less a pronounced surface texture with the $90^{\circ}$ orientation showing an increased profile.

- $\quad$ FRP pile texture and waviness appeared to have a significant influence on pile performance with CFRP piles ranging from just 5\% capacity increase to up to $40 \%$ 
by changing pile fiber direction and surface texture. In contrast, the GFRP piles presented virtually same ultimate capacity at a $40 \%$ increase over steel despite changes in fiber orientation.

- The pile-soil adhesion coefficient $\alpha$ was compared to published values in literature and for all piles the measured values were lower than the suggested trend for cohesive soils with similar undrained shear strength. This can be attributed partially to the fact that no pile set-up was allowed to take place as the pile load tests were carried out immediately following driving.

- Lateral loading of the piles showed that the lower stiffness of the FRP piles leads to increased pile head deflections at similar loading levels compared to the baseline steel pile. These results agree with similar tests carried out in sandy soils

- The modelling of the steel, $\mathrm{C0}$, and G0 piles under lateral loading was carried out using LPILE numerical software to compare common design methods to the performance of FRP piles. The steel pile presented comparable results while both FRP piles presented higher pile head deflections compared to the numerical simulation. In the analysis, linear elastic properties were provided as input as it is the common practice in pile design. FRP piles however can present non-linear behaviour under loading which can lead to the measured discrepancies.

- Field compressive pile load tests showed that the general behaviour and trend of the FRP piles compared to the steel pile is consistent with the laboratory results: in all cases the FRP piles presented higher or at least similar capacity to the steel pile. It was observed that boundary conditions did not influence the laboratory test results to a significant margin as pile response was similar in field and lab tests.

- Field lateral pile load tests showed a similar linear pile response to laboratory results; however, for all piles a significantly stiffer response was measured. With respect to 
the behaviour of the FRP piles, it was evident that the carbon C0/90 pile presented a stiffer response compared to the glass G90 pile. This is in disagreement with laboratory results which showed no significant difference in stiffness between the two pile materials. Field results are in better agreement with the 3-point bending tests which indicated that the carbon piles to be stiffer. This discrepancy could have been caused by the deformation of the steel drum in the hoop direction.

All of the findings, based on these research programmes, show good a correlation between the the FRP and steel piles. In general, FRP materials, either through element testing or pile load testing, showed consistently on par or higher shearing strength compared to steel piles. This is a good indication that the surface of these FRP piles can act as load bearing members with comparable capacities to driven steel piles when acting as mainly frictional piles. Advantages of FRP piles in clays are mainly attributed to increased service life, especially in contaminated or harsh environments. In addition, with the similarities between steel pipe piles and hollow FRP piles, no specialized equipment is needed for the installation and testing. Based on the results found in this work, FRP piles appear to be a viable alternative to steel pipe piles with respect to the geotechnical performance in soft clays. Both carbon and glass FRP piles performed comparatively similar in terms of shear strength, and no significant difference was measured in terms of lateral capacity between the two materials. Further testing is needed in order to assess the influence of the increased stiffness of CFRP over GFRP particularly under lateral loading. At time of writing, the manufacturer and provider of the FRP materials has indicated that the cost of carbon fiber raw materials are double that of glass fibers, making the glass FRP materials a viable alternative in composite piling. Further work and full scale pile load tests are needed to corroborate the results of this study. 


\subsection{RECOMMENDATIONS FOR FUTURE RESEARCH}

The results presented in this thesis indicate that FRP piles are a viable material to use in the industry as load bearing members. Further work is needed in the form as full scale instrumented pile load tests in order to corroborate the results presented within.

Furthermore, full scale pile load test data is needed for comparison to capacity estimates calculated from pile driving analyses for validation of PDA procedures on FRP piles. Pile load tests are needed in order to characterize pile deformation caused by soil interaction, this in turn can be related to settlement of FRP piles. Additionally pilot projects and long term monitoring performance of FRP piles under working loads and various soil conditions are needed before widespread acceptance of this piling material can be achieved.

The non-linearity effects, particularly shear deformation effects under lateral loads and to some extent under lateral loads should be considered. These effects have been reported to lead to excessive deflections particularly for hollow FRP pipes. Further study of these effects can lead better understanding of when using concrete in-filled sections, and what degree of in-filling. In addition, further testing under cyclic lateral loading modes should be considered in order to assess the seismic response of this new material.

Pile manufacturing and quality control for the repeatability of similar pile surface roughness should be investigated in order to produce a reliable material of known elastic properties and consistent geotechnical performance. Manufacturing through a casting method using pre-woven FRP fabrics as opposed to traditional filament wound manufacturing can lead to more consistent pile surface production, in addition with rougher interface. 
Research and application of FRP piles is still in its infancy mainly due to lack of funding, high initial capital costs and lack of a proven track record. Increased interest and research in this area can lead to this novel material to a wider use. 


\subsection{REFERENCES}

Afshin, A. and Rayhani, M. T., Characterization of Pile Capacity over Time in Leda Clay. Geotechnical and Geological Engineering, Under Review for Publication.

Arey, D. W. and Wood, D. M., 1987. An Evaluation of Direct Simple Shear Tests on Clay. Geotechnique, 37(1), pp. 25-35.

Ashford, S. A. and Jakrapiyanun, W., 2001. Drivability of Glass FRP Composite Piling. Journal of Composite Construction, 5, pp. 58-60.

ASTM D1143, 2007. Standard Test Methods for Deep Foundations Under Static Axial Compressive Load, ASTM International, West Conshohocken, PA, 2007, DOI:10.1520/D1143_D1143M-07E01.

ASTM D2487, 2011. Standard Practice for Classification of Soils for Engineering Purposes (Unified Soil Classification System), ASTM International, West Conshohocken, PA, 2011, DOI:10.1520/D2487-11.

ASTM D2573, 2008. Standard Test Method for Field Vane Shear Test in Cohesive Soil, West, ASTM International, West Conshohocken, PA, 2008, DOI: 10.1520/D2573-08.

ASTM D3966, 2007. Standard Test Methods for Deep Foundations Under Lateral Load, ASTM International, West Conshohocken, PA, 2007, DOI:10.1520/D3966-07.

ASTM D422, 2007. Standard Test Method for Particle-Size Analysis of Soils, ASTM International, West Conshohocken, PA, 2007, DOI:10.1520/D0422-63R07.

ASTM D4318, 2010. Standard Test Methods for Liquid Limit, Plastic Limit, and Plasticity Index of Soils, ASTM International, West Conshohocken, PA, 2010, DOI:10.1520/D4318-10.

ASTM D4945, 2012. Standard Test Method for High-Strain Dynamic Testing of Deep Foundations, ASTM International, West Conshohocken, PA, 2012, DOI: 10.1520/D494512.

ASTM D5321, 2008. Standard Test Method for Determining the Coefficient of Soil and Geosynthetic or Geosynthetic and Geosynthetic Friction by the Direct Shear Method, ASTM International, West Conshohocken, PA, 2008, DOI:10.1520/D5321-08.

ASTM D6528, 2007. Standard Test Method for Consolidated Undrained Direct Simple Shear Testing of Cohesive Soils, ASTM International, West Conshohocken, PA, 2007.

ASTM D698, 2012. Standard Test Methods for Laboratory Compaction Characteristics of Soil Using Standard Effort (12 $400 \mathrm{ft}-\mathrm{lbf} / \mathrm{ft} 3$ (600 kN-m/m3), ASTM International, West Conshohocken, PA, 2012, DOI:10.1520/D0698-12. 
Brinch Hansen, J., 1961. The Ultimate Resistance of Rigid Piles Against Transversal Forces. Geoteknisk Institut, Copenhagen, Bull No. 12.

Broms, B. B., 1964a. Lateral Resistance of Piles in Cohesive Soils. Journal of Soil Mechanics and Foundations Division, ASCE, 90(2), pp. 27-67.

Broms, B. B., 1964b. Lateral Resistance of Piles in Cohesionless Soils. Journal of Soil Mechanics and Foundation Division, ASCE, 90(3), pp. 123-156.

Brummund, W. F. and Leonards, G. A., 1973. Experimental study of static and dynamic friction between sand and typical construction materials. Journal of Testing Evaluation , 1(2), pp. 162-165.

Burland, J., 1973. Shaft Friction of Piles in Clay; A Simple Fundemental Approach. Ground Engineering, Foundation Publications Ltd., 6(3), pp. 30-42.

Canadian Geotechnical Society, 2007. Canadian Geotechnical Engineering Manual. 4th ed. Richmond, BC, BiTech Publishers Ltd.

Chattopadhyay, B. and Pise, P., 1986. Uplift Capacity of Piles in Sand. Journal of Geotechnical Engineering, ASCE, 112(9), pp. 888-904.

Chellis, R. D. Pile Foundations. New York: McGraw Hill, 1961

Chin, F. K., 1970. Estimation of the Ultimate Load of Piles Not Carried to Failure. Proceedings of the Second Southeast Asian Conference on Soil Engineering, pp. 83-91, Singapore.

Chu, L. M. and Yin, J. H., 2006. Study on soil-cement grout interface shear strength of soil nailing. Geomechanics and Geoengineering: An International Journal, 1(4), p. 259 273.

Coduto, D. P. Foundation Design Principles and Practices. Upper Saddle River, New Jersey: Prentice-Hall, Inc. 2001.

Cox, W. R., Reese, L. C. and Grubbs, B. R., 1971. Field Testing of Laterally Loaded Piles in Sand. Offshore Technological Conference, Huston TX, pp. 459-472.

Davisson, M. T., 1972. High Capacity Piles. Proceedings, Lecture Series, Innovations in Foundation Construction, ASCE, Illinois Section, Chicago, March 22, pp. 81-112.

De Nicola, A. and Randolph, M. F., 1993. Tensile and Compressive Shaft Capacity of Piles in Sand. Journal of Geotechnical Engineering, ASCE, 119(12), pp. 1952-1973.

De Nicola, A. and Randolph, M. F., 1999. Centrifuge modelling of pipe piles in sand under axial loads. Géotechnique, 49(3) pp. 295-318. 
DeBeer, E. E., 1967. Proefondervindlijke Bijdrage Tot de Studie Van Het Grensdraag Vermogen Van Zand onder Funderingen Op Staal. Tijdshift der Openbar Verken van Belgie, Issue 6.

Ensoft Inc., 2013. LPILE v. 6. [Online] Available at: http://www.ensoftinc.com/ [Accessed 2307 2013].

Fam, A. Z., 2000. Concrete Filled Fiber Reinforced Polymer Tubes for Axial and Flexural Structural Members. PhD Thesis, University of Manitoba, Winnipeg, Canada.

Fam, A. Z. and RizKalla, S. H., 2001a. Behavior of Axially Loaded Concrete-Filled Circular Fiber-Reinforced Polymer Tubes. ACI Structural Journal, 98(3), pp. 280-289.

Fam, A. Z. and Rizkall, S. H., 2001b. Confinement model for axially loaded concrete confined by FRP tubes. ACI Structural Journal, 98(4), pp. 251-261.

Fam, A. Z. and Rizkalla, S. H., 2002. Flexural Behaviour of Concrete-Filled FiberReinforced Polymer Circular Tubes. Journal of Composites for Construction, 6(2), pp. 123-132.

Fellenius, B. H., 1975. Test Loading of Piles: Methods, Interpretation, and New Proof Testing Procedure. Journal of the Geotechnical Engineering Division, 101(9), pp. 855869.

Fleming, W. G. K. et al., 1992. Piling Engineering. New York: Halsted Press.

Franke, E., 1984. Group Action Between Vertical Piles under Horizontal Loads. Proceedings of the International Geotechnical Seminar on Deep Foundations on Bored and Auger Piles, Ghent, Belgium, pp. 83-93.

Frost, J. D. and Han, J., 1999. Behaviour of Interfaces Between Fiber-Reinforced Polymers and Sands. Journal of Geotechnical and Environmental Engineering, 125(8), pp. 633-640.

Giraldo, J., Rayhani, M. T., 2013. Influence of Fiber-reinforced Polymers onPile-Soil Interface Strength in Clays. Advances in Civil Engineering Materials, 2(1), ID ACEM20120043.

Goble, G. G., 1999. Geotechnical Related Development and Implementation of Load and Resistance Factor Design (LRFD) Methods - Synthesis 276 , Washington DC: Transportation Research Board.

Goh, A. T. C. and Donald, I. B., 1984. Investigation of Soil-Concrete Interface by Simple Shear Apparatus. Perth, Australia, fourth Australia-New Zealand Conference on Geomechanics.

Guades, E., Aravinthan, T., Islam, M. and Manalo, A., 2012. A review on the driving performance of FRP composite piles. Composite Structures, 94 pp. 932-1942. 
Han, J. and Frost, D. J., 1999. Buckling of Vertically Loaded Fiber Reinforced Polymer Piles. Journal of Reinforced Plastics and Composites, 18(4), pp. 290-318.

Hollaway, L. C., 2010. A review of the present and future utilisation of FRP composites in the civil infrastructure with reference to their important in-service properties.

Construction and Building Materials. 24, pp. 2419-2445.

Iskander, M., 2002. Recent Developments in FRP Composite Piling Practice.

Transportation Research Board Annual Meeting, Paper No: 02-3589.

Iskander, M. G., Hanna, S. and Stachula, A., 2001. Driveability of FRP Composite Piling. Journal of Geotechnical and Geoenvironmental Engineering, 127, pp. 169-176.

Iskander, M. G. and Hassan, M., 1998. State of the Practice Review in Composite Piling. Journal of Composites for Construction, pp. 116-120.

Ismael, N. B. and Klym, T. W., 1979. Uplift and Bearing Capacity of Short Piers in Sands. Journal of Geotechincal Engineering, ASCE, 105(5), pp. 579-594.

Ji, G., Ouyang, Z. and Li, G., 2009. Experimental investigation into the interfacial shear strength of AGS-FRP tube confined concrete pile. Engineering Structures, 31, pp. 23092316.

Johnston, I. W., Lam, T. S. K. and Williams, A. F., 1987. Constant Normal Stiffness Direct Shear Testing for Socketed Pile Design in Weak Rock. Geotechnique, 37(1), pp. 83-89.

Kishida, H. I. and Uesegui, H., 1987. Tests of the interface between sand and steel in simple shear apparatus. Geotechnique, 37(1), pp. 45-52.

Kondner, R. L., 1963. Hyperbolic Stress-Strain Response: Cohesive Soils. ASCE, Journal for Soil Mechanics and Foundation Engineering, 89(1), pp. 115-413.

Lemos, L. J. L. and Vaughan, P. R., 2000. Clay-Interface Shear Resistance. Geotechnique, 50(1), pp. 55-64.

Lupini, J. F., Skinner, A. E. and Vaughan, P. R., 1981. Drained Residual Strength of Cohesive Soils. Geotechnique, 31(2), pp. 181-213.

McRostie, G.C. and Crawford, C.B., 2001. Canadian Geotechnical Research Site No. 1 at Gloucester. Canadian Geotechnical Journal, 38, pp. 1134-1141.

Matlock, H., 1970. Correlation for Design of Laterally Loaded Piles in Soft Clay. Proceedings Offshore Technology Conference, paper OTC 1204.

Meyerhof, G., 1976. Bearing Capacity and Settlement of Pile Foundations. Journal of Geotechnical Engineering - The 11th Terzaghi Lecture, ASCE, Volume 102, GT3, pp. 195-228. 
Mirmiran, A., Shahawy, M., El Khoury, C. and Naguib, W., 2000. Large Beam-Column Tests on Concrete-Filled Composite Tubes. ACI Structural Journal, Issue 97, pp. 268276.

O'Rourke, T. D., Drusche, I. S. J. and Netravali, A. N., 1990. Shear Strenght Characteristics of Sand-Polymer Interfaces. Journal of Geotechnical Engineering, 116(3), pp. 451-469.

O'Neil L. C. and Reese M. W. 1999. Drilled Shafts: Construction Procedures and Design Methods, FHWA-IF-99-025, Federal Highway Administration, Washington D.C.

Ovando-Shelley, E., 1995. Direct shear tests on Mexico City clay with reference to friction pile behaviour. Geotechnical and Geological Engineering, 13, pp. 1-16.

Pando, A. M., Flitz, M. G., Dove, J. E. and Hoppe, E. J., 2002. Interface Shear Tests on FRP Composite Piles. Deep Foundations, pp. 1486-1500.

Pando, A. M., Ealy, C. D., Flitz, M. G., Lesko, J.J., and Hoppe, E. J., 2003. A Laboratory and Field Study of Composite Piles for Bridge Substructures, McLean, VA, Federal Highway Administration, Report No. FHWA-HRT-04-043.

Pile Dynamics, Inc, 2010. Pile Driving Analyzer. [Online] Available at: http://www.pile.com/pdi/products/pda/ [Accessed 22 July 2013].

Potyondy, J. G., 1961. Skin Friction Between Various Soils and Interface and Construction Materials. Geotechnique, 11(4), pp. 3-18.

Poulos, H. G., 1971. Behaviour of Laterally Loaded Piles: I-Single Piles. Journal of Soil Mechanics and Foundation Division. ASCE, 93(5), pp. 711-731.

Poulos, H. G. and Davis, E. H. Pile Foundation Analysis and Design. New York: John Wiley and Sons, Inc, 1980.

Prakash, S. and Sharma, H. D. Pile Foundations in Engineering Practice. New York: John Wiley and Sons, Inc, 1990.

Randolph M. F., Carter J. P. and Wroth C. P., 1979. Driven piles in clay - the effects of installation and subsequent consolidation. Géotechnique, 29(4), pp. 361-393.

Randolph, M. F., Murphy, B. S., 1985. Shaft Capacity of Driven Piles in Clay. Proceedings of $17^{\text {th }}$ Ann. Offshore Technol. Conf. Huston, 1, pp. 371-378.

Randolph, M. F., 2003. Science and Empiricism in Pile Foundation Design. Geotechnique, 53(10), pp. 847-875.

Rao, K. and Venkatesh, K., 1985. Uplift Behaviour of Short Piles in Uniform Sand. Soils and Fountations - Japanese Society of Soil Mechanics and Foundation Engineering, 25(4), pp. 1-7. 
Rausche, F., Goble, G. G. and Likins, G. E., 1985. Dynamic Determination of Pile Capacity. Journal of the Geotechnical Engineering, ASCE, 111(3), pp. 367-383.

Rausche, F., Moses, F. and Goble, G. G., 1972. Soil Resistance Predictions From Pile Dynamics. Journal of the Soil Mechanics and Foundations Division, ASCE, 125, pp. 418440.

Reese, L. C. and Welch, R. C., 1970. Lateral Loading of Deep Foundations in Stiff Clays. Journal of Geotechnical Engineering Division, ASCE, 101(7), pp. 633-649.

Rouaiguia, A., 2012. Residual shear strength of clay-structure interfaces. International Journal of Civil and Environmental Engineering, 10(3), pp. 6-18.

Sakr, M., Naggar El, H. and Nehdi, M., 2004. Novel Toe Driving for Thin-Walled Piles and Performance of Fiber-Renforced Polymer (FRP) Pile Segments. Canadian Geotechnical Journal, 41, pp. 313-325.

Selvadurai, A. P., Bauer, G. E. and Nicholas, T. J., 1980. Screw Plate Testing of a Soft Clay. Canadian Geotechnical Journal, 17(4), pp. 445-472.

Silvestri, V., Karam, G., Tonthat, A. and St-Amour, Y., 1989. Direct and Simple Shear Testing of Two Canadian Sensitive Clays. Geotechnical Testing Journal, 12(1), pp. 1121.

Skempton, A. W., 1951. The Bearing Capacity of Clays. Building Research Congress, pp. Div. I, pp. 180.

Skempton, A. W., 1964. Long Term Stability of Clay Slopes. Geotechnique, 14(2), pp. 77-102.

Smith, E., 1960. Pile Driving Analysis by the Wave Equation. Journal for Soil Mechanics and Foundation Division, ASCE, 86, pp. 35-61.

Sowa, V. A., 1970. Pulling Capacity of Concrete Cast in situ Bored Piles. Canadian Geotechnical Journal, 7, pp. 482-495.

Stark, T. and Eid, H. T., 1994. Drained Residual Strength of Cohesive Soils. Journal of Geotechnical Engineering, 120(5), pp. 856-871.

Taha, A. M., 2010. Interface Shear Behaviour of Sensitive Marine Clay - Leda Clay. Master's Thesis, University of Ottawa, Ottawa, Ontario, Canada.

Tomlinson, M., 1957. The Adhesion of Piles Driven in Clay Soils. Proceedings 4th International Conference on Soil Mechanics and Foundation Engineering, 2, pp. 66-71.

Tomlinson, M, 1994. Pile Design and Construction Practice. New York: E \& FN Spon, an Imprint of Chapman \& Hall, $4^{\text {th }}$ Edition, 1994. 
Uesugi, M., 1987. Friction between dry sands and construction materials. PhD thesis, Tokyo Institute of Technology, Tokyo, Japan.

Uesugi, M. and Kishida, H., 1986. Influential Factors of Friction Between Sand and Dry Sands. Japanese Society of Soil Mechanics and Foundation Engineering, 26(2), pp. 3346.

Ulitskii, V. M., 1995. History of Pile Foundation Engineering. Soil Mechanics and Foundation Engineering, 32(3), pp. 110-114.

Vesic, A., 1977. Design of Pile Foundations - Synthesis of Highway Practice No. 42. Transportation Research Board - National Cooperative Highway Research Program. Washington.

Yoshimi, Y. and Kishida, T., 1981. A Ring Torsion Apparatus for Evaluating Friction Between Soil and Metal Surfaces. Geotechical Testing Journal, 4(4), pp. 145-152. 


\section{APPENDIX A}

\section{Interface testing lab photos and sheared interfaces}

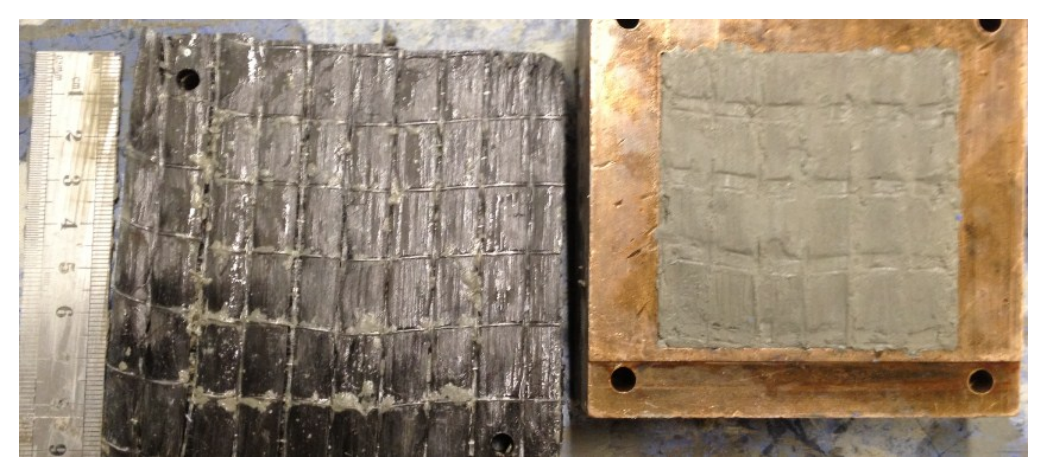

Figure $1-\mathrm{C} 0$-soil shearing interface

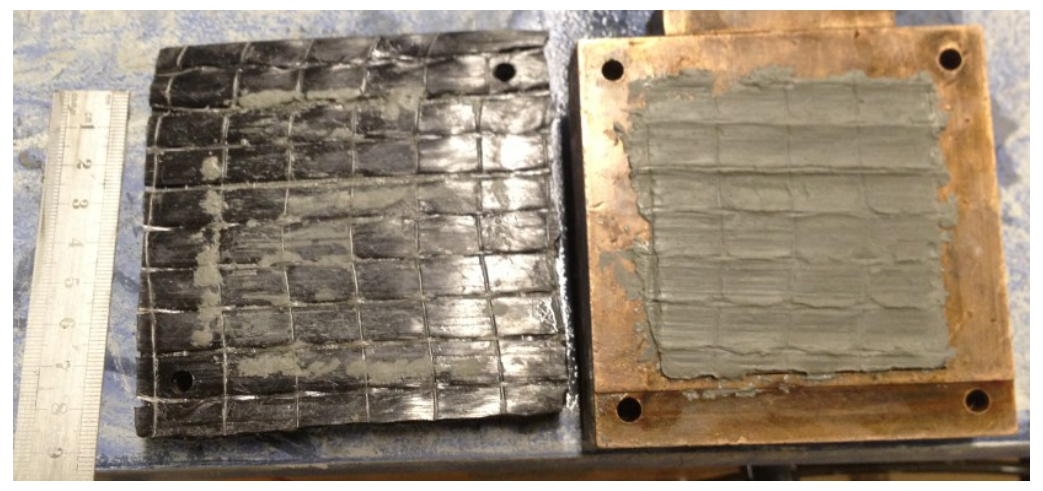

Figure 2 - C90-soil shearing interface

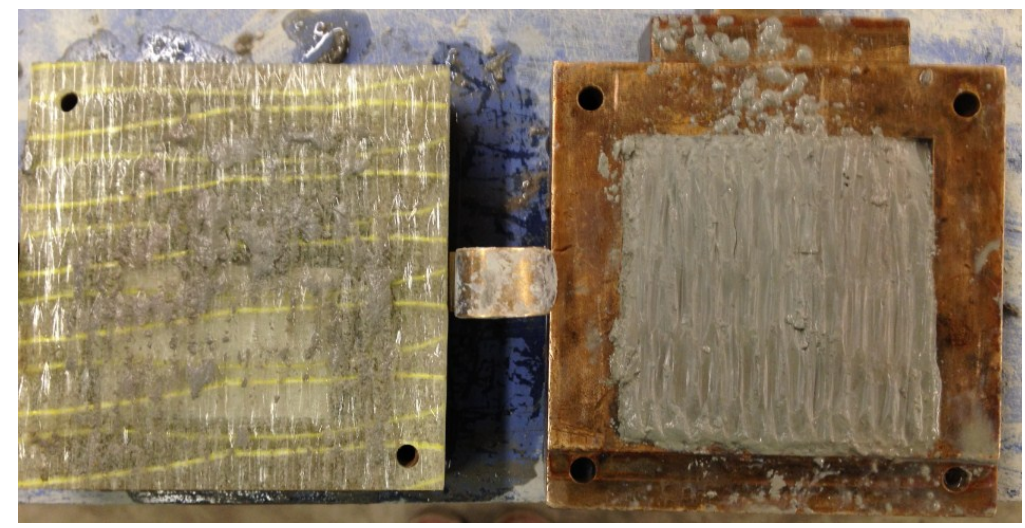

Figure 3 - G0-soil shearing interface 


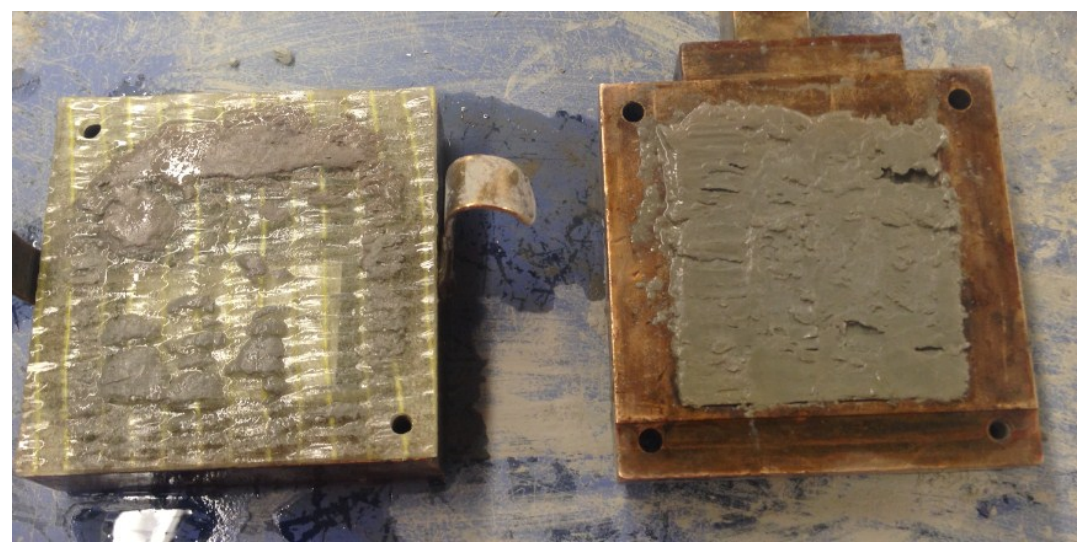

Figure 4 - G90-soil shearing interface

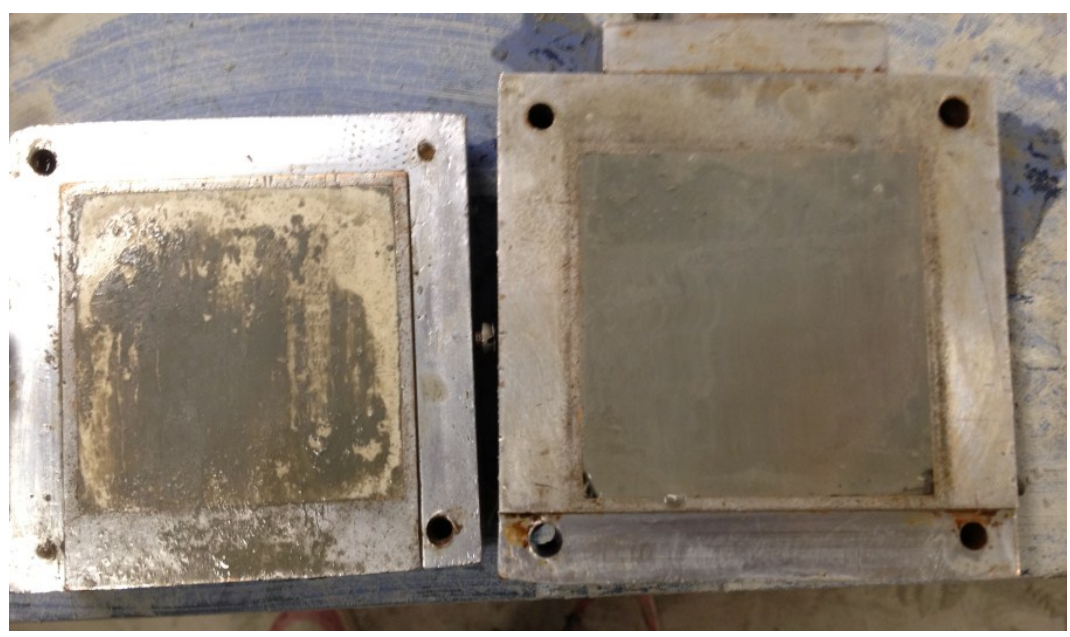

Figure 5 - Concrete-soil interface

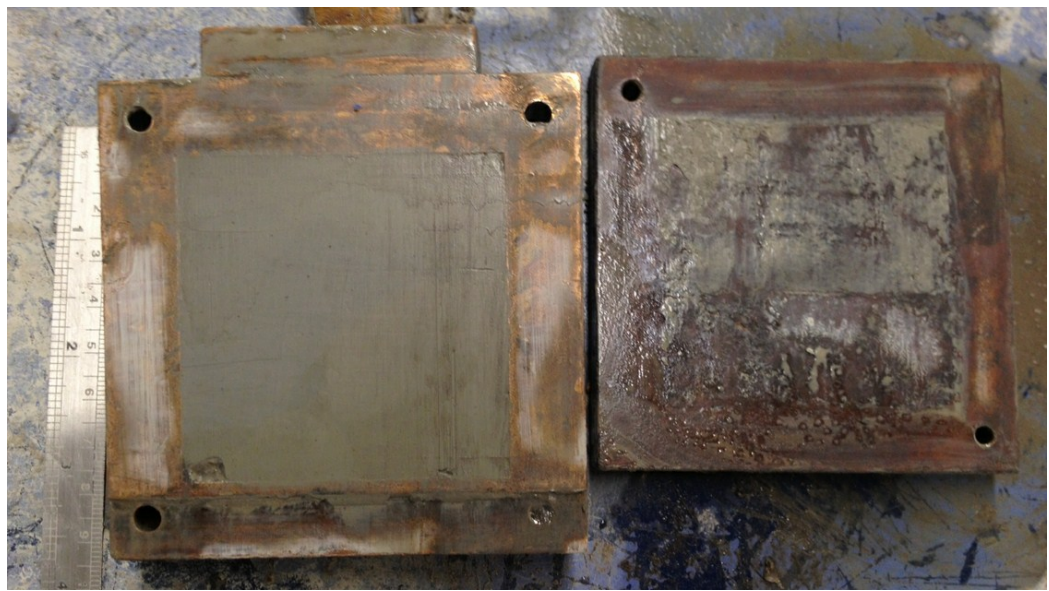

Figure 6 - Steel-soil interface 


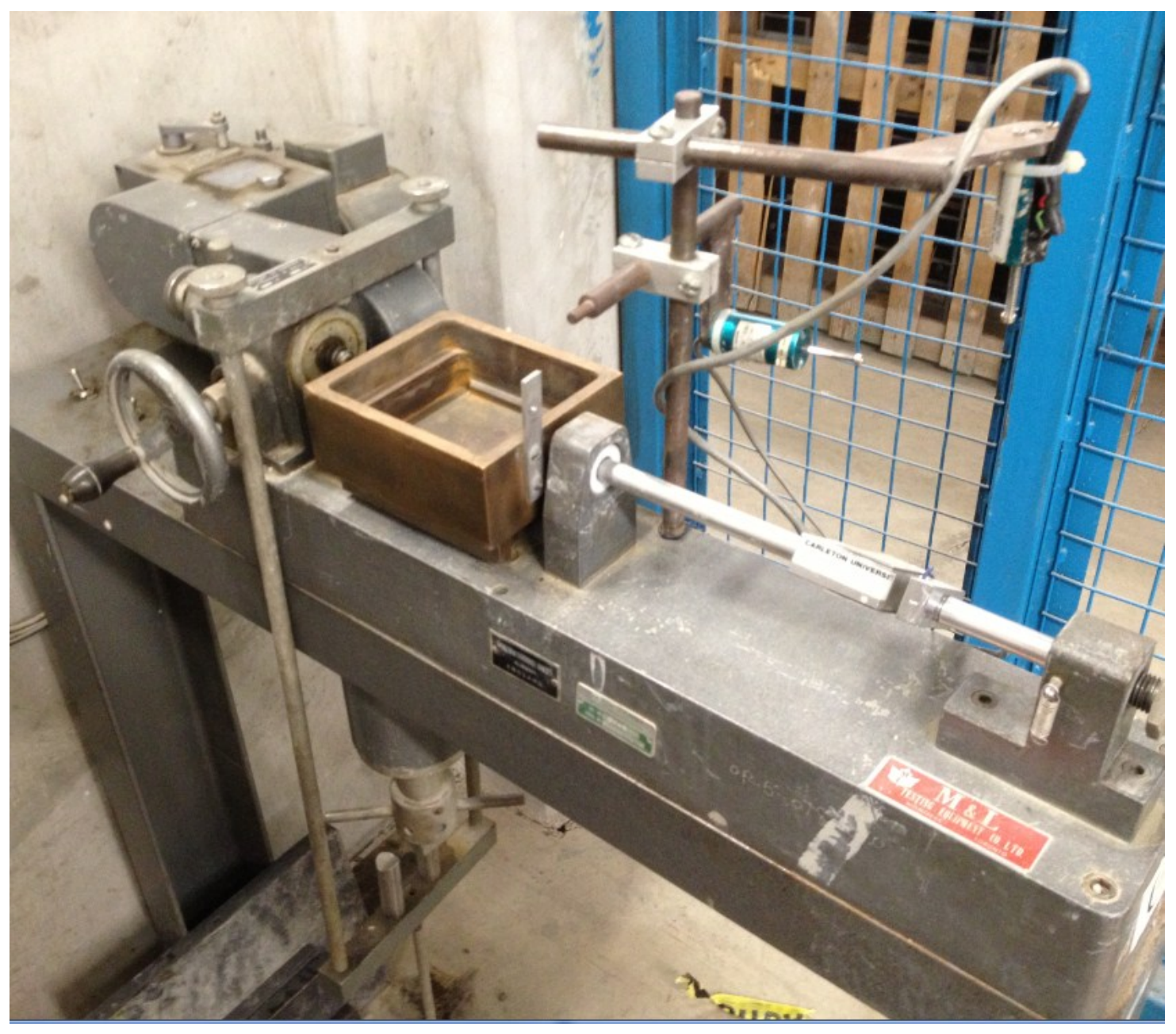

Figure 7 - Direct shear apparatus 


\section{APPENDIX B}

\section{Dataset of interface testing program}

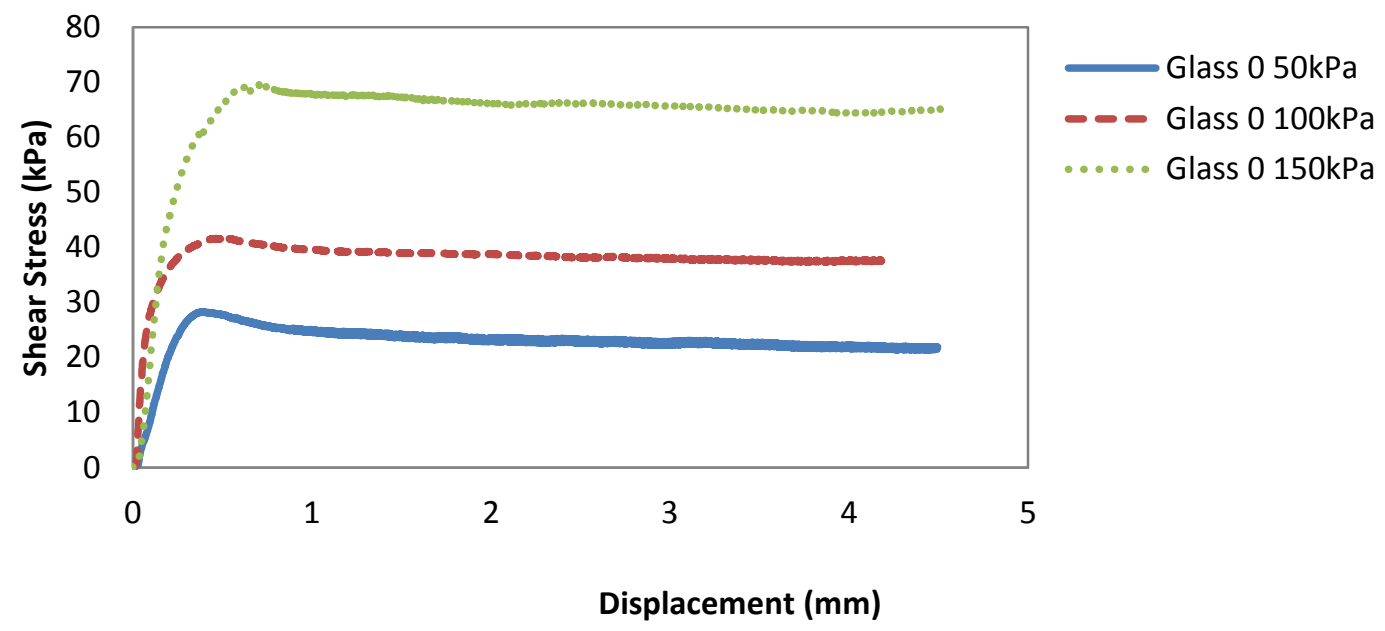

Figure 1 - Glass 0 direct shear test results, slow shearing rate

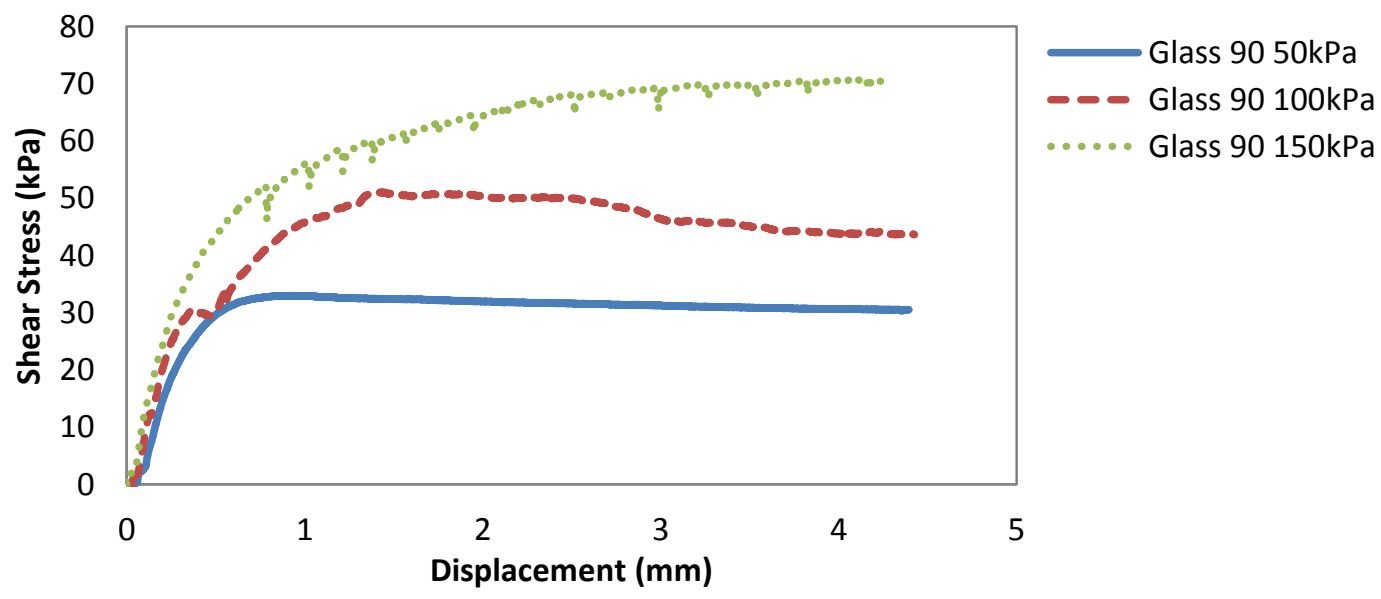

Figure 2 - Glass 90 direct shear test results, slow shearing rate 


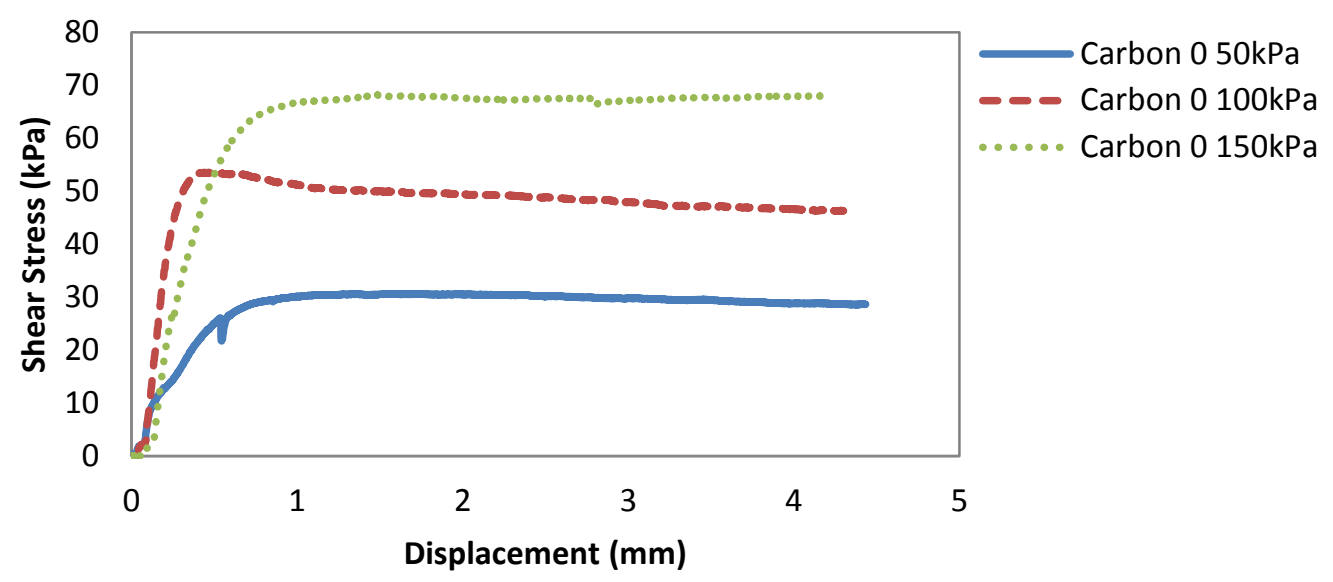

Figure 3 - Carbon 0 direct shear test results, slow shearing rate

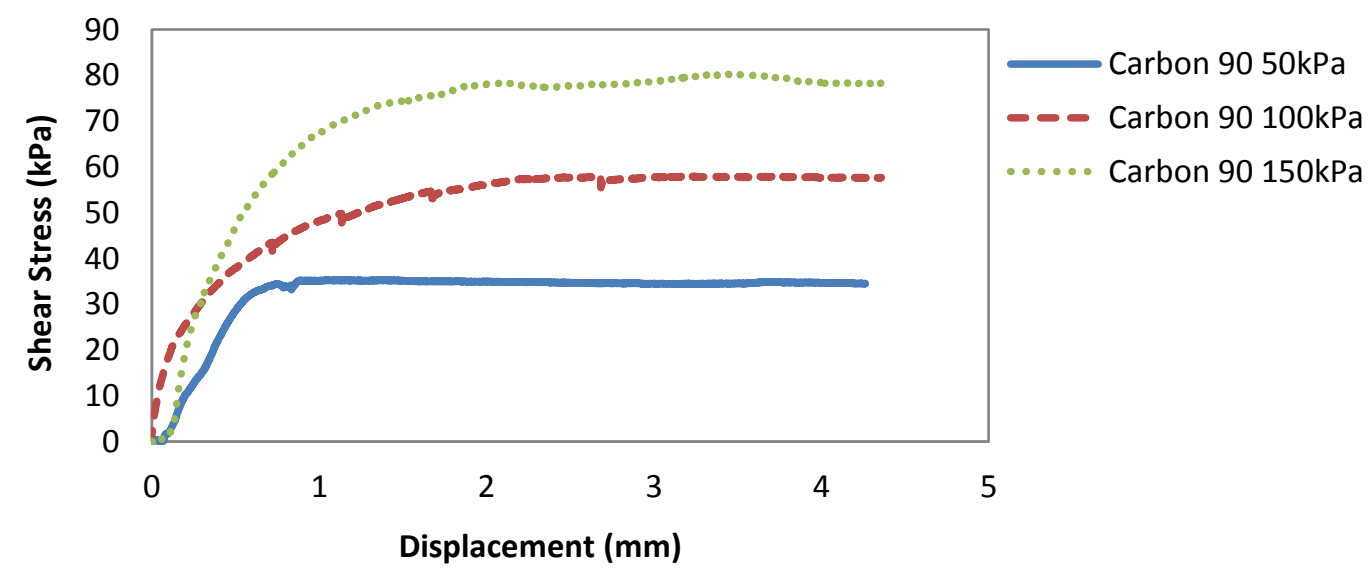

Figure 4 - Carbon 90 direct shear test results, slow shearing rate

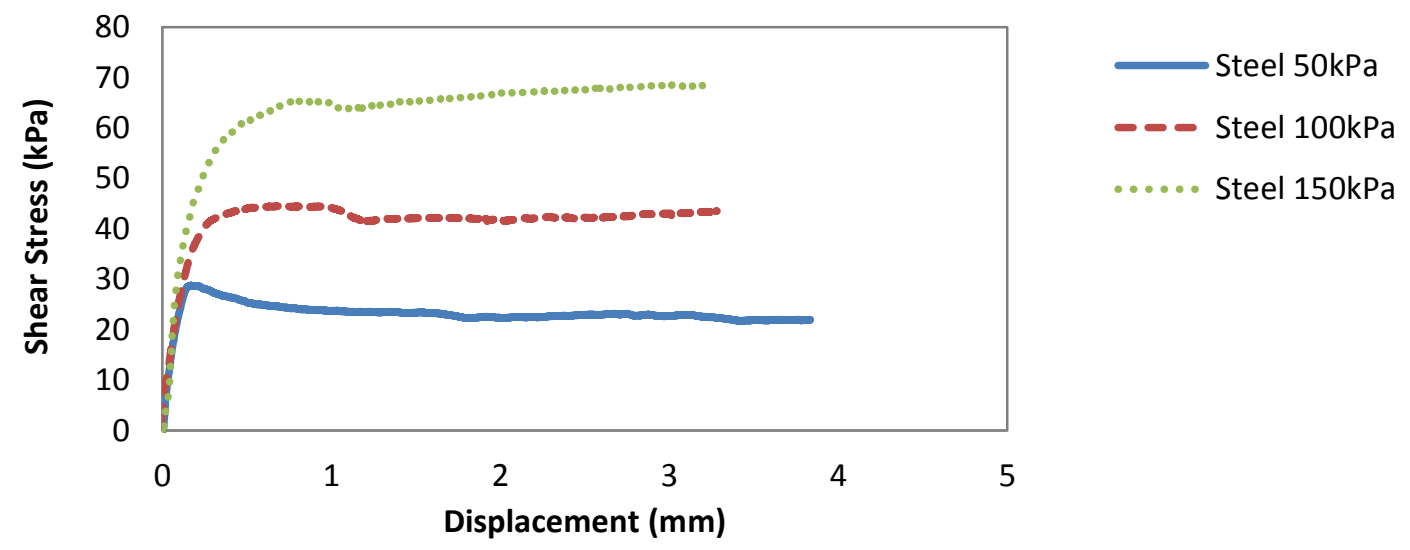

Figure 5 - Steel-clay direct shear test results, slow shearing rate 


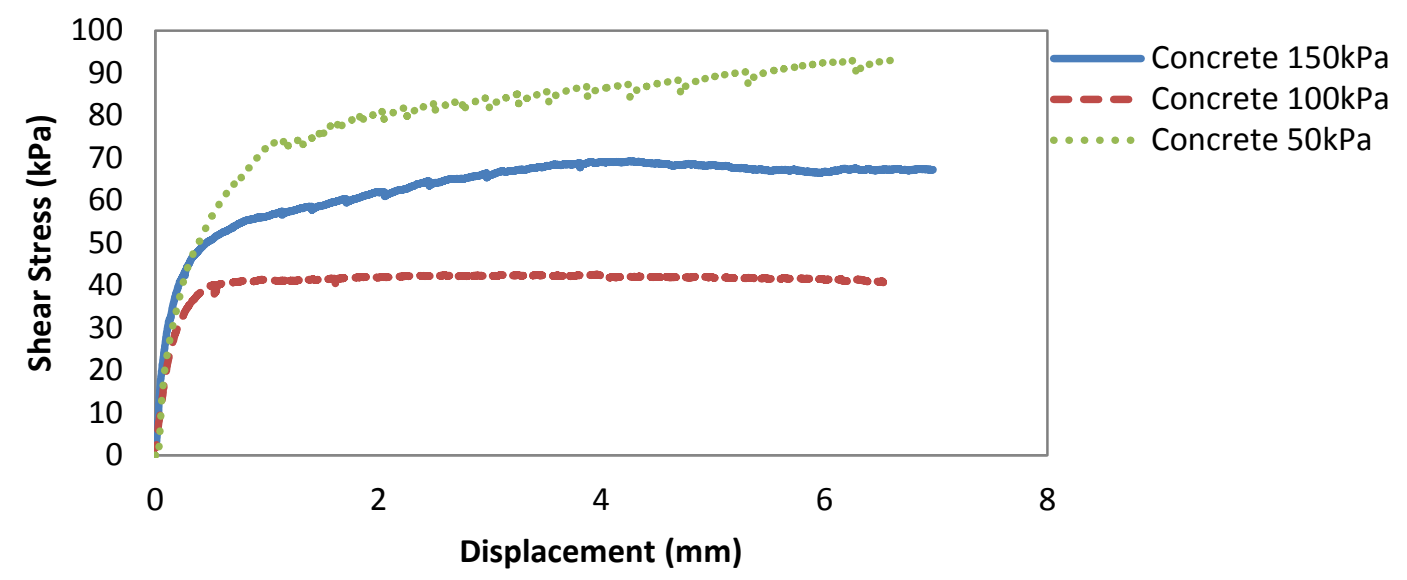

Figure 6 - Concrete-clay direct shear test results, slow shearing rate

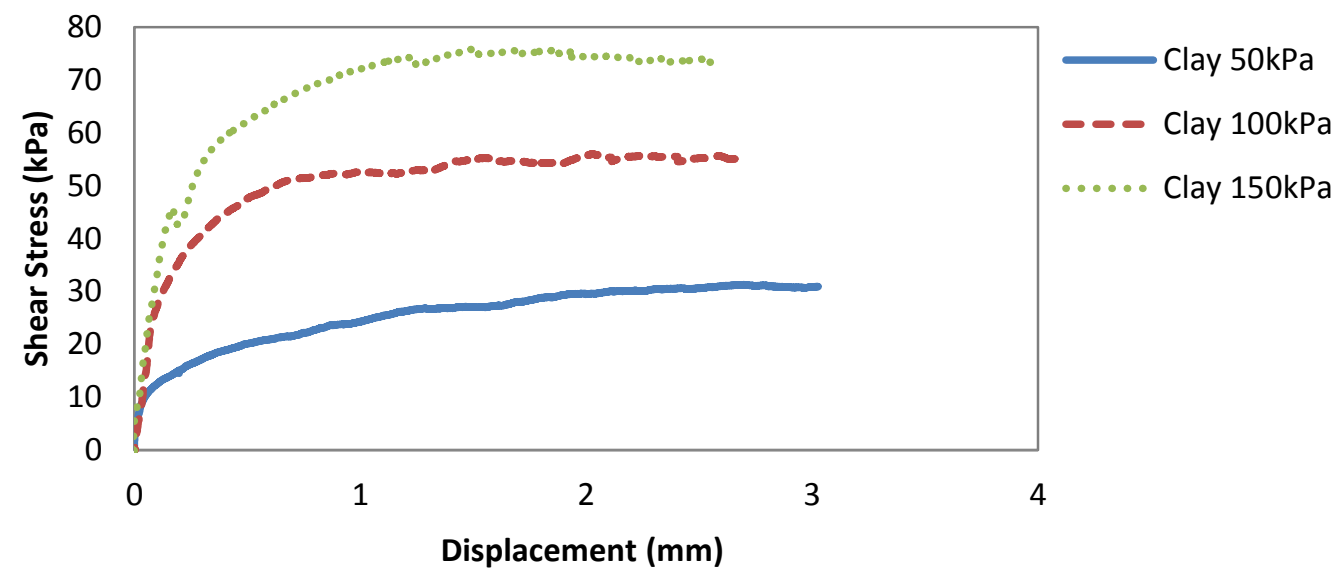

Figure 7 - Clay direct shear test results, slow shearing rate

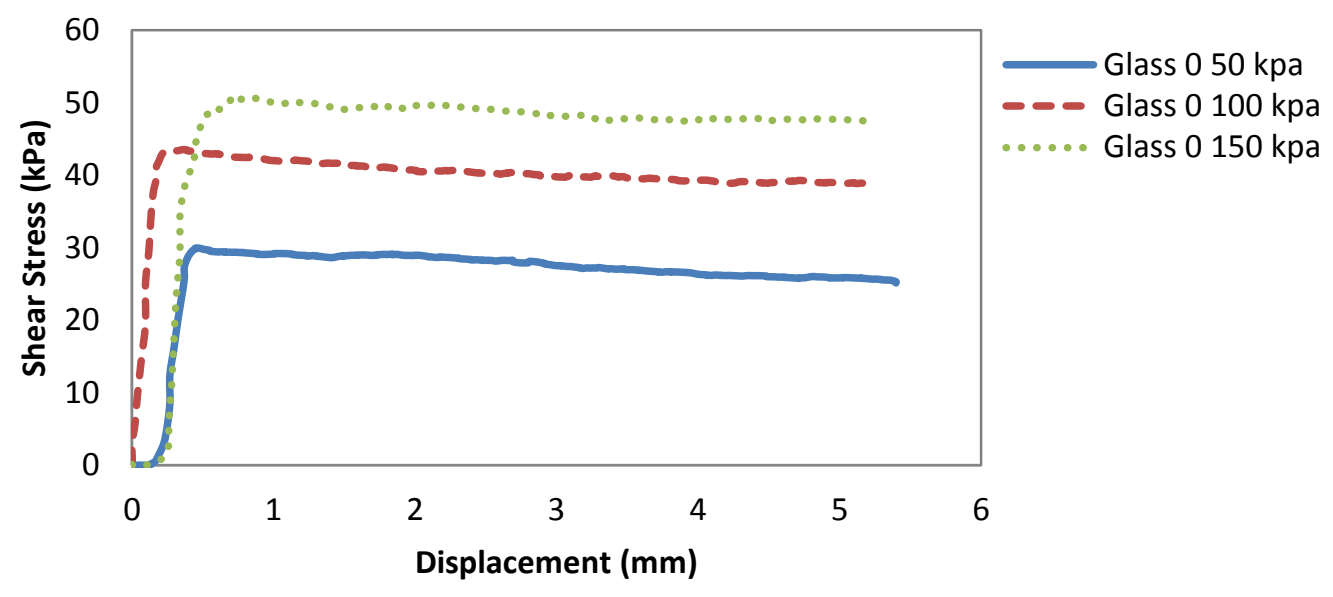

Figure 8 - Glass 0 direct shear test results, fast shearing rate 


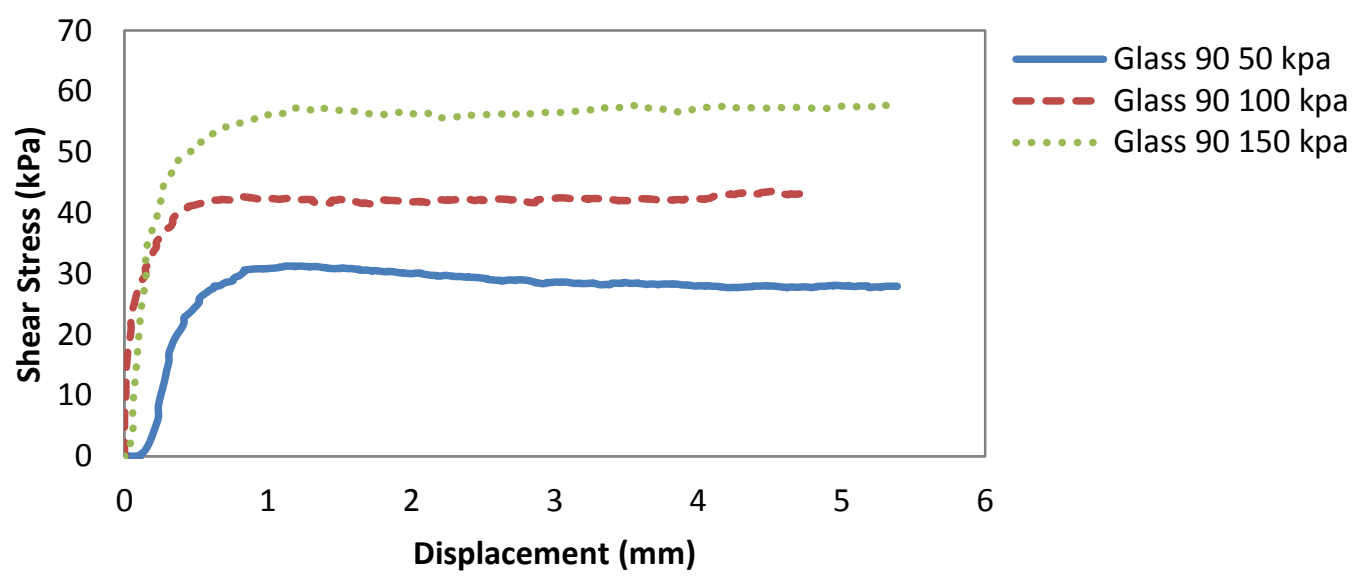

Figure 9 - Glass 90 direct shear test results, fast shearing rate

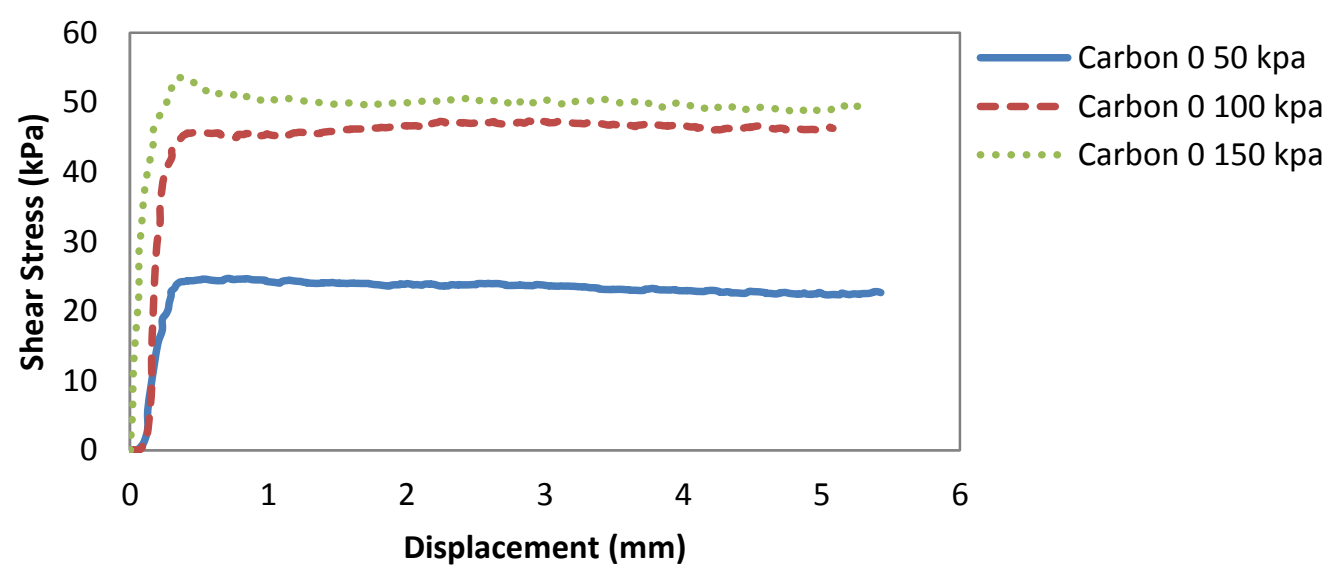

Figure 10 - Carbon 0 direct shear test results, fast shearing rate

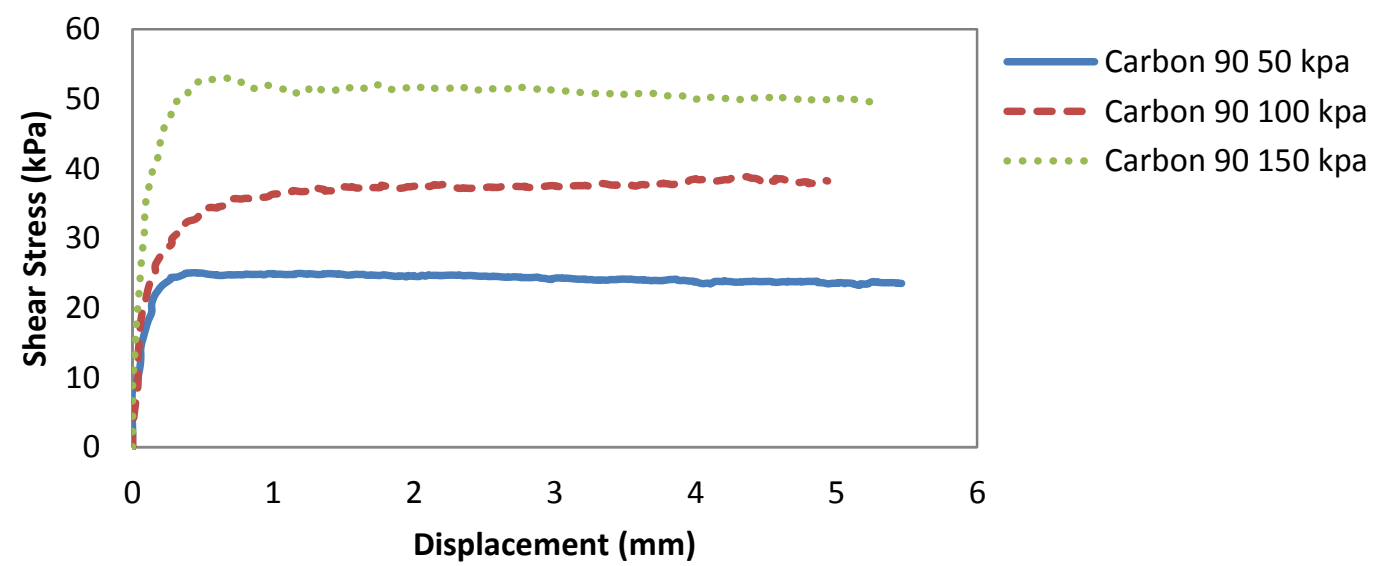

Figure 11 - Carbon 90 direct shear test results, fast shearing rate 


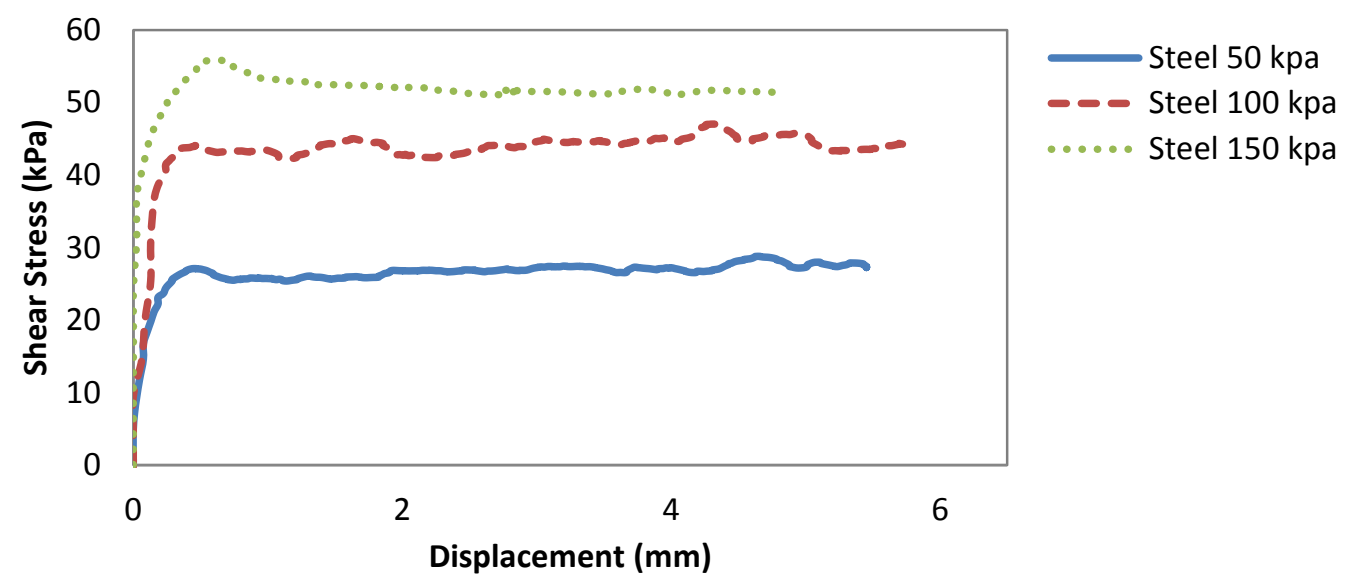

Figure 12 - Steel-clay direct shear test results, Fast shearing rate

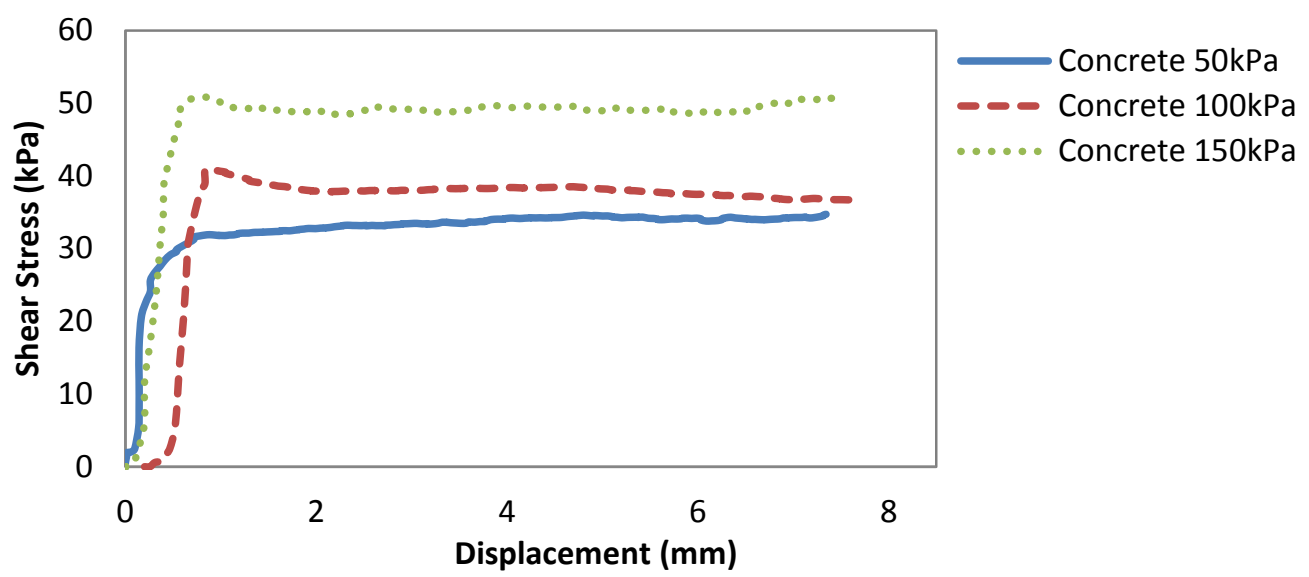

Figure 13 - Concrete-clay direct shear test results, Fast shearing rate

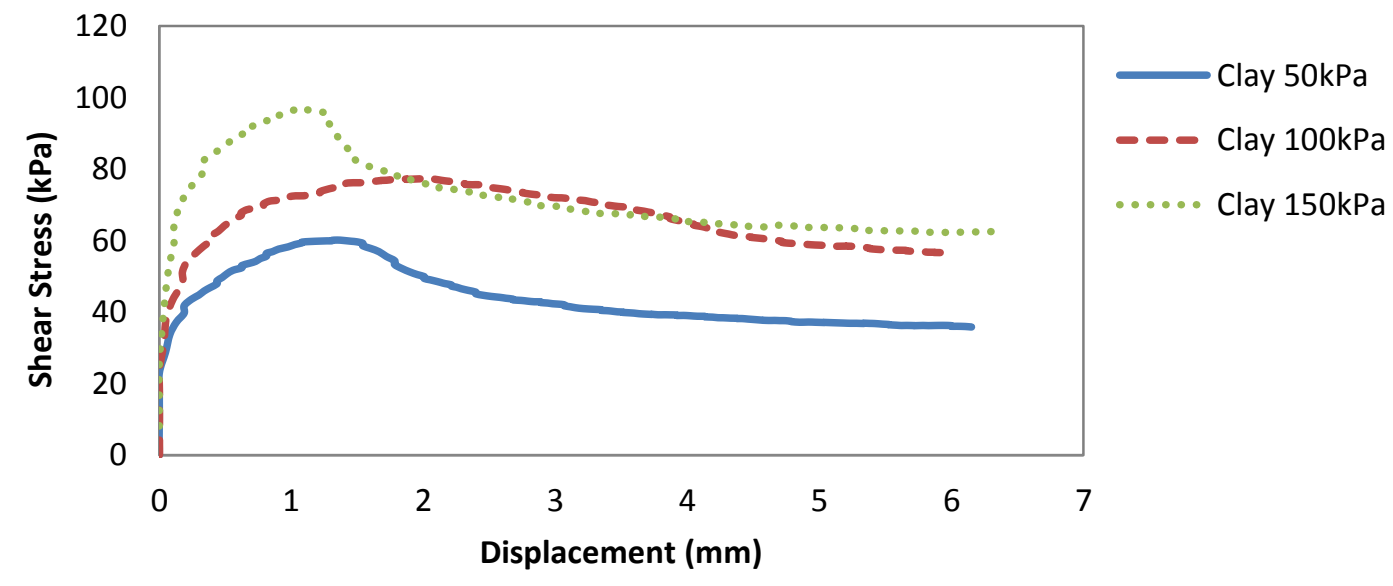

Figure 14 - Clay direct shear test results, Fast shearing rate 


\section{APPENDIX C}

\section{Pile load testing lab photos and FRP Pile manufacture}

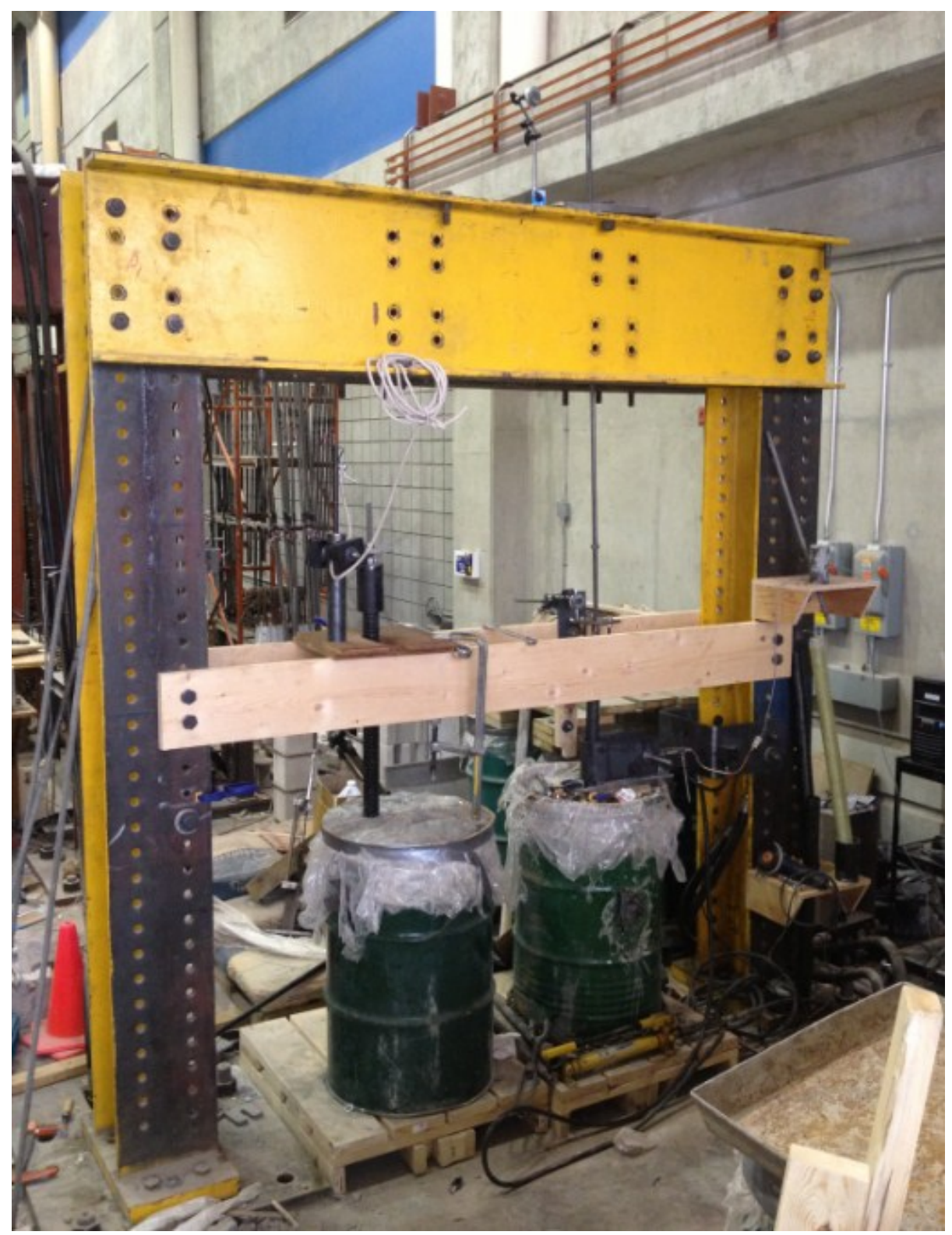

Figure 1 - Reaction frame, clay samples and FRP piles pre-driving 


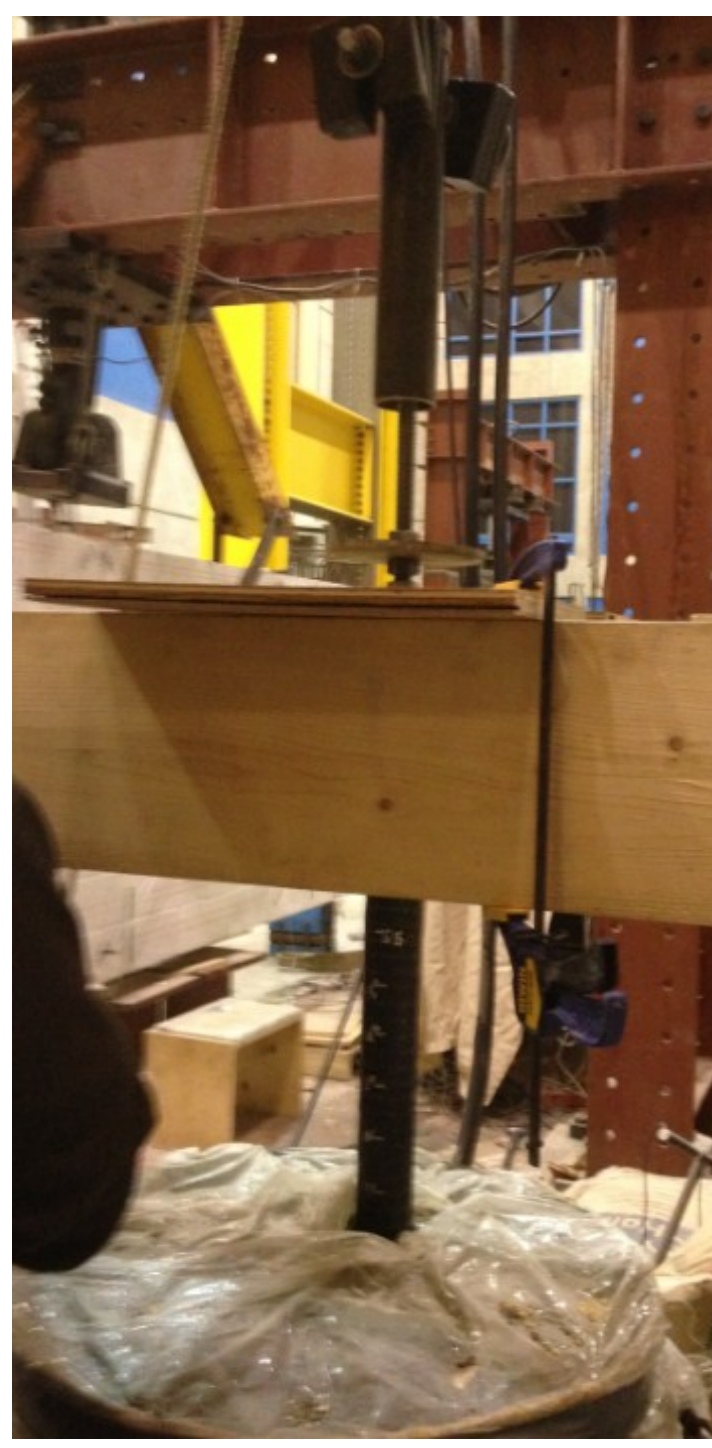

a)

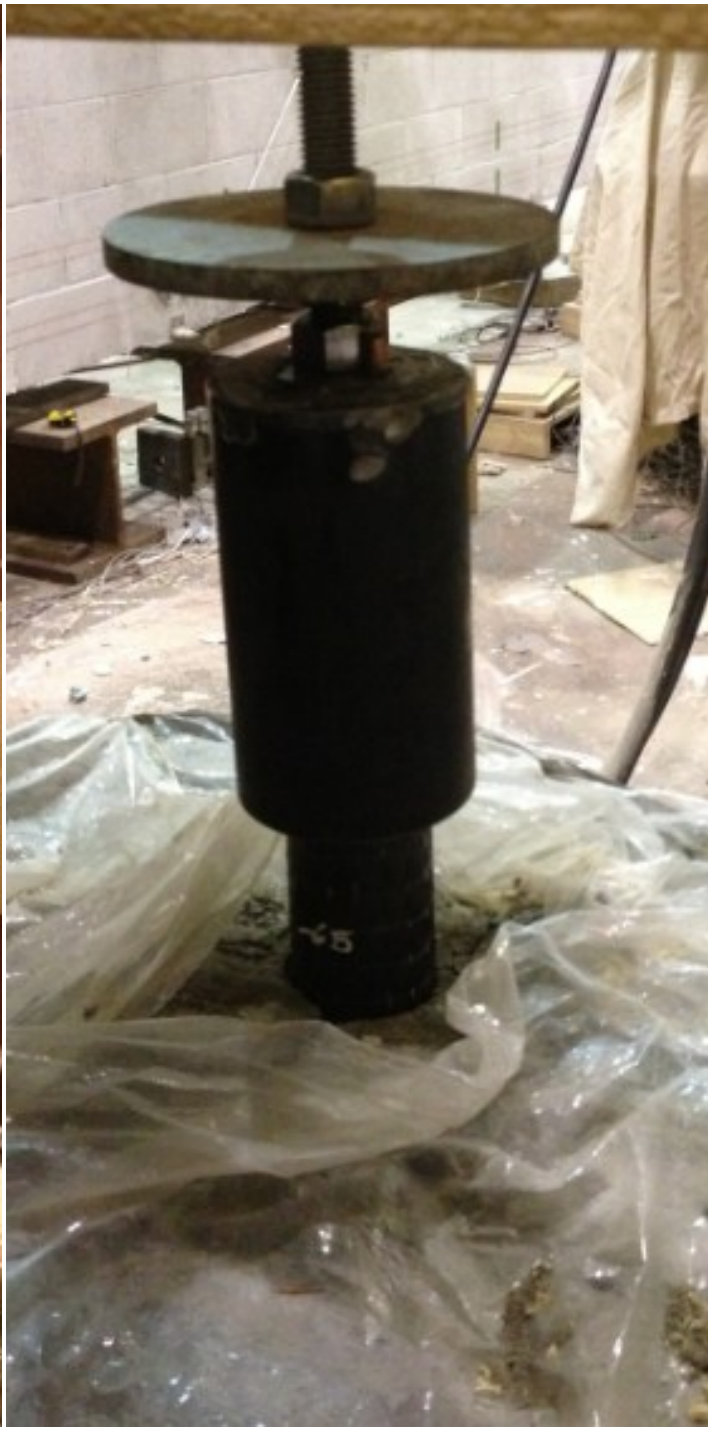

b)

Figure 2 - a) Pile Driving with drop hammer, b) At end of driving 


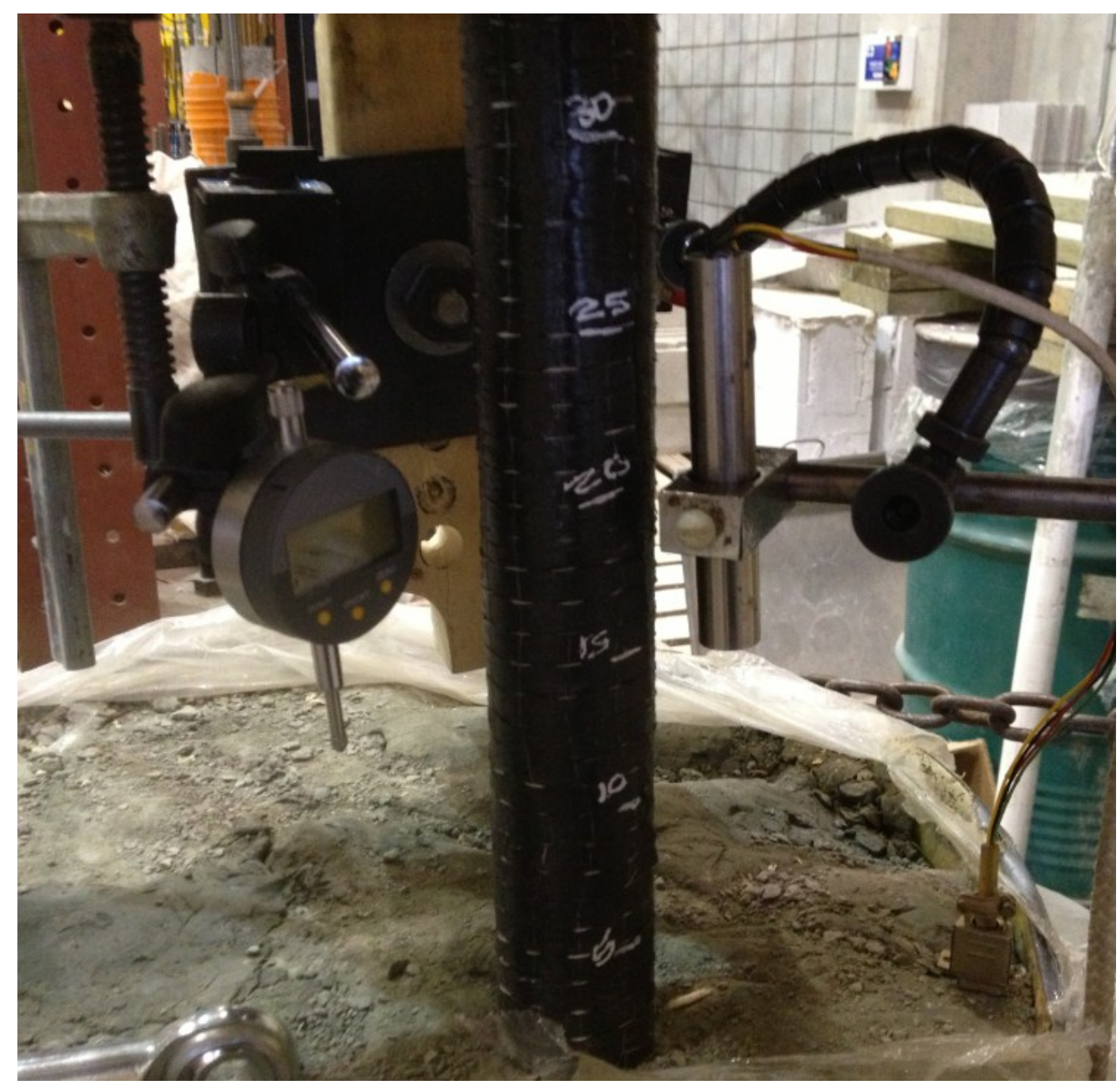

Figure 3 - FRP pile during driving conditions 


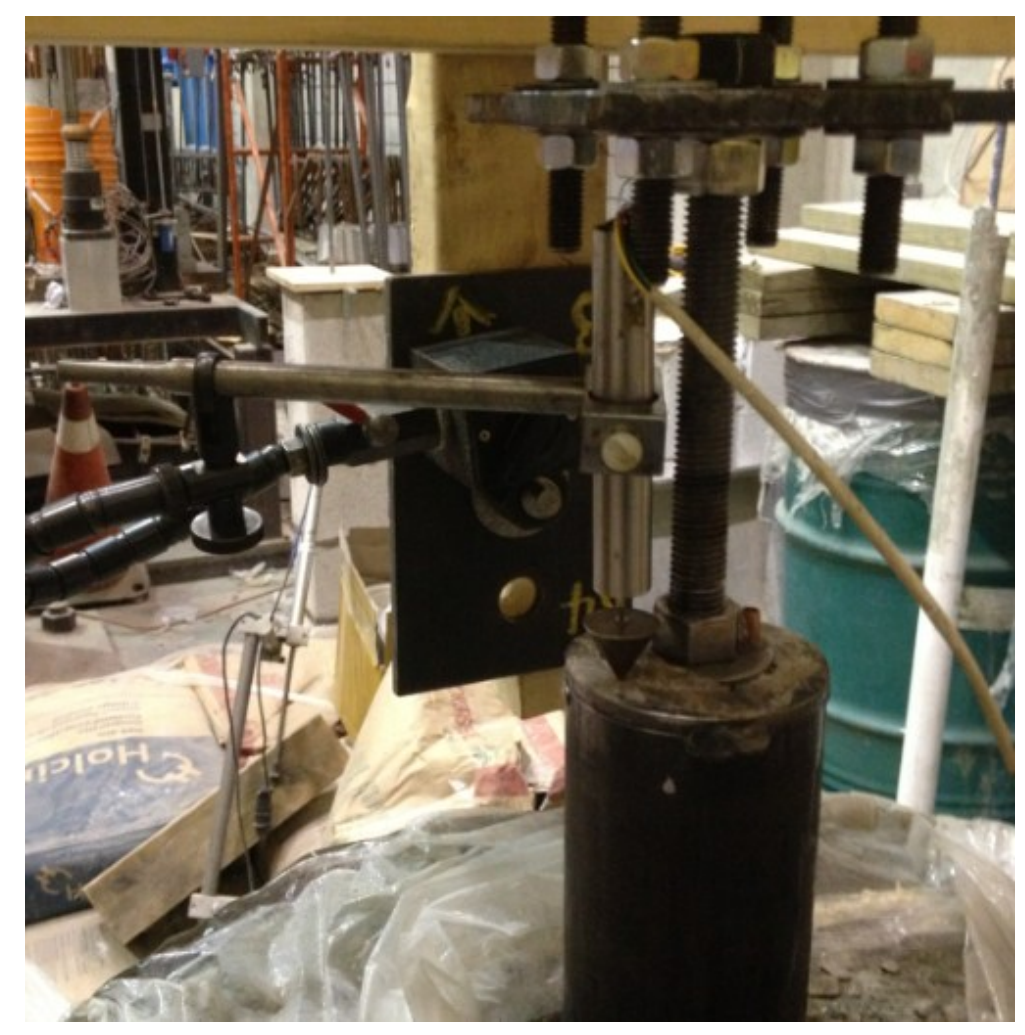

Figure 4 - Axial loading experimental setup

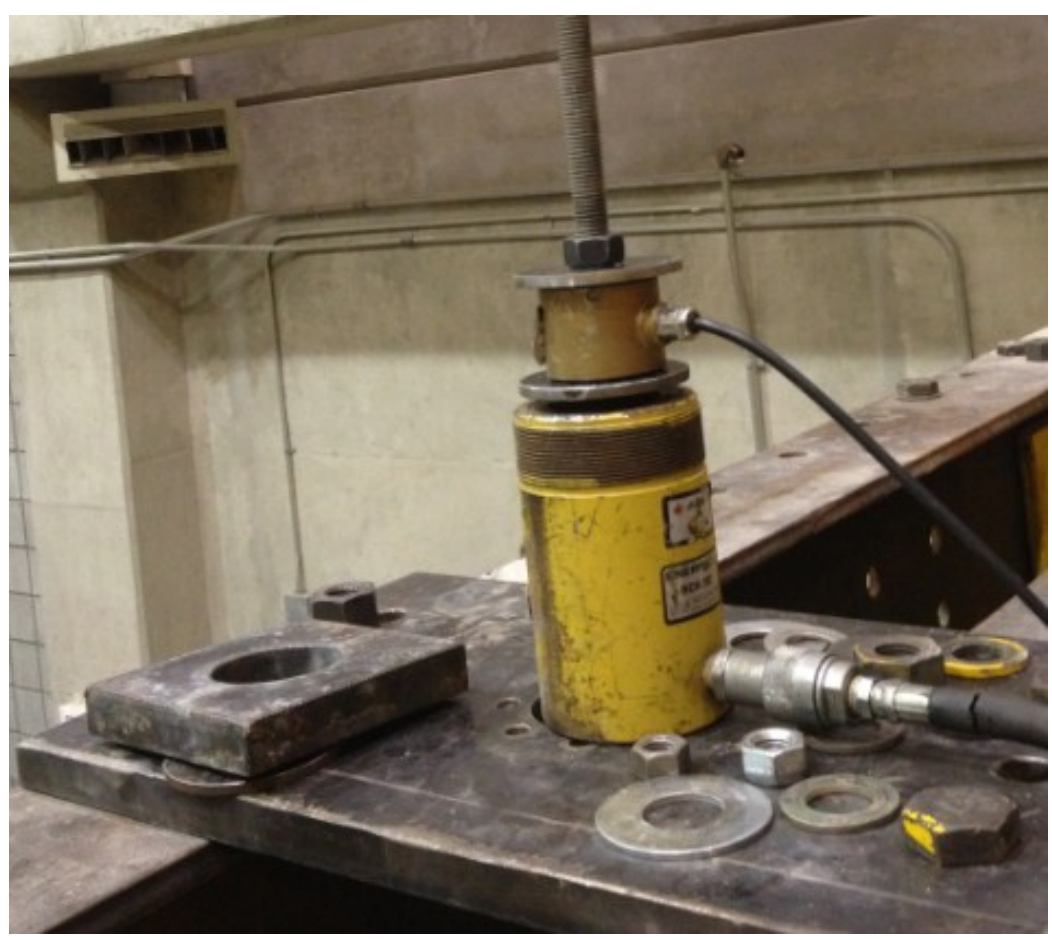

Figure 5 - Hydraulic jack and load cell for axial load test 


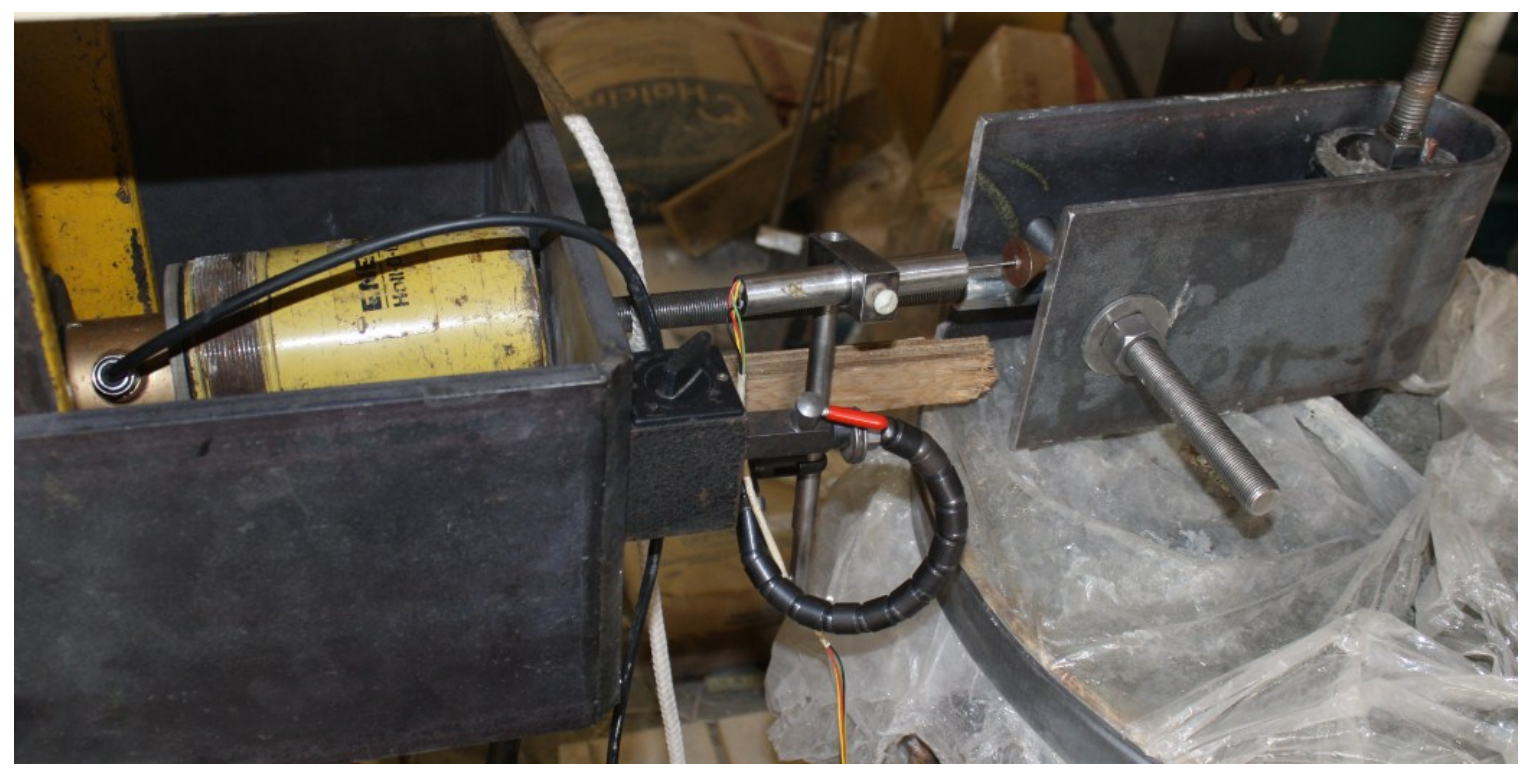

Figure 6 - Lateral loading experimental setup

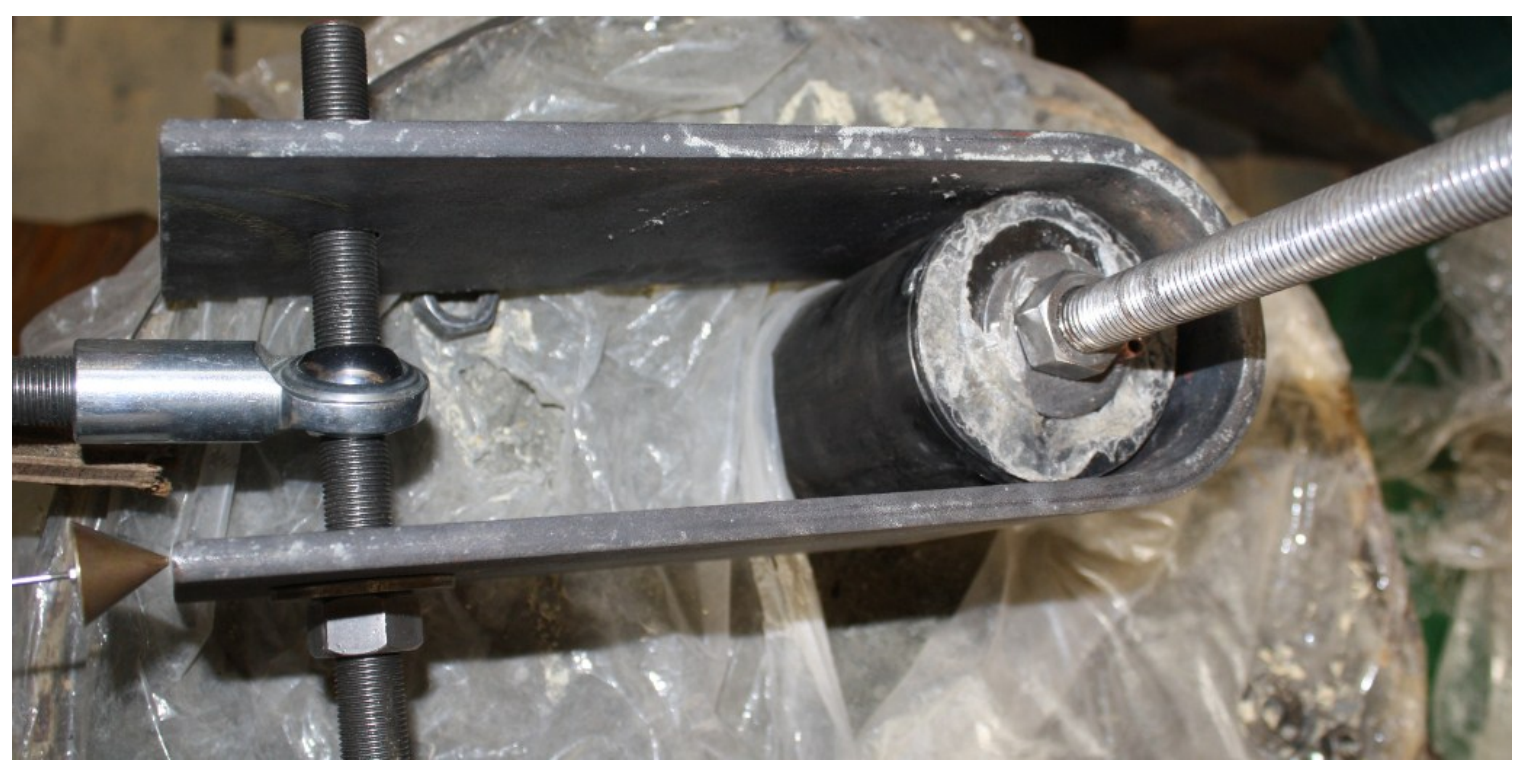

Figure 7 - Lateral Loading Experimental Setup 


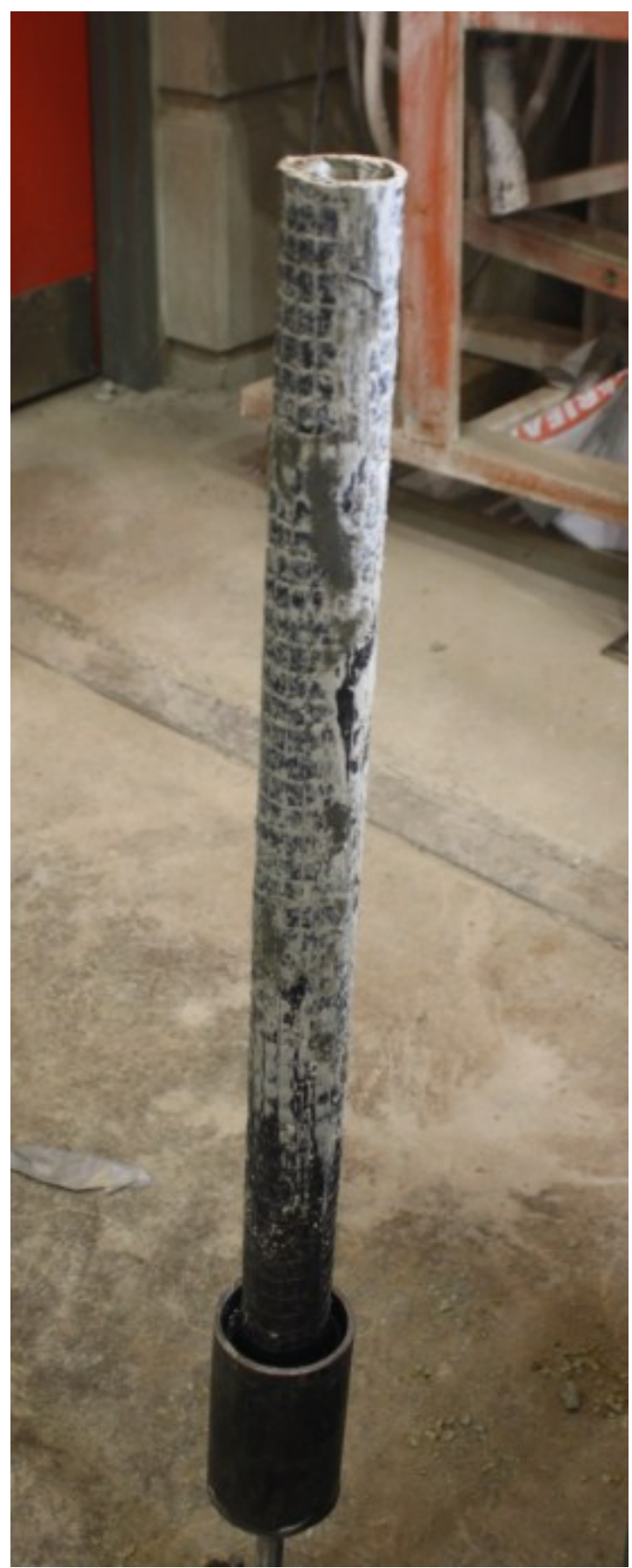

a)

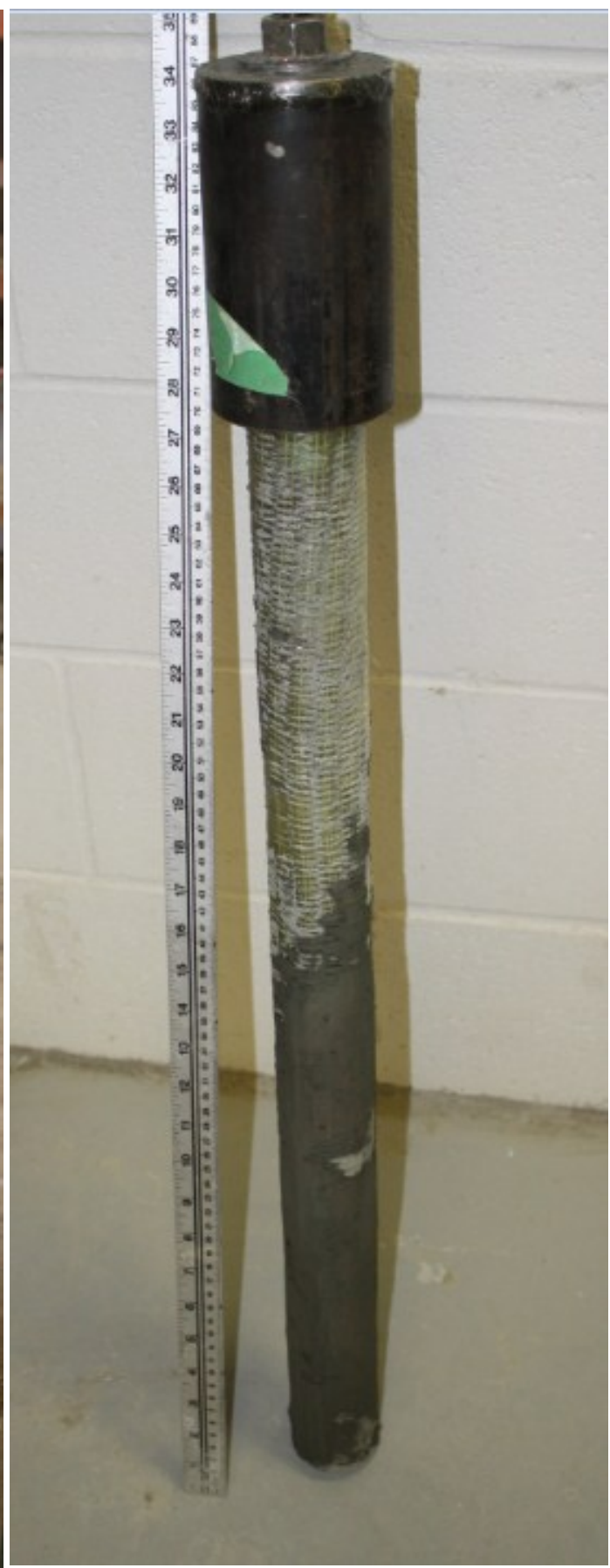

b)

Figure 8 - Extracted FRP piles showing soil interaction a) CFRP b) GFRP 


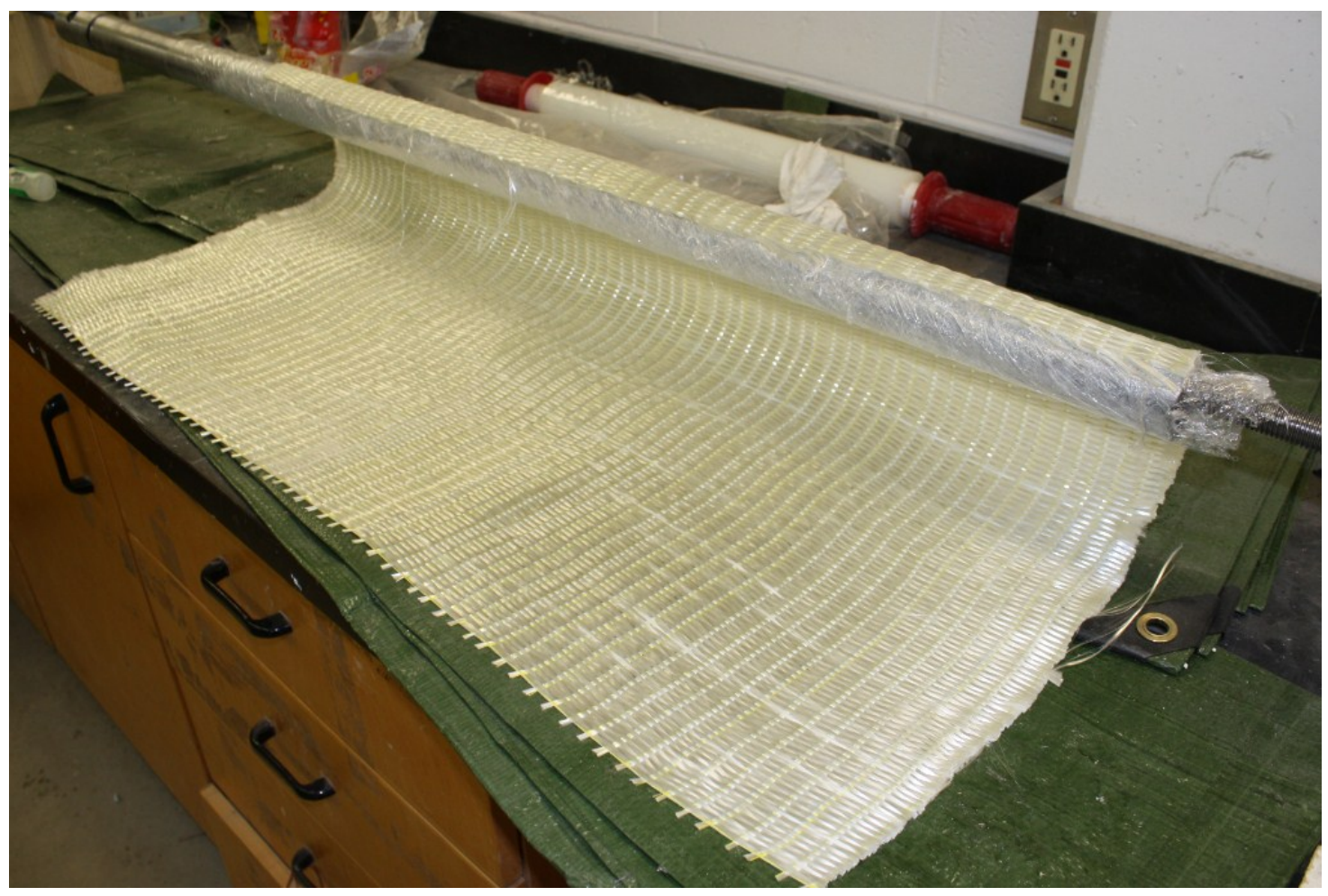

Figure 9 - GFRP pile manufacturing around steel mandrel

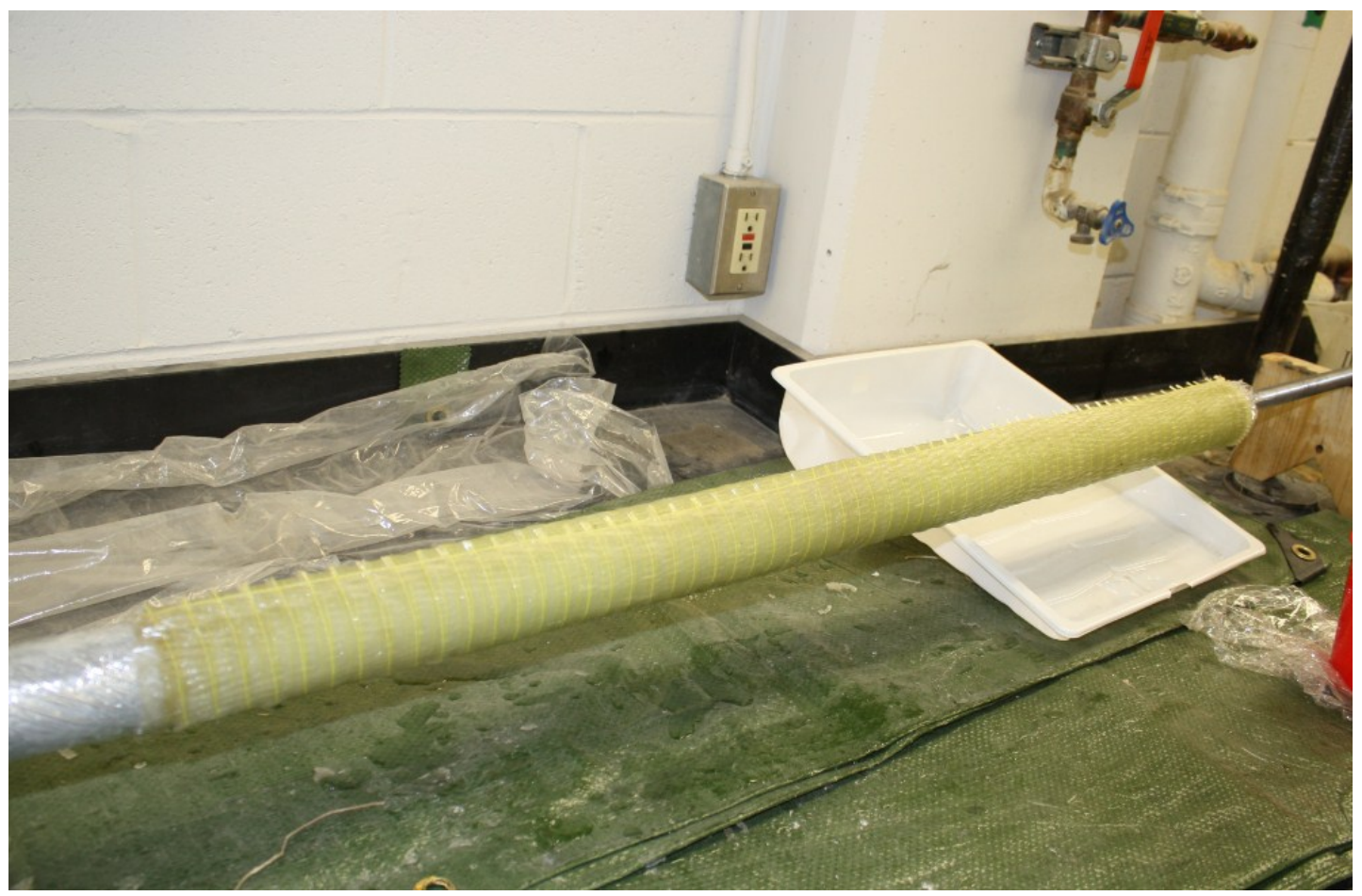

Figure 10 - GFRP pile manufacturing, Epoxy curing stage 


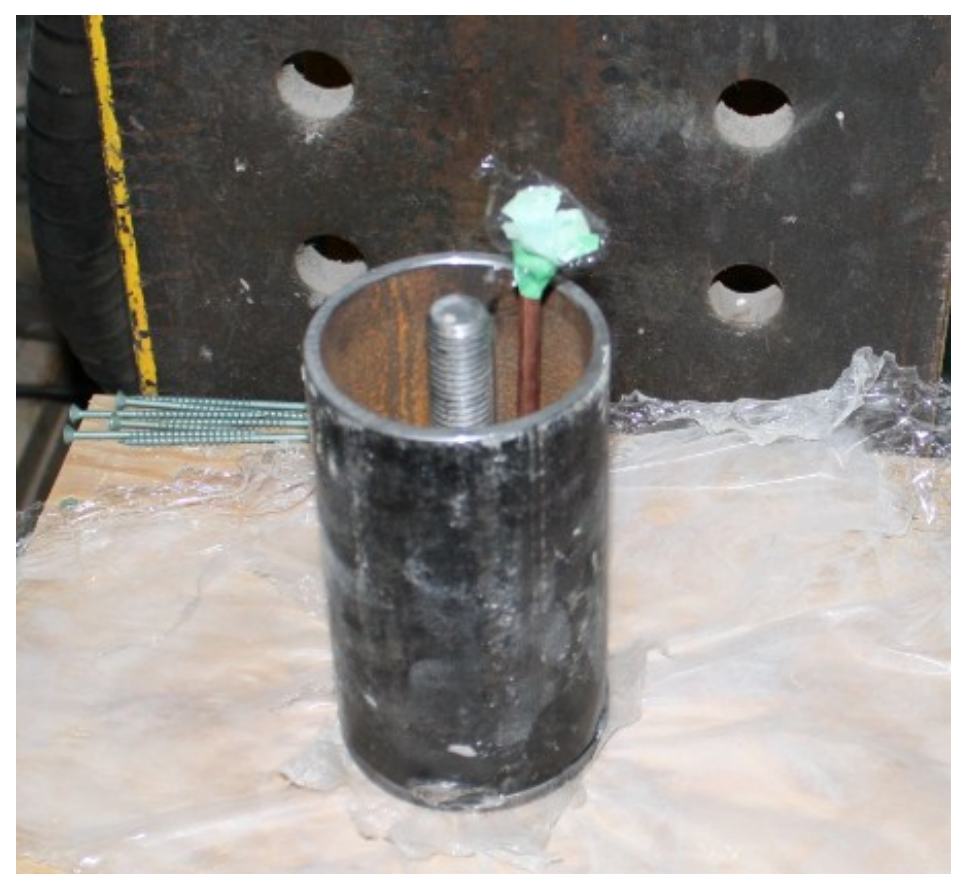

Figure 11 - Pilecap preparation

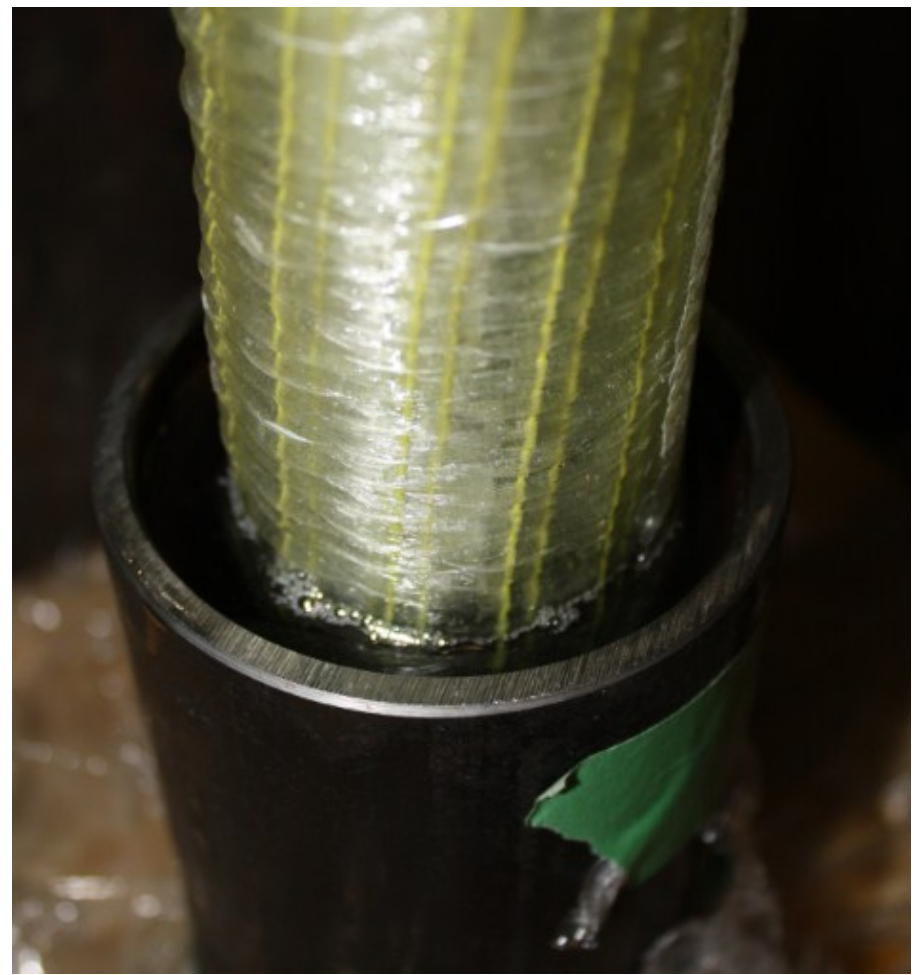

Figure 12 - Pilecap - FRP pile epoxy infill connection 


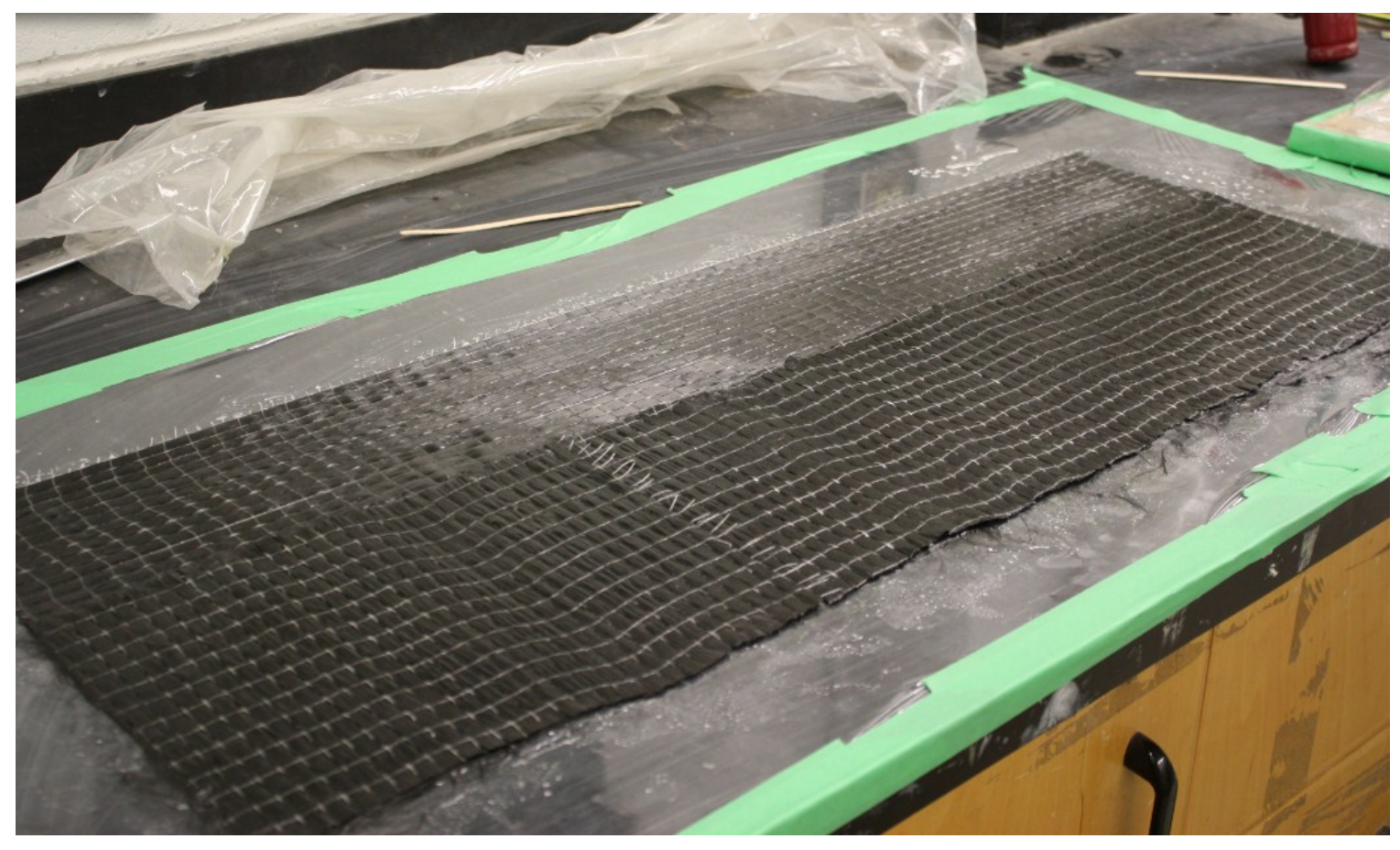

Figure 13 - CFRP fabric layup for pile casting

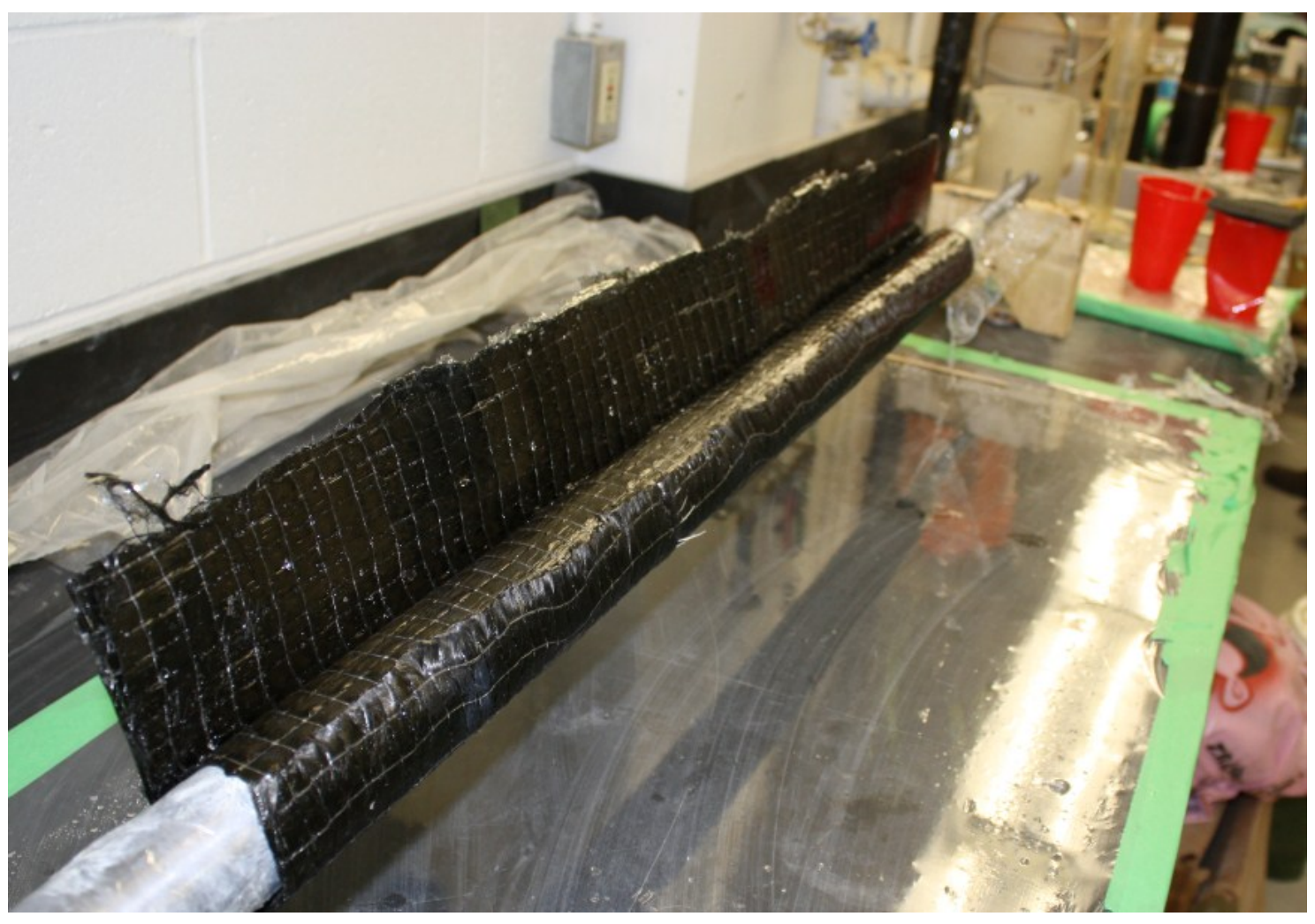

Figure 14 - CFRP pile casting in shape and curing 


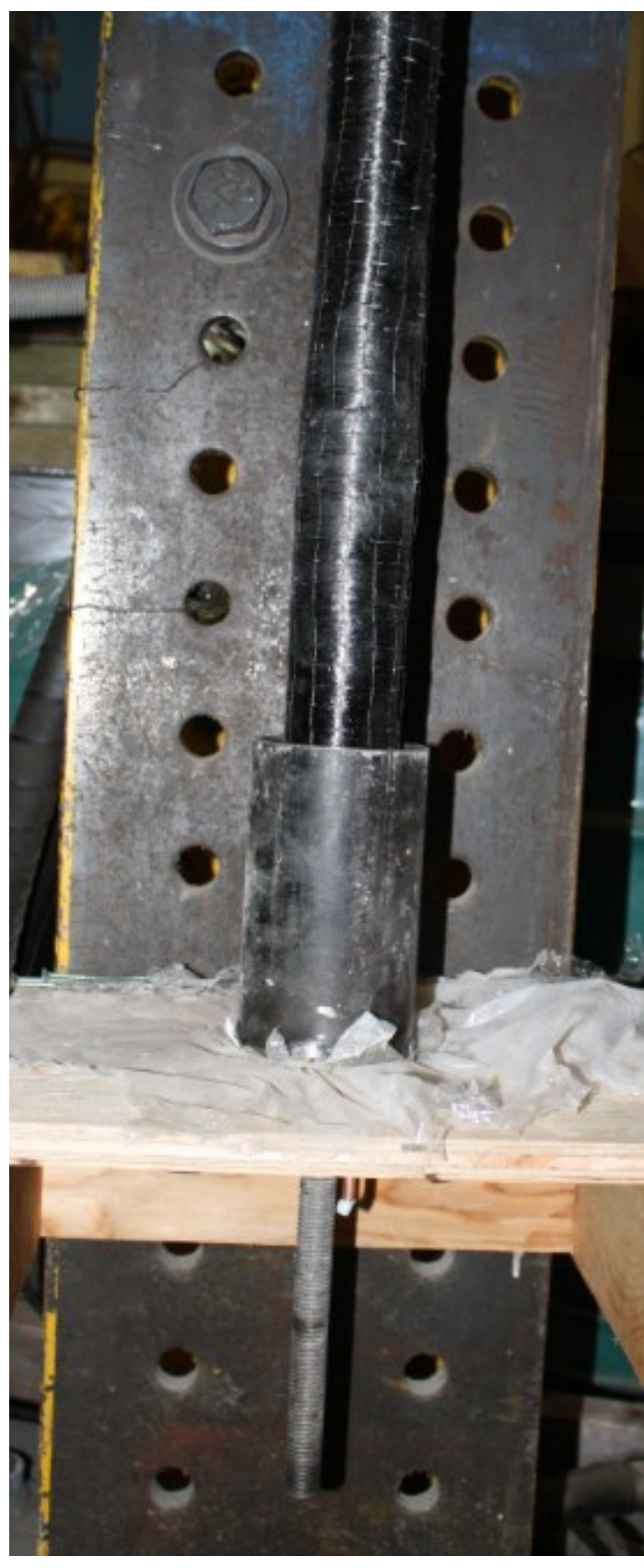

a)

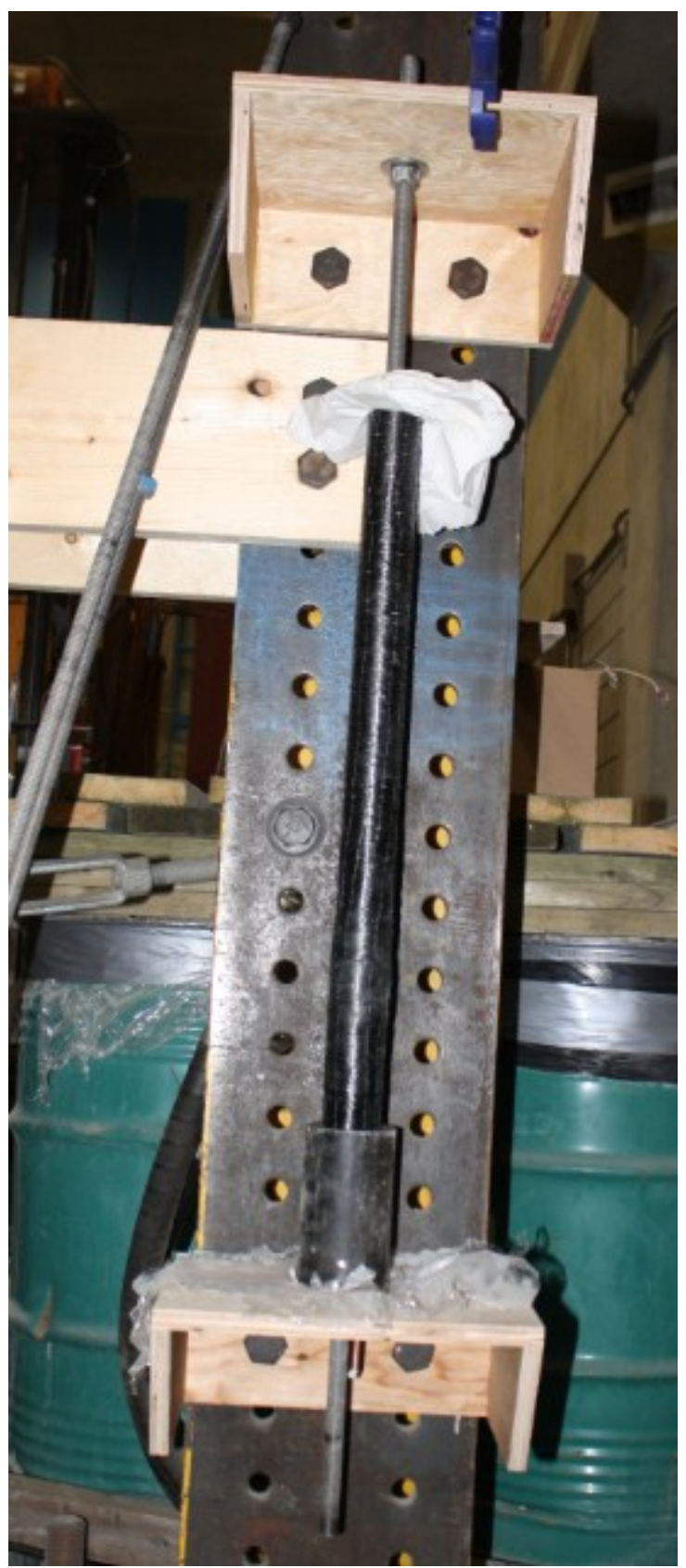

b)

Figure 15 - a) FRP pile and pilecap and b) coupling platforms ensuring vertical alignment 


\section{APPENDIX D}

\section{Geo-Studio boundary condition analysis results for pile load tests}

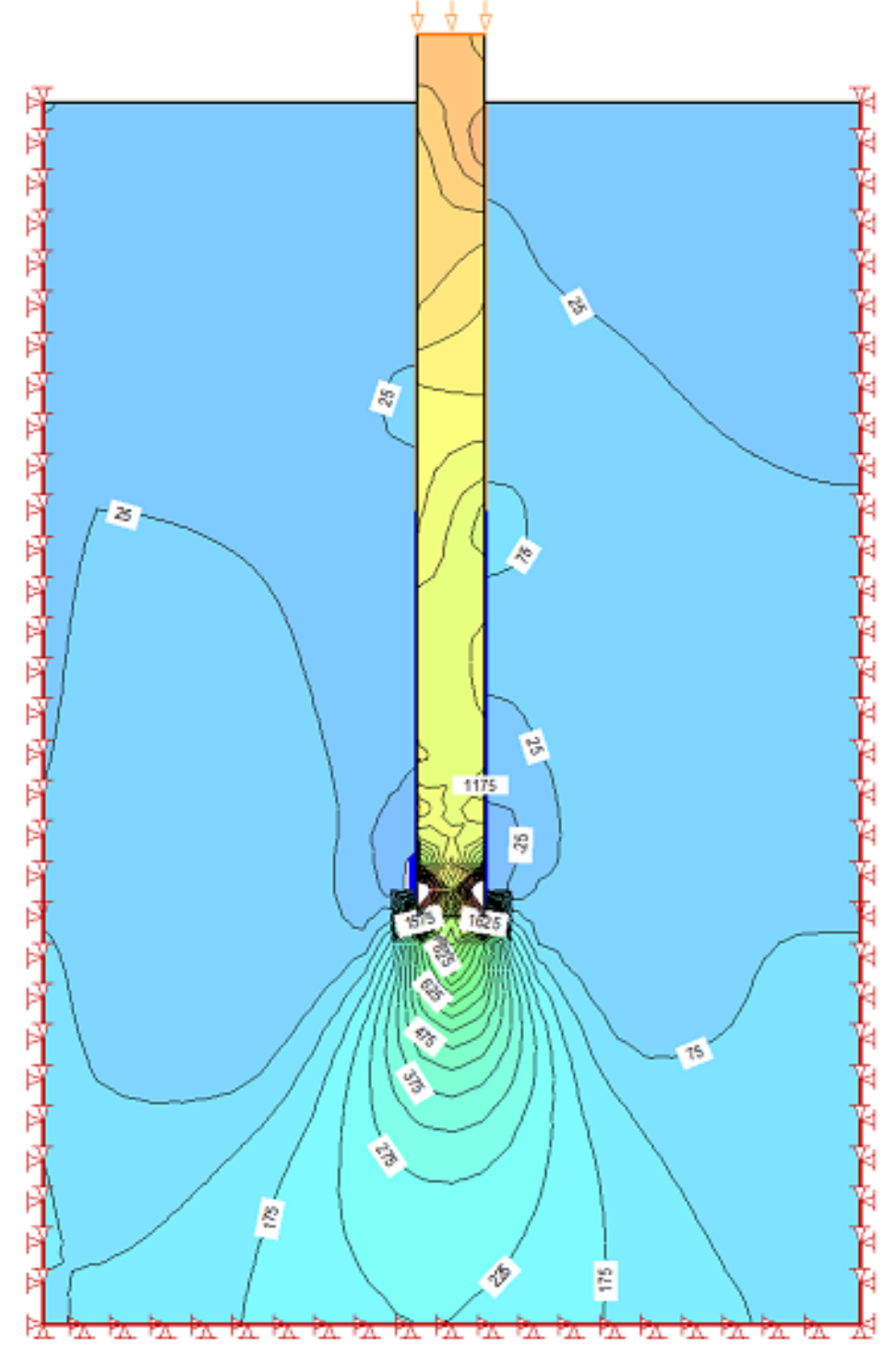

Figure 1 - Sigma/W numerical simulation of clay drum boundary conditions under axial compression 


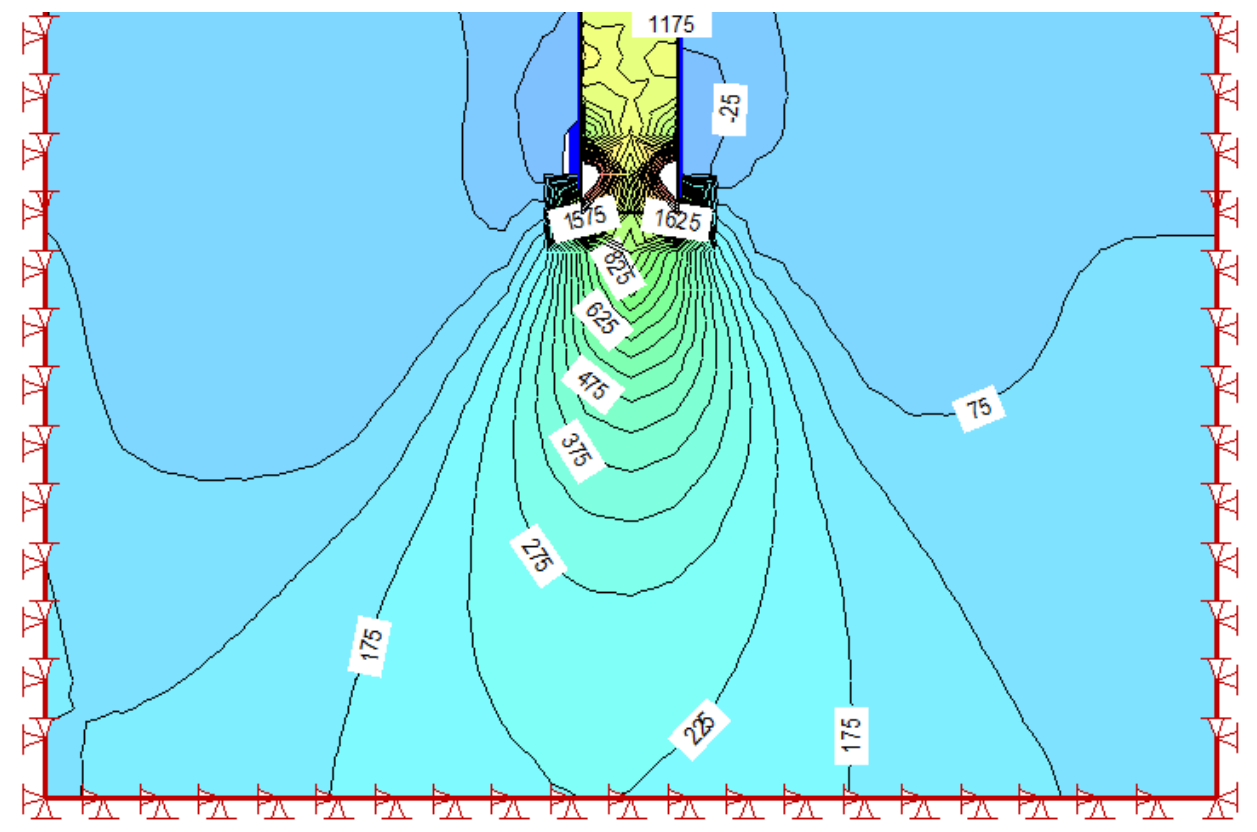

Figure 2 - Enlargement at toe stress distribution, induced stresses at lower boundary are approximately $10 \%$ to those at the pile toe 


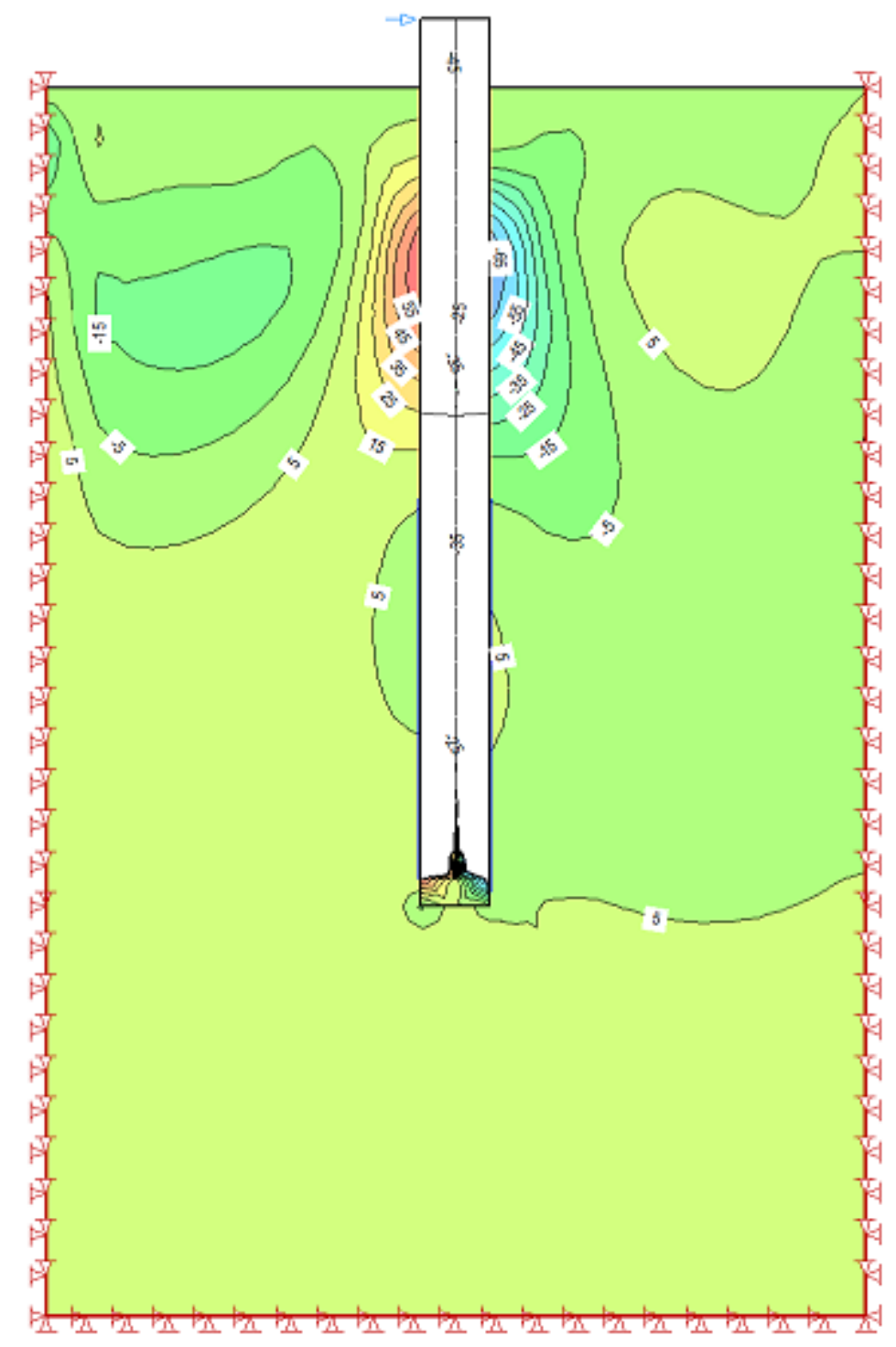

Figure 3 - Sigma/W numerical simulation of clay drum boundary conditions under lateral loading. Soil disturbance extends to a maximum of $1.5 \mathrm{~d}$, well below affecting the boundary region. 


\section{APPENDIX E}

\section{3-point FRP pipe bending test photos}

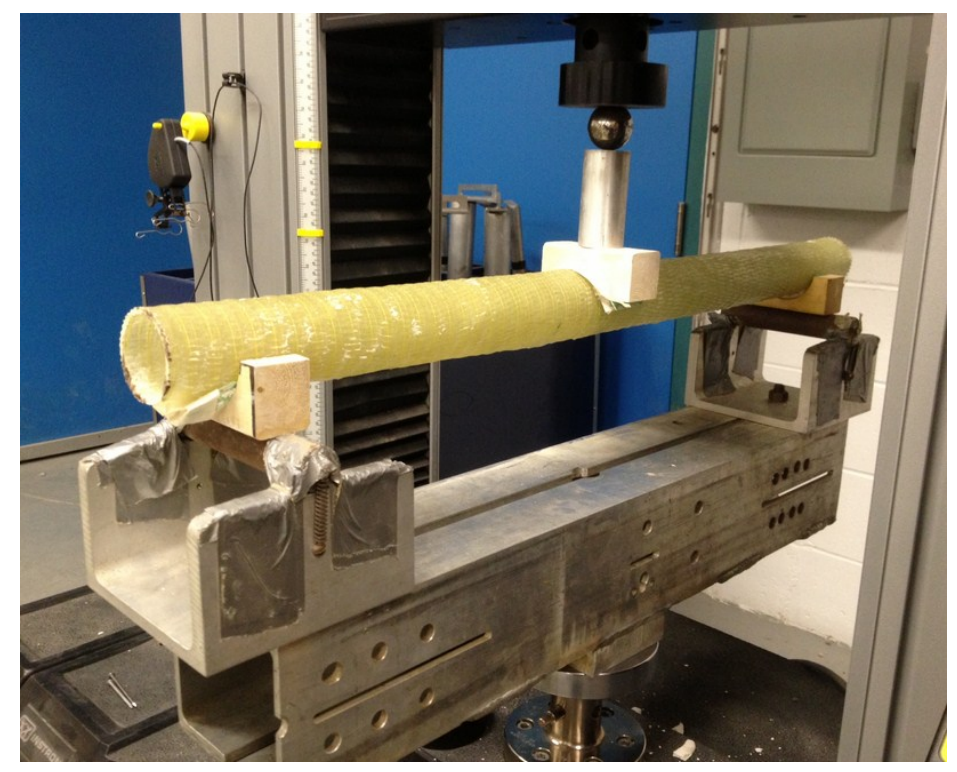

Figure $1-3$ - point bending test experimental setup for a GFRP pipe

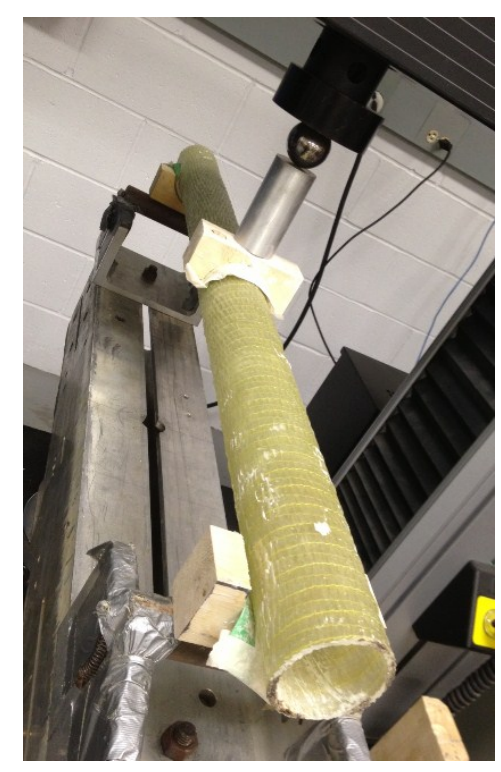

a)

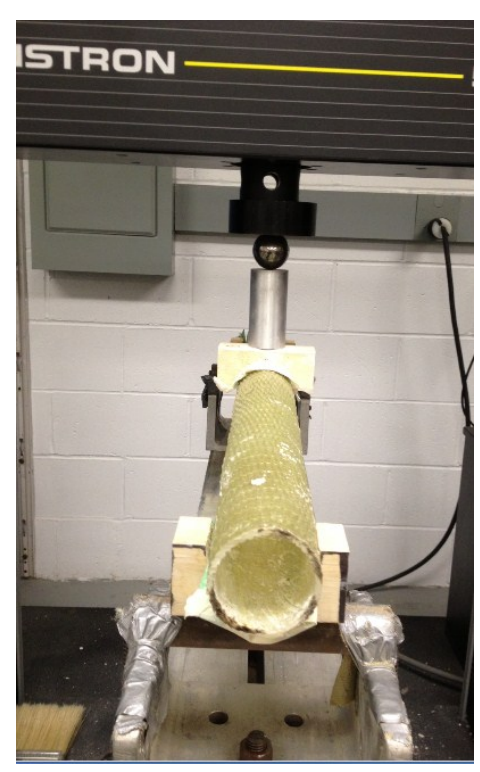

b)

Figure 2 - Saddle wood supports are used to avoid stress concentrations at a) supports, b) loading point 


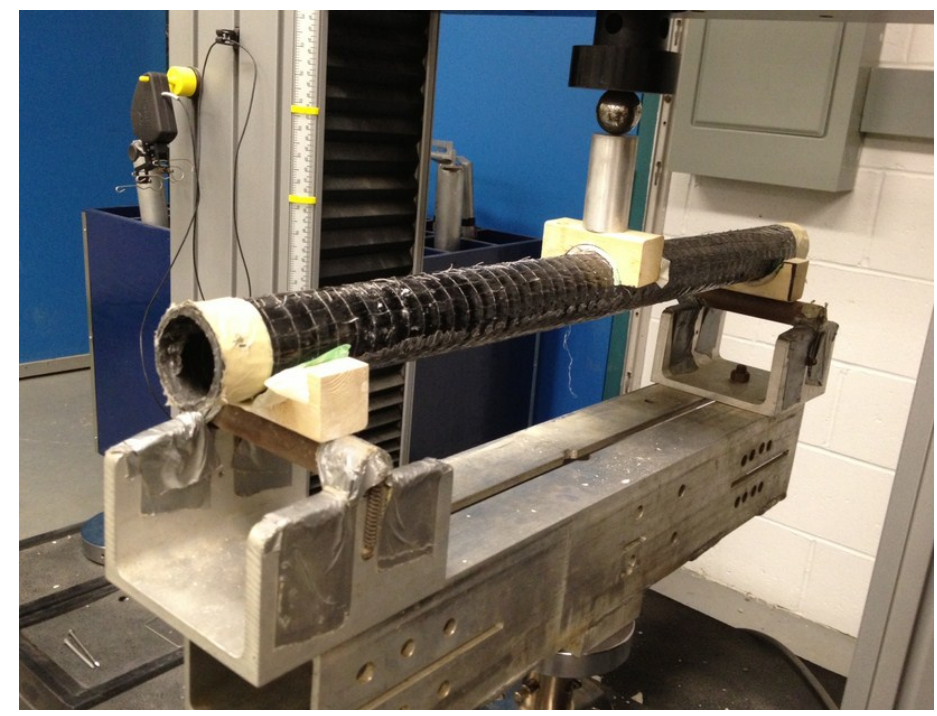

Figure 3 - 3-point bending test experimental setup for a CFRP pipe

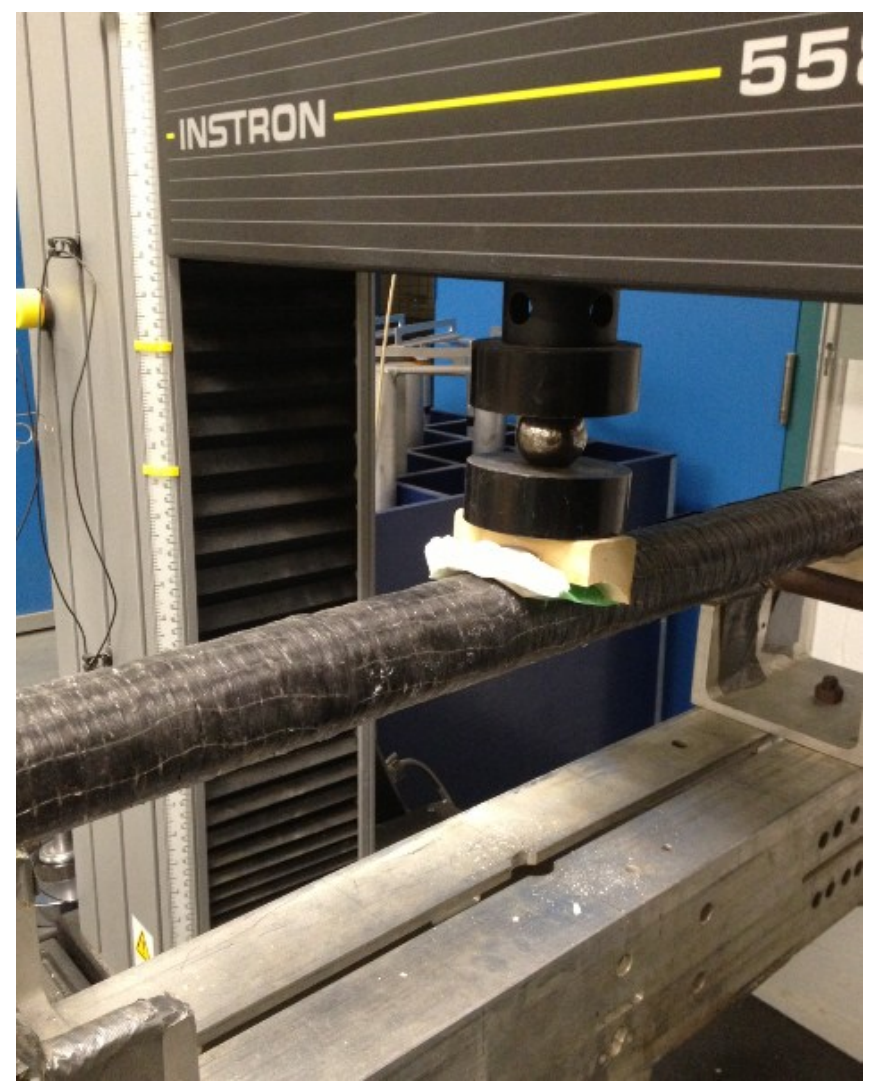

Figure 4 - Fast drying cement used with wood cushion to apply loading point 


\section{APPENDIX F}

\section{Field test Photos}

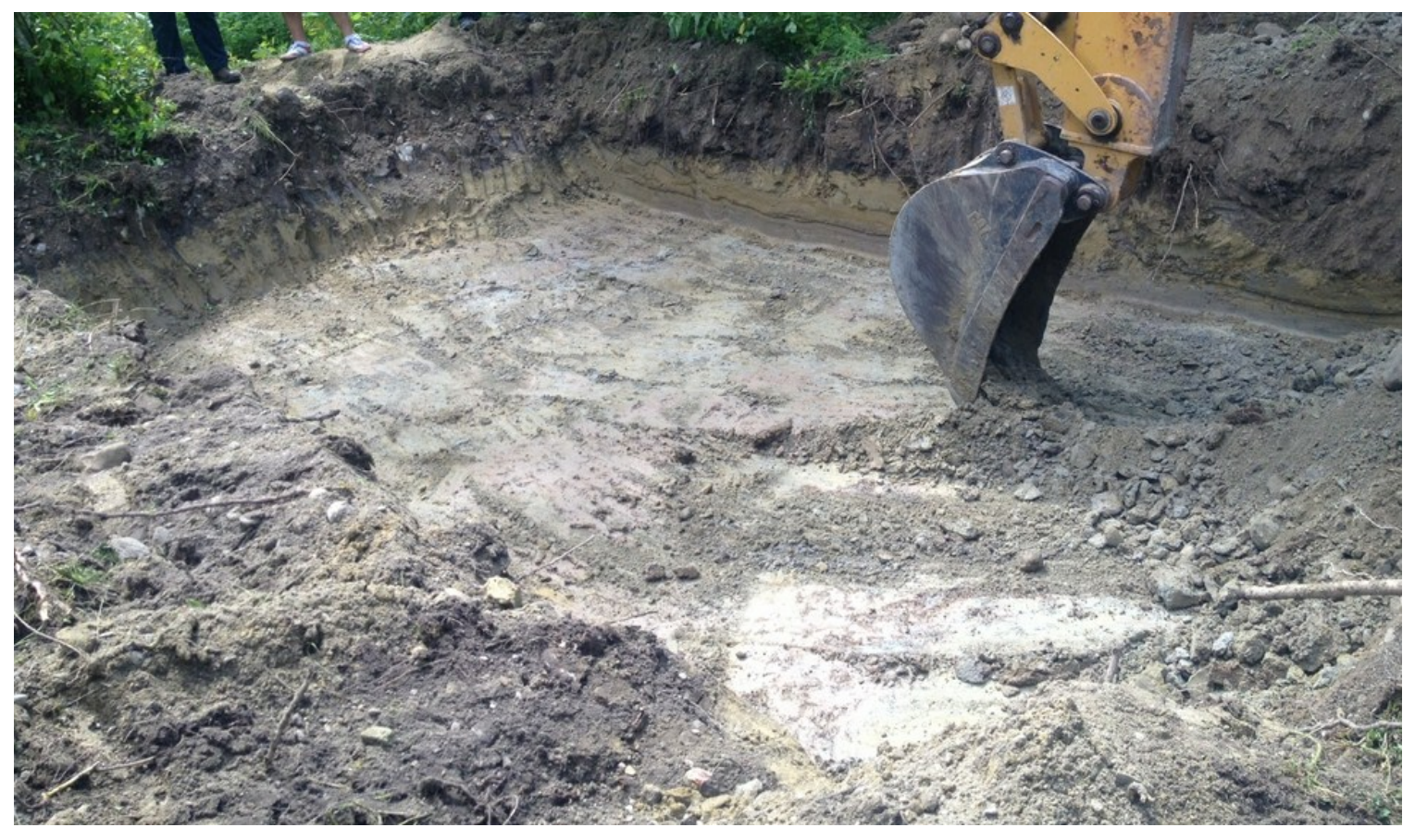

Figure 1 - Test pit during excavation

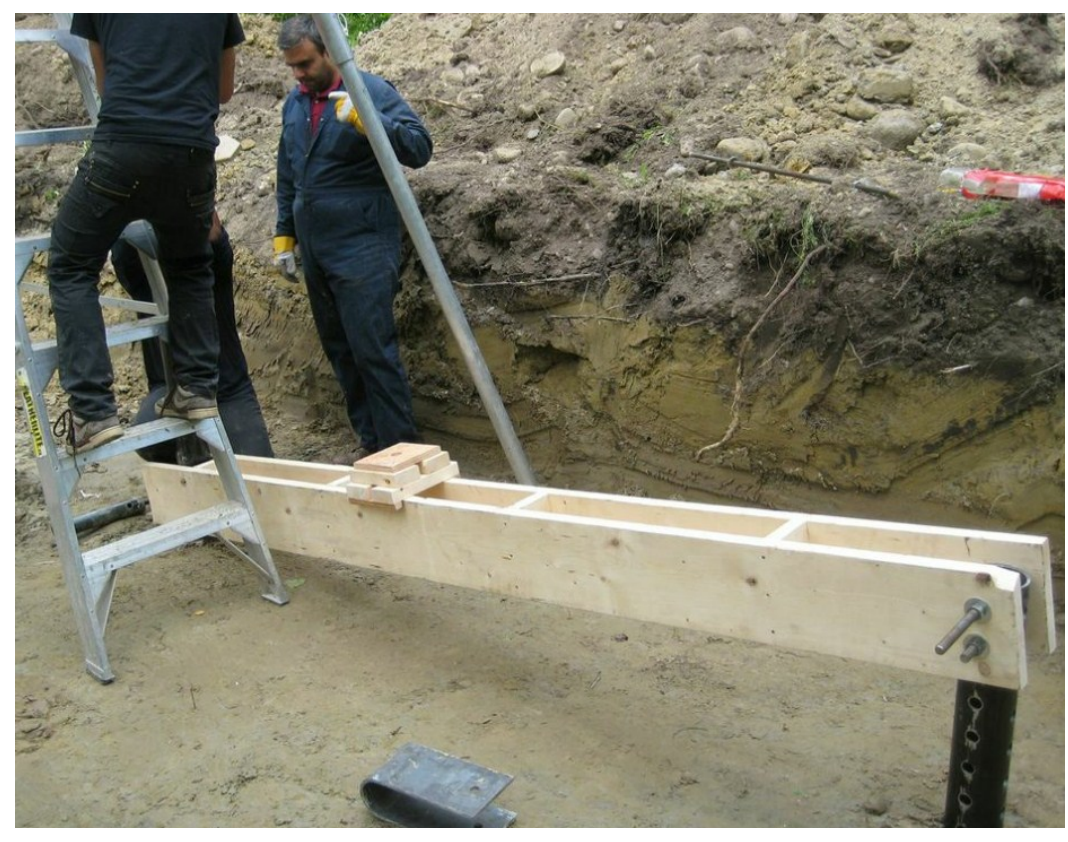

Figure 2 - Installation of reaction piles and frame 


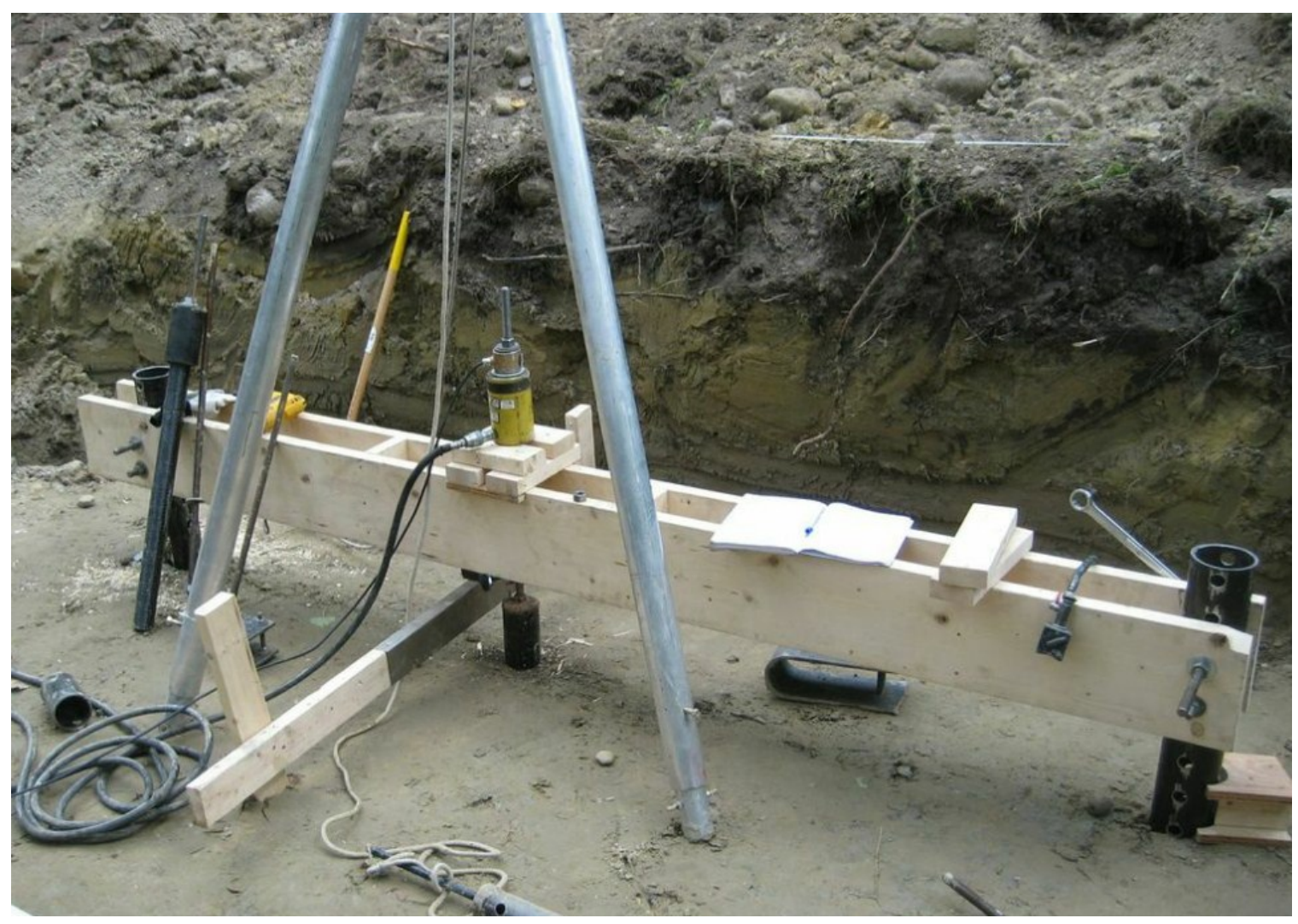

Figure 4 - Experimental setup and testing of axial pile response

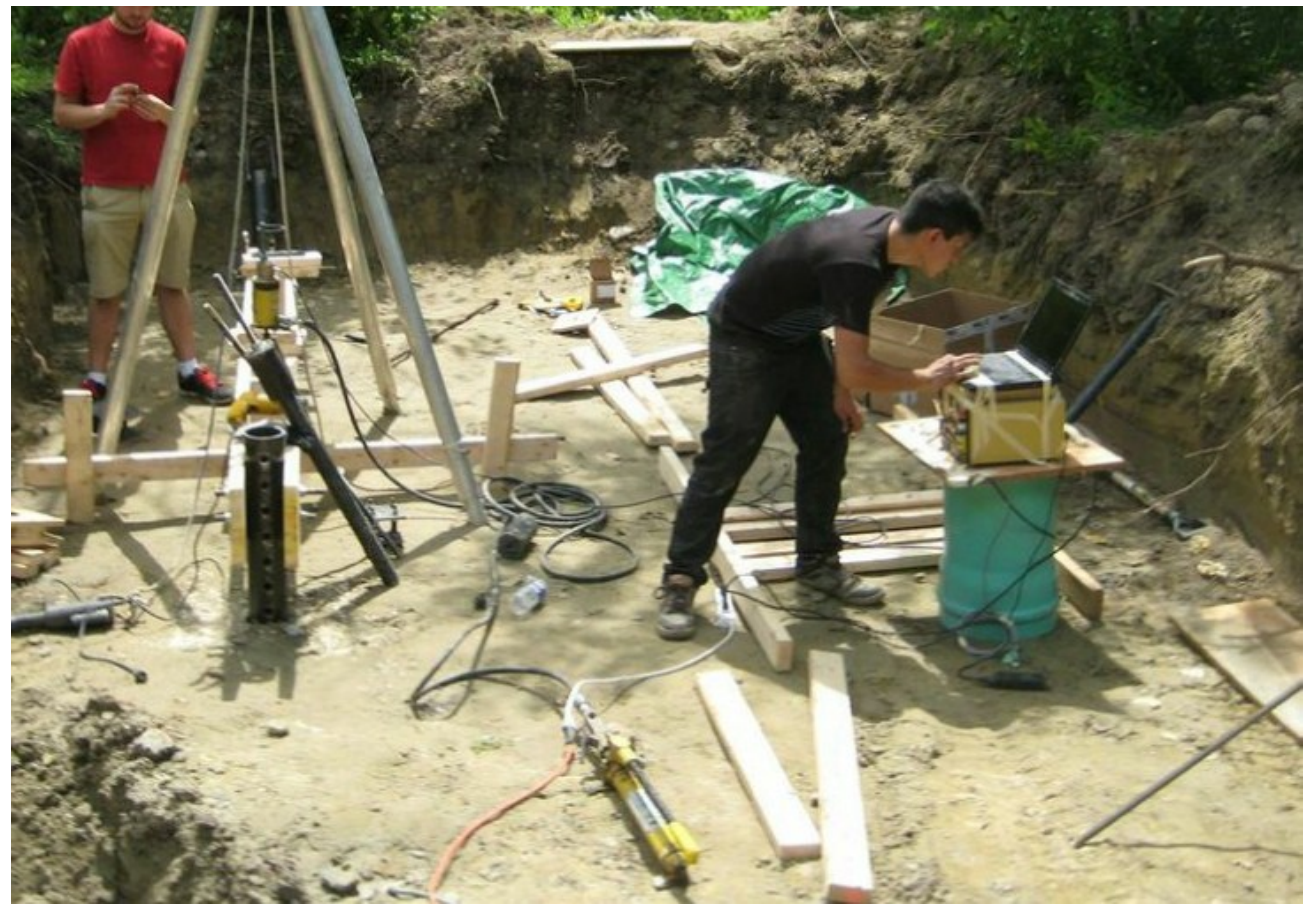

Figure 5 - Experimental setup and data logging station 

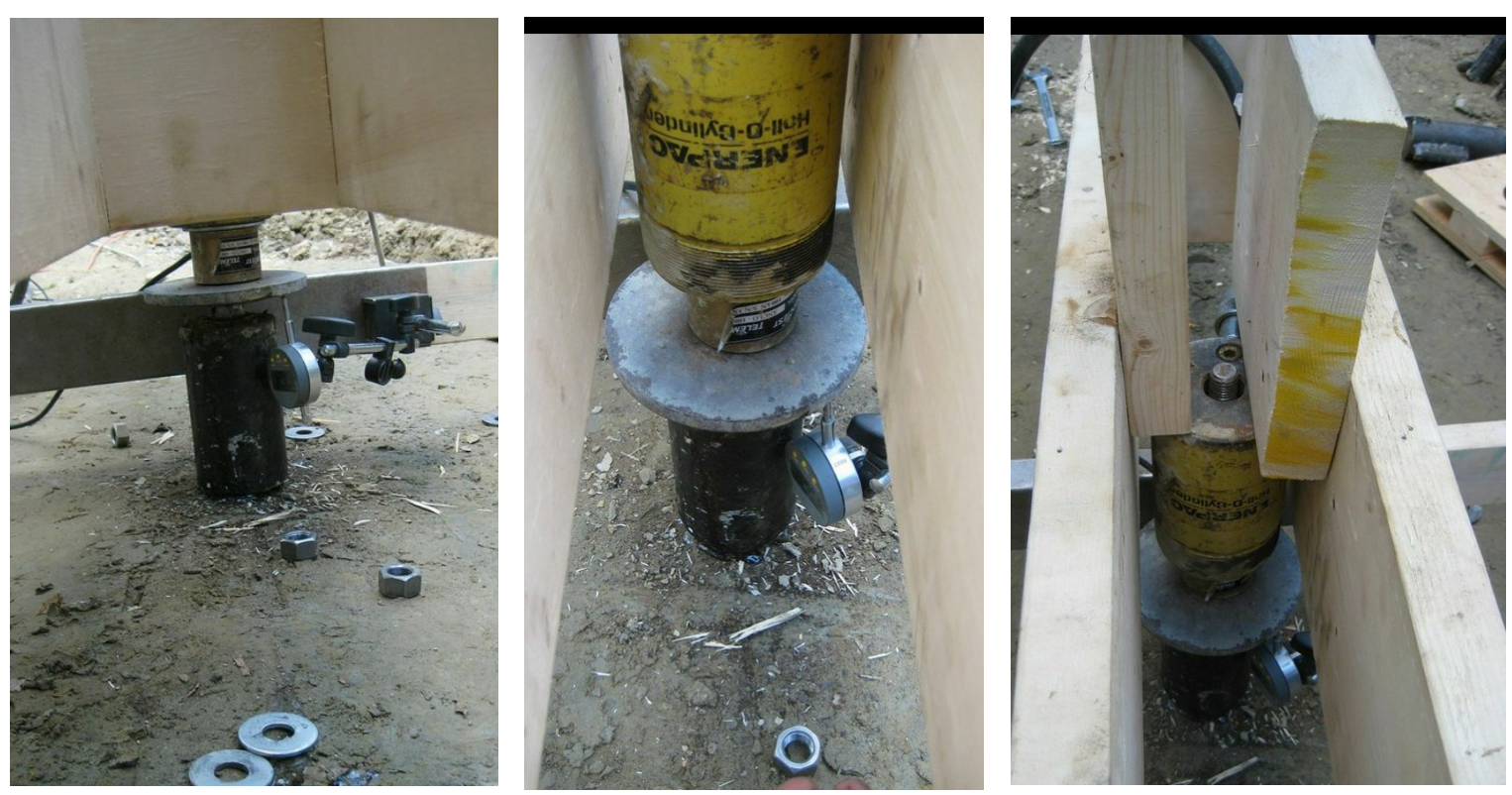

Figure 5 - Compressive axial load tests

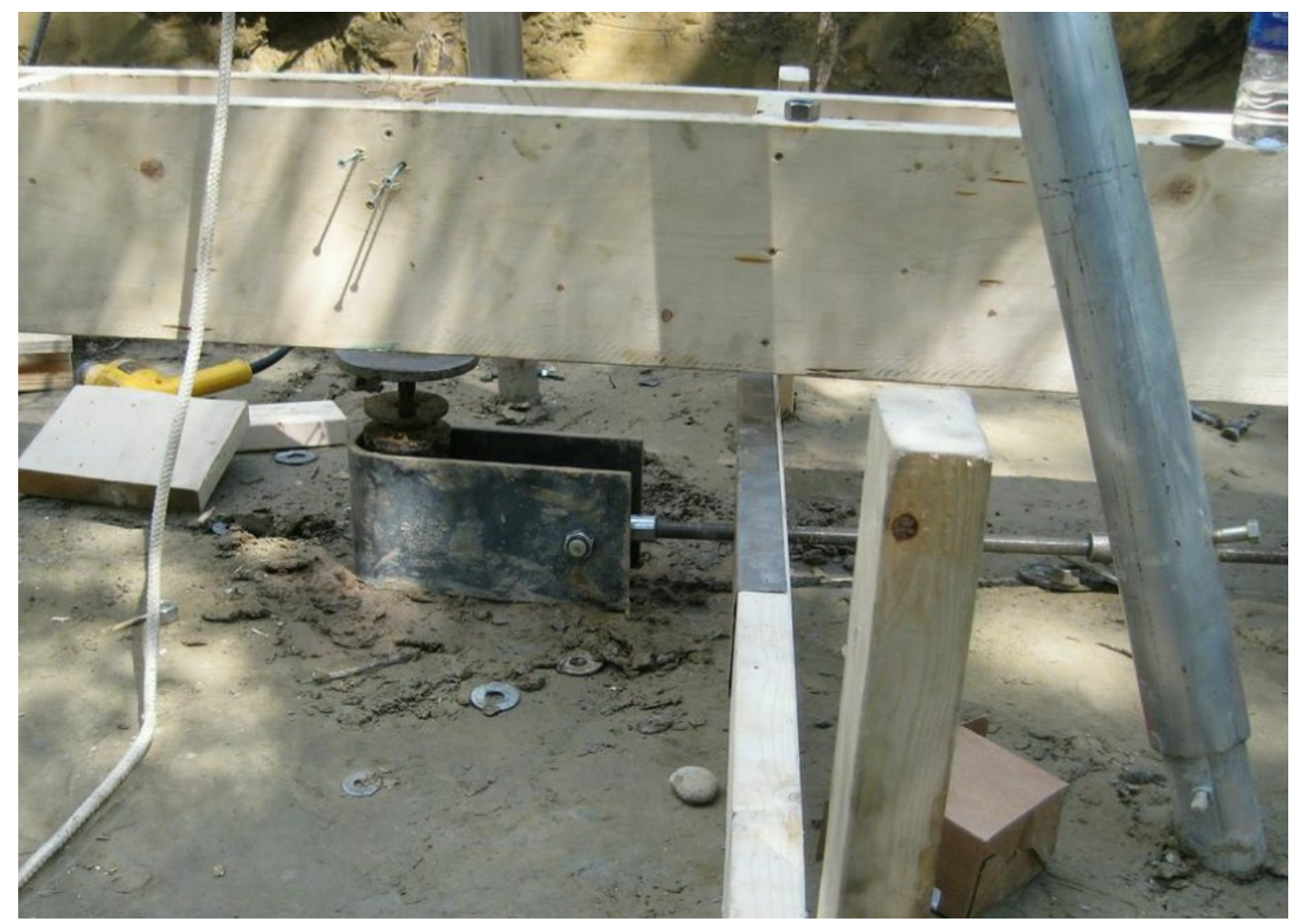

Figure 6 - Lateral load test experimental setup and reference frame 


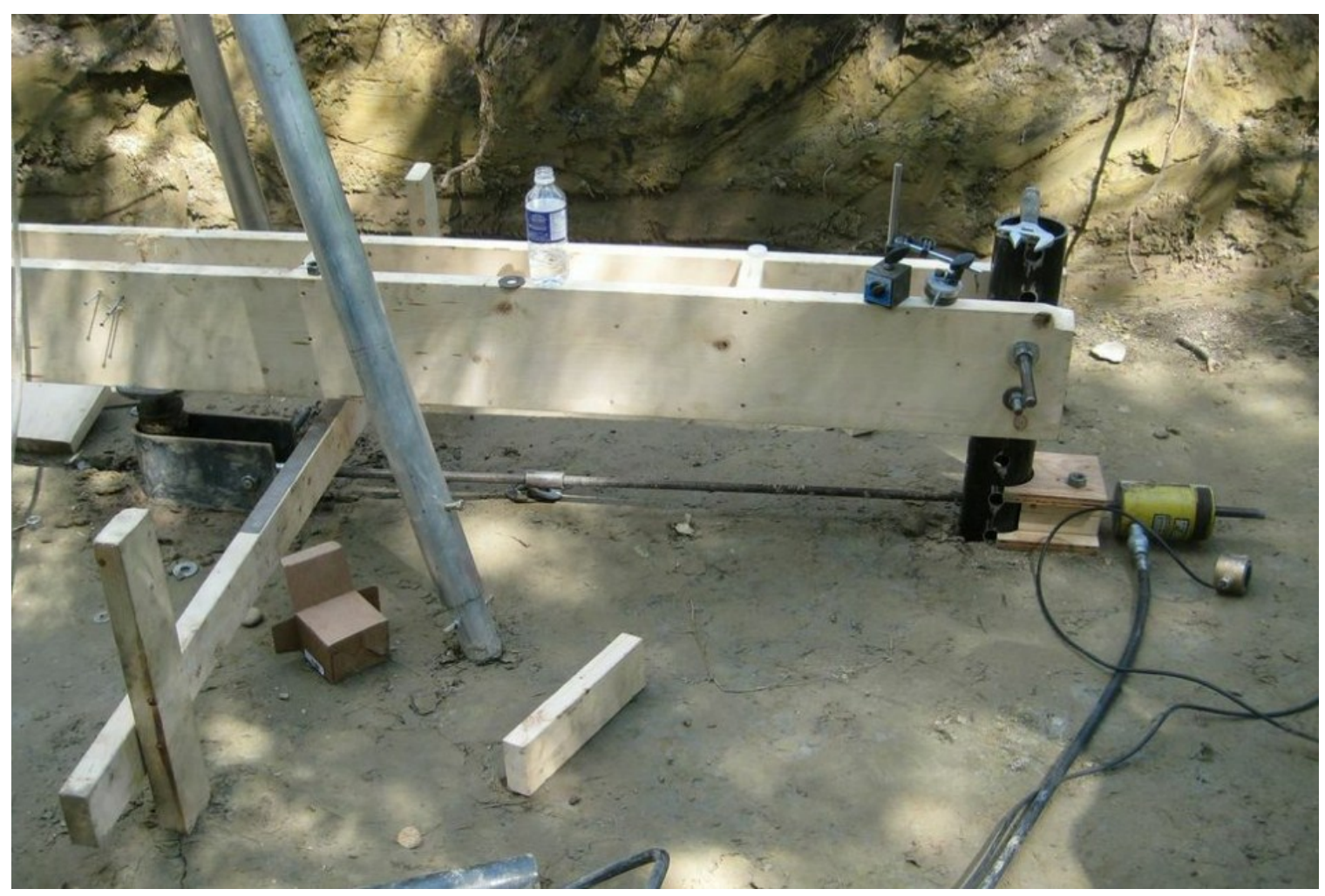

Figure 7 - Lateral load experimental setup

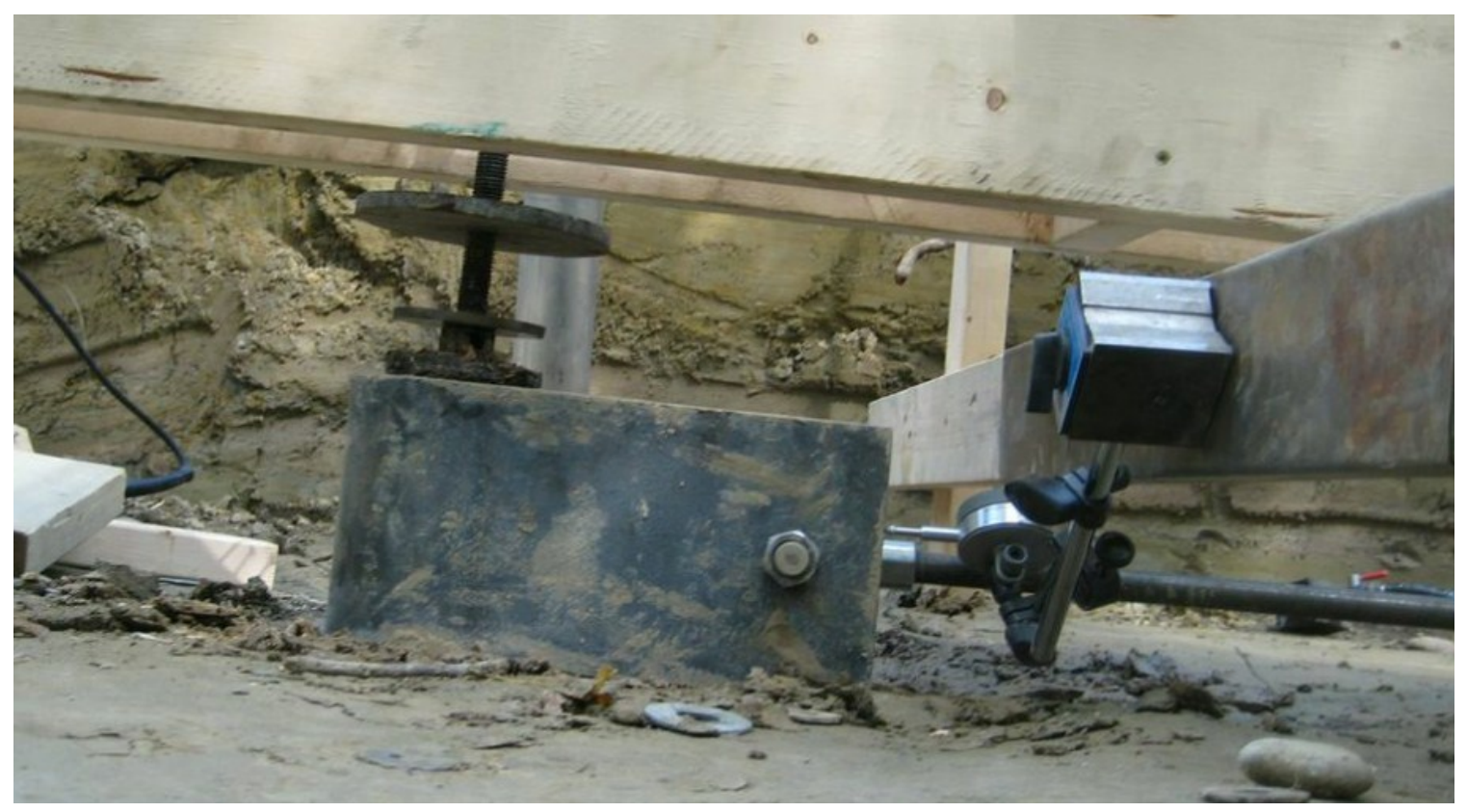

Figure 8 - Lateral load testing 
In this thesis, a research program aimed at investigating the performance of fiber reinforced polymers (FRPs) piles in soft clays is presented. FRP materials have experienced a surge in interest during the recent decades due to their favorable properties such as resistance to corrosion and degradation in comparison to steel and concrete particularly in harsh or contaminated soil conditions such as waterfront applications. The results of this experimental program indicate that for all of the FRP pile interfaces tested the interface shear strength is higher or at least on par with steel pile interfaces. The findings presented in this work show that the FRP piles are a viable alternative to steel piles. Further studies in the form of full scale pile load tests are needed in order to corroborate the results presented herein. 